\title{
Cock LANE AND \\ COMMON-SENSE
}

\section{BY}

ANDREW LANG. 


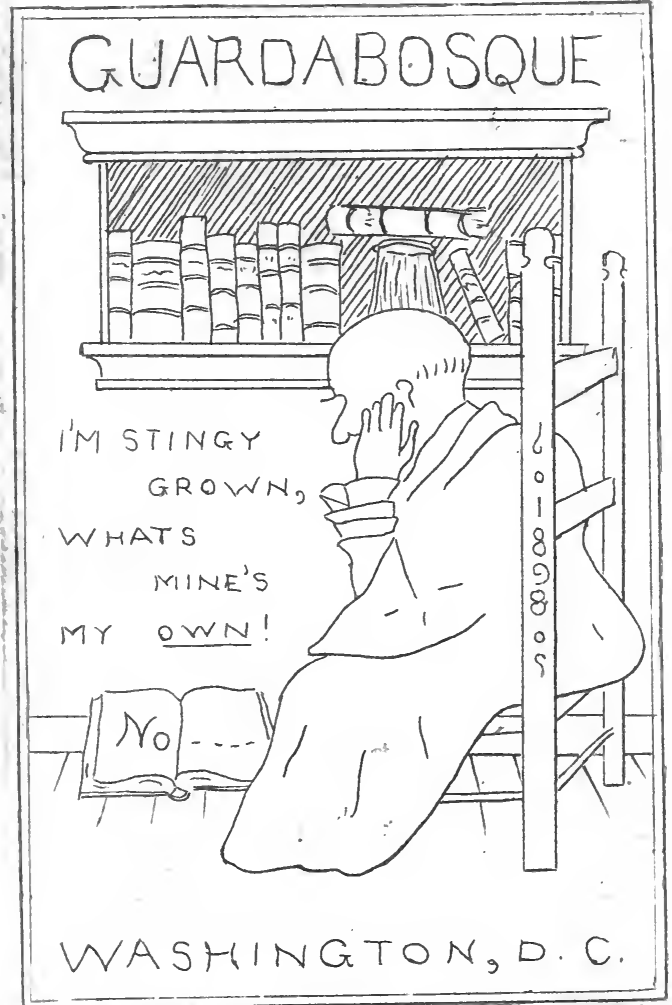




\title{
COCK LANE
}

\author{
AND
}

COMMON-SENSE

BY

ANDREW LANG

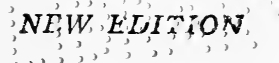

LONDON

LONGMANS, GREEN, AND CO. AND NEW YORK: 15 EAST 16th STREET

1894

$p+5$ 
491408

$$
5 F 1031
$$

THE ABERDEEN UNIVERSITY PRESS.

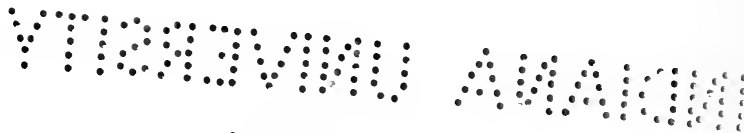




\section{Digitized by the Internet Archive in 2010 with funding from Indiana University}





\section{JAMES PAYN, EsQ.}

\section{Dear Payn,}

Spirits much more rare and valuable than those spoken of in this book are yours. Whatever 'Mediums' may be able to do, you can 'transfer'. High Spirits to your readers; one of whom does not hope to convert you, and will be fortunate enough if, by this work, he can occasionally bring a smile to the lips of his favourite ¿novelist.

With more affection and admiration thain can be publicly expressed,

\section{Believe me,}

Yours ever, 


\section{CONTENTS.}

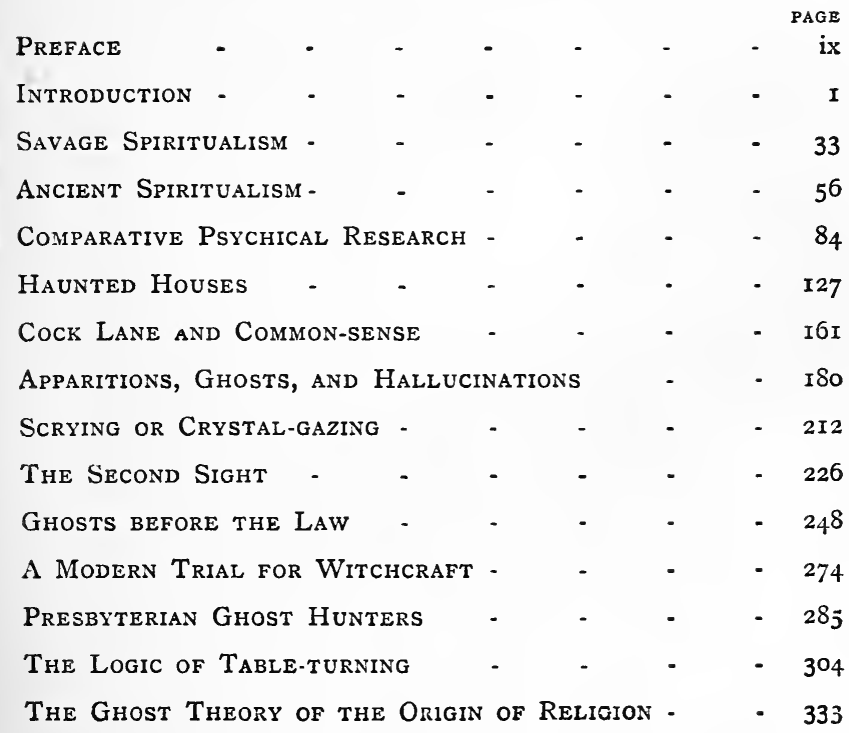




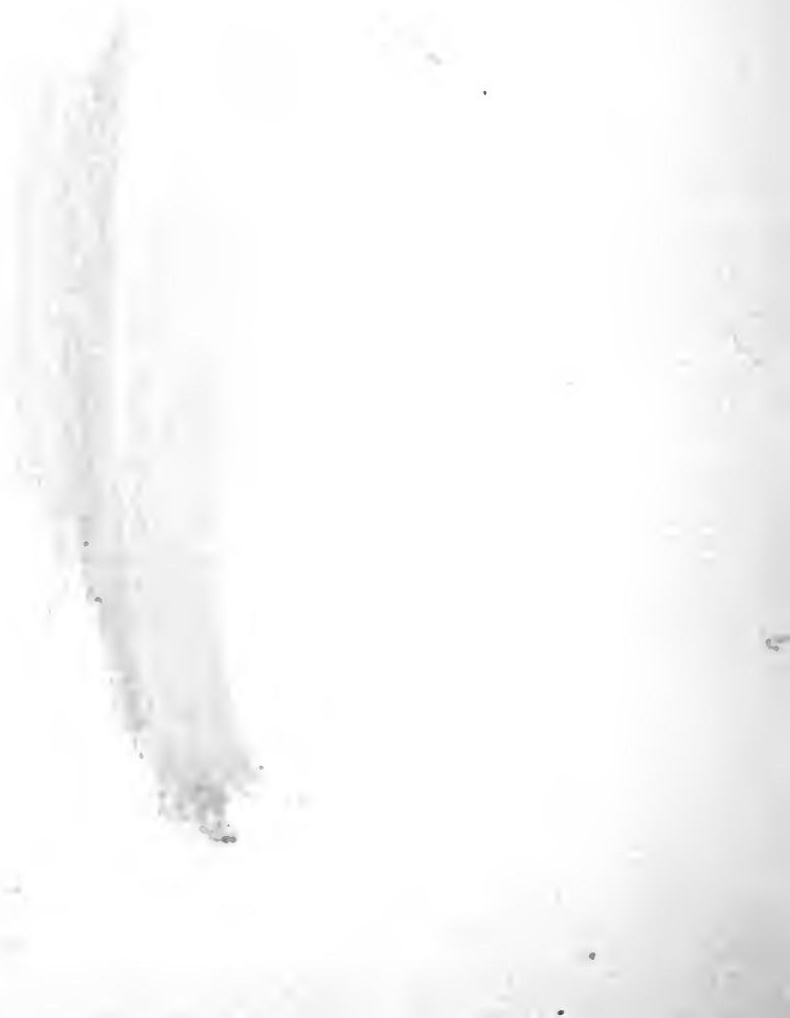




\section{PREFACE.}

THIs book deals with topics which it seems difficult to discuss in a spirit of fairness and right reason. While engaged on the essays, the author has gleaned the remonstrances of a few philosophers and friends. One of these thinkers (a rural dean) points out that human evidence is very untrustworthy, that he himself has been described as wearing the kilt, whereas he wears the trews; as editor of the Monk's Vade-Mecum, a paper which he never saw; as constant in his devotion to a large green umbrella, his umbrella, in fact, being blue, and so forth. ${ }^{1}$

The writer has answered that these objections apply to all human evidence, and that several of the statements in this volume are not the chatter of personal paragraph-makers, but are, in some cases, attested on oath, in others, have survived strict cross-examination.

Again, the writer has urged that the testimony to abnormal events is much on a par with that

1 These, of course, are fanciful examples. 
for anthropological details, manners and customs. When Anthropology first challenged the interpretation of myths given by Philologists, we were told that Anthropology relied on mere travellers' tales. It was answered that the coincidence of report, in all ages and countries, and from all manner of independent observers, unaware of each other's existence, was a strong proof of general accuracy, while the statements of learned and scholarly men, like Codrington, Callaway, and many others, confirmed the strange stories of travellers like Herodotus, of missionaries, traders and adventurers. The same test of evidence, universally coincident, applies to many of the alleged phenomena in this book. Indeed, the anthropological aspect of the phenomena led to the writing of the essays.

The author. was next informed that many 'ghost stories' had broken down, like a noted one from China, and it was inferred that all were equally incapable of standing examination. But this is not really the case; many of them (whatever we may think about them) are not destroyed by comparison of dates. In anthropology we receive many reports, as that such a people has no religion, or that it practises this or that custom, whereas later inquiry proves that 
it has plenty of religion, and that the custom is absent from its institutions. But we do not, therefore, conclude that all anthropological evidence is worthless, because some of it is incorrect. This is an argument of no value in any branch of human affairs. In every field of study there occur incorrect descriptions, and, in all, the bias of witnesses has to be allowed for: illusions of memory, of vanity, of the artistic instinct have to be discounted.

But these illusions, and other idola, are not all on one side. Let any one compare Sir David Brewster's letter to his daughter on the phenomena which he witnessed in the presence of Home, with his contemporary letter to the Times on the same subject. ${ }^{1}$ In which letter did Sir David tell the truth ? ${ }^{2}$ Here we have a trained observer, an authority in exact science, who flatly contradicts himself about an event not a week old at the time of his writing. He has one story for the public, a story directly contradictory of it for his family circle.

Next we are informed that hallucinations occur, and that chance coincidences are common. Precisely, hallucinations do occur; the

1 Brewster's Life, p. 257, I869.

${ }^{2}$ The letter to the Times is published in the Life of D. D. Home. 
only question is, do coincidences corresponc? with them more frequentlyt than the laws of chance allow for, or are the hallucinations and the coincidences so common as to suggest a causal connection? Lord Brougham, as a boy, made a covenant with a friend that he who died first should appear to the survivor. The friend went to India. Many years passed; the friend was not in Lord Brougham's conscious mind when he appeared to that nobleman in his bath! The friend's day for dying chanced to coincide with Lord Brougham's day for having an hallucination. This is very scientific, but it is also scientific to ask whether such coincidences are more frequent than mere chance will explain. Oddly enough the writer's rural friend, already spoken of, at once introduces the phrase, 'the supernatural'. This argument is a mere survival. Nobody is talking about 'the supernatural'; we are merely discussing the rather unusual. A 'wraith,' if wraiths there be, is as 'natural' as an indigestion.

Then we come to imposture. The 'rapping trick,' says another friend, 'is one of the oldest things in the world'. 'That is one reason why it interests us: a secular and world-wide imposture is a matter of curious interest, like a fairy tale which is found all the world over. 
But is it impossible that impostures are imitations of real phenomena which gave the suggestion? In many cases, as we show, the explanations offered by common-sense are inconsistent, inadequate, and can only be accepted by aid of a strong bias which influences the reasoner. No doubt the writer himself has a bias. He is conscious of a bias in favour of fair play and ordinary logic. He is unconscious of a bias in favour of 'common-sense'. Fair play and right reason have but rarely been applied to these subjects. The old inquirers of the Restoration frankly avowed their desire to confute scepticism. From I 720 to our own day Rationalism has been just as prejudiced, and hardly less frank. It has been often said that, when exact inquiry is made, all 'ghosts' will vanish, as in the Chinese case, and such inquiry, it is urged, should be made. But when people make it, they are accused of superstition. Common-sense bullied several generations, tili they were positively afraid to attest their own unusual experience. Then it was triumphantly proclaimed that no unusual experiences were ever attested. Even now many people dare not say what they believe about occurrences witnessed by their own senses. All this frame of mind is as unphilosophical as may be. On 
the other side we have writers, like the late Mr. Dale Owen, who avow and display a potent bias in favour of establishing a belief in a future life. They, too, just like the sceptics, blink awkward facts. Mr. Dale Owen gives the story of the Stockwell mystery, but does not give Hone's account of Braidley's account of the medium's confession of imposture, whatever it may be worth. In brief, the themes are not treated with scientific fairness as a general rule. Arguments are advanced and accepted on both sides which would scarcely be looked at in any other matter.

The writer has endeavoured to be fair, and trusts that, relatively speaking, he has succeeded. To his mind the most plausible theory is that our savage ancestors were subject to great mental confusion; that they did not distinguish between dreams and waking; that their conditions of life and scanty supplies of food were favourable to trances and hallucinations; and that they practised a kind of elementary hypnotism. From all this would arise a set of unfounded beliefs. These beliefs, like myths and customs, would endure among the peasant classes. The folk would inherit the traditions as to what hallucinatory phenomena they might expect, and, as a result of self-suggestion and of 
expectant attention, these phenomena they would actually behold. This would account for the continuity of phenomena, which again are fraudulently imitated by mediums.

This is a conceivable and even probable theory. The writer, however, cannot say that he holds it with exclusive and perfect conviction. He does not feel perfectly assured that Lord Crawford, Sir David Brewster, Mr. Crookes, Mr. Hamilton Aïdé, and many others, were deceived by conjuring (on all occasions), or saw tables and people float about in the air, because of the traditional influence exercised by savage hallucinations. Again, the spontaneous and unexpected hallucinations coincident with deaths, cannot be explained on this system, and seem to demand more continued and exact study, while 'collective hallucinations' of several persons at the same time are a theme worthy of the notice of psychologists.

It is obvious that, if we have not yet discovered the limits of human faculty (as many historical cases, like that of Joan of Arc, and some modern experiments, seem to indicate), the fact is of great interest, and possibly of momentous consequence. The matter cannot be got rid of by the sneer which many of its aspects invite, nor can anything be estab- 
lished by the assertions of gullible and excited witnesses.

Of the essays in this book, 'Savage Spiritualism' appeared in Longman's Magazine. Additions and alterations have been made. Much of 'Comparative Psychical Research' was published in the Contemporary Review, but the essay is now nearly double its original length. The essay on 'Hallucinations' was, in part, published in Blackwood's Magazine as 'Ghosts up to Date'. 'Ghosts before the Law' was in Blackwood's Magazine. The author has to thank the editors and publishers of these serials for leave to reprint the essays. None of the other chapters, which are ten in all, has been previously published. 


\section{INTRODUCTION.}

Nature of the subject. Persistent survival of certain Ani. mistic beliefs. Examples of the Lady Onkhari, Lucian, General Campbell. The Anthropological aspect of the study. Difference between this Animistic belief, and other widely diffused ideas and institutions. Scientijic ad-

a mission of certain phenomena, and rejection of others. Connection between the rejected and accepted phenomena. The attitude of Science. Difficulties of investigation illustrated. Dr. Cartenter's Theory of unconscious Cerebration. Illustration of this Theory. The Failure of the Inquiry by the Dialectical Society. Professor Huxley, Nr. G. H. Lewes. Absurdiiy and charlatanism of 'Spiritualism'. Historical aspect of the subject. Universality of Animistic Beliefs, in every stage of culture. Not peculiar to savagery, ignorance, the Dark Ages, or periods of Religions crisis. Nature of the Evidence.

IT is not without hesitation that this book is offered to the reader. Very many people, for very various reasons, would taboo the subjects here discoursed of altogether. These subjects are a certain set of ancient beliefs, for example the belief in clairvoyance, in 'hauntings,' in events transcending ordinary natural laws. The peculiarity of these beliefs is, that they have survived the wreck of faith in such elements of witchcraft as metamorphosis, and power to cause tempest or drought. To 
study such themes is 'impious,' or 'superstitious,' or 'useless'. Yet to a pathologist, or anthropologist, the survivals of beliefs must always be curious and attractive illustrations of human nature.

Ages, empires, civilisations pass, and leave some members even of educated mankind still, in certain points, on the level of the savage who propitiates with gifts, or addresses with prayers, the spirits of the dead.

An example of this endurance, this secular survival of belief, may be more instructive and is certainly more entertaining than a world of assertions. In his Études Égyptiennes (Tome i. fascic. 2) M. Maspero publishes the text and translation of a papyrus fragment. This papyrus was discovered still attached to a statuette in wood, representing 'the singer of Ammen, Kena,' in ceremonial dress. The document is a letter written by an ancient Egyptian scribe, "To the Instructed Khou of the Dame Onkhari,' his own dead wife, the Khou, or $K h$, being the spirit of that lady. The scribe has been 'haunted' since her decease, his home has been disturbed, he asks Onkhari what he has done to deserve such treatment: "What wrong have I been guilty of that I should be in this state of trouble? what have I done that thou should'st help to assail me? no crime has been wrought against thee. From the hour of my marriage till this day, what have I wrought against thee that I need conceal?'

He vows that, when they meet at the tribunal of Osiris, he will have right on his side. 
This letter to the dead is deposited in the tomb of the dead, and we may trust that the scribe was no longer annoyed by a Khou, which being instructed, should have known better. To take another ancient instance, in his Philopseudes Lucian introduces a kind of club of superstitious men, telling ghost stories. One of them assures his friend that the spectre of his late wife has visited and vexed him, because he had accidentally neglected to burn one of a pair of gilt shoes, to which she was attached. She indicated the place where the shoe was lying hidden, and she was pacified. Lucian, of course, treats this narrative in a spirit of unfeeling mirth, but, if such tales were not current in his time, there would have been no point in his banter. Thus the belief in the haunting of a husband by the spirit of his wife, the belief which drives a native Australian servant from the station where his gin is buried, survived old Egypt, and descended to Greece. We now take a modern instance, closely corresponding to that of the Instructed Khou of the Dame Onkhari.

In the Proceedings of the Psychical Society (part xiv. p. 477) the late General Campbell sends, from Gwalior House, Southgate, N., April 27, I884, a tale of personal experiences and actions, which exactly reproduces the story of the Egyptian Scribe. The narrative is long and not interesting, except as an illustration of survival,-in all senses of the word.

General Campbell says that his wife died in July, I882. He describes himself as of advanced age, and cautious in forming opinions. In I882 he had never given any consideration to 'the subject of ultra- 
mundane indications'. Yet he recounts examples of 'about thirty inexplicable sounds, as if inviting my attention specially, and two apparitions or visions, apparently of a carefully calculated nature, seen by a child visitor, a blood relation of my late wife, whom this child had never seen, nor yet any likeness of her'. The general then describes his house, a new one, and his unsuccessful endeavours to detect the cause of the knocks, raps, crashes, and other disturbances. Unable to discover any ordinary cause, he read some books on 'Spiritualism,' and, finally, addressed a note, as the Egyptian Scribe directed a letter, to the 'agent ': ${ }^{1}$ Give three raps if from my deceased wife!

He was rewarted by three crashing sounds, and by other peculiar phenomena. All these, unlike the scribe, he regarded as sent 'for my particular conviction and comfort'.

These instances prove that, from the Australian blacks in the Bush, who hear raps when the spirits come, to ancient Egypt, and thence to Greece, and last, in our own time, and in a London suburb, similar experiences, real or imaginary, are explained by the same hypothesis. No 'survival' can be more odd and striking, none more illustrative of the permanence, in human nature, of certain elements. To examine these psychological curiosities may, or may not, be 'useful,' but, at lowest, the study may rank as a branch of Mythology, or of Folk-lore.

It is in the spirit of these sciences, themselves parts of a general historical inquiry into the past and present

${ }^{1}$ Not the house-agent. 
of our race, that we would glance at the anecdotes, legends, and superstitions which are here collected. The writer has been chiefly interested in the question of the Evidence, its nature and motives, rather than in the question of Fact. It is desirable to know why independent witnesses, practically everywhere and always, tell the same tales. To examine the origin of these tales is not more 'superstitious' than to examine the origin of the religious and heroic mythologies of the world. It is, of course, easy to give both mythology, and 'the science of spectres,' the go by. But antiquaries will be inquiring, and these pursuits are more than mere 'antiquarian old womanries'. We follow the stream of fable, as we track a burn to its head, and it leads us into shy, and strange scenes of human life, haunted by very fearful wild-fowl, and rarely visited save by the credulous. There may be entertainment here, and, to the student of his species, there may be instruction.

On every side we find, as we try to show, in all ages, climates, races, and stages of civilisation, consentient testimony to a set of extraordinary phenomena. Equally diffused we find fraudulent imitations of these occurrences, and, on one side, a credulity which has accepted everything, on the other hand, a scepticism which denies and laughs at all the reports. But it is a question whether human folly would, everywhere and always, suffer from the same delusions, undergo the same hallucinations, and elaborate the same frauds. The problem is one which, in other matter, always haunts the student of man's development: he is accustomed to find similar myths, rites, customs, 
fairy tales, all over the world; of some he can trace the origin to early human imagination and reason, working on limited knowledge; about others, he asks whether they have been independently evolved in several places, or whether they have been diffused from a single centre. In the present case, the problem is more complicated. Taboos, totemism, myths explanatory of natural phenomena, customs like what, with Dr. Murray's permission, we call the Couvadc, are either peculiar to barbarous races, or, among the old civilised races, existed as survivals, protected by conservative Religion. But such things as 'clairvoyance,' 'levitation,' 'veridical apparitions,' 'movements of objects without physical contact,' 'rappings,' 'hauntings,' persist as matters of belief, in full modern civilisation, and are attested by many otherwise sa.e, credible, and even scientifically trained modern witnesses. In this persistence, and in these testimonies, the alleged abnormal phenomena differ from such matters as nature-myths, customs like Suttee, Taboo, Couvade, and Totemism, the change of men into beasts, the raising of storms by art-magic. These things our civilisation has dropped, the belief in other wild phenomena many persons in our civilisation retain.

The tendency of the anthropologist is to explain this fact by Survival and Revival. Given the savage beliefs in magic, spirit rapping, clairvoyance, and so forth, these, like Märchen, or nursery tales, will survive obscurely among peasants and the illiterate generally. In an age of fatigued scepticism and rigid physical science, the imaginative longings 
of men will fall back on the savage or peasant necromancy, which will be revived perhaps in some obscure American village, and be run after by the credulous and half-ivitted. Then the wished-for phenomena will be supplied by the dexterity of charlatans. As it is easy to demonstrate the quackery of paid 'mediums,' as that, at all events, is a vera causa, the theory of Survival and Revival seems adequate. Yet there are two circumstances which suggest that all is not such plain sailing. The first is the constantly alleged occurrence of 'spontaneous 'and sporadic abnormal phenomena, whether clairvoyance in or out of hypnotic trance, of effects on the mind and the senses apparently produced by some action of a distant mind, of hallucinations coincident with remote events, of physical prodigies that contradict the law of gravitation, or of inexplicable sounds, lights, and other occurrences in certain localities. These are just the things which Medicine Men, Mediums and classical Diviners have always pretended to provoke and produce by certain arts or rites. Secondly, whether they do or do not occasionally succeed, apart from fraud, in these performances, the 'spontaneous' phenomena are attested by a mass and quality of evidence, ancient, mediaval and modern, which would compel attention in any other matter. Living, sane, and scientifically trained men now,not to speak of ingenious, and intelligent, if superstitious observers in the past,-and Catholic gleaners of contemporary evidence for saintly miracle, and witnesses, judges, and juries in trials for witchcraft, are undeniably all ' in the same tale'. 
Now we can easily devise an explanation of the stories told by savages, by fanatics, by peasants, by persons under ecclesiastical influence, by witches, and victims of witches. That is simple, but why are sane, scientific, modern observers, and even disgusted modern sceptics, in a tale, and that just the old savage tale? What makes them repeat the stories they do repeat? We do not so much ask: 'Are these stories true?' as, 'Why are these stories told?' Professor Ray Lankester puts the question thus, and we are still at a loss for an answer.

Meanwhile modern science has actually accepted as real, some strange psychological phenomena which both science and common-sense rejected, between I720 and I840, roughly speaking. The accepted phenomena are always reported, historically, as attendant on the still more strange, and still rejected occurrences. We are thus face to face with a curious question of evidence: To what extent are some educated modern observers under the same illusions as Red Men, Kaffirs, Eskimo, Samoyeds, Australians, and Maoris? To what extent does the coincidence of their testimony with that of races so differently situated and trained, justify curiosity, interest, and perhaps suspense of judgment?

The question of the value of the facts is one to be determined by physiologists, physicians, physicists, and psychologists. It is clear that the alleged phenomena, both those now accepted and those still rejected, attend, or are said to attend, persons of singular physical constitution. It is not for nothing that Iamblichus, describing the constitution of his diviner, 
or seer, and the phenomena which he displays, should exactly delineate such a man as St. Joseph of Cupertino, with his miracles as recounted in the Acta Sanctorum ${ }^{1}$ (I603-I663). Now certain scientific, and (as a layman might suppose), qualified persons, aver that they have seen and even tested, in modern instances, the phenomena insisted on by Iamblichus, by the Bollandists, and by a great company of ordinary witnesses in all climes, ages, and degrees of culture. But these few scientific observers are scouted in this matter, by the vast majority of physicists and psychologists. It is with this majority, if they choose to find time, and can muster inclination for the task of prolonged and patient experiment, that the ultimate decision as to the portée and significance of the facts must rest. The problem cannot be solved and settled by anateurs, nor by 'common-sense,' that

Delivers brawling judgments all day long,

On all things, unashamed.

Ignorance, however respectable, and however contemptuous, is certainly no infallible oracle on any subject. Meanwhile most representatives of physical science, perhaps all official representatives, hold aloof,-not merely from such performances or pretences as can only be criticised by professional conjurers,-but from the whole mass of reported abnormal events. As the occurrences are admitted, even by believers, to depend on fluctuating and unascertained personal conditions, the reluctance of physicists to examine them is very natural and intelligible.

${ }^{1}$ Porphyry, Epistola xxi. Iamblichus, De Myst., iii, 2. 
Whether the determination to taboo research into them, and to denounce their examination as of perilous moral consequence, is scientific, or is obscurantist, every one may decide for himself. The quest for truth is usually supposed to be regardless of consequences, meanwhile, till science utters an opinion, till Roma locuta est, and does not, after a scrambling and hasty inquiry, or no inquiry at all, assert a prejudice; mere literary and historical students cannot be expected to pronounce a verdict.

Spiritualists, and even less convinced persons, have frequently denounced official men of science for not making more careful and prolonged investigations in this dusky region. It is not enough, they say, to unmask one imposture, or to sit in the dark four or five times with a 'medium'. This affair demands the close scrutiny of years, and the most patient and persevering experiment.

This sounds very plausible, but the few official men of science, whose names the public has heard, -and it is astonishing how famous among his peers a scientific character may be, while the public has never heard of him-can very easily answer their accusers : 'What,' they may cry, 'are we to investigate? It is absurd to ask us to leave our special studies, and sit for many hours, through many years, probably in the dark, with an epileptic person, and a few hysterical believers. We are not conjurers or judges of conjuring.' Again, is a man like Professor Huxley, or Lord Kelvin, to run about the country, examining every cottage where there are rumours of curious noises, and where stones and 
other missiles are thrown about, by undetectcd hands? That is the business of the police, and if the police are baffled, as in a Cock Lane affair at Port Glasgow, in 1864 , and in Paris, in 1846 , we cannot expect men of science to act as amateur detectives. ${ }^{1}$ Again, it is hardly to be expected that our chosen modern leaders of opinion will give themselves up to cross-examining ladies and gentlemen who tell ghost stories. Barristers and solicitors would be more useful for that purpose. Thus hardly anything is left which physical science can investigate, except the conauct and utterances of the hysterical, the epileptic, the hypnotised and other subjects who are occasionally said to display an abnormal extension of the perceptive faculties, for example, by way of clairvoyance. To the unscientific intelligence it seems conceivable that if Home, for example, could have been kept in some such establishment as the Salpetrière for a year, and could have been scrutinised and made the subject of experiment, like the other hysterical patients, his pretensions might have been decided on once for all. But he merely performed a few spcciosa miracula under tests established by one or two English men of science, and believers

1 The Port Glasgow stcry is in Report of the Dialectical Society, p. 200. The flooring was torn up; walls, ceilings, cellars, were examined by the police, and attempts were made to imitate the noises, without success. In this case, as at Rerrick in the end of the seventeenth century, and elsewhere, 'the appearance of a hand moving up and down' was seen by the family, 'but we could not catch it: it quietly vanished, and we only felt cold air'. The house was occupied by a gardener, Hugh McCardle. Names of witnesses, a sergeant of police, and others, are appended. 
and disbelievers are still left to wrangle over him. they usually introduce a question of moral character. Now a few men of science in England like Dr. Gregory about I $\delta_{5 I}$, and like Dr. Carpenter, and a larger number on the continent, have examined and are examining these peculiarities. Their reports are often sufficiently astonishing to the lay mind.

No doubt when, if ever, a very large and imposing body of these reports is presented by a cloud of scientific witnesses of esteemed reputation, then official science will give more time and study to the topic than it is at present inclined to bestow. Mr. Wallace has asserted that, "whenever the scientific men of any age have denied, on a priori grounds, the facts of investigation, they have always been wrong'.' He adds that Galileo, Harvey, Jenner, Franklin, Young, and Aiago, when he 'wanted even to discuss the subject of the electric telegraph,' were "vehemently opposed by their scientific contemporaries,' 'laughed at as dreamers,' ' ridiculed,' and so on, like the early observers of palæolithic axes, and similar prehistoric remains. This is true, of course, but, because some correct ideas were laughed at, it does not follow that whatever is laughed at is correct. The squarers of the circle, the discoverers of perpetual motion, the inquirers into the origin of language, have all been ridiculed, and ruled out of court, the two former classes, at least, justly enough. Now official science apparently regards all the long and universally rumoured ${ }^{1}$ Report of Dialectical Society, p. 86. 
abnormal occurrences as in the same category with Keely's Motor, and Perpetual Motion, not as in the same category with the undulatory theory of light, or the theory of the circulation of the blood. Clairvoyance, or ghosts, or suspensions of the law of gravitation, are things so widely contradictory of general experience and of ascertained laws, that they are pronounced to be impossible; like perpetual motion they are not admitted to a hearing.

As for the undeniable phenomenon that, in every land, age, and condition of culture, and in every stage of belief or disbelief, some observers have persistently asserted their experience of these occurrences; as for the phenomenon that the testimonies of Australian blacks, of Samoyeds, of Hiurons, of Greeks, of European peasants, of the Catholic and the Covenanting clergy, and of some scientifically trained modern physicians and chemists, are all coincident, official physical science leaves these things to anthropology and folk-lore. Yet the coincidence of such strange testimony is a singular fact in human nature. Even people of open mind can, at present, say no more than that there is a great deal of smoke, a puzzling quantity, if there be no fire, and that either human nature is very easily deluded by simple conjuring tricks, or that, in all stages of culture, minds are subject to identical hallucinations. The whole hocus-pocus of 'spirit-writing' on slates and in pellets of paper, has been satisfactorily exposed and explained, as a rather simple kind of leger-de-main. But this was a purely modern sort of trickery; the old universal class of useless miracles, said to occur spon- 
taneously, still presents problems of undeniable psychological interest.

For example, if it be granted, as apparently it was by Dr. Carpenter, that, in certain circumstances, certain persons, wide awake, can perform, in various ways, intelligent actions, and produce intelligent expressions automatically, without being conscious of what they are doing, then that fact is nearly as interesting and useful as the fact that we are descended from protozoa. Thus Dr. Carpenter says that, in 'table-talking,' 'cases have occasionally occurred in the experience of persons above suspicion of intentional deception, in which the answers given by the movements of tables were not only unknown to the questioners, but were even contrary to their belief at the time, and yet afterwards proved to be true. Such cases afford typical examples of the doctrine of unconscious cerebration, for in several of them it was capable of being distinctly shown that the answers, although contrary to the belief of the questioners at the time, were true to facts of which they had been formerly cognisant, but which had vanished from their recollection; the residua of these forgotten impressions giving rise to cerebral changes which prompted the responses without any consciousness on the part of the agents of the latent springs of their actions.' It is, apparently, to be understood that, as the existence of latent unconscious knowledge was traced in 'several ' cases, therefore the explanation held good in all cases, even where it could not be established as a fact.

Let us see how this theory works out in practice. 
Smith, Jones, Brown and Robinson are sitting with their hands on a table. All, ex hypothesi, are honourable men, 'above suspicion of intentional deception'. They ask the table where Green is. Smith, Jones and Robinson have no idea, Brown firmly believes that Green is in Rome. The table begins to move, kicks and answers, by aid of an alphabet and knocks, that Green is at Machrihanish, where, on investigation, he is proved to be. Later, Brown is able to show (let us hope by documentary evidence), that he had heard Green was going to Machrihanish, instead of to Rome as he had intended, but this remarkable change of plans on Green's part had entirely faded from Brown's memory. Now we are to take it, ex hypothesi, that Brown is the soul of honour, and, like Mr. Facey Rumford, 'wouldn't tell a lie if it was ever so'. The practical result is that, while Brown's consciousness informs him, trumpet-tongued, that Green is at Rome, 'the residue of a forgotten impression' makes him (without his knowing it) wag the table, which he does not intend to do, and forces him to say through the tilts of the table, that Green is at Machrihanish, while he believes that Green is at Rome.

The table-turners were laughed at, and many, if not all of them, deserved ridicule. But see how even this trivial superstition illuminates our knowledge of the human mind! A mere residuum of a forgotten impression, a lost memory which Brown would have sworn, in a court of justice, had never been in his mind at all, can work his muscles, while he supposes that they are not working, can 
make a table move at which three other honourable men are sitting, and can tell all of them what none of them knows. Clearly the expedient of table-turning in court might be tricd by conscientious witnesses, who have forgotten the circumstances on which they are asked to give evidence. As Dr. Carpenter remarks, quoting Mr. Lecky, 'our doctrine of unconscious cerebration inculcates toleration for differences not merely of belief, but of the moral standard'. And why not toleration for 'immoral' actions? If Brown's residuum of an impression can make Brown's muscles move a table to give responses of which he is ignorant, why should not the residuum of a forgotten impression that it would be a pleasant thing to shoot Mr. Gladistone or Lord Salisbury, make Brown unconsciously commit that solecism? It is a question of degree. At all events, if the unconscious seif can do as much as Dr. Carpenter believed, we cannot tell how many other marvels it may perform; we cannot know till we investigate further. If this be so, it is, perhaps, hardly wise or scientific to taboo all investigation. If a mere trivial drawing-room amusement, associated by some with an absurd 'animistic hypothesis,' can, when explained by Dr. Carpenter, throw such unexpectedly blinding light on human nature, who knows how much light may be obtained from a research into more serious and widely diffused superstitious practices? The research is, undeniably, beset with the most thorny of difficulties. Yet whosoever agrees with Dr. Carpenter must admit that, after one discovery so singular as 'unconscious cerebration,' in its effect on tables, some one is bound 
to go further in the same field, and try for more. IVe are assuming, for the sake of argument, the accuracy of Dr. Carpenter's facts. ${ }^{1}$

More than twenty years ago an attempt was made by a body called the 'Dialectical Society,' to investigate the phenomena styled spiritualistic. This well-meant essay had most unsatisfactory results. ${ }^{2}$

First a committee of inquiry was formed, on the motion of Dr. Edmunds. The committee was heterogeneous. Many of the names now suggest little to the reader. Mr. Bradlaugh we remember, but he chiefly attended a committee which sat with D. D. Home, and it is admitted that nothing of interest there occurred. Then we find the Rev. Maurice Davies, who was wont to write books of little distinction on semi-religious topics. Mr. H. G. Atkinson was a person interested in mesmerism. Kisch, Moss, and Quelch, with Dyte and Isaac Meyers, Bergheim and Geary, Hannah, Hillier, Reed (their names go naturally in blank verse), were, doubtless, all most estimable men, but scarcely boast of scientific fame. Serjeant Cox, a believer in the phenomena, if not in their spiritual cause, was of the company, as was Mr. Jencken, who married one of the Miss Foxes, the first authors of modern thaumaturgy. Professor Huxley and Mr. G. H. Lewes were asked to join, but declined to march to Sarras, the spiritual city, with

${ }^{1}$ For ourselves, we have never seen or heard a table give any responses whatever, any more than we have seen the ghosts, heard the raps, or viewed the flights of men in the air which we chronicle in a later portion of this work.

${ }^{2}$ Report on Spiritualism, Longmans, London, 1871 . 
the committee. This was neither surprising nor reprehensible, but Professor Huxley's letter of refusal appears to indicate that matters of interest, and, perhaps, logic, are differently understood by men of science and men of letters. ${ }^{1}$ He gave two reasons for refusing, and others may readily be imagined by the sympathetic observer. The first was that he had no time for an inquiry involving much trouble, and (as he justly foresaw) much annoyance. Next, he had no interest in the subject He had once examined a case of 'spiritualism,' and detected an imposture. 'But, supposing the phenomena to be genuine, they do not interest me If anybody would endow me with the faculty of listening to the chatter of old women and curates in the nearest cathedral town, I should decline the privilege, having better things to do.' Thus it would not interest Professor Huxley if some new kind of telephone should enable him to hear all the conversation of persons in a town (if a cathedral town) more or less distant. He would not be interested by the 'genuine' fact of this extension of his faculties, because he would not expect to be amused or instructed by the contents of what he heard. Of course he was not invited to listen to a chatter, which, on one hypothesis, was that of the dead, but to help to ascertain whether or not there were any genuine facts of an unusual nature, which some persons explained by the animistic hypothesis. 'To mere 'bellettristic triflers' the existence of genuine abnormal and unexplained facts seems to have been the object of inquiry, and we must peni-

$$
1 \text { Report, p. } 229 .
$$


tently admit that if genuine communications could really be opened with the dead, we would regard the circumstance with some degree of curious zest, even if the dead were on the intellectual level of curates and old women. Besides, all old women are not imbeciles, history records cases of a different kind, and even some curates are as intelligent as the apes, whose anatomy and customs, about that time, much occupied Professor Huxley. In Balaam's conversation with his ass, it was not so much the fact that mon ane parle bien which interested the prophet, as the circumstance that mon ane parlc. Science has obviously soared very high, when she cannot be interested by the fact (if a fact) that the dead are communicating with us, apart from the value of what they choose to say.

However, Professor Huxley lost nothing by not joining the committee of the Dialectical Society. Mr. G. H. Lewes, for his part, hoped that with Mr. Alfied Russel Wallace to aid (for he joined the committee) and with $\mathrm{Mr}$. Crookes (who apparently did not) 'we have a right to expect some definite result'. Any expectation of that kind was doomed to disappointment. In Mr. Lewes's own experience, which was large, 'the means have always been proved to be either deliberate imposture . . . or the well-known effects of expectant attention'. That is, when Lord Adare, the Master of Lindsay, and a cloud of other witnesses, thought they saw heavy bodies moving about of their own free will, either somebody cheated, or the spectators beheld what they did behold. because they expected to do so, 
even when, like M. Alphonse Karr, and Mr. Hamilton Aidé, they expected nothing of the kind. This would be Mr. Lewes's natural explanation of the circumstances, suggested by his own large experience.

The results of the Dialectical Society's inquiry were somewhat comic. The committee reported that marvels were alleged, by the experimental subcommittees, to have occurred. Sub-committee No. I averred that 'motion may be produced in solid bodies without material contact, by some hitherto unrecognised force'. Sub-committees 2 and 3 had many communications with mysterious intelligences to vouch for, and much erratic behaviour on the part of tables to record. No. 4 had nothing to report at all, and No. 5 which sat four times with Home had mere trifles of raps. Home was ill, and the séances were given up.

So far, many curious phenomena were alleged to have occurred, but now Dr. Edmunds, who started the whole inquiry, sent in a separate report. He complained that convinced spiritualists hacl 'captured' the editing sub-committee, as people say, and had issued a report practically spiritualistic. He himself had met nothing more remarkable than impudent frauds or total failure. 'Raps, noises, and movements of various kinds,' he had indeed witnessed, and he heard wondrous tales from truthful people, 'but I have never been able to see anything worthy of consideration, as not being accounted for by unconscious action, delusion, or imposture'. Then the editors of the Report contradicted Dr. 
Edmunds on points of fact, and Mr. A. R. Wallace disabled his logic, ${ }^{1}$ and $\mathrm{Mr}$. Geary dissented from the Report, and the editors said that his statements were incorrect, and that he was a rare attendant at séances, and Serjeant Cox vouched for more miracles, and a great many statements of the most astounding description were made by Mr. Varley, an electrician, by $\mathrm{D}$. D. Home, by the Master of Lindsay (Lord Crawford) and by other witnesses who had seen Home grow eight inches longer and also shorter than his average height; fly in the air; handle burning coals unharmed, cause fragrance of various sweet scents to fill a room, and, in short, rival St. Joseph of Cupertino in all his most characteristic performances. Unluckily Mr. Home, not being in the vein, did not one of these feats in presence of Mr. Bradlaugh and sub-committee No. 5. These results are clearly not of a convincing and harmonious description, and thus ended the attempt of the Dialectical Society. Nobody can do otherwise than congratulate Professor Huxley and Mr. Lewes, on their discreet reserve. The inquiry of the Dialectical Society was a failure;

${ }^{1} \mathrm{Mr}$. Wallace may be credited with scoring a point in argument. Dr. Edmunds had maintained that no amount of evidence would make him believe in certain obvious absurdities, say the lions in Trafalgar Square drinking out of the fountains. Mr. Wallace replied: "The asserted fact is either possible or not possible. If possible, such evidence as we have been considering would prove it; if not possible, such evidence could nct exist.' No such evidence exists for the lions ; for the phenomena of so-called spiritualism, we have consentient testimony in every land, period and stage of culture. That certainly makes a difference, whatever the weight and value of the difference may be. 
the members of the committees remained at variance ; and it is natural to side with the sceptics rather than with those who believed from the first, or were converted (as many are said to have been) during the experiments. Perhaps all such inquiries may end in no more than diversity of opinion. These practical researches ought not to be attempted by the majority of people, if by any. On many nervous systems, the mere sitting idly round a table, and calling the process a séance, produces evil effects.

As to the idea of purposely evoking the dead, it is at least as impious, as absurd, as odious to taste and sentiment, as it is insane in the eyes of reason. This protest the writer feels obliged to make, for while he regards the traditional, historical and anthropological curiosities here collected as matters of some interest, in various aspects, he has nothing but abhorrence and contempt for modern efforts to converse with the manes, and for all the profane impostures of 'spiritualism'.

On the question of the real existence of the reported phenomena hereafter chronicled, and on the question of the bortée of the facts, if genuine, the writer has been unable to reach any conclusion, negative or affirmative. Even the testimony of his senses, if they ever bore witness to any of the speciosa miracula, would fail to convince him on the affirmative side. There seems to be no good reason why one observer should set so much store by his own impressions of sense, while he regards those of all other witnesses as fallible. On the other hand, the writer feels unable to set wholly aside the concurrent 
testimony of the most diverse people, in times, lands and conditions of opinion the most various. The reported phenomena fall into regular groups, like the symptoms of a disease. Is it a disease of observation? If so, the topic is one of undeniable psychological interest. To urge this truth, to produce such examples as his reading affords, is the purpose of the author.

The topic has an historical aspect. In what sorts of periods, in what conditions of general thought and belief, are the alleged abnormal phenomena most current? Every one will answer: In ages and lands of ignorance and superstitions; or, again: In periods or religious, or, so to say, of irreligious crisis. As Mr. Lecky insists, belief in all such matters, from fairies to the miracles of the Gospel, declines as rationalism or enlightenment advances. Yet it is not as Mr. Lecky says, before reason that they vanish, not before learned argument and examination, but just before a kind of sentiment, or instinct, or feeling, that events contradictory of normal experience seem ridiculous, and incredible.

Now, if we set aside, for the present, ecclesiastical miracles, and judicial witchcraft, and fix our attention on such minor and useless marvels as clairvoyance, 'ghosts,' unexplained noises, unexplained movements of objects, one doubts whether the general opinion as to the ratio of marvels and ignorance is correct. The truth is that we have often very scanty evidence. If we take Athens in her lustre, we are, undeniably, in an age of enlightenment, of the Aufklärung. No rationalistic, philo- 
sophical, cool-headed contemporary of Middleton, of Hume, of Voltaire, could speak more contemptuously about ghosts, and about the immortality of the soul, than some of the Athenian gentlemen who converse with Socrates in the Dialogues. Yet we find that Socrates and Plato, men as well educated, as familiar with the refined enlightenment of Athens as the others, take to some extent the side of the old wives with their fables, and believe in earth-bound spirits of the dead. Again, the clear-headed Socrates, one of the pioneers of logic, credits himself with 'premonitions,' apparently with clairvoyance, and assuredly with warnings which, in the then existing state of psychology, he could only regard as 'spiritual'. Hence we must infer that belief, or disbelief, does not depend on education, enlightenment, pure reason, but on personal character and genius. The same proportionate distribution of these is likely to recur in any age.

Once more, Rome in the late Republic, the Rome of Cicero, was 'enlightened,' as was the Greece of Lucian; that is the educated classes were enlightened. Yet Lucretius, writing only for the educated classes, feels obliged to combat the belief in ghosts and the kind of Calvinism which, but for his poem, we should not know to have been widely prevalent. Lucian, too, mocks frequently at educated belief in just such minor and useless miracies as we are considering, but then Lucian lived in an age of cataclysm in religion. Looking back on history we find that most of historical time has either been covered with dark ignorance, among savages, among the populace, or in all classes; 
or, on the other hand, has been marked by enlightenment, which has produced, or accompanied, religious or irreligious crises. Now religious and irreligious crises both tend to beget belief in abnormal occurrences. Religion welcomes them as miracles divine or diabolical. Scepticism produces a reaction, and 'where no gods are spectres walk'. Thus men cannot, or, so far, men have not been able to escape from the conditions in which marvels flourish. If we are savages, then Vuis and Brewin beset the forest paths and knock in the lacustrine dwelling perched like a nest on reeds above the water; tornaks rout in the Eskimo hut, in the open wood, in the gunyeh, in the Medicine Lodge. If we are European peasants, we hearthe Brownie at work, and see the fairies dance in their grassy ring. If we are devoutly Catholic we behold saints floating in mid-air, or we lay down our maladies and leave our crutches at Lourdes. If we are personally religious, and pass days in prayer, we hear voices like Bunyan; see visions like the brave Colonel Gardiner or like Pascal; walk environed by an atmosphere of light, like the seers in Iamblichus, and like Mrs. Carlyle's ancestor, Welsh, the son-in-law of Knox. We are attended by a virtuous sprite who raps and moves tables as was a pious man mentioned by Bodin and a minister cited by Wodrow. We work miracles and prophesy, like Mr. Blair of St. Andrews (I639-I662); we are clairvoyant, like Mr. Cameron, minister of Lochend, or Loch-Head, in Kintyre (1679). If we are dissolute, and irreligious like Lord Lyttelton, or like Middleton, that enemy of Covenanters, we see ghosts, as they did, and have 
premonitions If we live in a time of witty scepticism, we take to the magnetism of Mesmer. If we exist in a period of learned and scientific scepticism, and are ourselves trained observers, we may still watch the beliefs of Mr. IVallace and the experiments witnessed by Mr. Crookes and Dr. Huggins.

Say we are Protestants, and sceptical, like Reginald Scot (I584), or Whigs, like De Foe, we then exclaim with Scot, in his Discovery of Witchcraft ( ${ }_{584}$ ), that minor miracles, moving tables, have gone out with benighted Popery, as De Foe also boasts in his History of the Devil. Alas, ot the table we must admit cppur si muove; it moves, or is believed by foreign savants to move, for a peasant medium, Eusapia Paladino. Mr. Lecky declares (I865) that Church miracles have followed Hop o' my Thumb; they are lost, with no track of white pebbles, in the forest of Rationalism. ${ }^{1}$ And then Lourdes comes to contradict his expectation, and Church miracles are as common as blackberries. Enfin, mankind, in the whole course of its history, has never got quit of experiences which, whatever their cause, drive it back on the belief in the marvellous. ${ }^{2}$

1 This illustration is not Mr. Lecky's.

2 We have here thrown together a crowd of odd experiences. The savages' examples are dealt with in the next essay; the Catholic marvels in the essay on 'Comparative Psychical Research'. For Pascal, consult L'Amulette de Pascal, by M. Lélut; for Iamblichus, see essay on 'Ancient Spiritualism'. As to Welsh, the evidence for the light in which he shone is printed in Dr. Hill Burton's Scot Abroad (i. 289), from a Wodrow MS. in Glasgow University. Mr. Welsh was minister of Ayr. He was meditating in his garden late at night. One ot his friends 'chanced to open a window towards the place where he walked, and saw clearly a strange light surround 
It is a noteworthy circumstance that (setting apart Church miracles, and the epidemic of witchcraft which broke out simultaneously with the new learning of the Renaissance, and was fostered by the enlightened Protestantism of the Reformers, the Puritans, and the Covenanters, in England, Scotland and America) the minor miracles, the hauntings and knockings, are not more common in one age than in another. Our evidence, it is true, does not quite permit us to judge of their frequency at certain periods. The reason is obvious. We have no newspapers, no miscellanies of daily life, from Greece, Rome, and the Middle Ages. We have from Greece and Rome but few literary examples of 'Psychical Research,' few collections of books on 'Bogles' as Scott called them. We possess Palæphatus, the life of Apollonius of Tyana, jests in Lucian, argument and exposition from Pliny, Porphyry, Iamblichus, Plutarch, hints from Plato, Plautus, Lucretius, from St. Augustine and other fathers. Suetonius chronicles noises and hauntings after the death of Caligula, but, naturally, the his-

him, and heard him speak strange words about his spiritual joy'. Hill Burton thinks that this verges on the Popish superstition. The truth is that eminent ministers shared the privileges of Mediums and of some saints. Examples of miraculous cures by ministers, of clairvoyance on their part, of spirit-raps attendant on them, and of prophecy, are current on Presbyterian hagiology. No ministers, to our knowledge, were 'levitated,' but some nearly flew out of their pulpits. Patrick Walker, in his Biographia Prcsbyteriana, vol. ii.p. 2I, mentions a supernatural light which floated round The Sweet Singers, Meikle John Gibb and his friends, before they burned a bible. Mr. Gibb afterwards excelled as a pow-wow, or Medicine Man, among the Red Indians. 
torian does not record similar disturbances in the paupcrum tabernaa.

Classical evidence on these matters, as about Greek and Roman folk-lore in general, we have to sift painfully from the works of literary authors who were concerned with other topics. Still, in the region of the ghostly, as in folk-lore at large, we have relics enough to prove that the ancient practices and beliefs were on the ordinary level of to-day and of all days: and to show that the ordinary numbers of abnormal phenomena were supposed to be present in the ancient civilisations. In the Middle Ages-the 'dark ages'-modern opinion would expect to find an inordinate quantity of ghostly material. But modern opinion would be disappointed. Setting aside saintly miracles, and accusations of witchcraft, the minor phenomena are very sparsely recorded. In the darkest of all 'dark ages,' when, on the current hypothesis, such tales as we examine ought to be most plentiful, even witch-trials are infrequent. Mr. Lecky attributes to these benighted centuries 'extreme superstition, with little terrorism, and, consequently, little sorcery'. The world was capable of believing anything, but it believed in the antidote as well as in the bane, in the efficacy of holy water as much as in the evil eye. When, with the dawn of enlightenment in the twelfth century, superstition became cruel, and burned witch and heretic, the charges against witches do not, as a rule, include the phenomena which we are studying. Witches are accused of raising storms, destroying crops, causing deaths and blighting marriages, by sympathetic 
magic ; of assuming the shapes of beasts, of having intercourse with Satan, of attending the Sabbat. All these fables, except the last, are survivals from savage beliefs, but none of these occurrences are attested by modern witnesses of all sorts, like the 'knockings,' ' movements,' 'ghosts,' 'wraiths,' ' second sight,' and clairvoyance.

The more part of mediæval witchcraft, therefore, is not quod semper, quod ubique, quod ab omnibus. The facts were facts: people really died or were sterile, flocks suffered, ships were wrecked, fields were ruined; the mistake lay in attributing these things to witchcraft. On the other hand, the facts of rappings, ghosts, clairvoyance, in spite of the universally consentient evidence, are very doubtful facts after all. Their existence has to be established before we look about for their cause. Now, of records about these phenomena the Middle Ages produce but a very scanty supply. The miracles which were so common were seldom of this kind; they were imposing visions of devils, or of angels, or of saints ; processions of happy or unhappy souls; views of heaven, hell, or purgatory. The reason is not far to seek: ecclesiastical chroniclers, like classical men of letters, recorded events which interested themselves; a wraith, or common ghost ('matter of daily experience,' says Lavaterus, and, later, contradicts himself), or knocking sprite, was beneath their notice. In mediæval sermons we meet a few edifying wraiths and ghosts, returning in obedience to a compact made while in the body. Here and there a chronicle, as of Rudolf of Fulda (858), vouches 
for communication with a rapping bogle. Grimm has collected several cases under the head of 'Housesprites,' including this ancient one at Capmunti, near Bingen. ${ }^{1}$ Gervase of Tilbury, Marie de France, John Major, Froissart, mention an occasional follet, brownie, or knocking sprite. The prayers of the Church contain a petition against the spiritus percutiens, or spirit who produces 'percussive noises'. The Norsemen of the Viking age were given to second sight, and Glam 'riding the roofs,' made disturbances worthy of a spectre peculiarly able-bodied. But, not counting the evidence of the Icelandic sagas, mediæval literature, like classical literature, needs to be carefully sifted before it yields a few grains of such facts as sane and educated witnesses even now aver to be matter of their personal experience. No doubt the beliefs were prevalent, the Latin prayer proves that, but examples were seldom recorded.

Thus the dark ages do not, as might have been expected, provide us with most of this material. The last forty enlightened years give us more bogics than all the ages between St. Augustine and the Restoration. When the dark ages were over, when learning revived, the learned turned their minds to 'Psychical Research,' and Wier, Bodin, Le Loyer, Georgius Pictorius, Petrus Thyraeus, James VI., collected many instances of the phenomena still said to survive. Then, for want of better materials, the unhappy, tortured witches dragged into their confessions all the folk-lore which

${ }^{1}$ Teutonic Mythology, English translation, vol. ii. p. ${ }^{114}$. He cites Pertz, i. 372 . 
they knew. Second sight, the fairy world, ghosts, 'wraiths,' ' astral bodies' of witches whose bodies of flesh are elsewhere, volatile chairs and tables, all were spoken of by witches under torture, and by sworn witnesses. ${ }^{1}$ Resisting the scepticism of the Restoration, Glanvil, More, Boyle, and the rest, fought the Sadducee with the usual ghost stories. Wodrow, later (I7OI-I73I), compiled the marvels of his Analecta. In spite of the cold common-sense of the eighteenth century, sporadic outbreaks of rappings and feats of impulsive pots, pans, beds and chairs insisted on making themselves notorious. The Wesley case would never have been celebrated if the sons of Samuel Wesley had not become prominent. John Wesley and the Methodists revelled in such narratives, and so the catena of testimonies was lengthened till Mesmer came, and, with Mesmer, the hypothesis of a 'fluidic force' which in various shapes has endured, and is not, even now, wholly extinct. Finally Modern Spiritualism arrived, and was, for the most part, an organised and fraudulent copy of the old popular phenomena, with a few cheap and vulgar variations on the theme.

In the face of these facts, it does not seem easy to aver that one kind of age, one sort of 'culture' is more favourable to the occurrence of, or belief in, these phenomena than another. Accidental circumstances, an increase, or a decrease of knowledge

${ }^{1}$ A very early turning table, of $\mathrm{II}_{7} \mathrm{O}$, is quoted from Giraldus Cambrensis by Dean Stanley in his Canterbury Menorials, p. Io3. The table threw off the weapons of Becket's murderers. This was at South Malling. See the original in Wharton's Anglia Sacra, ii. 425 . 
and education, an access of religion, or of irreligion, a fashion in intellectual temperament, may bring these experiences more into notice at one moment than at another, but they are always said to recur, at uncertain intervals, and are always essentially the same.

To prove this by examples is our present business. In a thoroughly scientific treatise, the foundation of the whole would, of course, be laid in a discussion of psychology, physiology, and the phenomena of hypnotism. But on these matters an amateur opinion is of less than no value. The various schools of psychologists, neurologists, 'alienists,' and employers of hypnotism for curative or experimental purposes, appear to differ very widely among themselves, and the layman may read but he cannot criticise their works. The essays which follow are historical, anthropological, antiquarian. 


\section{SAVAGE SPIRITUALISM.}

'Shadow,' or Magic of the Dìne Hareskins: its four categories. These are characteristic of all Savage Spiritualism. The subject somei'hat neglected by Anthropologists. Uniformity of phenomena. Mr. Tylor's theory of the origin of 'Animism'. Question whether there are any phenomena not explained by Mr. Tylor's theory. Examples of uniformity. The savage hypnotic trance. Hareskin examples. Cases from British Guiana. Australian rapping spirits. Maori oracles. A Maori 'séance'. The North American Indian Magic Lodge. Modern and old Jesuit descriptions. Movements of the Lodge. Insensibility of Red Indian Medium to fire. Similar case of D. D. Home. Flying table in Thibet. Other instances. Montezuma's 'astral body'. Miracles. Question of Diffusion by borrowing, or of independent evolution.

Philosophers among the Dènè Hareskins in the extreme north of America recognise four classes of 'Shadow' or magic. Their categories apply sufficiently closely to all savage sorcery (excluding sympathetic magic), as far as it has been observed. We have, among the Hareskins :-

I. Beneficent magic, used for the healing of the sick.

2. Malevolent magic: the black art of witchcraft. 
3. Conjuring, or the working of merely sportive miracles.

4. Magic for ascertaining the truth about the future or the distant present-clairvoyance. This is called 'The Young Man Bound and Bounding,' from the widely-spread habit of tying-up the limbs of the medium, and from his customary convulsions.

To all of these forms of magic, or spiritualism, the presence and aid of 'spirits' is believed to be necessary, with, perhaps, the exception of the sportive or conjuring class. A spirit helps to cure and helps to kill. The free spirit of the clairvoyant in bondage meets other spirits in its wanderings. Anthropologists, taking it for granted that 'spirits' are a mere 'animistic hypothesis'-their appearances being counterfeited by imposture-have paid little attention to the practical magic of savages, as far as it is not merely sympathetic. and based on the doctrine that ' like cures like'.

Thus Mr. Sproat, in his excellent work, Scenes and Studies of Savage Life, frankly admits that in Vancouver Island the trickery and hocus-pocus of Aht sorcery were so repugnant to him that he could not occupy himself with the topic. Some other travellers have been more inquisitive; unlettered sojourners among the wilder peoples have shared their superstitions, and consulted their oracles, while one or two of the old Jesuit missionaries were close and puzzled observers of their 'mediumship'.

Thus enough is known to show that savage spiritualism wonderfully resembles, even in minute details, that of modern mediums and séances, while 
both have the most striking parallels in the old classical thaumaturgy.

This uniformity, to a certain extent, is not surprising, for savage, classical, and modern spiritualism all repose on the primæval animistic hypothesis as their metaphysical foundation. The origin of this hypothesis-namely, that disembodied intelligences exist and are active-is explained by anthropologists as the result of early reasonings on life, death, sleep, dreams, trances, shadows, the phenomena of epilepsy, and the illusions of starvation. This scientific theory is, in itself, unimpeachable; normal phenomena, psychological and physical, might suggest most of the animistic beliefs. ${ }^{1}$

At the same time 'veridical hallucinations,' if there are any, and clairvoyance, if there is such a thing, would do much to originate and confirm the animistic opinions. Meanwhile, the extraordinary similarity of savage and classical spiritualistic rites, with the corresponding similarity of alleged modern phenomena, raises problems which it is more easy to state than to solve. For example, such occurrences as 'rappings,' as the movement of untouched objects, as the lights of the séance room, are all easily feigned. But that ignorant modern knaves should feign precisely the same raps, lights, and movements as the most remote and unsophisticated barbarians, and as the educated Platonists of the fourth century after Christ, and that many of the other phenomena should be identical in each case, is certainly noteworthy. This

${ }^{1}$ See Mr. Tylor's Primitive Culture, chap. xi., for the best statement of the theory. 
kind of folk-lore is the most persistent, the most apt to revive, and the most uniform. We have to decide between the theories of independent invention; of transmission, borrowing, and secular tradition; and of a substratum of actual fact.

Thus, either the rite of binding the sorcerer was invented, for no obvious reason, in a given place, and thence reached the Australian blacks, the Eskimo, the Dènè Hareskins, the Davenport Brothers, and the Neoplatonists; or it was independently evolved in each of several remote regions; or it was found to have some actual effect-what we cannot guess--on persons entranced. We are hampered by not knowing, in our comparatively rational state of development, what strange things it is natural for a savage to invent. That spirits should knock and rap seems to us about as improbable an idea as could well occur to the fancy. Were we inventing a form for a spirit's manifestations to take, we never should invent that. But what a savage might think an appropriate invention we do not know. Meanwhile we have the mediæval and later tales of rapping, some of which, to be frank, have never been satisfactorily accounted for on any theory. But, on the other hand, each of us might readily invent another common 'manifestation' - the wind which is said to accompany the spirit.

The very word spiritus suggests air in motion, and the very idea of abnormal power suggests the trembling and shaking of the place wherein it is present. Yet, on the other side, the 'cold non-natural wind' of séances, of Swedenborg, and of a hundred 
stories, old or new, is undeniably felt by some sceptical observers, even on occasions where no professional charlatan is engaged. As to the trembling and shaking of the house or hut, where the spirit is alleged to be, we shall examine some curious evidence, ancient and modern, savage and civilised. So of the other phenomena. Some seem to be of easy natural invention, others not so; and, in the latter case, independent evolution of an idea not obvious is a difficult hypothesis, while transmission from the Pole to Australia, though conceivable, is apt to give rise to doubt.

Meanwhile, one phenomenon, which is usually said to accompany others much more startling, may now be held to have won acceptance from science. This is what the Dènè Hareskins call the Sleep of the Shadow, that is, the Magical Sleep, the hypnotic trance. Savages are well acquainted with this abnormal condition, and with means of producing it, and it is at the bottom of all their more mysterious non-sympathetic magic. Before Mesmer, and even till within the last thirty years, this phenomenon, too, would have been scouted; now it is a commonplace of physiology. For such physical symptoms as introverted eyes in seers we need look no further than Martin's account of the second-sighted men, in his book on the Hebrides. The phenomenon of anæsthesia, insensibility to pain, in trance, is not unfamiliar to science, but that red-hot coals should not burn a seer or medium is, perhaps, less easily accepted; while science, naturally, does not recognise the clairvoyance, and still less the 'spiritual' 
attendants of the seer in the Sleep of the ShadowNevertheless, classical, modern, and savage spiritual. ists are agreed in reporting these last and most startling phenomena of the magic slumber in certain cases.

Beginning with what may be admitted as possible, we find that the Dène Hareskins practise a form of healing under hypnotic or mesmeric treatment. ${ }^{1}$ The physician (who is to be pitied) begins by a three days' fast. Then a 'magic lodge,' afterwards to be described, is built for him in the forest. Here he falls into the Sleep of the Shadow; the patient is then brought before him. In the lodge, the patient confesses his sins to his doctor, and when that ghostly friend has heard all, he sings and plays the tambour, involing the spirit to descend on the sick man. The singing of barbarous songs was part of classical spiritualism; the Norse witch, in The Saga of Eric the Red, insisted on the song of Warlocks being chanted, which secured the attendance of 'many powerful spirits'; and modern spiritualists enliven their dark and dismal programme by songs. Presently the Hareskin physician blows on the patient, and bids the malady quit him. He also makes 'passes' over the invalid till he produces trance; the spirit is supposed to assist. Then the spirit extracts the $\sin$ which caused the suffering, and the illness is cured, after the patient has been awakened by a loud cry. In all this affair of confession one is inclined to surmise a mixture of

${ }^{1}$ Petitot, Traditions Indiennes du Canada Nord-Ouest, p. 434. 
Catholic practice, imitated from the missionaries. It is also not, perhaps, impossible that hypnotic treatment may occasionally have been of some real service.

Turning to British Guiana, where, as elsewhere, hysterical and epileptic people make the best mediums, or 'Peay-men,' we are fortunate in finding an educated observer who submitted to be peaied. Mr. Im Thurn, in the interests of science, endured a savage form of cure for headache. The remedy was much worse than the disease. In a hammock in the dark, attended by a peay-man armed with several bunches of green boughs, Mr. Im Thurn lay, under a vow not to touch whatever might touch him. The peay-men kept howling questions to the kenaimas, or spirits, who answered. 'It was a clever piece of ventriloquism and acting.'

'Every now and then, through the mad din, there was a sound, at first low and indistinct, and then gathering in volume, as if some big, winged thing came from far towards the house, passed through the roof, and then settled heavily on the floor; and again, after an interval, as if the same winged thing rose and passed away as it had come,' while the air was sensibly stirred. A noise of lapping up some tobacco-water set out for the kenaimas was also audible. The rustling of wings, and the thud, 'were imitated, as I afterwards found, by skilfully shaking the leafy boughs, and then dashing them suddenly against the ground'. Mr. Im Thurn bit one of the boughs which came close to his face, and caught leaves in his teeth. As a 
rule he lay in a condition scarcely conscious: 'It seems to me that my spirit was as nearly separated from my body as is possible in any circumstances short of death. Thus it appears that the efforts of the peay-man were directed partly to the separation of his own spirit from his body, and partly to the separation of the spirit from the body of his patient, and that in this way spirit holds communion with spirit.' But Mr. Im Thurn's headache was not alleviated! The whirring noise occurs in the case of the Cock Lane Ghost ( 1762 ), in Iamblichus, in some 'haunted houses,' and is reported by a modern lady spiritualist in a book which provokes sceptical comments. Now, had the peay tradition reached Cock Lane, or was the peay-man counterfeiting, very cleverly, some real phenomenon ? ${ }^{1}$

We may next examine cases in which, the savage medium being entranced, spirits come to him and answer questions. Australia is so remote, and it is so unlikely that European or American spiritualists suggested their ideas to the older blacks (for mediumship seems to be nearly extinct since the settling of the country), that any transmission of such notions to the Black Fellows must be very ancient. Our authorities are Mr. Brough Smyth, in Aborigines of Victoria (i. 472), and Messrs. Fison and Horvitt, in Kamilaroi and Kurnai, who tell just the same tale. The spirits in Victoria are called Mrarts, and are

1 Very possibly the whirring roar of the turndun, or $\dot{\rho} \rho \mu \beta o s$, in Greek, Zuñi, Yoruba, Australian, Maori and South African mysteries is connected with this belief in a whirring sound caused by spirits. See Custom and Myth. 
understood to be the souls of Black Fellows dead and gone, not demons unattached. The mediums, now very scarce, are Birraarks. They were consulted as to things present and future. The Birraark leaves the camp, the fire is kept low, and some one 'cooees' at intervals. 'Then a noise is heard. The narrator here struck a book against the table several times to describe it.' This, of course, is 'spirit-rapping'. The knocks have a home among the least cultivated savages, as well as in mediæval and modern Europe. Then whistles are heard, a phenomenon lavishly illustrated in certain séances held at Rio de Janeiro ${ }^{1}$ where children were mediums. The spiritual whistle is familiar to Glanvil and to Homer. Mr. Wesley, at Epworth (I7I6), noted it among all the other phenomena. The Mrarts are next heard 'jumping down,' like the kenaimas. Questions are put to them, and they answer. They decline, very naturally, to approach a bright fire. The medium (Birraark) is found entranced, either on the ground where the Mrarts have been talking, or at the top of a tree, very difficult to climb, 'and up which there are no marks of any one having climbed'. The blacks, of course, are peculiarly skilled in detecting such marks. In maleficent magic, as among the Dènè Hareskins, the Australian sorcerer is tied up, ' his head, body, and limbs wound round with stringy bark cords'.$^{2}$ 'T' he enchantment is believed to drag the victim, in a trance, towards the sorcerer. This binding is customary among the Eskimo, and, as Mr. Myers has noted, was used in ${ }^{1}$ Proc. S. P. R., xix. 180. ${ }^{2}$ Brough Smyth, i. 475 . 
the rites described by the Oracles in 'trance utterances,' which Porphyry collected in the fourth century. Whether the binding was thought to restrain the convulsions of the mediums, or whether it was, originally, a 'test 'condition,' to prevent the medium from cheating (as in modern experiments), we cannot discover. It does not appear to be in use among the Maoris, whose speciality is 'trance utterance'.

A very picturesque description of a Maori séance is given in Old New Zealand. ${ }^{1}$ The story loses greatly by being condensed. A popular and accomplished young chief had died in battle, and his friends asked the Tohunga, or medium, to call him back. The chief was able to read and write; he had kept a journal of remarkable events, and that journal, though ' unceasingly searched for,' had disappeared. This was exactly a case for a test, and that which was given would have been good enough for spiritualists, though not for more reasonable human beings. In the village hall, in flickering firelight, the friends, with the English observer, the 'Pakeha Maori,' were collected. The medium, by way of a 'cabinet,' selected the darkest corner. The fire burned down to a red glow. Suddenly the spirit spoke, 'Salutation to my tribe,' and the chief's sister, a beautiful girl, rushed, with open arms, into the darkness; she was seized and held by her friends. The gloom, the tears, the sorrow, nearly overcame the incredulity of the Englishman, as the Voice came, 'a strange melancholy sound, like the sound of a wind blowing into a hollow vessel '. 'It is well with me,' it said; 
'my place is a good place.' They asked of their dead friends; the hollow answers replied, and the Englishman 'felt a strange swelling of the chest'. The Voice spoke again: 'Give my large pig to the priest,' and the sceptic was disenchanted. He now thought of the test. " "We cannot find your book," I said; "where have you concealed it?" The answer immediately came: "Between the Tahuhu of my house and the thatch, straight over you as you go into the door"', Here the brother rushed out. 'In five minutes he came back, with the book in his hand.' After one or two more remarks the Voice came, "Farewell!" from deep beneath the ground. "Farewell!" again from high in air. "Farewell!" once more came moaning through the distant darkness of the night. The deception was perfect. "A ventriloquist," said I, "or-or, perhaps the devil.", The séance had an ill end: the chief's sister shot herself.

This was decidedly a well-got-up affair for a colonial place. The Maori oracles are precisely like those of Delphi. In one case a chief was absent, was inquired for, and the Voice came, ' $\mathrm{He}$ will return, yet not return'. Six months later the chief's friends went to implore him to come home. They brought him back a corpse; they had found him dying, and carried away the body. In another case, when the Maori oracle was consulted as to the issue of a proposed war, it said: 'A desolate country, a desolate country, a desolate country!' The chiefs, of course, thought the other country was meant, but they were deceived, as Crosus was by Delphi, when 
he was told that he 'would ruin a great empire'. In yet another case, the Maoris were anxious for the spirits to bring back a European ship, on which a girl had fled with the captain. The Pakeha Maori was present at this séance, and heard the "hollow, mysterious whistling Voice, "The ship's nose I will batter out on the great sea"'. Even the priest was puzzled, this, he said, was clearly a deceitful spirit, or atua, like those of which Porphyry complains, like most of them in fact. But, ten days later, the ship came back to port; she had met a gale, and sprung a leak in the bow, called, in Maori, 'the nose' (ihu). It is hardly surprising that some Europeans used to consult the oracle.

Possibly some spiritualists may take comfort in these anecdotes, and allege that the Maori mediums were 'very powerful '. This is said to have been the view taken by some American believers, in a very curious case, reported by Kohl, but the tale, as he tells it, cannot possibly be accurate. However, it illustrates and strangely coincides with some stories related by the Jesuit, Père Lejeune, in the Canadian Mission, about I637. The instances bear both on clairvoyance and on the force which is said to shake houses as well as to lift tables, in the legends of the modern thaumaturgists. We shall take Kohl's tale before those of the old Jesuit. Kohl first describes the 'Medicine Lodge,' already alluded to in the account of Dènè Hareskin magic.

The 'lodge' answers to what spiritualists call 'the cabinet,' usually a place curtained off in modern practice. Behind this the medium now gets up his 
'materialisations,' and other cheap mysteries. The classical performers of the fourth century also knew the advantage of a close place, ' ' where the power would not be scattered'. This idea is very natural, granting the 'power'. The modern Ojibway 'close place,' or lodge, like those seen by old Jesuit fathers, ' is composed of stout posts, connected with basketwork, and covered with birch bark. It is tall and narrow, and resembles a chimney. It is very firmly built, and two men, even if exerting their utmost strength, would be unable to move, shake, or bend it.' 2 On this topic Kohl received information from a gentleman who 'knew the Indians well, and was even related to them through his wife'. He, and many other white people thirty years before, saw a Fossakeed, or medium, crawl into such a lodge as Kohl describes, beating his tambour. 'The entire case began gradually trembling, shaking, and oscillating slowly amidst great noise. . . . It bent back and forwards, up and down, like the mast of a vessel in a storm. I could not understand how those movements could be produced by a man inside, as we could not have caused them from the exterior.' 'Two voices, 'both entirely different,' were then heard within. 'Some spiritualists' (here is the weakest part of the story) 'who were present explained it through modern spiritualism.' Now this was not before 1859 , when Kohl's book appeared in English, and modern spiritualism, as a sect of philosophy, was not born till $I 848$, so that, thirty years before $I 859$, in I829, there

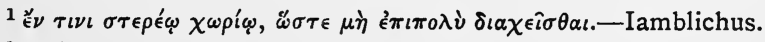

${ }^{2}$ Kohl, Kitchi-Gami, p. $27 \delta$. 
were no modern spiritualists. This, then, is absurd. However, the tale goes on, and Kohl's informant says that he knew the Fossakeed, or medium, who had become a Christian. On his deathbed the white man asked him how it was done: 'now is the time to confess all truthfully'. The converted one admitted the premisses-he was dying, a Christian man-but, 'Believe me, I did not deceive you at that time. I did not move the lodge. It was shaken by the power of the spirits. I could see a great distance round me, and believed I could recognise the most distant objects.' This ' with an expression of simple truth'. It is interesting, but the interval of thirty years is a naked impossibility. In I829 there were queer doings in America. Joe Smith's Mormons 'spoke with tongues,' like Irving's congregation at the same time, but there.were no modern spiritualists. Kohl's informant should have said 'ten years ago,' if he wanted his anecdote to be credited, and it is curious that Kohl did not notice this circumstance.

We now come to the certainly honest evidence of the Perre Lejeune, the Jesuit missionary. In the Relations de la Nouvelle France (I634), Lejeune discusses the sorcerers, who, as rival priests, gave him great trouble. He describes the Medicine Lodge just as Kohl does. The fire is put out, of course, the sorcerer enters, the lodge shakes, voices are heard in Montagnais and Algonkin, and the Father thought it all a clumsy imposture. The sorcerer, in a very sportsmanlike way, asked him to go in himself and try what he could make of it. 'You'll find that your body remains below and your soul mounts 
aloft.' The cautious Father, reflecting that there were no white witnesses, declined to make the experiment. This lodge was larger than those which Kohl saw, and would have held half a dozen men. This was in I634; by I637 Père Lejeune began to doubt whether his theory that the lodge was shaken by the juggler would hold water. Two Indians-one of them a sorcerer, Pigarouich, 'me descouvrant avec grande sincerité toutes ses malices'- 'making a clean breast of his tricks'-vowed that they did not shake the lodge-that a great wind entered fort promptement et rudement, and they added that the 'tabernacle' (as Lejeune very injudiciously calls the Medicine Lodge), 'is sometimes so strong that a single man can hardly stir it'. The sorcerer was a small weak man. Lejeune himself noted the strength of the structure, and saw it move with a violence which he did not think a man could have communicated to it, especially not for such a length of time. He was assured by many (Indian) witnesses that the tabernacle was sometimes laid level with the ground, and again that the sorcerer's arm and legs might be seen projecting outside, while the lodge staggered about-nay, more, the lodge would rock and sway after the juggler had left it. As usual, there was a savage, Auiskuouaskousit, who had seen a juggler rise in air out of the structure, while others, looking in, saw that he was absent. St. Theresa had done equal marvels, but this does not occur to the good Father.

The savage with the long name was a Christian catechumen, and yet he stood to it that he had seen 
a sorcerer disappear before his very eyes, like the second-sighted Highlander in Kirk's Secret Commonwealth (I69I). 'His neibours often perceaved this man to disappear at a certane place, and about one hour after to become visible.' It would be more satisfactory if the Father had seen these things himself, like Mrs. Newton Crosland, who informs the world that, when with Robert Chambers and other persons of sanity, she felt a whole house violently shaken, trembling, and thrilling in the presence of a medium-not a professional, but a young lady amateur. Here, of course, we greatly desire the evidence of Robert Chambers. Spirits came to Swedenborg with a wind, but it was only strong enough to flutter papers; 'the cause of which,' as he remarks with naïveté, 'I do not yet understand'. If Swedenborg had gone into a Medicine Lodge, no doubt, in that 'close place,' the phenomena would have been very much more remarkable. In 1853 Père Arnaud visited the Nasquapees, and describes a séance. 'The conjurers shut themselves up in a little lodge, and remain for a few minutes in a pensive attitude, cross-legged. Soon the lodge begins to move like a table turning, and replies by bounds and jumps to the questions which are put to the conjurer.' ${ }^{1}$ The experiment might be tried with a modern medium.

Father Lejeune, in I637, gives a case which reminds us of Home. According to Home, and to Mrs. S. C. Hall, and other witnesses, when ' in power' he could not only handle live coals without

${ }^{1}$ Hind's Explorations in Labrador, ii. 102. 
being burned, but he actually placed a large glowing coal, about the size of a cricket-ball, on the pate of Mr. S. C. Hall, where it shone redly through Mr. Hall's white locks, but did him no manner of harm. Now Father Pijart was present, tesmoin oculaire, when a Huron medicine-man heated a stone red hot, put it in his mouth, and ran round the cabin with it, without receiving any harm. Father Brébeuf, afterwards a most heroic martyr, sent the stone to Father Lejeune; it bore the marks of the medicine-man's teeth, though Father Pijart, examining the man, found that lips and tongue had no trace of burn or blister He reasonably concluded that these things could not be done 'sans l'opêration de quelque Démon'. That an excited patient should not feel fire is, perhaps, admissible, but that it should not scorch either Mr. Hall, or Home, or the Huron, is a large demand on our credulity. Still, the evidence in this case (that of Mr. Crookes and Lord Crawford) is much better than usual.

It would be strange if practices analogous to modern 'table-turning' did not exist among savage and barbaric races. Thus Mr. Tylor, in Primitive Culture (ii. I56), quotes a Kutuchtu Lama who mounted a bench, and rode it, as it were, to a tent where the stolen goods were concealed. The bench was believed, by the credulous Mongols, to carry the Lama! Among the Manyanja of Africa thefts are detected by young men holding sticks in their hands. After a sufficient amount of incantation, dancing, and convulsions, the sticks became possessed, the men 'can hardly hold them,' and are dragged after them in the required direc- 
tions. $^{1}$ These examples are analogous to the use of the Divining Rod, which is probably moved unconsciously by honest 'dowsers'; 'sometimes they believe that they can hardly hold it'. These are cases of movement of objects in contact with human muscles, and are therefore not at all mysterious in origin. A regular case of movement without contact was reported from Thibet, by M. Tschérépanoff, in I855. The modern epidemic of table-turning had set in, when M. Tschérépanoff wrote thus to the Abeille Russe: "The Lama can find stolen objects by following a table which flies before him'. But the Lama, after being asked to trace an object, requires an interval of some days, before he sets about finding it. When he is ready he sits on the ground, reading a Thibetan book, in front of a small square table, on which he rests his hands At the end of half an hour he rises and lifts his hands from the surface of the table: presently the table also rises from the ground, and follows the direction of his hand. The Lama elevates his hand above his head, the table reaches the level of his eyes: the Lama walks, the table rushes before him in the air, so rapidly that he can scarcely keep up with its flight. The table then spins round, and falls on the earth, the direction in which it falls, indicates that in which the stolen object is to be sought. M. Tschérépanoff says that he saw the table fly about forty feet, and fall. The stoler object was not immediately discovered, but

1 Rowley, Universities' Mission to Central Africa, p. 2I7: cited by Mr. Tylor.

${ }^{2}$ Quoted in La Table Parlante, a French serial, No. I, p. 6. 
a Russian peasant, seeing the line which the table took, committed suicide, and the object was found in his hut. The date was I83I. M. Tschérépanoff could not believe his eyes, and searched in vain for an iron wire, or other mechanism, but could find nothing of the sort. This anecdote, if it does not prove a miracle, illustrates a custom. ${ }^{1}$

As to clairvoyance among savages, the subject is comparatively familiar. Montezuma's priests predicted the arrival of the Spaniards long before the event. On this point, in itself well vouched for, Acosta tells a story which illustrates the identity of the 'astral body,' or double, with the ordinary body. In the witch stories of Increase Mather and others, where the possessed sees the phantasm of the witch, and strikes it, the actual witch proves to be injured. Story leads to story, and Mr. Thomas Hardy somewhere tells one to this effect. A farmer's wife, a woman of some education, fell asleep in the afternoon, and dreamed that a neighbour of hers, a woman, was sitting on her chest. She caught at the figure's arm in her dream, and woke. Later in the day she met her neighbour, who complained of a pain in the arm, just where the farmer's wife seized it in her dream. The place mortified and the poor lady died. To return to Montezuma. An honest labourer was brought before him, who made this very tough statement. He had been carried by an eagle into a cave, where he saw a man in splendid dress sleeping heavily. Beside him stood a burning stick

${ }^{1}$ Colonel A. B. Ellis, in his work on the Yorubas (1894), reports singular motions of a large wooden cylinder. It is used in ordeals. 
of incense such as the Aztecs used. A voice announced that this sleeper was Montezuma, prophesied his doom, and bade the labourer burn the slumberer's face with the flaming incense stick. The labourer reluctantly applied the flame to the royal nose, 'but he moved not, nor showed any feeling'. On this anecdote being related to Montezuma, he looked on his own face in a mirror, and 'found that he was burned, the which he had not felt till then'.'

On the Coppermine River the medicine-man, according to Hearne, prophesies of travellers, like the Highland second-sighted man, ere they appear. The Finns and Lapps boast of similar powers. Scheffer is copious on the clairvoyant feats of Lapps in trance. The Eskimo Angakut, when bound with their heads between their legs, cause luminous apparitions, just as was done by Mr. Stainton Moses, and by the mediums known to Porphyry and Iamblichus; the Angakut also send their souls on voyages, and behold distant lands. One of the oddest Angekok stories in Rink's Tales and Traditions of the Eskimo (p. 324) tells how some children played at magic, making 'a dark cabinet,' by hanging jackets over the door, to exclude the light. "The slabs of the floor were lifted and rushed after them:' a case of 'movement of objects without physical contact'. This phenomenon in future attended the young medium's possessions, even when he was away from home. This particular kind of manifestation, so very common in trials for witchcraft, and in

${ }^{1}$ The Natural and Morall History of the East and West Indies, p. 566 , London, 1604 . 
modern spiritualistic literature, does not appear to prevail much among savages. Persons otherwise credible and sane tell the authorities of the Psychical Society that, with only three amateurs present, things are thrown about, and objects are brought from places many miles distant, and tossed on the table. These are technically termed apports. The writer knows a case in which this was attested by a witness of the most unimpeachable character. But savages hardly go so far. Bishop Callaway has an instance in which 'spirits' tossed objects into the midst of a Zulu circle, but such things are not usual. Savages also set out food for the dead, but they scarcely attain to the credulity, or are granted the experience, of a writer in the Medium. ${ }^{1}$ This astonishing person knew a familiar spirit. At dinner, one day, an empty chair began to move, 'and in answer to the question whether it would have some dinner, said "Yes" '. It chose croquets de pomme de terre, which were placed on the chair in a spoon, lest the spirit, whose manners were rustic, should break a plate. 'In a few seconds I was told that it was eaten, and looking, found the half of it gone, with the marks showing the teeth.' Perhaps few savages would have told such a tale to a journal which ought to have a large circulation-among believers.

The examples of savage spiritualism which have been adduced might probably receive many additions ; those are but gleanings from a large field carelessly harvested. The phenomena have been but casually studied; the civilised mind is apt to see, in savage séances, nothing but noisy buffoonery. We have

${ }^{1}$ February 9, 1872. Quoted by Mr. Tylor, in Primitive Culture, ii. 39,1873 . 
shown that there is a more serious belief involved, and we have adduced cases in which white men were not unconscious of the barbarian spell. It also appears that the now recognised phenomena of hypnotism are the basis of the more serious savage magic. The production of hypnotic trances, perhaps of hypnotic hallucinations, is a piece of knowledge which savages possessed (as they were acquainted with quinine), while European physicians and philosophers ignored or laughed at it. Tobacco and quinine were more acceptable gifts from the barbarian. His magic has now and then been examined by a competent anthropologist, like Mr. Im Thurn, and Castren closely observed the proceedings of the bound and bounding Shamans among the Samoyeds. But we need the evidence both of anthropologists and of adepts in conjuring. They might detect some of the tricks, though Mr. Kellar, a professional conjurer and exposer of spiritualistic imposture, has been fairly baffled (he says) by $Z$ ulus and Hindus, while educated Americans are puzzled by the Pawnees. Mr. Kellar's plan of displaying a few of his own tricks was excellent: the dusky professionals were stimulated to show theirs, which, as described, were miracles. The Pakeha Maori, already quoted, saw a Maori Tohunga perform 'a very good miracle as times go,' but he does not give any particulars. The late Mr. Davey, who started as a Spiritualist catechumen, managed, by conjuring, to produce answers to questions on a locked slate, which is as near a miracle as anything. But Mr. Davey is dead, and he never published his secret, while it is im- 
probable that Mr. Maskelyne will enrich his reppertoire by travelling among $Z$ ulus, Hindus, and Pawnees. As savages cease to be savages, our opportunities of learning their mystic lore must decrease.

To one point in this research the notice of students in folk-lore may be specially directed. In the attempt to account for the diffusion of popular tales, such as Cinderella, we are told to observe that the countries most closely adjacent to each other have the most closely similar variants of the story. This is true, as a rule ; but it is also true that, while Scandinavian regions have a form of Cindevella with certain peculiarities not shared by Southern Europe, those crop up sporadically, far away, among Kaffirs and the Indian 'aboriginal' tribe of Santhals The same phenomenon of diffusion occurs when we find savage mediums tied up in their trances, all over the North, among Canadian Hareskins, among Samoyed and Eskimo, while the practice ceases at a given point in Labrador, and gives place to Medicine Lodges. The binding then reappears in Australia, and in the ancient Greek spiritualistic ceremonial. The writer is not acquainted with 'the bound and bounding young man' in the intervening regions, and it would be very interesting to find connecting cases, stepping-stones, as it were, by which the rite passed from the Australian continent to the Levant and the frozen North. If no such stepping-stones can be discovered, say in Africa and Southern Asia, the hypothesis that the practice has been invented in one place, and thence transmitted, will suffer some discredit. 


\section{ANCIENT SPIRITUALISM.}

M. Littré on 'demoniac affections,' a subject, in his opinion, worthy of closer study. Outbreak of Modern Spiritualism. Its relations to Greek and Esyptian Spiritualism recognised. Popular and literary sources of Modern Spiritualism. Neoplatonic thaumaturgy not among these. Porphyry and Iamblichus. The discerning of Spirits. The ancient attempts to prove 'spirit identity'. The test of 'spirit lights' in the ancient world. Perplexities of Porphyry. Dreams. The Assynt Murder. Eusebius on Ancient Spiritualism. The evidence of Texts from the Papyri. Evocations. Lights, levitation, airy music, ancesthesia of Mediums, ancient and modern. Alternative hypotheses: conjuring, 'sugrestion' and collective hallucination, actual fact. Strange case of the Rev. Stainton Moses. Tabular statement showing historical continuity of alleged phenomena.

In the Revue des Deux Mondes, for I856, tome i., M. Littré published an article on table-turning and ' rapping spirits'. M. Littré was a savant whom nobody accused of superstition, and France possessed no clearer intellect. Yet his attitude towards the popular marvels of the day, an attitude at once singular and natural, shows how easily the greatest minds can pay themselves with words. A curious reader, in that period of excitement about 'spiritualism,' would turn to the Revue, attracted by M. Littré's 
name. He would ask: 'Does M. Littré accept the alleged facts; if so, how does he explain them?' And he would find that this guide of human thought did not, at least, reject the facts; that he did not (as he well might have done) offer imposture as the general explanation; that he regarded the topic as very obscure, and eminently worthy of study,-and that he pooh-poohed the whole affair!

This is not very consistent or helpful counsel. Like the rest of us, who are so far beneath M. Littré in grasp and in weight of authority, he was subject to the idola fori, the illusions of the market-place. It would never do for a great scientific sceptic to say, 'Here are strange and important facts of human nature, let us examine them as we do all other natural phenomena,' it would never do for such a man to say that without qualification. So he concluded his essay in the pooh-pooh tone of voice. He first gives a sketch of abnormalities in 'mortal experience, as in the case of mental epidemics, of witchcraft, of the so-called prophets in the Cevennes, of the Jansenist marvels. He mentions a nunnery where, 'in the sixteenth century,' there occurred, among other phenomena, movements of inanimate objects, pottery specially distinguishing itself, as in the famous 'Stockwell mystery'. Unluckily he supplies no references for these adventures.' The Revue, being written for men and women of the world, may discuss such topics, but need not offer exact citations. M. Littre, on the strength of his historical sketch, decides, most correctly, that there is rien de nouveau, nothing new, in

${ }^{1}$ Revue des Deux Mondes, 1856 , tome i. p. $\$_{53}$. 
the spirit-rapping epidemic. 'These maladies never desert our race.' But this fact hardly explains why 'vessels were dragged from the hands' of his nuns in the sixteenth century.

In search of a cause, he turns to hallucinations. In certain or uncertain physical conditions, the mind can project and objectify, its own creations. Thus Gleditch saw the dead Maupertuis, with perfect distinctness, in the salle of the Academy at Berlin. Had he not known that Maupertuis was dead, he could have sworn to his presence (p. 866). Yes: but how does that explain volatile pots and pans? Well, there are collective hallucinations, as when the persecuted in the Cevennes, like the Covenanters, heard non-existent psalmody And all witches told much the same tale; apparently because they were collectively hallucinated. Then were the spectators of the agile crockery collectively hallucinated? M. Littré does not say so explicitly, though this is a conceivable theory. He alleges after all his scientific statements about sensory troubles, that 'the whole chapter, a chapter most deserving of study, which contains the series of demoniac affections (affections demoniaques), has hardly been sketched out'.

Among accounts of 'demoniac affections,' descriptions of objects moved without contact are of frequent occurrence. As M. Littré says, it is always the same old story. But why is it always the same old story? There were two theories before the world in $I 856$. First there was the 'animistic hypothesis,' 'spirits' move the objects, spirits raise the medium in the air, spirits are the performers of the airy 
music. Then there was the hypothesis of a force or fluid, or faculty, inherent in mankind, and notable in some rare examples of humanity. This force, fluid, agency, or what you will, counteracts the laws of gravitation, and compels tables, or pots, to move untouched.

To the spiritualists M. Littré says, 'Bah!' to the partisans of a force or fluid, he says, 'Pooh!' 'If your spirits are spirits, why do they let the world wag on in its old way, why do they confine themselves to trivial effects?'

The spiritualist would probably answer that he did not understand the nature and limits of spiritual powers.

To the friends of a force or faculty in our nature, M. Littré remarks, in effect, ' Why don't you use your force? why don't you supply a new motor for locomotives? Pooh!' The answer would be that it was not the volume and market value of the force, but the existence of the force, which interested the inquirer. When amber, being rubbed, attracted straws, the force was as much a force, as worthy of scientific study, as when electricity is employed to bring bad news more rapidly from the ends of the earth.

These answers are obvious: M. Littré's satire was not the weapon of science, but the familiar test of the bourgeois and the Philistine. Still, he admitted, nay, asserted strongly, that the whole series of 'demoniac affections' was 'most worthy of investigation,' and was 'hardly sketched out'. In a similar manner, Brierre de Boismont, in his work on hallu- 
cinations, explains a number of 'clairvoyant' dreams, by ordinary causes. But, coming to a vision which he knew at first hand, he breaks down: 'We must confess that these explanations do not satisfy us, and that these events seem rather to belong to some of the deepest mysteries of our being '. ${ }^{1}$ There is a point at which the explanations of commonsense arouse scepticism.

Much has been done, since 1856 , towards producing a finished picture, in place of an ébauche. The accepted belief in the phenomena of hypnotism, and of unconscious mental and bodily actions-' automatisms'-has expelled the old belief in spirits from many a dusty nook. But we still ask: 'Do objects move untouched? why do they move, or if they move not at all (as is most probable) why is it always the same story, from the Arctic circle to the tales of witches, and of mediums ?'

There is little said about this particular phenomena (though something is said), but there is much about other marvels, equally widely rumoured of, in the brief and $\operatorname{dim}$ Greek records of thaumaturgy. To examine these historically is to put a touch or two on the picture of 'demoniac affections,' which M. Littré desired to see executed. The Greek mystics, at least, believed that the airy music, the movements of untouched objects, the triumph over gravitation, and other natural laws, for which they vouch, were caused by 'demons,' were 'demoniac affections'. To compare the statements of Eusebius and Iamblichus with those of modern men of science and other

${ }^{1}$ Hallucinations, English translation, p. 182, London, 1859. 
modern witnesses, can, therefore, only be called superfluous and superstitious by those who think M. Littré superstitious, and his desired investigation 'superfluous'.

When the epidemic of 'spiritualism' broke out in the United States (I848-I852) students of classical literature perceived that spiritualism was no new thing, but a recrudescence of practices familiar to the ancient world Even readers who had confined their attention to the central masterpieces of Greek literature recognised some of the revived 'phenomena'. The 'Trance Medium,' the 'Inspirational Speaker' was a reproduction of the maiden with a spirit of divination, of the Delphic Pythia. In the old belief, the god dominated her, and spoke from her lips, just as the 'control,' or directing spirit, dominates the medium. But there were still more striking resemblances between ancient and modern thaumaturgy, which were only to be recognised by readers of the late Neoplatonists, such as Porphyry, and of the Christian Fathers, such as Eusebius, who argued against the apologists of heathenism. The central classical writers, from Homer to Tacitus, are not superstitious; they accept the orthodox state magic of omens, of augurs, of prodigies, of oracles, but anything like private necromancy is alien and distasteful to them. We need not doubt that sorcery and the consultation of the dead were being practised all through the classical period, indeed we know that it was so. Plato legislates against sorcery in a practical manner; whether it does harm or not, men are persuaded that it does harm; it is vain to argue 
with them, therefore the wizard and witch are to be punished for their bad intentions. ${ }^{1}$

There were regular, and, so to speak, orthodox oracles of the dead. They might be consulted by such as chose to sleep on tombs, or to visit the cavern of Trophonius, or other chasms which were thought to communicate with the under world. But the idea of bringing a shade, or a hero, a demon, or a god into a private room, as in modern spiritualism, meets us late in such works as the Letter of Porphyry, and the Reply of Iamblichus, written in the fourth century of our era. If we may judge by the usual fortune of folk-lore, these private spiritualistic rites, without temple, or state-supported priestly order, were no new things in the early centuries of Christianity, but they had not till then occupied the attention of philosophers and men of letters. The dawn of our faith was the late twilight of the ancient creeds, the ciassic gods were departing, belief was waning, ghosts were walking, even philosophers were seeking for a sign. The mysteries of the East had invaded Hellas.

The Egyptian theory and practice were of special importance. Bycertain sacramental formulæ, often found written on papyrus, the gods could be constrained, and made, like mediæval devils, the slaves of the magician. Examples will occur later. This idea was alien to the Greek mind, at least to the philosophic Greek mind. The Egyptians, like Michael Scott, had books of dread, and an old Egyptian romance turns on the evils which arose, as to William of Deloraine, from the possession of 
such a volume. ${ }^{1}$ Half-understood strings of Hebrew, Syriac, and other 'barbarous' words and incantations occur in Greek spells of the early Christian age. Again, old Hellenic magic rose from the lower strata of folk-lore into that of speculation. The people, the folk, is the unconscious self, as it were, of the educated and literary classes, who, in a twilight of creeds, are wont to listen to its promptings, and return to the old ancestral superstitions long forgotten.

The epoch of the rise of modern spiritualism was analogous to that when the classical and oriental spiritualism rose into the sphere of the educated consciousness In both periods the marvellous 'phenomena' were practically the same, and so were the perplexities, the doubts, the explanatory hypotheses of philosophical observers. This aspect of the modern spiritualistic epidemic did not escape attention. Dr. Leonard Marsh, of the University of Vermont, published, in I854, a treatise called The Apocatastasis, or Progress Backwards. He proved that the marvels of the Foxes, of Home, and the other mediums, were the old marvels of Neoplatonism. But he draws no conclusion except that spiritualism is retrogressive. His book is wonderfully ill-printed, and, though he had some curious reading, his style was cumbrous, jocular, and verbose. It may, therefore, be worth while, in the light of anthropological research, to show how very closely human nature has repeated its past performances.

The new marvels were certainly not stimulated by literary knowledge of the ancient thaumaturgy. 
Modern spiritualism is an effort to organise and ' exploit' the traditional and popular phenomena of rapping spirits, and of ghosts. Belief in these had always lived an underground life in rural legend, quite unharmed by enlightenment and education. So far, it resembled the ordinary creeds of folk-lore. It is probable that, in addition to oral legend, there was another and more literary source of modern thaumaturgy. Books like Glanvil's, Baxter's, those of the Mathers and of Sinclair, were thumbed by the people after the literary class had torgotten them. Moreover, the Foxes, who started spiritualism, were Methodists, and may well have been familiar with 'old Jeffrey,' who haunted the Wesleys' house, and with some ol the stories of apparitions in Wesley's Arminian Magazine.

If there were literary as well as legendary sources of nascent spiritualism, the sources were these. Porphyry, Iamblichus. Eusebius, and the life of Apollonius of Tyana, cannot have influenced the illiterate parents of the new thaumaturgy. This fact makes the repetition, in modern spiritualism, of Neoplatonic theories and Neoplatonic marvels all the more interesting and curious.

The shortest cut to knowledge of ancient spiritualism is through the letter of Porphyry to Anebo, and the reply attributed to Iamblichus. Porphyry, the disciple of Plotinus, was a seeker for truth in divine things. Prejudice, literary sentiment, and other considerations, prevented him from acquiescingin the Christian verity. The ordinary paganism shocked him, both by its obscene and undignified 
myths, and by many features of its ritual. $\mathrm{He}$ devised non-natural interpretations of its sacred legends, he looked for a visible or tangible 'sign,' and he did not shrink from investigating the thaumaturgy of his age. His letter of inquiry is preserved in fragments by Eusebius, and St. Augustine: Gale edited it, and, as he says, offers us an Absyrtus (the brother of Medea, who scattered his mutilated remains) rather than a Porphyry. ${ }^{1}$ Not all of Porphyry's questions interest us for our present purpose. He asks, among other things: How can gods, as in the evocations of gods, be made subject to necessity, and compelled to manifest themselves ? ${ }^{2}$

How do you discriminate between demons, and gods, that are manifest, or not manifest? How does a demon differ from a hero, or from a mere soul of a dead man?

By what sign can we be sure that the manifesting agency present is that of a god, an angel, an archon, or a soul? For to boast, and to display phantasms, is common to all these varieties. ${ }^{3}$

In these perplexities, Porphyry resembles the anxious spiritualistic inquirer. A 'materialised spirit' alleges himself to be Washington, or Franklin, or the lost wife, or friend, or child of him who seeks the mediums. How is the inquirer, how was Porphyry to know that the assertion is correct, that it is not the mere 'boasting' of some vulgar spirit? In the same way, when messages are given through a

1 The references are to Parthey's edition, Berlin, I857.

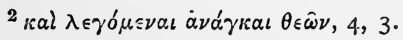

'All are, ior Porphyry, 'phantasmogenetic agencies'. 
medium's mouth, or by raps, or movements of a table, or a planchette, or by automatic writing, how (even discounting imposture) is the source to be verified? How is the identity of the spirit to be established? This question of discerning spirits, of identifying them, of not taking an angel for a devil, or vice versa, was most important in the Middle Ages. On this turned the fate of Joan of Arc: Were her voices and visions of God or of Satan? They came, as in the cases mentioned by Iamblichus, with a light, a hallucination of brilliance. When Jean Bréhal, Grand Inquisitor of France, in I450-I 456, held the process for rehabilitating Joan, condemned as a witch in I43I, he entered learnedly into the tests of 'spirit-identity'.' St. Theresa was bidden to try to exorcise her visions, by the sign of the Cross. Saint or sorcerer? it was always a delicate inquiry.

Iamblichus, in his reply to Porphyry's doubts, first enters into theology pretty deeply, but, in book ii. chap. iii. he comes, as it were, to business. The nature of the spiritual agency present on any occasion may be ascertained from his manifestations or epiphanies. All these agencies show in a light, we are reminded inevitably of the light which accompanied the visions of Colonel Gardiner and of Pascal. Joan of Arc, too, in reply to her judges, averred that a light (claritas) usually accompanied the voices which came to her. ${ }^{2}$ These things, if we call them hallucinations, were, at least, hallucinations of the good and great, and must be regarded not

${ }^{1}$ Fean Bréhal, par P.P. Bélon et Balme, Paris, s.a., p. I05.

${ }^{2}$ Procis de Condemnation, i. 75 . 
without reverence. But modern spiritualistic and ghostly literature is full of lights which accompany 'manifestations,' or attend the nocturnal invasions of apparitions. Examples are so common that they can readily be found by any one who studies Mrs. Crowe's Night Side of Nature, or Home's Life, or Phantasms of the Living, or the Proceedings of the Psychical Society. Meantime Homer, and Theocritus in familiar passages, attest this belief in light attendant on the coming of the divine, while the Norse Sagas, and the well-known tale of Sir Charles Lee's daughter and the ghost of her mother (I662), speak for the same belief in the pre-Christian north, and in the society of the Restoration. ${ }^{1}$ A light always comes among the Eskimo, when the tornak, or familiar spirit, visits the Angekok or sorcerer. Here, then, is harmony enough in the psychical beliefs of all time, as when we learn that lights were flashed by the spirits who beset the late Rev. Stainton Moses. ${ }^{2}$ Unluckily, while we have this cloud of witnesses to the belief in a spiritual light, we are still uncertain as to whether the seeing of such a light is a physical symptom of hallucination. This is the opinion of M. Lélut, as given in his Amulette de Pascal (p. 30I): 'This globe of fire . . . is a common constituent of hallucinations of sight, and may be regarded at once as their most elementary form, and their highest degree of intensity'. M. Lélut knew the phenomenon among mystics whom he had observed in

1 Appended to Beaumont's work on Spirits, 1705.

${ }^{2}$ See Mr. Lillie's Modern Mystics, and, better, Mr. Myers, in Proceedings S. P. R., Jan., 1894 . 
his practice as an 'alienist'. He also quotes a story told of himself by Benvenuto Cellini. If we can admit that this hallucination of brilliant light may be produced in the conditions of a séance, whether modern, savage, or classical, we obtain a partial solution of the problem presented by the world-wide diffusion of this belief. Of course, once accepted as an element in spiritualism, a little phosphorus supplies the modern medium with a requisite of his trade. $^{1}$

Returning to Iamblichus, he classifies his phantasmogenetic agencies by the kind of light they show; greater or less, more or less divided, more or less pure, steady or agitated (ii. 4). The arrival of demons is attended by disturbances. ${ }^{2}$ Heroes are usually very noisy in their manifestations: a hero is a polter-geist, 'sounds echo around' (ii. 8). There are also subjective moods diversely generated by diverse apparitions; souls of the dead, for example, prompt to lust (ii. 9). On the whole, a great deal of experi-

${ }^{1}$ Origen. or whoever wrote the Philosophoumena, gives a recipe for producing a luminous figure on a wall. For moving lights, he suggests attaching lighted tow to a bird, and letting it loose. Maury translates the passages in La Magic, pp. 58-59. Spiritualists, of course, will allege that the world-wide theory of spectral lights is based on fact, and that the hallucinations are not begotten by subjec. tive conditions, but by a genuine 'phantasmogenetic agency'. Two men of science, Baron Schrenk-Notzing, and Dr. Gibotteau, vouch for illusions of light accompanying attempts by living agents to transfer a hallucinatory vision of themselves to persons at a distance (Fo:ırnal S. P. R., iii. 307 ; Proceedings, viii. 467). It will be asserted by spiritualists that disembodied asencies produce the same eftect in a higher degree.

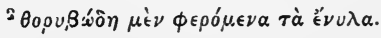


ence is needed by the thaumaturgist, if he is to distinguish between one kind of manifestation and another. Even Inquisitors have differed in opinion.

Iamblichus next tackles the difficult question of imposition and personation by spirits. Thus a soul, or a spirit, may give itself out for a god, and exhibit the appropriate phantasmagorı: may boast and deceive (ii. Io). This is the resuit of some error or blunder in the ceremony of evocation. ${ }^{1}$ A bad or low spirit may thus enter. disguisea as a demon or god, and may utter deceitful words But al: arts, says our guide, are liable to errors, and the 'sacred art' must not be judged by its occasional imperfections. We know the same kind of excuses in modern times.

Porphyry went on to ask questions about divination and clairvoyance. We often ascertain the future, he says, in dreams, when our bodies are lying still and peaceful: when we are in no convulsive ecstasy such as diviners use. Many persons prophesy ' in enthus1astic and divinely seized moments, awake, in a sense, yet not in their habitual state of consciousness'. Music of certain kinds, the water of certain holy wells, the vapours of Branchidæ, produce such ecstatic effects. Some 'take darkness for an ally' (dark séances), some see visions in water, others on a wall, others in sun or moon. As an example of ancient visions in water, we may take one from the life of Isidorus, by Damascius. Isidorus, and his biographer, were acquainted with women who beheld in pure water in a glass vessel the phantasms of

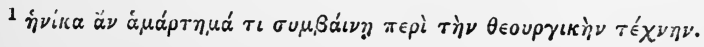


future events. ${ }^{1}$ This form of divination is still practised, though crystal balls are more commonly used than decanters of water. Ancient and modern superstition as in the familiar case of Dr. Dee, attributes the phantasms to spiritual agency

Is a divine being compelled, Porphyry asks, to aid in these efforts, or is it only the soul of the seer, as some believe, which hallucinates itself, by the aid of points de reperve? ${ }^{2}$ Or is there a blending of the soul's operations with the divine inspiration? Or are demons in some way evolved out of something abstracted from living bodies? He seems to hint at some such theory of 'exuvious fumes' from the 'circle,' as more recent inquirers have imagined. The young appear to be peculiarly sensitive to vapours, invocations, and other magical methods, which affect the human constitution, and the young are usually engaged as seers. Hence visions are probably subjective. Ecstasy, madness, fasts and vigils seem particularly favourable to divination. Or are there certain mystic correspondences in the nature of things, which may be detected? Thus stones and herbs are used in evocations; 'sacred bonds' are tied (as in the Eskimo hypnotism and in Australia) ; closed doors are opened, the heavenly bodies are observed. Some suppose that there is a race of false and counterfeiting spirits, which, indeed, Iamblichus admits. These act the parts of gods, demons, and souls of the dead. Again, the conjurer plays on our expectant attention. Omitting some remarks no longer appropriate, Porphyry

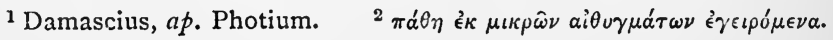


asks what use there is in chanting barbarous and meaningless words. $\mathrm{He}$ is inclined to think that the demon, or guardian spirit of each man is only part of his soul,-in fact his 'subliminal self'. And generally, he suspects that the whole affair is ' a mere imaginative deceit, played off on itself by the soul'.

Replying as to divination, Iamblichus says that the right kind of dreams are between sleeping and waking when we hear a voice giving directions. A modern example occurred in the trial of the Assynt murderer in I83I. One Kenneth Fraser, called 'the dreamer,' said in the trial: 'I was at home when I had the dream. It was said to me in my sleep by a voice like a man's voice, that the pack (of the murdered pedlar) was lying in sight of the place. I got a sight of the place just as if I had been awake. I never saw the place before, but the voice said in Gaelic, "the pack of the merchant is lying in a cairn of stones, in a hollow near to their house". The voice did not name Macleod's house.' The pack was, however, not found there, but in a place hard by, which Kenneth had not seen in his dream. Oddly enough, the murderer had originally hidden the pack, or some of its contents, in a cairn of stones, but later removed it. In the 'willing game,' as played by Mr. Stuart Cumberland, the seeker usually goes first to the place where the hider had thought of concealing the object, though later he changed his mind. Macleod was hanged, he confessed his guilt. ${ }^{1}$

${ }^{1}$ Life of Hugh Macleod (Noble, Inverness). As an example of the growth of myth, see the version of these facts in Fraser's Magazine for 1856 . Even in a sermon preached immediately after 
Iamblichus believed in dreams of this kind, and in voices heard by men wide awake, as in the case of Joan of Arc. When an invisible spirit is present, he makes a whirring noise, like the Cock Lane Ghost ! ${ }^{1}$ Lights also are exhibited; the medium then by some mystic sense knows what the spirit means. The soul has two lives, one animal, one intellectual; in sleep the latter is more free, and more clairvoyant. In trance, or somnambulism, many cannot feel pain even if they are burned, the god within does not let fire harm them (iii. 4). This, of course, suggests Home's experiments in handling live coals, as $\mathrm{Mr}$. Crookes and Lord Crawford describe them. Compare the Berserk 'coal-biters' in the saga of Egil, and the Huron coal-biter in the preceding essay. 'They do not then live an animal life.' Sword points do not hurt them. Their actions are no longer human. 'Inaccessible places are accessible to them, when thus borne by the gods; and they tread on fire unharmed; they walk across rivers. . . . They are not themselves, they live a diviner life, with which they are inspired, and by which they are possessed.' Some are convulsed in one way, some in another, some are still. Harmonies are heard (as in Home's case and that of Mr. Stainton Moses). Their bodies are elongated (like Home's), or broadened, or float in mid-air, as in a hundred tales of mediums and saints. Sometimes the medium sees a light when the spirit takes possession of him, sometimes all present see it

the event, it was said that the dreamer found the pack by revelation of his dream!

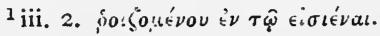


(iii. 6). Thus Wodrow says (as we have already shown), that Mrs. Carlyle's ancestor, Mr. Welsh, shone in a light as he meditated; and Patricis Walker tells the same tale about two of the fanatics called 'Sweet Singers'.

From all this it follows, Iamblichus holds, that spiritual possession is a genuine objective fact and that the mediums act under real spiritual control. Omitting local oracles, and practices apparently analogous to the use of planchette, Iamblichus regards the heavenly light as the great source of and evidence for the external and spiritual character and cause of divination (iii. I4). Iamblichus entirely rejects all Porphyry's psychological theories of hallucinations, of the demon or 'genius' as 'subliminal self,' and asserts the actual, objective, sensible action of spirits, divine or dæmonic. What effect Iamblichus produced on the inquiring Porphyry is uncertain. In his De Abstinentia (ii. 39) he gives in to the notion of deceitful spirits.

In addition to the evidence of Porphyry, Iamblichus, Eusebius and other authors of the fourth century, some recently published papyri of the same period throw a little light on the late Greek thaumaturgy. ${ }^{1}$ Thus Papyrus cxxv. verso (about the fifth century) ' contains elaborate instructions for a magical process, the effect of which is to evoke a goddess, to transform her into the appearance of an old woman, and to bind to her the service of the person using the spell. . . '

${ }^{1}$ Greek Papyri in the British Museum; edited by F. G. Kenyon, M.A., London, 1893 . 
Obviously we would much prefer a spell for turning an old woman into a goddess. The document is

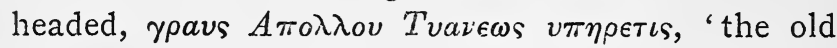
serving woman of Apollonius of 'Tyana,' and it ends, $\eta \pi \rho a \xi \iota \varsigma \delta \varepsilon \delta$ $\iota \mu a \sigma \tau a \iota$, 'it is proved by practice'.

You take the head of an ibis, and write certain characters on it in the blood of a black ram, and go to a cross-road, or the sea-shore, or a river-bank at midnight : there you recite gibberish and then see a pretty lady riding a donkey, and she will put off her beauty like a mask and assume the appearance of old age, and will promise to obey you : and so forth.

Here is a 'constraint put on a god' as Porphyry complains. Reginald Scot, in his Discovery of Witchcraft (1584), has a very similar spell for alluring an airy sylph, and making her serve and be the mistress of the wizard! There is another papyrus (xlvi.), of the fourth century, with directions for divination by aid of a boy looking into a bowl, says the editor (p. 64). There is a long invocation full of 'barbarous words,' like the medireval nonsense rhymes used in magic. There is a dubious reading, $\beta a \theta \rho o v$ or $\beta \circ \theta \rho o v$; it is suggested that the boy is put into a pit, as it seems was occasionally done. ${ }^{1}$ It is clear that a spirit is supposed to show the boy his visions. A spell follows for summoning a visible deity. Then we have a recipe for making a ring which will enable the owner to know the thoughts of men. The god is threateneci if he does not serve the magicians. All manner of fumigations, plants, and stones are used in these

1 See notice in Classical Revicw, February, 1894. 
idiotic ceremonies, and to these Porphyry refers The papyri do not illustrate the phenomena described by Iamblichus, such as the 'light,' levitation, music of unknown origin, the resistance of the medium to fire and sword points, and all the rest of his list of prodigies. Iamblichus probably looked down on the believers in these spells written on papyrı with extreme disdain. They are only interesting as folk-lore, like the rhymes of incantation preserved in Reginald Scot's Discovery of Witchcraft.

There were other analogies between modern, ancient, and savage spiritualism. The medium was swathed, or tied up, like the Davenport Brothers, like Eskimo and Australian conjurers, like the Highland seer in the bull's hide. ${ }^{1}$ The medium was understood to be a mere instrument like a flute, through which the 'control,' the god or spirit, spoke.' This is still the spiritualistic explanation of automatic speech. Eusebius goes so far as to believe that ' earthbound spirits' do speak through the medium, but a much simpler theory is obvious. ${ }^{3}$ Indeed where automatic performances of any sort-by writing, by the kind of 'Ouija' or table pointing to letters,

${ }^{1}$ See oracles in Eusebius, Pracp. Evang., v. 9. The medium was tied up in some way, he had to be unloosed and raised from the ground. The inspiring agency, in a hurry to be gone, gave directions for the

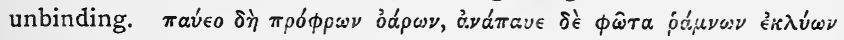

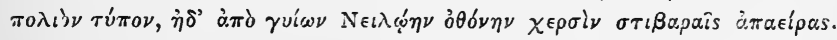
The binding of the Highland seer in a bull's hide is described by Scott in the Lady of the Lake. A modern Highland seer has ensconced himself in a boiler! The purpose is to concentrate the 'force'.

$$
{ }^{2} \text { Praep. Evang., v. } 8 . \quad \quad{ }^{3} \text { Ibid., v. I5, } 3 .
$$


as described by Ammianus Marcellinus (xxix. 29)-or by speaking, are concerned, we have the aid of psychology, and the theory of 'unconscious cerebration' to help us. But when we are told the old tales of whirring noises, of 'bilocation,' of 'levitation,' of a mystic light, we are in contact with more difficult questions.

In brief, the problem of spiritualism in general presents itself to us thus: in ancient, modern, and savage thaumaturgy there are certain automatic phenomena. The conjurer, priest, or medium acts, or pretends to act, in various ways beyond his normal consciousness. Savages, ancient mystics, and spiritualists ascribe his automatic behaviour to the control of spirits, gods or demons. No such hypothesis is needed.

On the other side, however, are phenomena not automatic, 'spiritual' lights, and sounds; interferences with natural laws, as when bodies are lifted in the air, or are elongated, when fire does not fasten on them, and so on. These phenomena, in ancient times, followed on the performance of certain mystic rites. They are now said to occur without the aid of any such rites. Gods and spirits are said to cause them, but they are only attained in the presence of certain exceptional persons, mediums, saints, priests, conjurers. Clearly then, not the rites, but the peculiar constitution of these individuals is the cause (setting imposture aside) of the phenomena, of the hallucinations, of the impressions, or whatever they are to be styled. That is to say, witnesses, in other matters credible, aver that they receive these 
peculiar impressions in the society of certain persons and not in that of people in general. Now these impressions are, everywhere, in every age and stage of civilisation, essentially identical. Is it stretching probability almost beyond what it will bear, to allege that all the phenomena, in the Arctic circle as in Australia, in ancient Alexandria as in modern London, are, always, the result of an imposture modelled on savage ideas of the supernatural?

If so we are reduced to the choice between actual objective facts of unknown origin (frequently counterfeited of course), and the theory,-which really comes to much the same thing,-of identical and collective hallucinations in given conditions. On either hypothesis the topic is certainly not without interest for the student of human nature. Even if we could, at most, establish the fact that people like Iamblichus, Mr. Crookes, Lord Crawford, Jesuits in Canada, professional conjurers in Zululand, Spaniards in early Peru, Australian blacks, Maoris, Eskimo, cardinals, ambassadors, are similarly hallucinated, as they declare, in the presence of priests, diviners, Home, Zulu magicians, Biraarks, Jossakeeds, angakut, tohungas, and saints, and Mr. Stainton Moses, still the identity of the false impressions is a topic for psychological study. Or, if we disbelieve this cloud of witnesses, if they voluntarily fabled, we ask, why do they all fable in exactly the same fashion? Even setting aside the animistic hypothesis, the subject is full of curious neglected problems.

Once more, if we admit the theory of intentional imposture by saints, angakut, Zulu medicine-men, 
mediums, and the rest, we must grant that a trick which takes in a professional conjurer, like Mr. Kellar, is a trick well worthy of examination. How did his $Z$ ulu learn the method of Home, of the Egyptian diviners, of St. Joseph of Cupertino ? ${ }^{1}$ Each solution has its difficulties, while practical investigation is rarely possible. We have no Home with us, at present, and the opportunity of studying his effects carefully was neglected. It was equally desirable to study them whether he caused collective hallucinations, or whether his effects were merely those of ordinary, though skilful, conjuring. For Home, whatever his moral character may have been, was a remarkable survival of a class of men familiar to the mystic Iamblichus, to the savage races of the past and present, and (as far as his marvels went) to the biographers of the saints. 'I am one of those,' says the Zulu medicine-man, in Mr. Rider Haggard's Allan's Wife, 'who can make men see what they do not see.' The class of persons who are said to have possessed this power appear, now and then, in all human history, and have at least bequeathed to us a puzzle in anthropology. This problem has recently been presented, in what may be called an acute form, by the publication of the 'Experiences of Mr. Stainton Moses'.? Mr. Moses was a clergyman and schoolmaster; in both capacities he appears to have been industrious.

${ }^{1}$ Dr. Hodgson, in Proceedings S. P. R., Jan., I894, makes Mr. Kellar's evidence as to Indian 'levitation' seem far from convincing! As a professional conjurer, and exposer of spiritualistic imposture, Mr. Kellar has made statements about his own experiences which are not easily to be harmonised.

${ }^{2}$ Proceedings S. P. R. Jan., 1894. 
conscientious, and honourable. He was not devoid of literature, and had contributed, it is said, to periodicals as remote from mysticism as Punch, and the Saturday Review. He was a sportsman, at least he was a disciple of our father, Izaak Walton. 'Most anglers are quiet men, and followers of peace, so simply wise as not to sell their consciences to buy riches, and with them vexation, and a fear to die,' says Izaak.

In early middle age, about I874, Mr. Moses began to read such books as Dale Owen's, and to sit 'attentive of his trembling' table, by way of experiment. He soon found that tables bounded in his presence, untouched. Then he developed into a regular 'medium'. Inanimate objects came to him through stone walls. Scent of all sorts, and, as in the case of St. Joseph of Cupertino, of an unknown sort, was scattered on people in his company. He floated in the air. He wrote 'automatically'. Knocks resounded in his neighbourhood, in the open air. 'Lights' of all varieties hovered in his vicinity. He spoke 'automatically,' being the mouth-piece of a 'spirit,' and very dull were the spirit's sermons. After a struggle he believed in 'spirits,' who twanged musical notes out in his presence. He became editor of a journal named Light; he joined the Psychical Society, but left it when the society pushed materialism so far as to demonstrate that certain professional mediums were convicted swindlers.

The evidence for his marvels is the testimony of a family, perfectly respectable, named Speer, and of a few other witnesses whom nobody can suspect of conscious inaccuracy. There remain, as documents, his 
books, his MS. notes, and other corroborative notes kept by his friend Dr. Speer, a sceptic, and other observers.

It is admitted that $\mathrm{Mr}$. Moses was not a cautious logician, his inferences are problematic, his generalisations hasty. As to the facts, it is equally difficult to believe in them, and to believe that $\mathrm{Mr}$. Moses was a conscious impostor, and his friends easy dupes. He cannot have been an impostor unconsciously in a hypnotic state, in a 'trance,' because his effects could not have been improvised. If they were done by jugglery, they required elaborate preparations of all sorts, which must have been made in full ordinary consciousness If we fall back on collective hallucination, then that hallucination is something of world-wide diffusion, ancient and continuous, for the effects are those attributed by Iamblichus to his mystics, by the Church to her saints, by witnesses to the 'possessed,' by savages to medicine-men, and by Mr. Crookes and Lord Crawford to D. D. Home. Of course we may be told that all lookers-on, from Eskimo to Neoplatonists and men of science, know what to expect, and are hallucinated by their own expectant attention. But, when they expect nothing, and are disappointed by having to witness prodigies, the same old prodigies, what is the explanation?

The following tabular statement, altered from that given by Mr. Myers in his publication of $\mathrm{Mr}$. Moses and Dr. Speer's MS. notes, will show the historical identity of the phenomena. Mr. Moses was the agent in all; those exhibited by other ancient and modern agents are marked with a cross. 


\begin{tabular}{|c|c|c|c|c|c|c|c|c|}
\hline & 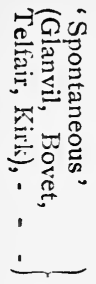 & 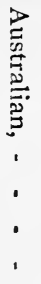 & 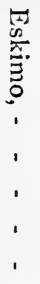 & 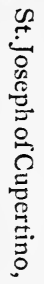 & 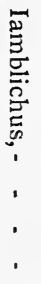 & $\begin{array}{l}\ominus \\
\theta \\
0 \\
7 \\
0 \\
3 \\
0 \\
1 \\
1 \\
1\end{array}$ & $\begin{array}{l}0 \\
0 \\
\vdots \\
0 \\
0 \\
0 \\
\vdots \\
\vdots \\
0 \\
\vdots \\
2 \\
0 \\
0 \\
0 \\
0 \\
0\end{array}$ & 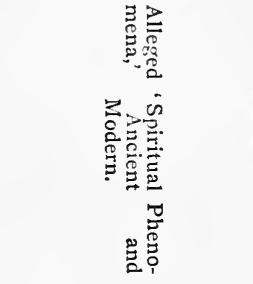 \\
\hline & $x$ & $v$ & & & & $x$ & $\times$ & 'Intelligent Raps.' \\
\hline & $\times$ & & $\times$ & & $\times$ & $\times$ & $\times$ & $\begin{array}{l}\text { 'Movement of objects } \\
\text { untouched.' }\end{array}$ \\
\hline & $x$ & $\times$ & $\times$ & $x$ & $\times$ & $\times$ & $x$ & $\begin{array}{l}\text { 'Levitation' (floating in } \\
\text { air of seer). }\end{array}$ \\
\hline $\begin{array}{l}\text { The 'object' } \\
\text { being the } \\
\text { medium in } \\
\text { some cases. }\end{array}$ & $x$ & & & & & & $\times$ & $\begin{array}{l}\text { Disappearance and Re- } \\
\text { appearance of objects. }\end{array}$ \\
\hline & & & & & & & $\times$ & $\begin{array}{l}\text { Passage of Matter } \\
\text { through Matter. }\end{array}$ \\
\hline & & & & & & $\times$ & $\times$ & $\begin{array}{l}\text { Direct writing. That } \\
\text { is, not by any detected } \\
\text { human agency. }\end{array}$ \\
\hline & & & & & & $\times$ & $\times$ & $\begin{array}{l}\text { Sounds made on instru- } \\
\text { ments supernormally. }\end{array}$ \\
\hline & $x$ & & & & $\times$ & $x$ & $x$ & $\begin{array}{l}\text { Direct sounds. That is, } \\
\text { by no detected human } \\
\text { agency. }\end{array}$ \\
\hline & & & & $x$ & & $\times$ & $\times$ & Scents. \\
\hline & $x$ & & $x$ & & $x$ & $\times$ & $\times$ & Lights. \\
\hline & & & & & & $x$ & $x$ & Objects 'materialised'. \\
\hline & $x$ & & & & & $x$ & $\times$ & $\begin{array}{l}\text { Hands materialised, } \\
\text { touched or seen. }\end{array}$ \\
\hline
\end{tabular}


There are here twelve miracles! Home and Iamblichus add to Mr. Moses's répertoire the alteration of the medium's height or bulk. This feat still leaves Mr. Moses 'one up,' as regards Home, in whose presence objects did not disappear, nor did they pass through stone walls. The questions are, to account for the continuity of collective hallucinations, if we accept that hypothesis, and to explain the procedure of $\mathrm{Mr}$. Moses, if he were an impostor. He did not exhibit before more than seven or eight private friends, and he gained neither money nor dazzling social success by his performances.

This page in the chapter of 'demoniac affections' is thus still in the state of ébauche. Mr. Moses believed his experiences to be 'demoniac affections,' in the Neoplatonic sense. Could his phenomena have been investigated by the Archbishop of Canterbury, Dr. Parker, Messrs. Maskelyne and Cook, and Professor Huxley, the public mind might have arrived at some conclusion on the subject. But Mr. Moses's chief spirit, known in society as 'Imperator,' declined to let strangers look on. He testified his indignation in a manner so bruyant, he so banged on tables, that Mr. Moses and his friends thought it wiser to avoid an altercation.

This exclusiveness of 'Imperator' certainly donne furieusement à penser. If spirits are spirits they may just as well take it for understood that performances 'done in a corner' are of no scientific value. But we are still at a loss for a 'round' and satisfactory 
hypothesis which will colligate all the alleged facts, and explain their historical continuity. We merely state that continuity as a historical fact. Marvels of savages, Neoplatonists, saints of Church or Covenant, 'spontaneous' phenomena, Mediumistic phenomena, all hang together in some ways. Of this the Church has her own explanation. 


\section{COMPARATIVE PSYCHICAL RESEARCH.}

A Party at Ragley Castle. The Miraculous Conformist. The Restoration and Scepticism. Experimental Proojs of Spiritual Existence. Glanvill. Boyle. More. The Gentleman's Butler. 'Levitation.' Witchcraft. Movements of Objects. The Drummer of Tedworth. Haunted' Houses. Rerrick. Glenluce. Ghosts. 'Spectral Evi. dence.' Continuity and Uniformity of Stories. St. Joseph of Cupertino, his Flights. Modern Instances. Theory of Induced Hallucination. Ibn Batuta. Animated Furniture. From China to Peru. Rapping Spirit at Lyons. The Imposture at Orleans. The Stockwell Mystery. The Demon of Spraiton. Modern Instances. The Wesleys. Theory of Imposture. Conclusion.

IN the month of February, I665, there was assembled at Ragley Castle as curious a party as ever met in an English country-house. The hostess was the Lady Conway, a woman of remarkable talent and character, but wholly devoted to mystical speculations. In the end, unrestrained by the arguments of her clerical allies, she joined the Society of Friends, by the world called Quakers. Lady Conway at the time when her guests gathered at Ragley, as through all her later life, was suffering from violent chronic headache. The party at Ragley was invited to meet her latest medical attendant, an unlicensed practitioner, Mr. Valentine Greatrakes, or Greatorex; his 
name is spelled in a variety of ways. Mr. Greatrakes was called 'The Irish Stroker' and 'The Miraculous Conformist' by his admirers, for, while it was admitted that Dissenters might frequently possess, or might claim, powers of miracle, the gift, or the pretension, was rare among members of the Established Church. The person of Mr. Greatrakes, if we may believe Dr. Henry Stubbe, physician at Stratford-on-Avon, diffused a pleasing fragrance as of violets. Lord Herbert of Cherbury, it will be remembered, tells the same story about himself in his memoirs. Mr. Greatrakes 'is a man of graceful personage and presence, and if my phantasy betrayed not my judgement,' says Dr. Stubbe, 'I observed in his eyes and meene a vivacitie and spritelinesse that is nothing common'.

This Miraculous Conformist was the younger son of an Irish squire, and a person of some property. After the Restoration-and not beforc-Greatrakes felt 'a strong and powerful impulse in him to essay' the art of healing by touching, or stroking. $\mathrm{He}$ resisted the impulse, till one of his hands having become 'dead' or numb, he healed it by the strokes of the other hand. From that moment Greatrakes practised, and became celebrated; he cured some diseased persons, failed wholly with others, and had partial and temporary success with a third class. The descriptions given by Stubbe, in his letter to the celebrated Robert Boyle, and by Foxcroft, Fellow of King's College, Cambridge, leave little doubt that 'The Irish Stroker' was most successful with hypochondriacal and hysterical 
patients. He used to chase the disease up and down their bodies, if it did not 'fly out through the interstices of his fingers,' and if he could drive it into an outlying part, and then forth into the wide world, the patient recovered. So Dr. Stubbe reports the method of Greatrakes. ${ }^{1} \mathrm{He}$ was brought over from Ireland, at a charge of about $£$ I55, to cure Lady Conway's headaches. In this it is confessed that he entirely failed; though he wrought a icw miracles of healing among rural invalids. To meet this fragrant and miraculous Conformist, Lady Conway invited men worthy of the privilege, such as the Rev. Joseph Glanvill, F.R.S., the author of Sadducismus Trimmphatus, his friend Dr. Henry More, the Cambridge Platonist, and other persons interested in mystical studies. Thus at Ragley there was convened the nucleus of an unofficial but active Society for Psychical Research, as that study existed in the seventeenth century.

The object of this chapter is to compare the motives, methods, and results of Lady Conway's circle, with those of the modern Society for Psychica! Research. Both have investigated the reports of abnormal phenomena. Both have collected and published narratives of eye-witnesses. The moderns. however, are much more strict on points of evidence than their predecessors. They are not content to watch, but they introduce 'tests,' generally with the most disenchanting results. The old researchers were animated by the desire to establish the tottering

${ }^{1}$ The Miraculous Conformist. A letter to the Honourabie Robert Boyle, Esq. Oxford: University Press, 1666. 
faith of the Restoration, which was endangered by the reaction against Puritanism. Among the fruits of Puritanism, and of that frenzied state of mind which accompanied the Civil War, was a furious persecution of 'witches'. In a rare little book, Select Cases of Conscience, touching Witches and Witchcraft, by John Gaule, 'preacher of the Word at Great Siaughton in the county of Huntington' (London, I $6 \div 6$ ), we find the author not denying the existence of witchcraft, but pleading for calm, learned and judicial investigation. To do this was to take his life in his hand, for Matthew Hopkins, a fanatical miscreant, was ruling in a Reign of Terror through the country. The clergy of the Church of England, as Hutchinson proves in his Treatise of Witchcraft (second edition, London, I720), had been comparatively cautious in their treatment of the subject. Their record is far from clean, but they had exposed some impostures, chiefly, it is fair to say, where Nonconformists, or Catholics, had detected the witch. With the Restoration the general laxity went so far as to scoff at witchcraft, to deny its existence, and even, in the works of Wagstaff and Webster, to minimise the leading case of the Witch of Endor. Against the 'drollery of Sadducism,' the Psychical Researchers within the English Church, like Glanvill and Henry More, or beyond its pale, like Richard Baxter and many Scotch divines, defended witchcraft and apparitions as outworks of faith in general. The modern Psychical Society, whatever the predisposition of some of its members may be, explores abnormal phenomena, not in the interests of faith, but 
of knowledge. Again, the old inquirers were dominated by a belief in the devil. They saw witchcraft and demoniacal possession, where tine moderns see hysterics and hypnotic conditions.

For us the topic is rather akin to mythology, and 'folk-psychology,' as the Germans call it. We are interested, as will be shown, in a most curious question of evidence, and the value of evidence. It will again appear that the phenomena reported by Glanvill, More, Sinclair, Kirk, Telfair, Bovet, are identical with those examined by Messis. Gurney, Myers, Kellar (the American professional conjurer), and many others. The differences, though interesting, are rather temporary and accidental than essential.

A few moments of attention to the table talk of the party assembled at Ragley will enable us to understand the aims, the methods, and the ideas of the old informal society. By a lucky accident, fragments of the conversation may be collected from Glanvill's Sadducismus Triumphatus, ${ }^{1}$ and from the correspondence of Glanvill, Henry More, and Robert Boyle. Mr. Boyle, among more tangible researches, devoted himself to collecting anecdotes, about the second sight. These manuscripts are not published in the six huge quarto volumes of Boyle's works; on the other hand, we possess Lord Tarbet's answer to his questions. ${ }^{2}$ Boyle, as his letters show, was a rather chary believer in witchcraft and possession. He referred Glanvill to his

${ }^{1}$ Fourth edition, London, 1726.

2In Kirk's Secret Commonwealth, I6gr. London: Nutt, I893. 
kinsman, Lord Orrery, who had enjoyed an experience not very familiar; he had seen a gentleman's butler float in the air!

Now, by a great piece of good fortune, Mr. Greatrakes the fragrant and miraculous, had also been an eye-witness of this miracle, and was able to give Lady Conway and her guests the fullest information. As commonly happened in the seventeenth century, though not in ours, the marvel of the butler was mixed up with ordinary folk-lore. In the records and researches of the existing Society for Psychical Research, folk-lore and fairies hold no place. The Conformist, however, had this tale to tell: the butler of a gentleman unnamed, who lived near Lord Orrery's seat in Ireland, tell in, one day, with the good people, or fairies, sitting at a feast. The fairies, therefore, endeavoured to spirit him away, as later they carried off Mr. Kirk, minister of Aberfoyle, in I692. Lord Orrery, most kindly, gave the butler the security of his castle, where the poor man was kept, 'under police protection,' and watched, in a large room. Among the spectators were Mr. Greatrakes himself, and two bishops, one of whom may have been Jeremy Taylor, an active member of the society. Late in the afternoon, the butler was 'perceived to rise from the ground, whereupon Mr. Greatrix and another lusty man clapt their hands over his shoulders, one of them before, and the other behind, and weighed him down with all their strength, but he was forcibly taken up from them; for a considerable time he was carried in the air to and fro, over their heads, several of the 
company still running under him, to prevent him receiving hurt if he should fall;' so says Glanvill. Faithorne illustrates this pleasing circumstance by a picture of the company standing out, ready to 'field the butler, whose features display great concern. ${ }^{1}$

Now we know that $\mathrm{Mr}$. Greatrakes told this anecdote, at Ragley, first to Mrs. Foxcroft, and then to the company at dinner. Mr. Alfred Wallace, F.R.S., adduces Lord Orrery and Mr. Greatrakes as witnesses of this event in private life. $\mathrm{Mr}$ Wallace, however, forgets to tell the world that the fairies, or good people; were, or were believed to be, the agents. ${ }^{2}$ Fairies still cause levitation in the Highlands. Campbell of Islay knew a doctor, one of whose patients had in vain tried to holci down a friend who was seized and carried to a distance of two miles by the sluagh, the fairy folk. ${ }^{3}$ Glanvill admits that Lord Orrery assured Lady Roydon, one of the party at Ragley, that the Irish tale was true: Henry More had it direct from Mir. Greatrakes.

Here is a palpably absurd legend, but the reader is requested to observe that the phenomenon is said to have occurred in all ages and countries. IVe

${ }^{1}$ In the Salem witch mania, a similar case of levitation was reported by the Rev. Cotton Mather. He produced a cloud of witnesses, who could not hold the woman down. She would fly up. Mr. Miather sent the signed depositions to his opponent, Mr. Calef. But Calef would not believe, for, said he, 'the age of miracles is past '. Which was just the question at issue! See Beaumont's Trcatise of Spirits, p. 148, London, ${ }^{1705}$.

2 Miracles and Modern Spiritualism, p. 7. London: Burns, 1875 . ${ }^{3}$ Popular Tales, iv. 340. 
can adduce the testimony of modern Australian blacks, of Greek philosophers, of Peruvians just after the conquest by Pizarro, of the authors of Lives of the Saints, of learned New England divines, of living observers in England, India, and America. The phenomenon is technically styled 'levitation,' and in England was regarded as a proof either of witchcraft or of 'possession'; in Italy was a note of sanctity; in modern times is a peculiarity of 'mediumship'; in Australia is a token of magical power; in Zululand of skill in the black art; and, in Ireland and the West Highlands, was attributed to the guile of the fairies. Here are four or five distinct hypotheses. Part of our business, therefore, is to examine and compare the forms of a fable current in many lands, and reported to the circle at Ragley by the Miraculous Conformist.

Mr. Greatrakes did not entertain Lady Conway and her friends with this marvel alone. He had been present at a trial for witchcraft, in Cork, on September II, I66I. In this affair evidence was led to prove a story as common as that of 'levitation'-namely, the mysterious throwing or falling of stones in a haunted house, or around the person of a patient bewitched. Cardan is expansive about this manifestation. The patient was Mary Longdon, the witch was Florence Newton of Youghal. Glanvill prints the trial from a document which he regards as official, but he did not take the trouble to trace $\mathrm{Mr}$. Aston, the recorder or clerk (as Glanvill surmises), who signed every page of the manuscript. Mr. Alfred Wallace quotes the tale, without citing his authority. 
The witnesses for the falling of stones round the bewitched girl were the maid herself, and her master, John Pyne, who deposed that she was 'much troubled with little stones that were thrown at her wherever she went, and that, after they had hit her, would fall on the ground, and then vanish, so that none of them could be found'. This peculiarity beset Mr. Stainton Moses, when he was fishing, and must have 'put down' the trout. Objects in the maid's presence, such as Bibles, would 'fly from her,' and she was bewitched, and carried off into odd places, like the butler at Lord Orrery's. Nicholas Pyne gave identical evidence. At Ragley, Mr. Greatrakes declared that he was present at the trial, and that an awl would not penetrate the stool on which the unlucky enchantress was made to stand: a clear proof of guilt.

Here, then, we have the second phenomenon which interested the circle at Ragley; the flying about of stones, of Bibles, and other movements of bodies. Though the whole affair may be called hysterical imposture by Mary Longdon (who vomited pins, and so forth, as was customary), we shall presently trace the reports of similar events, among people of widely remote ages and countries, 'from China to Peru'.

Among the guests at Ragley, as we said, was Dr. Joseph Glanvill, who could also tell strange tales at first hand, and from his own experience. He had investigated the case of the disturbances in Mr. Mompesson's house at 'Tedworth, which began in March, I66I. These events, so famous among our 
ancestors, were precisely identical with what is reported by modern newspapers, when there is a 'medium' in a family. The troubles began with rappings on the walls of the house, and on a drum taken by Mr. Mompesson from a vagrant musician. This man seems to have been as much vexed as Parolles by the loss of his drum, and the Psychical Society at Ragley believed him to be a magician, who had bewitched the house of his oppressor. While Mrs. Mompesson was adding an infant to her family the noise ceased, or nearly ceased, just as, at Epworth, in the house of the Rev. Samuel Wesley, it never vexed Mrs. Wesley at her devotions. Later, at Tedworth, "it followed and vexed the younger children, beating their bedsteads with that violence, that all present expected when they would fall in pieces'. . . It would lift the children up in their beds. Objects were moved: lights flitted around, and the Rev. Joseph Glanvill could assure Lady Conway that he had been a witness of some of these occurrences. He saw the "little modest girls in the bed, between seven and eight years old, as I guessed'. He saw their hands outside the bed-clothes, and heard the scratchings above their heads, and felt 'the room and windows shake very sensibly'. When he tapped or scratched a certain number of times, the noise answered, and stopped at the same number. Many more things of this kind Glanvill tells. $\mathrm{He}$ denies the truth of a report that an imposture was discovered, but admits that when Charles II. sent gentlemen to stay in the house, nothing unusual occurred. But these researchers stayed only for a 
single night. He denied that any normal cause of the trouble was ever discovered. Glanvill told similar tales about a house at Welton, near Daventry, in $165^{8}$. Stones were thrown, and all the furniture joined in an irregular corroboree. Too late for Lady Conway's party was the similar disturbance at Gast's house of Little Burton June, 1677. Here the careful student will note that 'they saw a hand holding a hammer, which kept on knocking'. This hand is as familiar to the research of the seventeenth as to that of the nineteenth century. We find it again in the cele. brated Scotch cases of Rerrick (I695), and of Glenluce, while 'the Rev. James Sharp' (later Archbishop of St. Andrews), vouched for it, in 1659 , in a tale told by him to Lauderdale, and by Lauderdale to the Rev. Richard Baxter. ${ }^{1}$ Glanvill also contributes a narrative of the very same description about the haunting of Mr. Paschal's house in Soper Lane, London: the evidence is that of $\mathrm{Mr}$. Andrew Paschal, Fellow of Queen's College, Cambridge. In this case the trouble began with the arrival and coincided with the stay of a gentlewoman, unnamed, 'who seemed to be principally concerned'. As a rule, in these legends, it is easy to find out who the 'medium' was. The phenomena here were accompanied by ' a cold blast or puff of wind,' which blew on the hand of the Fellow of Queen's College, just as it has often blown, in similar circumstances, on the hands of $\mathrm{Mr}$. Crookes, and of other modern amateurs. It would be tedious to analyse all Glanvill's tales of

1 The anecdote is published by Charles Kirkpatrick Sharpe, in a letter of Lauderdale's, affixed to Sharpe's edition of Law's Mcmorialls. 
rappings, and of volatile furniture. We shall see that, before his time, as after it, precisely similar narratives attracted the notice of the curious. Glanvill generally tries to get his stories at first hand and signed by eye-witnesses.

Lady Conway was not behind her guests in personal experiences. Her ladyship was concerned with a good old-fashioned ghost. We say 'old-fashioned' of set purpose, because while modern tales of 'levitation' and flighty furniture, of flying stones, ct rappings, of spectral hands, of cold psychical winds, are exactly like the tales of old, a change, an observed change, has come over the ghost of the nineteenth century. Readers of the Proceedings of the Psychical Society will see that the modern ghost is a purposeless creature. He appears nobody knows why; he has no message to deliver, no secret crime to reveal, no appointment to keep, no treasure to disclose, no commissions to be executed, and, as an almost invariable rule, he does not speak, even if you speak to him. The recent inquirers, notably Mr. Myers, remark with some severity on this vague and meaningless conduct of apparitions, and draw speculative conclusions to the effect that the ghost, as the Scotch say, 'is not all there'. But the ghosts of the seventeenth century were positively garrulous. One remarkable specimen indeed behaved, at Valogne, more like a ghost of our time than of his own. ${ }^{1}$ But, as a common rule, the ghosts in whom Lady Conway's friends were interested had a purpose: some revealed the spot where a skeleton lay; some urged the pay-

${ }^{2}$ See Ghosts before the Law. 
ment of a debt, or the performance of a neglected duty. One modern spectre, reported by Mr. Myers, wandered disconsolate till a debt of three shillings and tenpence was defrayed. ${ }^{1}$ This is, perhaps, the lowest figure cited as a pretext for appearing. The ghost vouched for by Lady Conway was disturbed about a larger sum, twenty-eight shillings. She, an elderly woman, persecuted by her visits David Hunter, 'neat-herd at the house of the Bishop of Down and Connor, at Portmore, in I663'. Mr. Hunter did not even know the ghost when she was alive; but she made herself so much at home in his dwelling that 'his little dog would follow her as well as his master'. The ghost, however, was invisible to Mrs. Hunter. When Hunter had at last executed her commission, she asked him to lift her up in his arms. She was not substantial like fair Katie King, when embraced by Mr. Crookes, but 'felt just like a bag of feathers; so she vanished, and he heard most delicate music as she went off over his head'. Lady Conway cross-examined Hunter on the spot, and expressed her belief in his narrative in a letter, dated Lisburn, April 29, 1663. It is true that contemporarysceptics attributed the phenomena to potheen, but, as Lady Conway asks, how could potheen tell Hunter about the ghost's debt, and reveal that the money to discharge it was hidden under her hearthstone?

The scope of the Ragley inquiries may now be understood. It must not be forgotten that witchcraft was a topic of deep interest to these students. They solemnly quote the records of trials in which it 
is perfectly evident that girls and boys, either in a spirit of wicked mischief, or suffering from hysterical illusions, make grotesque charges against poor old women. The witches always prick, pinch, and torment their victims, being present to them, though invisible to the bystanders. This was called 'spectral evidence'; and the Mathers, during the fanatical outbreaks at Salem, admit that this 'spectral evidence,' unsupported, is of no legal value. Indeed, taken literally, Cotton Mather's cautions on the subject of evidence may almost be called sane and sensible. But the Protestant inquisitors always discovered evidence confirmatory. For example, a girl is screaming out against an invisible witch ; a man, to please her, makes a snatch at the empty air where she points, and finds in his hand a fragment of stuff, which again is proved to be torn from the witch's dress. It is easy to see how this trick could be played. Again, a possessed girl cries that a witch is tormenting her with an iron spindle, grasps at the spindle (visible only to her), and, lo, it is in her hand, and is the property of the witch. Here is proof positive! Again, a girl at Stoke Trister, in Somerset, is bewitched by Elizabeth Style, of Bayford, widow. The rector of the parish, the Rev. William Parsons, deposes that the girl, in a fit, pointed to different parts of her body, 'and where she pointed, he perceived a red spot to arise, with a small black in the midst of it, like a small thorn'; and other evidence was given to the same effect. The phenomenon is akin to many which, according to medical and scientific testimony, occur to patients in the hypnotic state. 
The so-called stigmata of Louise Lateau, and of the shepherd boy put up by the Archbishop of Reims as a substitute for Joan of Arc, are cases in point. But Glanvill, who quotes the record of the trial (January, I664), holds that witchcraft is proved by the coincidence of the witch's confession that she, the devil, and others made an image of the girl and pierced it with thorns! The confession is a piece of pure folk-lore : poor old Elizabeth Style merely copies the statements of French and Scotch witches. The devil appeared as a handsome man, and as a black dog! Glanvill denies that she was tortured, or 'watched'-that is, kept awake till her brain reeled. But his own account makes it plain that she was 'watched' after her confession at least, when the devil, under the form of a butterfly, appeared in her cell.

This rampant and mischievous nonsense was dear to the psychical inquirers of the Restoration; it was circulated by Glanvill, a Fellow of the Royal Society; by Henry More; by Sinclair, a professor in the University of Glasgow; by Richard Baxter, that glory of Nonconformity, who revels in the burning of an 'old reading parson'-that is, a clergyman who read the Homilies, under the Commonwealth. This unlucky old parson was tortured into confession by being 'walked' and 'watched'that is, kept from sleep till he was delirious. Archbishop Spottiswoode treated Father Ogilvie, S.J., in the same abominable manner, till delirium supervened. Church, Kirk, and Dissent have no right to throw the first stone at each other. 
Taking levitation, haunting, disturbances, and apparitions, and leaving 'telepathy' or second sight out of the list for the present, he who compares psychical research in the seventeenth and nineteenth centuries finds himself confronted by the problem which everywhere meets the student of institutions and of mythology. The anthropologist knows that, if he takes up a new book of travels in the remotest lands, he will find mention of strange customs perfectly familiar to him in other parts of the ancient and modern world. The mythologist would be surprised if he encountered in Papua or Central Africa, or Sakhalin, a perfectly new myth. These uniformities of myth and custom are explained by ihe identical workings of the uncivilised intelligence on the same materials, and, in some cases, by borrowing, transmission, imitation.

Now, some features in witchcraft admit of this explanation. Highland crofters, even now, perforate the image of an enemy with pins; broken bottleends or sharp stones are put, in Russia and in Australia, in the footprints of a foe, for the purpose of laming him; and there are dozens of such practices, all founded on the theory of sympathy. Like affects like. What harms the effigy hurts the person whose effigy is burned or pricked. All this is perfectly intelligible. But, when we find savage 'birraarks' in Australia, fakirs in India, saints in mediæval Europe, a gentleman's butler in Ireland, boys in Somerset and Midlothian, a young warrior in $\mathrm{Zulu}$ land, Miss Nancy Wesley at Epworth in 1716 , and Mr. Daniel Home in London in $1856-70$, all triumph- 
ing over the law of gravitation, all floating in the air, how are we to explain the uniformity of stories palpably ridiculous?

The evidence, it must be observed, is not merely that of savages, or of persons as uneducated and as superstitious as savages. The Australian birraark, who flies away up the tree, we may leave out of account. The saints, St. Francis and St. Theresa, are more puzzling, but miracles were expected from saints. ${ }^{1}$ The levitated boy was attested to in a court of justice, and is designed by Faithorne in an illustration of Glanvill's book. He flew over a garden! But witnesses in such trials were fanciful people. Lord Orrery and Mr. Greatrakes may have seen the butler float in the air-after dinner. The exploits of the Indian 1akirs almost, or quite, overcome the scepticism of Mr. Max Müller, in his Gifford Lectures on Psychological Religion. Living and honourable white men aver that they have seen the feat, examined the performers, and found no explanation; no wires, no trace of imposture. (The writer is acquainted with a well vouched for case, the witness an English officer.) Mr. Kellar, an American professional conjurer, and exposer of spiritualistic pretensions, bears witness, in the North American Review, to a Zulu case of 'levitation,' which actually surpasses the tale of the gentleman's butler in strangeness. Cieza de Leon, in his Travels, translated by Mr. Markham for the Hakluyt Society, brings a similar anecdote from early Peru, in $1549 .^{2}$

1 See many examples in Li Fiorette de Misser Santo Francesco. ${ }^{2}$ Ch. cxviii. 
Miss Nancy Wesley's case is vouched for (she and the bed she sat on both rose from the floor) by a letter from one of her family to her brother Samuel, printed in Southey's Life of Wesley. Finally, Lord Lindsay anc Lord Adare published a statement that they saw Home float out of one window and in at another, in Ashley Place, S.W., on December I6, I868. Captain Wynne, who was also there, 'wrote to the Medium, to say I was present as a witness'. We need not heap up more examples, drawn from classic Greece, as in the instances of Abaris and Iamblichus. We merely stand speechless in the presence of the wildest of all fables, when it meets us, as identical myths and customs do-not among savages alone, but everywhere. practically speaking, and in connection with bar barous sorcery, with English witchcraft, with the saintliest of mediæval devotees, with African warriors, with Hindoo fakirs, with a little English girl in a quiet old country parsonage, and with an enigmatic American gentleman. Many living witnesses, of good authority, sign statements about Home's levitation. In one case, a large table, on which stood a man of twelve stone weight rose from the floor, and an eye-witness, a doctor, felt under the castors with his hands.

Of all persons subject to 'levitation,' Saint Joseph of Cupertino ( $1603-1663)$ was the most notable. The evidence is partly derived from testimonies collected with a view to his canonisation, within two years after his death. There is a full

${ }^{1}$ D. D. Home; his Life and Mission. p. 307, London, 1888. 
account of his life and adventures in Acta Sanctorum. ${ }^{1}$ St. Joseph died, as we saw, in $\mathrm{r} 663$, but the earliest biography of him, in Italian, was not published till fifteen years later, in 1678 . Unluckily the compiler of his legend in the Acta Sanctorum was unable to procure this work, by Nutius, which might contain a comparatively slight accretion of myths. The next life is of $I 7 \approx 2$, and the author made use of the facts collected for Joseph's beatification. There is another life by Pastrovicchi, in $\mathbf{r} 753$. He was canonised in that year, when all the facts were remote by about a century.

Joseph's parents were pauperes sed honesti; his father was a carpenter, his mother a woman of almost virulent virtue, who kept her son in great order. From the age of eight he was subject to cataleptic or epileptic fits and convulsions. After his novitiate he suffered from severe attacks of melancholia. His 'miracles' attracting attention, he was brought before the Inquisition at Naples, as an impostor. He was sent to an obscure and remote monastery, and thence to Assisi, where he was harshly treated, and fell into Bunyan's Slough of Despond, having much conflict with Apollyon.

He was next called to Rome, where cardinals testify that, on hearing sacred names, he would give a yell, and fall into ecstasy. Returning to Assisi he was held in high honour, and converted a Hanoverian Prince. He healed many sick people, and, having fallen into a river, came out quite dry. He could scarcely read, but was inspired with wonderful 
theological acuteness. He always yelled before falling into an ecstasy, afterwards, he was so much under the dominion of anæsthesia that hot coals, if applied to his body, produced no effect. 'Then he soared in air, now higher, now lower (a cardinal vouches for six inches), and in are pendulus harebat, like the gentleman's butler at Lord Orrery's.

Seventy separate flights, in-doors and out of doors, are recorded. In fact it was well to abstain from good words in conversation with St. Joseph of Cupertino, for he would give a shout, on hearing a pious observation, and fly up, after which social intercourse was out of the question. He was, indeed, prevented by his superiors from appearing at certain sacred functions, because his flights disturbed the proceedings, indeed everything was done by the Church to discourage him, but in vain. He explained his preliminary shout by saying that 'guns also make a noise when they go off,' so the Cardinal de Laurea heard him remark. He was even more fragrant than the Miraculous Conformist, or the late Mr. Stainton Moses, to whose séances scent was marvellously borne by 'spirits'. It must be remembered that contemporary witnesses attest these singular circumstances in the evidence taken two years after his death, for the beatification of Joseph. From Assisi he was sent to various obscure convents, where his miracles were as remarkable as ever. One Christmas Eve, hearing sacred music, he flew up like a bird, from the middle of the church to the high altar, where he floated for a quarter of an hour, yet upset none of the candles. An insane nobleman 
was brought to him to be healed. Seizing the afflicted prince by the hair of the head, he uttered a shout, and soared up with the patient, who finally came down cured! Once he flew over a pulpit, and once more than eighty yards to a crucifix. This is probably 'a record'. When some men were elevating a cross for a Calvary, and were oppressed by the weight, Joseph uttered a shriek, flew to them, and lightly erected the cross with his own hand. The flight was of about eighty yards. He flew up into a tree once, and perched on a bough, which quivered no more than if he had been a bird. A rather commonplace pious remark uttered in his presence was the cause of this exhibition. Once in church, he flew from his knees, caught a priest, lifted him up, and gyrated, latissimo rapiu, in mid air. In the presence of the Spanish ambassador and many. others, he once flew over the heads of the congregation. Once he asked a priest whether the holy elements were kept in a particular place. 'Who knows?' said the priest, whereon Joseph soared over his head, remained kneeling in mid air, and came down only at the request of his ecclesiastical superior. Joseph was clairvoyant, and beheld apparitions, but on the whole (apart from his moral excellence) his fights were his most notable accomplishment. On one occasion he 'casual remarked to a friend,' 'what an infernal smell' (infernalis odor), and then nosed out a number of witches and warlocks who were compounding drugs: 'standing at some considerable distance, standing, in fact, in quite another street'. 
Iamblichus, in the letter to Porphyry, describes such persons as St. Joseph of Cupertino. 'They have been known to be lifted up into the air. . . . The subject of the afflatus has not felt the application of fire. . . The more ignorant and mentally imbecile a youth may be, the more freely will the divine power be made manifest.' Joseph was ignorant, and 'enfeebled by vigil and fasts,' so Joseph was ' insensible of the application of fire,' and 'was lifted up into the air'. Yet the cardinals, surgeons, and other witnesses were not thinking of the pagan Iamblichus when they attested the accomplishments of the saint. Whence, then, comes the uniformity of evidence?

The sceptical Calef did not believe in these things, because they are 'miracles,' that is, contrary to experience. But here is experience enough to which they are not contrary.

There are dozens of such depositions, and here it is that the student of testimony and of belief finds himself at a deadlock. Believe the evidence we cannot, yet we cannot doubt the good faith, the veracity of the attesting witnesses. Had we only savage, or ancient and uneducated testimony, we might say that the uniformity of myths of levitation is easily explained. The fancy wants a marvel, it readily provides one by positing the infraction of the most universally obvious law, that of gravitation. Men don't fly ; let us say that a man flew, like Abaris on his arrow! This is rudimentary, but then witnesses whose combined testimony would prove almost anything else, declare that they saw the feat 
performed. Till we can find some explanation of these coincidences of testimony, it is plain that a province in psychology, in the relations between facts as presented to and as represented by mankind, remains to be investigated. Of all persons who have been levitated since St. Joseph, a medium named Eglinton was most subject to this infirmity. In a work, named There is no Death, by Florence Marryat, the author assures us that she has frequently observed the phenomenon. But Mr. Eglinton, after being 'investigated' by the Psychical Society, ' retired,' as $\mathrm{Mr}$. Myers says, 'into private life'. The tales told about him by spiritualists are of the kind usually imparted to a gallant, but proverbially confiding, arm of Her Majesty's service. As for Lord Orrery's butler, and the others, there are the hypotheses that a cloud of honourable and sane witnesses lied; that they were uniformly hallucinated, or hypnotised, by a glamour as extraordinary as the actual miracle would be ; or again, that conjuring of an unexampled character could be done, not only by Home, or Eglinton, in a room which may have been prepared, but by Home, by a Zulu, by St. Joseph of Cupertino, and by naked fakirs, in the open air. Of all these theories that of glamour, of hypnotic illusion, is the most specious. Thus, when Ibn Batuta, the old Arabian traveller, tells us that he saw the famous rope-trick performed in India-men climbing a rope thrown into the air, and cutting each other up, while the bodies revive and reunite-he very candidly adds that his companion, standing by, saw nothing out of the way, 
and declared that nothing occurred. ${ }^{1}$ This clearly implies that Ibn Batuta was hypnotised, and that his companion was not. But Dr. Carpenter's attempt to prove that one witness saw nothing, while Lord Lindsay and Lord Adare saw Home float out of one window, and in by another, turns out to be erroneous. The third witness, Captain Wynne, confirmed the statement of the other gentlemen.

We now approach the second class of marvels which regaled the circle at Ragley, namely, 'Alleged movements of objects without contact, occurring not in the presence of a paid medium,' and with these we shall examine rappings and mysterious noises. The topic began to attract modern attention when table-turning was fashionable. But in common table-turning there was contact, and Faraday easily demonstrated that there was conscious or unconscious pushing and muscular exertion. In I87 I Mr. Crookes made laboratory experiments with Home, using mechanical tests." He demonstrated, to his own satisfaction, that in the presence of Home, even when he was not in physical contact with the object, the object moved: e pur si muove. He published a reply to Dr. Carpenter's criticism, and the commonsense of ordinary readers, at least, sees no flaw in Mr. Crookes's method and none in his argument. The experiments of the modern Psychical Society, with paid mediums, produced results, in Mr. Myers's opinion, 'not wholly unsatisfactory,' but far from leading to an affirmative conclusion, if by 'satis-

${ }^{1}$ See Colonel Yule's Marco Polo.

${ }^{2}$ Quarterly Fournal of Science, July, $187 \mathrm{r}$. 
factory' Mr. Myers means 'affirmative '.1 The investigations of Mrs. Sidgwick were made under the mediumship of Miss Kate Fox (Mrs. Jencken). This lady began the modern 'spiritualism' when scarcely older than Mr. Mompesson's 'two modest little girls,' and was accompanied by phenomena like those of Tedworth. But, in Mrs. Sidgwick's presence the phenomena were of the most meagre; and the reasoning faculties of the mind decline to accept them as other than perfectly normal. The society tried Mr. Eglinton, who once was 'levitated' in the presence of Mr. Kellar, the American conjurer, who has publicly described feats like those of the gentleman's butler: ${ }^{2}$ But, after his dealings with the society, Mr. Eglinton has left the scene. ${ }^{3}$ The late Mr. Davey also produced results like $\mathrm{Mr}$. Eglinton's by confessed conjuring.

Mr. Myers concludes that 'it does not seem worth while, as a rule, to examine the testimony to physical marvels occurring in the presence of professional mediums'. He therefore collects evidence in the article quoted, for physical marvels occurring where there is no paid medium. Here, as in the business of levitation, the interest of the anthropologist and mythologist lies in the uniformity and identity of narratives from all countries, climates, and ages. Among the earliest rappings with which we chance to be familiar are those reported by Froissart in the case of the spirit Orthon, in the fourteenth century. The

\footnotetext{
${ }^{1}$ Proceedings S. P. R., xix. 146.

${ }^{2}$ North American Review, 1893.

${ }^{3}$ Proceedings S. P. R., x. 45-100; xix. I47.
} 
tale had become almost a fabliau, but any one who reads the amusing chapter will see that it is based on a belief in disturbances like those familiar to Glanvill and the Misses Fox. Cieza de Leon (I549) in the passage already quoted, where he describes the levitated Cacique of Pirza in Popyan, adds that 'the Christians saw stones talling trom the air' (as in the Greatrakes tale of the Youghal witch), and declares that, "when the chiet was sitting with a glass of liquor before him, the Christians saw the glass raised up in the air and put down empty, and a short time afterwards the wine was again poured into the cup from the air'. Mr. Home once equalled this marvel, ${ }^{1}$ and Ibn Batuta reports similar occurrences, earlier, at the court of the King of Delhi. There is another case in Histoire Prodigieuse d'une :eune Fille agitée d'un Esprit fantastique ct invisible. $^{2}$ A bourgeois of Bonneval was beset by a rapping rattle of a sprite. 'At dinner, when he would lay his hand on a trencher, it was carried ofi elsewhere, and the wineglass, when he was about drinking, was snatched from his hand.' So Mr. Wesley's trencher was set spinning on the table, when nobody touched it! In such affairs we may have the origin of the story of the Harpies at the court of Phineus.

In China, Mr. Dennys tells how 'food placed on the table vanished mysteriously, and many of the curious phenomena attributed to ghostly interference took place,' so that the householder was driven from

1 Incidents in my Life, i. I7o.

2 A Paris, chez la Veuve du Carroy, I62I. 
house to house, and finally into a temple, in 1874 , and all this after the death of a favourite but aggrieved monkey!' 'Throwing down crockery, trampling on the floor, etc.-such pranks as have attracted attention at home, are not unknown. . . . I must confess that in China, as elsewhere, these occurrences leave a bon $\hat{a}$ fide impression of the marvellous which can neither be explained nor rejected'. ${ }^{2}$

We have now noted these alleged phenomena, literally 'from China to Peru'. Let us next take an old French case of a noisy sprite in the nunnery of St. Pierre de Lyon. The account is by Adrien de Montalembert, almoner to Francis I. $^{3}$ The Bibliography of this very rare tract is curious and deserves attention. When Lenglet Dufresnoy was compiling, in I75I, his Dissertations sur les Apparitions he reprinted the tract from the Paris quarto of 1528 , in black letter. This example had been in the Tellier collection, and Dufresnoy seems to have borrowed it from the Royal Convent of St. Geneviève. Knowing that Cardinal Tencin had some acquaintance with the subject, Dufresnoy wrote to him, and publishes (vol. i. cxli.) his answer, dated October I8, I75 r, Lyons. The cardinal replied that, besides the

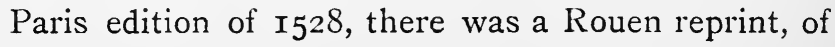

${ }^{1}$ Folk-lore of China, 1876, p. 79.

2 Op. cit., p. 74 .

${ }^{3}$ Paris. Quarto. Black letter. I528. The original is extremely rare. We quote from a copy once in the Tellier collection, reprinted in Recueil de Dissertations Anciennes et Nouvelles sur les Apparitions. Leloup: Avignon, I751, vol. ii. pp. I-87. 
I529, by Rolin Gautier, with engravings. Brunet says, that there are engravings in the Paris edition of 1528 , perhaps these were absent from the Tellier example. That of Rouen, which Cardinal Tencin collated, was in the Abbey of St. Peter, in Lyons. Some leaves had been thumbed out of existence, and their place was supplied in manuscript. The only difference was in chapter xxviii. where the printed Rouen text may have varied. In the MS. at all events, it is stated that on March $2 I$, the spirit of Sister Alix de Telieux struck thirty-three great strokes on the refectory of her convent, 'mighty and marvellous,' implying that her thirty-three years of purgatory were commuted into thirty-three days. A bright light, scarcely endurable, then appeared, and remained for some eight minutes. The nuns then went into chapel and sang a Te Deum.

At the end of the volume, a later hand added, in manuscript, that the truth of the contemporary record was confirmed by the tradition of the oldest sisters who had received it from eye-witnesses of the earlier generation. The writer says that she had great difficulty in finding the printed copy, but that when young, in 1630 , she received the tale from a nun, then aged ninety-four. This nun would be born in 1536 , ten years after these events. She got the story from her aunt, a nun, Gabrielle de Beaudeduit, qui étoit de ce tems-la. There is no doubt that the sisters firmly and piously believed in the story, which has the contemporary evidence of Adrien de Montalembert. Dufresnoy learned that a manuscript copy of the tract was in the library of the 
Jesuits of Lyons. He was unaware of an edition in $12 \mathrm{mo}$ of $\mathrm{I} 58 \mathrm{O}$, cited by Brunet.

To come to the story, one of our earliest examples of a 'medium,' and of communications by raps. The nunnery was reformed in I5I6. A pretty sister, Alix de Telieux, fled with some of the jewels, lived a 'gay' life, and died wretchedly in I524. She it was, as is believed, who haunted a sister named Anthoinette de Grolée, a girl of eighteen. The disturbance began with a confused half-dream. The girl fancied that the sign of the cross was made on her brow, and a kiss impressed on her lips, as she wakened one night. She thought this was mere illusion, but presently, when she got up, she heard, 'comme soubs ses pieds frapper aucuns petis coups,' 'rappings,' as if at the depth of four inches underground. This was exactly what occurred to Miss Hetty Wesley, at Epworth, in I7I6, and at Rio de Janeiro to a child named ' C.' in Professor Alexander's narrative. ${ }^{1}$ Montalembert says, in $I_{528}$, ' $I$ have heard these rappings many a time, and, in reply to my questions, so many strokes as I asked for were given'. Montalembert received information (by way of raps) from the 'spirit,' about matters of importance, qui ne pourroient estre cogneus de mortelle créature. ' Certainly,' as he adds, 'people have the best right to believe these things who have seen and heard them.'

The rites of the Church were conferred in the most handsome manner on the body of Sister Alix,

${ }^{1}$ Proceedings S. P. R., xix. I86. 'C.' is a Miss Davis, daughter of a gentleman occupying 'a responsible position as a telegraphist'. The date was 1888 . 
which was disinterred and buried in her convent. Exorcisms and interrogations of the spirit were practised. It merely answered questions by rapping 'Yes,' or 'No'. On one occasion Sister Anthoinette was 'levitated'. Finally, the spirit appeared bodily to her, said farewell, and disappeared aftei making an extraordinary fracas at matins. M. ntalembert conducted the religious ceremonies. One case of hysteria was developed; the sufferer was a novice. Of course it was attributed to diabolical possession The whole story in its pleasant old French, has an agreeable air of good faith But what interests us is the remarkable analogy between the Lyons rappings and those at Epworth, Tedworth, and countless other cases, old or of yesterday. We can now establish a catena of rappings and pour prendre date, can say that communications were established, through raps, with a so-called 'spirit,' more than three hundred years before the 'Rochester knockings' in America. Very probably wider research would discover instances prior to that of Lyons; indeed, Wierus, in De Praestigiis Daemonum, writes as if the custom was common.

It is usual to explain the raps by a theory that the 'medium' produces them through cracking his, or her, knee-joints. It may thus be argued that Sister Anthoinette discovered this trick, or was taught the trick, and that the tradition of her performance, being widely circulated in Montalembert's quarto, and by oral report, inspired later rappers, such as Miss Kate Fox, Miss 'C.' Davis, Miss Hetty Wesley, the gentlewoman at Mr. Paschal's, 
Mr. Mompesson's 'modest little girls,' Daniel Home, and Miss Margaret Wilson of Galashiels. Miss Wilson's uncle came one day to Mr. Wilkie, the minister, and told him the devil was at his house, for, said he, 'there is an odd knocking about the bed where my niece lies'. Whereupor the minister went with him, and found it so 'She, rising from her bed, sat down to supper, and from below there was such a knocking up as bred fear to all that were present. This knocking was just under her chair, where it was not possible for any mortal to knock up.' When Miss Wilson went to bed, and was in a deep sleep, ' her body was so lifted up that many strong men were not able to keep it down'.' The explanation about cracking the knee-joints hardly covers the levitations, or accounts for the tremendous noise which surrounded Sister Anthoinette at matıns, or for the bright light, a common spiritualistic phenomenon. Margaret Wilson was about twelve years of age. If it be alleged that little girls have a traditional method of imposture, even that is a curious and interesting fact in human nature.

As regards imposture, there exists a singular record of a legal process in Paris, I534. ${ }^{2}$

It may have been observed that the Lyons affair was useful to the Church, as against 'the damnable sect of Lutherans,' because Sister Alix attested the existence of purgatory. No imposture was detected,

${ }^{1}$ Satan's Invisible World Discovered. Edinburgh: Reid, 1685. Pp. 67.69.

${ }^{2}$ Manuscript 7170, A, de la Bibliothèque du Roi. Dissertations, ut supra, vol. i. pp. 95·129. 
and no reader of Montalembert can doubt his good faith, nor the sincerity of his kindness and piety. But such a set of circumstances might provoke imitation. Of fraudulent imitation the Franciscans of Orleans were accused, and for this crime they were severely punished. We have the Arrest des Commissaires $d u$ Conseil d'Etat du Roi, from MS. 7I70, A. of the Bibliothèque du Roi. ${ }^{1}$ We have also allusions in the Franciscanus, a satire in Latin hexameter by George Buchanan Finally, we have versions in Lavaterus, and in Wierus, De Curat. Laes. Maleficio (Amsterdam, I66o, p. 422). Wierus, born $\mathrm{I}_{5} \mathrm{I}_{5}$, heard the story when with Sleidan at Orleans, some years after the events. He gives the version of Sleidan, a notably Protestant version. Wierus is famous for his spirited and valuable defence of the poor women then so frequently burned as witches. He either does, or pretends to believe in devils, diabolical possession, and exorcism. but the exorcist, to be respectable, must be Protestant. Probably Wierus was not so credulous as he assumes to be, and a point of irony frequently peeps out. The story as told by Sleidan differs from that in the official record. In this document Adam Fumée counsellor of the king, announces that the Franciscans of Orleans have informed the king that they are vexed by a spirit, which gives itself out by signs (rappings), as the wife of François de St. Mesmin, Provost of Orleans. They ask the king to take cognisance of the matter. On the other side, St. Mesmin declares that the Franciscans have counterfeited the affair in hope

${ }^{1}$ Dufresnoy, op. cit., i. 95-129. 
of 'black-mailing' him. The king, therefore, appoints Fumée to inquire into the case. Thirteen friars are lying in prison in Paris, where they have long been 'in great wretchedness and poverty, and perishing of hunger,' a pretty example of the law's delay. A zommission is to try the case (November, I534). The trouble had begun on February 22, I533 (old style), when Father Pierre d'Arras at five A.M. was called into the dormitory of 'les enfans,'novices,-with holy water and everything proper. Knocking was going on, and by a system of knocks, the spirit said it wanted its body to be taken out of holy ground, said it was Madame St. Mesmin, and was damned for Lutheranism and extravagance! The experiment was repeated tefore churchmen and laymen, but the lay ubservers rushed up to the place whence the knocks came. where they found nothing. They hid some one there, after which there was no knocking. On a later day, the noises as in Cock Lane and elsewhere, began by scratching. "M. l'Official," the bishop's vicar, 'ouit gratter, qui etoit ?e commencement de ladite accoutummée tumulte dudit Esprit'. But no replies were given to questions, which the Franciscans attributed to the disturbance of the day before, and the breaking into various places by the people. One Alicourt seems to have been regarded as the ' medium,' and the sounds were heard as in Cock Lane and at Tedworth when he was in bed. Later experiments gave no results, and the friars were severely punished, and obliged to recant their charges against Madame de Mesmin. The case, scratches, raps, false accusations and all, is parallel 
to that of the mendacious 'Scratching Fanny,' examined by Dr. Johnson and Douglas, Bishop of Salisbury. In that affair the child was driven by threats to make counterfeit noises, but, as to the method of imposture at Orleans, nothing is said in the contemporary legal document.

We now turn to the account by Sleidan, in Wierus. The provost's wife had left directions for a cheap funeral in the Franciscan Church. This economy irritated the Fathers, who only got six pieces of gold, 'having expected much greater plunder'. 'Colimannus' (Colimant), an exorcist named in the process, was the ringleader. They stationed a lad in the roof of the church, who rapped with a piece of wood, and made a great noise 'when they mumbled their prayers at night'. St. Mesmin appealed to the king, the Fathers were imprisoned, and the youth was kept in Fumée's house, and plied with questions. He confessed the trick, and the friars were punished. Of all this confession, and of the mode of imposture, nothing is said in the legal process. From the whole affair came a popular saying, c'est l'esprit d'Orléans, when any fable was told. Buchanan talks of cauta parum pietas in fraude paranda.

The evidence, it may be seen, is not very coherent, and the Franciscans may have been the deceived, not the deceivers. ${ }^{1}$ Wierus himself admits that he often heard a brownie in his father's house, which frightened him not a little, and Georgius Pictorius avers that a noisy spirit haunted his uncle's house for thirty years, a very protracted practical

${ }^{1}$ Compare Bastian, Mensch., ii. 393, cited by Mr. Tylor. 
joke, if it was a practical joke. ${ }^{1}$ This was a stonethrowing demon.

A large book might easily be filled with old stories of mysterious flights of stones, and volatile chairs and tables. The ancient mystics of the Levant were acquainted with the phenomena, as Iamblichus shows. The Eskimo knew them well. Glanvill is rich in examples, the objects flying about in presence of a solitary spectator, who has called at a 'haunted house,' and sometimes the events accompany the presence of a single individual, who may, or may not be a convulsionary or epileptic. Sometimes they befall where no individual is suspected of constitutional electricity or of imposture.

We may select a laughable example from a rare tract. 'An authentic, candid, and circumstantial narrative of the astonishing transactions at Stockwell, in the county of Surrey, on Monday and Tuesday, the 6 th and 7 th of January, I772. Published with the consent and approbation of the family and other parties concerned, to authenticate which, the original copy is signed by them. London, I772, printed for J. Marks, bookseller, in St. Martin's Lane.'

The dramatis personce are old Mrs. Golding, of Stockwell parish, 'a gentlewoman of unblemished honour and character'; Mrs. Pain, her niece, a farmer's wife, 'respected in the parish'; Mary Martin, her servant, previously with Mrs. Golding; Richard Fowler, a labourer, living opposite Mrs. Pain; Sarah Fowler his wife-all these sign the

${ }^{1}$ De Materia Daemon. Isagoge, p. 539. Ap. Corn. Agripp., De Occult. Philosoph. Lyons, I6oo. 
document,-and Ann Robinson, Mrs. Golding's maid, just entered on her service Ann does not sign.

The trouble began at ten A.M on January 6, when Mrs. Golding heard a great smash of crockery, an event 'most incident to maids'. The lady went into the kitchen, when plates began to fall from the dresser 'while she was there and nobody near them'. Then a clock tumbled down, so did a lantern, a pan of salt beef cracked, and a carpenter, Rowlidge, suggested that a recent addition of a room above had shaken the foundation of the house. Mrs. Golding rushed into the house of Mr. Gresham, her next neighbour, and fainted. Meanwhile Ann Robinson was 'mistress of herself, though china fall,' and seemed in no hurry to leave the threatened dwelling. The niece of Mrs. Golding, Mrs. Pain. was sent for to Mr. Gresham's, Mrs. Golding was bled, when, lo, 'the blood sprang out of the basin upon the floor, and the basin broke to pieces!' A bottle of rum, of sympathetic character, also burst. Many of Mrs. Golding's more fragile effects had been carried into Mr. Gresham's : the glasses and china first danced, and then fell off the side-board and broke. Mrs. Golding, 'her mind one confused chaos,' next sought refuge at Mr. Mayling's for threequarters of an hour. Here nothing unusual occurred, but, at Mr. Gresham's (where Ann Robinson was packing the remains of her mistress's portable property) a 'mahogany waiter,' a quadrille box, a jar of pickles and a pot of raspberry jam shared the common doom. 'Their end was pieces.' Mrs. Pain now hospitably conveyed her aunt to her house at 
Rush Common, 'hoping all was over'. This was about two in the afternoon.

At eight in the evening, the whole row of pewter dishes, bar one, fell from a shelf, rolled about a little, and 'as soon as they were quiet, turned upside down; they were then put upon the dresser, and went through the same a second time'. Then of two eggs, one 'flew off, crossed the kitchen, struck a cat on the head, and then burst in pieces'. A pestle and a mortar presently 'jumped six feet from the floor'. The glass and crockery were now put on the floor, ' he that is Jown need fear no fall,' but the objects began to dance, and tumble about, and then broke to preces. A china bowl jumped eight feet but was not broken. However it tried again, and succeeded. Candlesticks, tea-kettles, a tumbler of rum and water, two hams, and a flitch of bacon joined in the corroboree. 'Most of the genteel families around were continually sending to inquire after them, and whether all was over or not.' All this while, Ann was 'walking backwards and forwards, nor could they get her to sit down, except for half an hour, at prayers, 'then all was quiet'. She remarked, with stoicism, 'these things could not be helped'. Fowler came in at ten, but fled in a fright at one in the morning. By five, Mrs. Golding summoned Mrs. Pain, who had gone to bed, 'all the tables, chairs, drawers, etc., were tumbling about'.

They rushed across to Fowler's where, as soon as Ann arrived, the old game went on. Fowler, therefore, like the landlord in the poem, 'did plainly say as how he wished they'd go away,' at the same 
time asking Mrs. Golding 'whether or not, she had been guilty of some atrocious crime, for which providence was determined to pursue her on this side the grave,' and to break crockery till death put an end to the stupendous Nemesis. "Having hitherto been esteemed a most deserving person,' Mrs. Golding replied, with some natural warmth, that ' her conscience was quite clear, and she could as well wait the will of providence in her own house as in any other place,' she and the maid went to her abode, and there everything that had previously escaped was broken. 'A nine-gallon cask of beer that was in the cellar, the door being open and nobody near it, turned upside down'; 'a pail of water boiled like a pot'. So Mrs. Golding discharged Miss Ann Robinson and that is all.

At Mrs. Golding's they took up three, and at Mrs. Pain's two pails of the fragments that were left. The signatures follow, appended on January II.

The tale has a sequel. In I8I7 an old $\mathrm{Mr}$. Braidley, who loved his joke, told Hone that he knew Ann, and that she confessed to having done the tricks by aid of horse-hairs, wires and other simple appliances. We have not Mr. Braidley's attested statement, but Ann's character as a Medium is under a cloud. Have all other Mediums secret wires? (Every-day Book, i. 62.)

Ann Robinson, we have seen, was a tranquil and philosophical maiden. Not so was another person who was equally active, ninety years earlier.

Bovet, in his Pandamonimm (I684), gives an account of the Demon of Spraiton, in I682. His 
authorities were 'J. G., Esquire', a near neighbour' to the place, the Rector of Barnstaple, and other witnesses. The 'medium' was a young servan't man, appropriately named Francis Fey, and employed in the household of Sir Philip Furze. Now, this young man was subject to 'a kind of trance, or extatick fit,' and 'part of his body was, occasionally, somewhat benumbed and seemingly deader than the other'. The nature of Fey's case, physically, is clear. He was a convulsionary, and his head would be found wedged into tight places whence it could hardly be extracted. From such a person the long and highly laughable tale of ghosts (a male ghost and a jealous female ghost) which he told does not much win our acceptance. True, Mrs. Thomasin Gidley, Anne Langdon, and a little child also saw the ghost in various forms. But this was probably mere fancy, or the hallucinations of Fey were infectious. But objects flew about in the young man's presence. ' One of his shoe-strings was observed (without the assistance of any hand) to come of its own accord out of his shoe and fling itself to the other side of the room; the other was crawling after it (!) but a maid espying that, with her hand drew it out, and it clasp'd and curl'd about her hand like a living eel or serpent. A barrel of salt of considerable quantity hath been observed to march from room to room without any human assistance,' and so forth. ${ }^{1}$

It is hardly necessary to add more modern instances. The 'electric girl' Angélique Cottin, who

${ }^{2}$ Aubrey gives a variant in his Miscellanies, on the authority of the Vicar of Barnstaple. He calls Fey 'Fry'. 
was a rival of Ann Robinson, had her powers well enough attested to arouse the curiosity of Arago. But, when brought from the country to Paris, her power, or her artifice, failed.

It is rather curious that tales of volatile furniture are by no means very common in trials for witchcraft. The popular belief was, and probably still is, that a witch or warlock could throw a spell over an enemy so that his pots, and pans, tables and chairs, would skip around. The disturbances of this variety, in the presbytery at Cideville, in Seine Inférieure (I850), came under the eye of the law, because a certain shepherd injudiciously boasted that he had caused them by his magic art. ${ }^{1}$ The curé, who was the victim, took him at his word, and the shepherd swain lost his situation. $\mathrm{He}$ then brought an action for defamation of character, but was non-suited, as it was proved that he had been the fanfaron of his own vices. In Froissart's amusing story of Orthon, that noisy sprite was hounded on by a priest. At Tedworth, the owner of the drum was ' wanted' on a charge of sorcery as the cause of the phenomena. The Wesleys suspected that their house was bewitched. But examples in witch trials are not usual. Mr. Graham Dalyell, however. gives one case, 'the firlote rynning about with the stuff popling,' on the floor of a barn, and one where 'the sive and the wecht dancit throw the hous '.

1 The Devonshire case, 'Story of a Something,' in Miss O'Neill's Devonshirc Idylls, is attested by a surviving witness.

2 Trials of Isobell Young, 1629, and of Jonet Thomson, Feb. 7, 1643. Darker Superstitions of Scotland, p. 593. 
A clasped knife opened in the pocket of Christina Shaw, and her glove falling, it was lifted by a hand invisible to several persons present. One is reminded of the nursery rhyme,- ' the dish it ran after the spoon'. In the presence of Home, even a bookcase is said to have forgotten itself, and committed the most deplorable excesses. In the article of Mr. iNyers, already cited, we find a table which jumps by the bedside of a dying man. ${ }^{1}$ A handbag of Miss Power's flies from an arm-chair, and hides under a table; raps are heard; all this when Miss Power is alone. Mr. H. W. Gore Graham sees a table move about. A heavy table of Mr. G. A. Armstrong's rises high in the air. A tea-table 'runs after' Professor Alexander, and 'attempts to hem me in,' this was at R1o de Janeiro, in the Davis family, where raps ' ranged irom hardly perceptible ticks up to resounding blows, such as might be struck by a wooden mallet'. A Mr. H. falls into convulsions, during which all sorts of things fly about. All these stories closely correspond to the tales in Increase Mather's Remarkable Providences in New England, in which the phenomena sometimes occur in the presence of an epileptic and convulsed boy, about 1680. To take one classic French case, Segrais declares that a M. Patris was lodgea in the Château d'Egmont. At dinner-time, he went into the room of a friend, whom he found lost in the utmost astonishment. A huge book, Cardan's De Subtilitate, had flown at him across the room, and the leaves had turned, under invisible fingers! There are ${ }^{1}$ Witness Rev. E. T. Vaughan, King's Langley. 1884. 
plenty of bogles in that book. M. Patris laughed at this tale, and went into the gallery, when a large chair, so heavy that two men could scarcely lift it, shook itself and came at him. He remonstrated, and the chair returned to its usual position. 'This made a deep impression on $M$ Patris, and contributed in no slight degree to make him a converted character' -à le faire devenir devot. ${ }^{1}$

Tales like this, with that odd uniformity of tone and detail which makes them curious, might be collected from old literature to any extent. Thus, among the sounds usually called 'rappings,' Mr. Crookes mentions, as matter within his own experience, 'a cracking like that heard when a frictional machine is at work'. Now, as may be read in Southey's Life of Wesley and in Clarke's Memoirs of the Wesleys, this was the very noise which usually heralded the arrival of 'Jeffrey,' as they called the Epworth 'spirit'.2 It has been alleged that the charming and ill-fated Hetty Wesley caused the disturbances. If so (and Dr. Salmon, who supports this thesis, does not even hazard a guess as to the modus operandi), Hetty must have been familiar with almost the whole extent of psychical literature, for she scarcely left a single phenomenon unrepresented. It does not appear that she supplied visible 'hands'. We have seen Glanvill lay stress on the apparition of a hand. In the case of the devil of Glenluce, 'there appeared a naked hand, and an arm from the

${ }^{1}$ Segraisiana, p. 213.

${ }^{2}$ Crookes's Notes of an Enquiry into the Phonomcna usually called Spiritual 86. London: Burns (secund ecition). 
elbow down, beating upon the floor till the house did shake again'.' At Rerrick, in I695, 'it knocked upon the chests and boards, as people do at a door'. 'And as I was at prayer,' says the Rev. Alexander Telfair, 'leaning on the side of a bed, I felt something thrusting my arm up, and casting my eyes thitherward, perceived a little white hand, and an arm from the elbow down, but it vanished presently.' ${ }^{2}$ The hands viewed, grasped, and examined by Home's clientele, hands which melted away in their clutch, are innumerable, and the phenomenon, with the 'cold breeze,' is among the most common in modern narratives.

Our only conclusion is that the psychological conditions which begat the ancient narratives produce the new legends. These surprise us by the apparent good faith in marvel and myth of many otherwise credible narrators, and by the coincidence, accidental or designed, with old stories not generally familiar to the modern public. Do impostors and credulous persons deliberately 'get up' the subject in rare old books? Is there a method of imposture handed down by one generation of bad little girls to another? Is there such a thing as persistent identity of hallucination among the sane? This was Coleridge's theory. but it is not without difficulties. These questions are the present results of Comparative Psychological Research.

${ }^{1}$ Satan's Invisible World Discovered, p. 75.

${ }^{2} A$ New Confutation of Sadducism, p. 5, writ by Mr. Alexander Telfair, London, ז6و6. 


\section{HAUNTED HOUSES.}

Reginald Scot on Protestant expulsion of Ghosts. His hoast premature. Savage hauntings. Red Indian example. Classical cases. Petrus Thyraus on Haunted Houses. His examples from patristic literature. Three species of hauntingspirits. Demons in disguises. Haliucinations, visual, auditory, and tactile. Are the sounds in Hannted Houses real or hallucinatory? All present do not always hear them. Interments in houses to stop hauntings. Modern example. The Restoration and Scepticism. Exceptional position of Dr. Johnson. Frequency of Haunted Houses in modern Folk-lore. Researches of the S. P. R. Failure of the Society to see Ghosts. Uncertain behaviour of Ghosts. The Society need a 'seer' or 'sensitive' comrade. The 'type' or normal kind of Haunted Houses. Some natural explanations. Historical continuity of type. Case of Sir Walter Scott. A haunted curacy. Modern instances. Miss Morton's case : a dumb ghost. Ghost, as is beiieved, of a man of letters. Mr. Harry's ghost raises his mosquito curtains. Columns of light. Mr. Podmore's theory. Hallucinations begotten by natural causes are 'telepathically' transferred, with variations, to strangers at a distance. Example of this process. Incredulity of Mr. Myers. The spontaneous phenomena reproduced at 'séanies'. A shost who followed a young lady. Singular experience of the writer in Haunted Houses. Experience negative. Thiory of 'dreams of the dead'. Difficulties of this 
theory: physical force exerted in dreams. Theory of Mr. James Sully. His unscientific method and carelessness as to evidence. Reflections.

REGinald Scot, the humane author who tried, in his Discovery of Witchoraft, I584 (xv. 39), to laugh witch trials away, has a trumphant passage on the decline of superstition. "Where are the soules that swarmed in time past? where are the spirits? who heareth their noises? who seeth their visions?' He decides that the spirits who haunt places and houses, may have gone to Italy, because masses are dear in England. Scot, as an ardent Protestant, conceived that haunted houses were 'a lewd invention,' encouraged, if not originated, by the priests, in support of the doctrine of purgatory. As a matter of fact the belief in 'haunting,' dates from times of savagery, when we may say that every bush has its bogle. The Church had nothing to do with the rise of the belief, though, early in the Reformation, some 'psychical phenomena' were claimed as experimental proofs of the existence of purgatory. Reginald Scot decidedly made his Protestant boast too soon. After 300 years of 'the Trewth,' as Knox called it, the haunted houses are as much part of the popular creed as ever. Houses stand empty, and are said to be 'haunted'. Here not the fact of haunting, but only the existence of the superstition is attested. Thus a house in Berkeley Square was long unoccupied, for reasons perfectly commonplace and intelligible. But the fact that it had no tenants needed to be explained, and was explained 
by a myth,- there were ghosts in the house! On the other hand, if Reginald Scot asked to-day, 'Who heareth the noises, who seeth the visions?' we could answer, 'Protestant clergymen, officers in the army, ladies, land-agents, solicitors, representatives of all classes, except the Haunted House Committee of the Psychical Society'.

Before examining the researches and the results of this learned body, we may glance at some earlier industry of investigators. The common savage beliefs are too well known to need recapitulation, and have been treated by Mr. Tylor in his chapter on 'Animism,' 1 and by Mr. Herbert Spencer in Principles of Psychology. The points of difference between these authors need not detain us here. As a rule the spirits which haunt the bush, or the forest, are but vaguely conceived of by the Australian blacks, or Red Men : they may be ghosts of the dead, or they may be casual spirits unattached. An example analogous to European superstition is given by John Tanner in his Narrative of a Captivity among the Red Indians, I830. In this case one man had slain his brother, or, at least, a man of his own Totem, and was himself put to death by the kindred. The spectres of both haunted a place which the Indians shunned, but Tanner (whose Totem was the same as that of the dead) passed a night on the scene. His dreams, if not his waking moments, for his account is indistinct, were disturbed by the ghosts. It is impossible to ascertain how far this

${ }^{1}$ Primitive Culture, vol. i. 368 ; ii. 304 . 
particular superstition was coloured by European influences. ${ }^{1}$

Over classical tales we need not linger. Pliny, Plutarch, Suetonius, St. Augustine, Lucian, Plautus (in the Mostellaria), describe, with more or less of seriousness, the apparitions and noises which haunted houses, public baths, and other places. Occasionally a slain man's phantom was anxious that his body should be buried, and the reported phenomena were akin to those in modern popular legends. Sometimes, in the middle ages, and later, the law took cognisance of haunted houses, when the tenant wished to break his lease. A collection of authorities is given elsewhere, in Ghosts before the Law. It is to be noticed that Bouchel, in his Bibliothèque du Droit Français, chiefly cites classical, not modern, instances.

Among the most careful and exhaustive postmediæval writers on haunted houses we must cite Petrus Thyræus of the Society of Jesus, Doctor in Theology. His work, published at Cologne in $\mathrm{I}_{598}$, is a quarto of 352 pages, entitled, 'Loca Infesta; That is, Concerning Places Haunted by Mischievous Spirits of Demons and of the Dead. Thereto is added a Tract on Nocturnal Disturbances, which are wont to bode the deaths of Men.' Thyræus begins, 'That certain places are haunted by spectres and spirits, is no matter of doubt,' wherein a modern reader cannot confidently follow him.

1 The reader may also consult Notes on the Spirit Basis of Belief and Custom, a rough draft printed for the Indian Government. While rich in curious facts, the draft contains very little about 'manifestations,' except in 'possession'. 
When it comes to establishing his position Thyræus most provokingly says, "we omit cases which are recent and of daily occurrence,' such as he heard narrated, during his travels, in 'a certain haunted castle'. A modern inquirer naturally prefers recent examples, which may be inquired into, but the old scholars reposed more confidence in what was written by respected authors, the more ancient the more authoritative. However Thyræus relies on the anthropological test of evidence, and thinks that his belief is confirmed by the coincident reports of hauntings, 'variis distinctissimisque locis et temporibus,' in the most various times and places. There is something to be said for this view, and the identity of the alleged phenomena, in all lands and ages, does raise a presumption in favour of some kind of abnormal occurrences, or of a common species of hallucinations. Like most of the old authors Thyræus quotes Augustine's tale of a haunted house, and an exorcism in De Civitate Dei (lib. xxii. ch. viii.). St. Gregory has also a story of one Paschasius, a deacon, who haunted some baths, and was seen by a bishop. ${ }^{1}$ There is a ghost who rode horses, and frightened the religious in the Life of Gregory by Joannes Diaconus (iv. 89). In the Life of Theodorus one Georgius, a disciple of his, mentions a house haunted by stone-throwing sprites, a very common phenomenon in the books of Glanvill, and Increase Mather, in witch trials, and in rural disturbances. Omitting other examnles Cardan $^{2}$ is cited for a house at Parma, in which during

1 Gregory, Dialogues, iv. 39.

${ }^{2}$ De Rorum Varietate, xvi. cap. xciii. 
a hundred years the phantom of an old woman was seen before the death of members of the family. This is a rare case of an Italian Banshie. William of Paris, in Bodin (iii. ch. vi.) tells of a stone-throwing fiend, very active in I447. The bogey of Bingen, a rapping ghost of 856 , is duly chronicled; he also threw stones. The dormitory of some nuns was haunted by a spectre who moaned, tramped noisily around, dragged the sisters out of bed by the feet, and even tickled them nearly to death! This annoyance lasted for three years, so Wierus says. ${ }^{1}$ Wodrow chronicles a similar affair at Mellantrae, in Annandale. Thyræus distinguishes three kinds of haunting sprites, devils, damned souls, and souls in purgatory. Some are mites, mild and sportive ; some are truculenti, ferocious. Brownies, or fauni, may act in either character, as Secutores et joculatores. They rather aim at teasing than at inflicting harm. They throw stones, lift beds, and make a hubbub and crash with the fuiniture. Succides, murderers, and spirits of murdered people, are all apt to haunt houses. The sprites occasionally appear in their proper form, but just as often in disguise : a demon, too, can appear in human shape if so disposed: demons being of their nature deceitful and fond of travesty, as Porphyry teaches us and as Law (I680) illustrates. Whether the spirits of the dead quite know what they are about when they take to haunting, is, in the opinion of Thyræus, a difficult question. Thomas Aquinas, following St. Augustine, inclines to hold that when there is an apparition of a dead man, the dead man is un- 
conscious of the circumstance. A spirit of one kind or another may be acting in his semblance. Thyræus rather fancies that the dead man is aware of what is going on.

Hauntings may be visual, auditory, or confined to the sense of touch. Auditory effects are produced by flutterings of air, noises are caused, steps are heard, laughter, and moaning. Laves domestici (brownies) mostly make a noise. Apparitions may be in tactile form of men or animals, or monsters. As for effects, some ghosts push the living and drive them along, as the Bride of Lammermoor, in Law's Mcmorialls, was ' harled through the house,' by spirits. The spirits of an amorous complexion seem no longer to be numerous, but are objects of interest to Thyræus as to Increase Mather. Thyræus now raises the diffcult question: 'Are the sounds heard in haunted houses real, or hallucinatory?' Ommis qui a spiritibus fit, simulatus est, specie sui fallit. The spirits having no vocal organs, can only produce noise. In a spiritual hurly-burly, some of the mortals present hear nothing (as we shall note in some modern examples), but may they not be prevented from hearing by the spirits? Or again, the sounds may be hallucinatory and only some mortals may have the power of hearing them. If there are visual, there may also be auditory hallucinations. ${ }^{1}$ On the whole Thyræus thinks that the sounds may be real on some occasions, when all present hear them, hallucinatory on others. But the

1 Si fallere possunt, ut quis videre se credat, cum videat revera extra se nihil: non poterunt fallere, ut credat quis se audire sonos, quos revera non audit? (p. 8r). 
sounds need not be produced on the furniture, for example, when they seem to be so produced. 'Often we think that the furniture has been all tossed about, when it really has not been stirred.' The classical instance of the disturbances which aroused Scott at Abbotsford, on the death of his agent Bullock, is in point here. 'Often a hammer is heard rapping, when there is no hammer in the house' (p. 82). These are curious references to phenomena, however we explain them, which are still frequently reported.

Thyræus thinks that the air is agitated when sounds are heard, but that is just the question to be solved.

As for visual phantasms, these Thyræus regards as hallucinations produced by spirits on the human senses, not as external objective entities. He now asks why the sense of touch is affected usually as if by a cold body. Beyond assuming the infiuence of spirits over the air, and, apparently, their power of using dead bodies as vehicles for themselves, Thyrreus comes to no distinct conclusion. He endeavours, at great length, to distinguish between haunters who are ghosts of the dead, and haunters who are demons, or spirits unattached. The former wail and moan, the latter are facetious. He decides that to bury dead bodies below the hearth does not prevent haunting, for 'the hearth has no such efficacy'. Such bodies are not very unfrequently found in old English houses, the reason for this strange interment is rot obvious, but perhaps it is explained by the superstition which Thyræus mentions. One might imagine that to bury people up and down a house would rather 
secure haunting than prevent it. And, indeed, at Passenham Rectory, where the Rev. G. M. Capell found seven skeletons in his dining-room, in I874, Mrs. Montague Crackanthrope and her nurse were 'obsessed' by 'a feeling that some one was in the room,' when some one was not. ${ }^{1}$ Perhaps seven burials were not sufficient to prevent haunting. The conclusion of the work of Thyræus is devoted to exorcisms, and orthodox methods of expelling spirits. The knockings which herald a death are attributed to the Lares, a kind of petty mischievous demons unattached. Such is the essence of the learned Jesuit's work, and the strange thing is that, in an age of science, people are still discussing his problems, and, stranger still, that the reported phenomena remain the same.

That the Church in the case of Thyræus, and many others; that medical science, in the person of Wierus (b. I5I5); that law, in the book of Bouchel, should have gravely canvassed the topic of haunted houses, was, of course, very natural in the dark ages before the restoration of the Stuarts, and the founding of the Royal Society. Common-sense, and 'drolling Sadduceeism,' came to their own, in England, with the king, with Charles II. After May 29, I66o, Webster and Wagstaffe mocked at bogles, if Glanvill and More took them seriously.

Before the Restoration it was distinctly dangerous to laugh at witchcraft, ghosts and hauntings. But the laughers came in with the merry monarch, and less by argument than by ridicule, by inveighing

${ }^{1}$ Proceedings S. P. R., xv. $4^{2}$. 
against the horror, too, of the hideous witch prosecutions, the laughers gradually brought hauntings and apparitions into contempt. Few educated people dared to admit that their philosophy might not be wholly exhaustive. Even ladies sneered at Dr. Johnson because he, having no dread of common-sense before his eyes, was inclined to hold that there might be some element of truth in a world-old and world-wide belief; and the romantic Anna Seward told, without accepting it, Scott's tale of 'The Tapestried chamber'. That a hundred years after the highday and triumph of common-sense, people of education should be found gravely investigating all that common-sense had exploded, is a comfortable thought to the believer in Progress. The world does not stand still.

A hundred years after the blue stockings looked on Johnson as the last survivor, the last of the Mohicans of superstition, the Psychical Society can collect some 400 cases of haunted houses in England.

Ten years ago, in I884, the society sifted out nineteen stories as in 'the first class,' and based on good first-hand evidence. Their analysis of the reports led them to think that there is a certain genuine type of story, and, that when a tale 'differs widely from the type, it proves to be incorrect, or unattainable from an authentic source'. This is very much the conclusion to which the writer is brought by historical examination of stories about hauntings. With exceptions, to be indicated, these tales all approximate to a type, and that is not the type of the magazine story. 
It may be well, in the first place, to make some negative statements as to what the committee does not discover. First, it has never yet hired a haunted house in which the sights and sounds continued during the tenancy of the curious observers. ${ }^{1}$ The most obvious inference is that the earlier observers who saw and heard abnormal things were unscientific, convivial, nervous, hysterical, or addicted to practical joking. This, however, is not the only possible explanation. As a celebrated prophet, by his own avowal had been 'known to be steady for weeks at a time,' so, even in a regular haunted house, the ghost often takes a holiday. A case is well known to the writer in which a ghost began his manouvres soon after a family entered the house. It made loud noises, it opened doors, turning the handle as the lady of the house walked about, it pulled her hair when she was in bed, plucked her dress, produced lights, and finally appeared visibly, a hag dressed in grey, to several persons. Then as if sated, the ghost struck work for years, when it suddenly began again, was as noisy as ever, and appeared to a person who had not seen it before, but who made a spirited if unsuccessful attempt to run it to earth.

The truth is, that magazine stories and superstitious exaggerations have spoiled us for ghosts. When we hear of a haunted house, we imagine that the ghost is always on view, or that he has a benefit night, at certain fixed dates, when you know where to have him. These conceptions are erroneous,

${ }^{1}$ There is one possible exception to this rule. 
and a house may be haunted, though nothing desirable occurs in presence of the committee. Moreover the committee, as far as the writer is aware, have neglected to add a seer to their number. This mistake, if it has been made, is really wanton. It is acknowledged that not every one has 'a nose for a ghost,' as a character of George Eliot's says, or eyes or ears for a ghost. It is thought very likely that, where several people see an apparition simultaneously, the spiritual or psychical or imaginative 'impact' is addressed to one, and by him, or her (usually her) handed on to the rest of the society. Now, if the committee do not provide themselves with a good 'sensitive' comrace, what can they expect, but what they get, that is, nothing? A witch in an old Scotch trial says, of her 'Covin,' or 'Circle,' 'We could do no great thing without our Maiden'. The committee needs a Maiden, as a Covin needed one, and among the visionaries of the Psychical Society, there must be some young lady who should be on the House Committee. Yet one writer in the Society's Proceeding's who has a very keen scent for an impostor, if not for a ghost, avers that, from the evidence, she believes that they are examining facts, and not the origin of fables.

These facts, as was said, differ from the stories in 'Christmas numbers'. The ghost in typical reports seldom or never speaks. It has no message to convey, or, if it has a message, it does not convey it. It does not unfold some tragedy of the past : in fact it is very seldom capable of being connected with any definite known dead person. The figure seen sometimes 
'varies with the seer'.' In other cases, however, different people attest having seen the same phantasm. Finally a new house seems just as likely to be haunted as an old house, and the committee appear's to have no special knowledge of very ancient family ghosts, such as Pearlin Jean, the Luminous Boy of Corby, or the rather large company of spectres popularly supposed to make themselves at home at Glamis Castle.

What then is the type, the typical haunted house, from which, if narratives vary much, they are apt to break down under cross-examination?

The phenomena are usually phenomena of sight, or sound, or both. As a rule the sounds are footsteps, rustling of dresses, knocks, raps, heavy bangs, noises as of dragging heavy weights, and of disarranging heavy furniture. These sometimes occur freely, where nobody can testify to having seen anything spectral. Next we have phantasms, mostly of figures beheld for a moment with 'the tail of the eye' or in going along a passage, or in entering a room where nobody is found, or standing beside a bed, perhaps in a kind of self-luminous condition. Sometimes these spectres are taken by visitors for real people, but the real people cannot be found; sometimes they are at once recognised as phantasms, because they are semi-transparent, or look very malignant, or because they glide and do not walk, or are luminous, or for some other excellent reason. The combination, in due proportions, of pretty frequent inexplicable noises, with occasional aim- 
less apparitions, makes up the type of orthodox modern haunted house story. The difficulty of getting evidence worth looking at (except for its uniformity) is obviously great. Noises may be naturally caused in very many ways: by winds, by rats, by boughs of trees, by water pipes, by birds. The writer has known a very satisfactory series of footsteps in an historical Scotch house, to be dispelled by a modification of the water pipes. Again he has heard a person of distinction mimic the noises made by his family ghosts (which he preserved from tests as carefully as Don Quixote did his helmet) and the performance was an admirable imitation of the wind in a spout. There are noises, however, which cannot be thus cheaply disposed of, and among them are thundering whacks on the walls of rooms, which continue in spite of all efforts to detect imposture. These phenomena, says Kiesewetter, were known to the Acadians of old, a circumstance for which he quotes no authority. ${ }^{1}$

Paracelsus calls the knocks pulsatio mortuorum, in his fragment on 'Souls of the Dead,' and thinks that the sounds predict misfortune, a very common belief. ${ }^{2}$ Lavaterus says, that such disturbances, in unfinished houses are a token of good luck!

Again there is the noise made apparently by violent movement of heavy furniture, which on immediate examination (as in Scott's case at Abbotsford) is found not to have been moved. The writer is acquainted with a dog, a collie, which was

${ }^{1}$ Geschichte des Neucron Occultismus, p. 451 .

${ }^{2}$ Opcra, 1605. 
once shut up alone in a room where this disturbance occurred. The dog was much alarmed and howled fearfully, but it soon ceased to weigh on his spirits.

When phantasms are occasionally seen by respectable witnesses, where these noises and movements occur, the haunted house is of a healthy, orthodox, modern type. But the phenomena are nothing less than modern, for Mather, Sinclair, Paracelsus, Wierus, Glanvill, Bovet, Baxter and other old writers are full of precisely these combinations of sounds and sights, while many cases occur in old French literature, old Latin literature, and among races of the lower barbaric and savage grades of culture.

One or two curious circumstances have rather escaped the notice of philosophers though not of Thyræus. First, the loudest of the unexplained sounds are occasionally not audible to all, so that (as when the noise seems to be caused by furniture dragged about) we may conjecture with Thyræus, that there is no real movement of the atmosphere, that the apparent crash is an auditory hallucination. The planks and heavy objects at Abbotsford had not been stirred, as the loud noises overhead indicated, when Scott came to examine them.

In a dreadfully noisy curacy vouched for by ' $a$ well-known Church dignitary,' who occupied the place, there was usually a frightful crash as of iron bars thrown down, at 2 A.M. on a Sunday morning. All the boxes and heavy material in a locked set of attics, seemed to be dancing about, but were never found to have been stirred. Yet this clergyman discovered that 'the great Sunday crash might 
manifest itself to some persons in the house without his wife or himself being conscious of it. Knowing how overwhelming the sound always appeared to me when I did hear it, I cannot but consider this one of the most wonderful things in the whole business.' ${ }^{1}$

In this case, in a house standing hundreds of yarcis apart from any neighbour, and occupied only by a parson, his wife, and one servant, these phenomena lasted for a year, with great regularity. There were the usual footsteps, the ordinary rappings were angry when laughed at, and the clergyman when he left at the end of a year, was as far as ever from having detected any cause. Indeed it is not easy to do so. A friend of the writer's, an accomplished man of law, was once actually consulted, in the interests of an enraged squire, as to how he could bring a suit against somebody for a series of these inexplicable disturbances. But the law contained no instrument for his remedy.

From the same report of the S. P. R. we take another typical case. A lady, in an old house, saw, in I873, a hideous hag watching her in bed; she kept the tale to herself, but, a fortnight later, her brother, a solicitor, was not a whit less alarmed by a similar and similarly situated phenomenon. In this house dresses were plucked at, heavy blows were struck, heavy footsteps went about, there were raps at doors, and nobody was ever any the wiser as to the cause. Here it may be observed that a ghost's power of making a noise, and exerting what seems to be great physical energy, is often in inverse ratio to his power

$$
\text { IS. P. R., vi. } 149 \text {. }
$$


of making himself generally visible, or, at all events, to his inclination so to do. Thus there is a long record of a haunted house, by the chief observer, Miss Morton, in P.S.P.R., pt. xxii. p. 3II. A lady had died of habits too convivial, in I878. In April, I882, Miss Morton's family entered, but nobody saw the ghost till Miss Morton viewed it in June. The appearance was that of a tall lady in widow's weeds, hiding her face with a handkerchief. From I882 to I884, Miss Morton saw the spectre six times, but did not name it to her family. Her sister saw the appearance in $I 882$, a maid saw it in I883, and two boys beheld it in the same year. Miss Morton used to follow the appearance downstairs and speak to it, but it merely gave a slight gasp, and seemed unable to converse. By way of testing the spectre, Miss Morton stretched threads at night from the railing of the stair to the wall, but the ghost descended without disturbing them. Yet her footsteps sounded on the stairs. This is, in fact, a crucial difficulty about ghosts. They are material enough to make a noise as they walk, but not material enough to brush away a thread! This ghost, whose visible form was so much en évidence, could, or did, make no noise at all, beyond light pushes at doors, and very light footsteps. In the curacy already described, noises were made enough to waken a parish, but no form was ever seen. Briefly, for this ghost there is a cloud of witnesses, all solemnly signing their depositions. These two examples are at the opposite poles between which ghostly manifestations vary, in haunted houses. 
A brief précis of 'cases' may show how these elements of noise, on one side, and apparitions, on the other, are commonly blended. In a detached villa, just outsıde 'the town of C.,' Mrs. W. remarks a. figure of a tall dark-haired man peeping round the corner of a folding door. She does not mention the circumstance. Two months later she sees the same sorrowful face in the drawing-room. This time she tells her husband. Later in the same month, when playing cricket with her children, she sees the face 'peeping round from the kitchen door'. Rather later she heard a deep vorce say in a sorrowful tone, ' I can't find it'; something slaps her on the back Her step-daughter. who had not heard of the phantasm, sees the same pale dark-moustached face, 'peeping round the folding doors'. She is then told Mrs W.'s story. Her little brother, later, sees the figure simultaneously with herself. She also hears the voice say, 'I can't find it,' at the same moment as Mrs. W. hears it. A year later, she sees the figure at the porch, in a tall hat! Neither lady had enjoyed any other hallucination. Nothing is known of the melancholy spectre, probably the ghost of a literary person, searching, always searching, for a manuscript poem by some total stranger who had worried him into his grave, and not left him at peace even there. This is a very solemn and touching story, and appeals tenderly and sadly to all persons of letters who suffer from the unasked for manuscripts of the general public.

2. Some ladies and servants in a house in Hyde Park Place, see at intervals a phantom housemaid: 
she is also seen by a Mr. Bird. There is no story about a housemaid, and there are no noises. This is not an interesting tale.

3. A Hindoo native woman is seen to enter a locked bath-room, where she is not found on inquiry. A woman had been murdered there some years before. The percipient, General Sir Arthur Becher, had seen other uncanny visions. A little boy, wakened out of sleep, said he saw an ayah. Perhaps he did.

4. A Mr. Harry, in the South of Europe, saw a white female figure glide through his library into his bedroom. Later, his daughters beheld a similar phenomenon. Mr. Harry, a gentleman of sturdy common-sense, 'dared his daughters to talk of any such nonsense as ghosts, as they might be sure apparitions were only in the imagination of nervous people'. He himself saw the phantasm seven or eight times in his bedroom, and twice in the library. On one occasion it lifted up the mosquito curtains and stared at Mr. Harry. As in the case of meeting an avalanche, 'a weak-minded man would pray, sir, would pray; a strong-minded man would swear, sir, would swear'. Mr. Harry was a strong-minded man, and behaved 'in a concatenation accordingly,' although Petrus Thyræus says that there is no use in swearing at ghosts. The phantasm seemed to be about thirty-five, her features were described as 'rather handsome,' and (unromantically) as 'oblong'. A hallucination, we need hardly say, would not raise the mosquito curtains, this ghost had more heart in it than most. 
5. Various people see 'a column of light vaguely shaped like a woman,' moving about in a room of a house in Sussex. One servant, who slept in the room in hopes of a private view, saw 'a ball of light with a sort of halo round it'. Again, in a very pretty story, the man who looked after an orphan asylum saw a column of light above the bed of one of the children. Next morning the little boy declared that his mother had come to visit him, probably in a dream.

On this matter of lights ${ }^{1} \mathrm{Mr}$. Podmore enters into argument with Mr. Frederick Myers. Mr. Myers, on the whole, believes that the phenomena of haunted houses are caused by influences of some sort from the minds of the dead. Mr. Podmore, if we understand him holds that some living person has had some empty hallucination, in a house, and that this is 'telepathically' handed on, perhaps to the next tenant, who may know nothing about either the person or the vision. Thus, a Miss Morris, much vexed by ghostly experiences, left a certain house in December, I886. Nearly a year later, in November, I887, a Mrs. G. came in. Mrs. G. did not know Miss Morris, nor had she heard of the disturbances. However sobs, and moans, and heavy thumps, and noises of weighty objects thrown about, and white faces, presently drove Mrs. G. to seek police protection. This only roused the ghost's ambition, and he 'came' as a man with freckles, also he walked about, shook beds, and exhibited lights. A figure in black, with a white face, now displayed 
itself: barristers and clergymen investigated, but to no purpose. They saw figures, heard crashes, and the divine did a little Anglican exorcism. The only story about the house showed that a woman had hanged herself with a skipping rope in the 'top back bedroom,' in I879. Here are plenty of phenomena, apparitions male and female. But Miss Morris, in addition to hearing noises, only saw a pale woman in black.

Mr. Podmore's theory comes in thus: 'the later experiences may have been started by thought transference from Miss Morris, whose thoughts, no doubt, occasionally turned to the house in which she had suffered so much agitation and alarm'. Moreover 'real noises' may have 'suggested' the visual hallucinations to Miss Morris. ${ }^{1}$ Mr. Podmore certainly cannot be accused of ordinary superstition. There is a house, and there is a tenant. She hears footsteps pounding up- and down-stairs, and all through her room, she says nothing and gets used to it. Let it be granted that these noises are caused by rats. After conquering her dislike to the sounds, three weeks after her entry to the house, Miss Morris meets a total stranger, deadly pale, in deep black, who vanishes. This phantasm has gathered round the nucleus which the rats provided by stamping upand down-stairs, and through Miss Morris's room. It is natural that a person who hears rats, or wind, or waterpipes, and makes up her mind not to mind it, should then see a phantasm of a pale woman in black; also should hear loud knocks at the door of her

$$
{ }^{1} \text { Proc. S. P. R., Nov., I889, p. } 269 .
$$


chamber. Miss Morris goes away, a year later comes Mrs. G., and Mrs. G., her children, her servants, a barrister and an exorcist, are all disturbed by

Noises.

Knocks.

Sobs.

Moans.

Thumps.

Dragging of heavy weights.

One dreadful white face.

One little woman.

Lights.

One white skirt hanging from the ceiling.

One footfall which played two notes on the piano (!).

One figure in brown.

One man with freckles.

Two human faces.

One shadow.

One 'part of the dress of a super-material being " (Barrister).

One form (Exorcist).

One small column of misty vapour.

Now all this catalogue of prodigies which drove Mrs. G. into the cold, bleak world, was caused, 'by thought transference from Miss Morris,' who had been absent for a year, and whose own hallucinations were caused by noises which may have been produced by rats, or what not.

This ingenious theory is too much for Mr. Myers's powers of belief: 'The very first effect of Miss Morris's ponderings was a heavy thump, followed by 
a deep sob and moan, and a cry of, "Oh, do forgive me," all disturbing poor Mrs. G. who had the ill luck to find herself in a bedroom about which Miss Morris was possibly thinking. . . . Surely the peace of us all rests on a very uncertain tenure.' Meanwhile Mr. Myers prefers to regard the whole trouble as more probably caused by the 'dreams of the dead' woman who hanged herself with a skipping rope, than by the reflections of Miss Morris. In any case the society seem to have occupied the house, and, with their usual bad luck, were influenced neither by the ponderings of Miss Moiris, nor by the frédaines of the lady of the skipping rope. ${ }^{1}$ It may be worth noticing that the raps, knocks, lights, and so forth of haunted houses, the 'spontaneous' disturbances, have been punctually produced at savage, classical, and modern séances. If these, from the days of the witch of Endor to our own, and from the polar regions to Australia, have all been impostures, at least they all imitate the 'spontaneous' phenomena reported to occur in haunted houses. The lights are essentiai in the séances described by Porphyry, Eusebius, Iamblichus: they were also familiar tc the covenanting saints. The raps are known to Australian black fellows. The phantasms of anımals, as at the Wesleys' house, may be beasts who play a part in the dead man's dream, or they may be incidental hallucinations, begotten of rats, and handed on by Miss Morris or any one else.

There remains a ghost who illustrates the story,

1 This is rather overstated; there were knocks, and raps, and footsteps (Proc. S. P. R., Nov., ISSg, p. 310). 
spread all over Europe, of the farmer who was driven from his house by a bogle. As his carts went along the road, the bogle was heard exclaiming, 'We're flitting to-day,' and it faithfully stayed with the family. This tale, current in Italy as well as in Northern England, might be regarded as a mere piece of folk-lore, if the incident had not reproduced itself in West Brompton. In 1870 the T.'s took a house here: now mark the artfulness of the ghost, it did nothing for eighteen months. In autumn, I87I, Miss 'T. saw a figure come out of the dining-room, and the figure was often seen, later, by five independent witnesses. It was tall, dressed in grey, and was chiefly fond of haunting Miss 'T.'s own room. It did not walk, it glided, making no noise. Mr. T. met it in the hall, once, when he came in at night, and from the street he saw it standing in the drawing-room window. It used to sigh and make a noise as of steps, when it was not visible, it knocked and moved furniture about, and dropped weights, but these sounds were sometimes audible only to one, or a few of the observers. In I 877 the T.'s left for another house, to which Miss T. did not repair till I879. Then the noises came back as badly as ever,- - the bogle had flitted,-and, on Christmas Day, I879, Miss T. saw her old friend the figure. Several members of the family never saw it at all. One lady, in another case, Miss Nettie Vatas-Simpson, tried to flap a ghost away with a towel, ${ }^{1}$ but he was not thus to be exorcised. He presently went out through a locked door. 
Such are the ordinary or typical phenomena of haunted houses. It is plainly of no use to take a haunted house for a month and then say it is not haunted because you see no ghosts. Even where they have been seen there are breaks of years without any 'manifestations'. Besides, the evidence shows that it is not every one who can see a ghost when he is there: Miss Morton's father could not see the lady in black, when she was visible to Miss Morton.

It is difficult to write with perfect seriousness about haunted houses. The writer will frankly confess that, when living in haunted houses (as he has done at various times when suffering from illness and overwork), he takes a very solemn view of the matter about bed-time. If ' expectant attention' on a mind strained by the schools, and a body enfeebled by bronchitis, could have made a man, who was the only occupant of the haunted wing of an old Scotch castle, see a ghost, the writer would have seen whatever there was to see. To be sure he could not rationally have regarded a spectre beheld in these conditions, as a well-authenticated ghost. ${ }^{1}$ As far as his experience of first-hand tales is concerned, the persons known to him who say they have seen ghosts in haunted houses, were neither unhealthy, nor, except in one solitary case, imaginative, nor were they expecting a ghost. The apparition was 'a little pleasant surprise'. The usual

1 To be frank, in a haunted house the writer did once see an appearance, which was certainly either the ghost or one of the maids; 'the Deil or else an outler quey,' as Burns says. 
seer is not an invalid, nor a literary person who can aiways be dismissed as 'imagnative,' though he is generally nothing of the kind. But it cannot be denied that ladies either see more ghosts than men or are less reluctant to impart information. The visionary lady who keeps up a regular telepathic correspondence with severa: triends is likely to see a ghost, and should certainly be entered at 'fixed local ghosts,' but there are slight objections to such evidence, as not free from suspicion of fancifulness.

Turning trom the seers to the seen, it is difficult or impossible even to suggest an hypothesis which will seem to combine the facts. The most plausible fancy is that which likens the apparitions to figures in a feverish dream Could we imagine a more or less bad man or woman dead, and fitfully living over again, 'in that sleep of death,' old events among old scenes, could we go further and believe that these dreams were capable of being made objective and visible to the living, then we might find a kind of theory of the process. But even if it were possible to demonstrate the existence of such a process, we are as far as ever from accounting for the force which causes noises, or hallucinations of noises, a force of considerable vigour, according to observers. Still less could we explain the rare cases in which a ghost produces a material effect on the inanimate or animate world, as by drawing curtains, or pulling people's hair and clothes,-all phenomena as well vouched for as the others. A picture projected by one mind on another, cannot conceivably produce these effects. They are such as ghosts have always produced, or 
been said to produce. Since the days of ancient Egypt, ghosts have learned, and have forgotten nothing. Unless we adopt the scientific and popular system of merely saying 'Fudge!' we find no end to the conundrums of the ghostly world. Ghosts scem to know as little about themselves as we do, so that, if we are to discover anything, we must make haste, before we become ghosts ourselves.

Writers on Psychology sometimes make a push at a theory of haunted houses. Mr. James Sully, for example, has done so in his book styled Illusions. ${ }^{1}$ Mr. Sully appears well pleased with his hypothesis, and this, granting the accuracy of a tale for which he is indebted to a gentleman who need not be cited here, argues an easily contented disposition. Here is the statement :

'A lady was staying at a country house. During the night and immediately on waking up she had (sic) an apparition of a strange-looking man in meảiæval costume, a figure by no means agreeable, and which seemed altogether unfamiliar to her. The next morning, on rising, she recognised the original of her hallucinatory image in a portrait hanging on the wall of her bedroom, which must have impressed itself on her brain before the occurrence of the apparition, though she had not attended to it. Oddly enough, she now learned for the first time that the house at which she was staying had the reputation of being haunted, and by the very same somewhat repulsive-looking mediæval personage that had troubled her inter-somnolent moments. The case 
seems to me to be typical with respect to the genesis of ghosts, and of the reputation of haunted houses.'

This anecdote affords much joy to the superstitious souls who deal in Psychical Research, or Ghost Hunting. Mr. Sully's manner of narrating it clearly proves the difference between Science and Superstition. For a Ghost Hunter or Psychical Researcher would not venture to publish a modern ghost story (except for mere amusement), if he had it not at first hand, or at second hand with corroboration at first hand. Science, however, can adduce a case without indicating the evidence on which it rests, as whether Mr. Sully's informant had the tale from the lady, or at third, fourth, fifth, or a hundredth hand. So much for the matter of evidence. Next, Mr. Sully does not tell us whether the lady 'had an apparition,' when she supposed herself to be awake, or asleep, or 'betwixt and between'. From the phrase 'inter-somnolent,' he appears to prefer the intermediate condition. But he does not pretend to have interrogated the lady, the 'percipient'. Again, the figure wore a 'mediæval costume,' the portrait represented a 'mediæval personage'. Does Mr. Sully believe that the portrait was an original portrait of a real person? and how many portraits of mediæval people does he suppose to exist in English country houses? Taking the Middle Ages as lasting till the beginning of the reign of Henry VIII., say till Holbein, we can assure Mr. Sully that they have left us very few portraits indeed. But perhaps it was a modern picture, a fanciful study of a man in mediæval costume. In that event, Mr. Sully's case is greatly 
strengthened, but he does not tell us whether the work of art was, or was not, contemporary with the Middle Ages. Neither does he tell us whether the lady was in the habit of seeing hallucinations.

The weakest point in the whole anecdote and theory is in the statement, 'oddly enough, she now learned for the first time that the house at which she was staying had the reputation of being haunted' by the mediæval personage. It certainly would be very odd if one picture in a house troubled 'the intersomnolent moments' of a succession of people, who, perhaps, had never seen, or, like the lady, never attended to it. Such 'troubles' are very rare: very few persons have seen a dream which, in Mr. Sully's words, 'left behind, for an appreciable interval after waking, a vivid after-impression, and in some cases, even the semblance of a sense perception'. Mathematicians may calculate the chances against a single unnoticed portrait producing this very rare effect, in a series of cases, so as to give rise to a belief in haunting, by mere casual coincidence. In the records of the Psychical Society, one observer speaks of seeing a face and figure at night, which he recognises next morning in a miniature on his chimneypiece. But, in this case, there was no story of haunting, there had been no series of similar impressions on successive occupants of the room, that is the circumstance which Mr. Sully finds 'odd enough,' a sentiment in which we may all agree with him. This is exactly the oddity which his explanation does not explain.

While psychological science, in this example, 
seems to treat matters of evidence rather laxly, psychical conjecture, on the other hand, leaves much unexplained. Thus Mr. Myers puts forward a theory which is, in origin, due to St. Augustine. The saint had observed that any one of us may be seen in a dream by another person, while our intelligence is absolutely unconscious of any communication. Apply this to ghosts in haunted houses. We may be affected by a hallucination of the presence of a dead man or woman, but he, or she (granting their continued existence after death), may know nothing of the matter. In the same way, there are stories of people who have consciously tried to make others, at a distance, think of them. The subjects of these experiments have, it is said, had a hallucination of the presence of the experimenter. But he is unaware of his success, and has no control over the actions of what old writers, and some new theosophists, call his 'astral body'. Suppose, then, that something conscious endures after death. Suppose that some one thinks he sees the dead. It does not follow that the surviving consciousness (ex hypothcsi) of the dead person who seems to be seen, is aware that he is 'manifesting' himself. As Mr. Myers puts it, 'ghosts must therefore, as a rule, represent-not conscious or central currents of intelligence-but mere automatic projections from consciousnesses which have their centres elsewhere,' àrà фp ф́ves

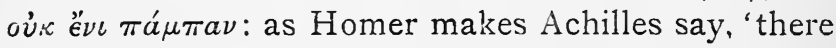
is no heart in them.' 1 All this is not inconceivable. But all this does not explain the facts, namely, the

$$
{ }^{1} \text { S. P. R., xv. } 64 \text {. }
$$


noises, often very loud, and the movements of objects, and the lights which are the common or infrequent accompaniments of apparitions in haunted houses. Now we have (always on much the same level of evidence) accounts of similar noises, and movements of untouched objects, occurring where living persons of peculiar constitution are present, or in haunted houses. These things we discuss in an essay on 'The Logic of Table-turning'. By parity of reasoning, or at least by an obvious analogy, we are led to infer that more than 'an automatic projection from the consciousness' of a dead man is present where he is not only seen, but heard, making noises, and perhaps moving objects. If this be admitted then psychical conjecture is pushed back on something very like the old theory of haunted houses, namely, that a ghost, or spiritual entity, is present and active there.

Long ago, in a little tale called 'Castle Perilous' (published in a volume named The Wrong Paradise), the author made an affable sprite explain all these phenomena. 'We suffer, we ghosts,' he said in effect, "from a malady akin to aphasia in the living. We know what we want to say, and how we wish to appear, but, just as a patient in aphasia uses the wrong word, we use the wrong manifestation.' 'This he illustrated by a series of apparitions on his own part, which, he declared, were involuntary and unconscious: when they were described to him by the percipient, he admitted that they were vulgar and distressing, though, as far as he was concerned, merely automatic. 
These remarks of the ghost, were, at least, explicit and intelligible. The theory which he stated with an honourable candour, and in language perfectly lucid, appears to have been adopted by $\mathrm{Mr}$. Frederick Myers, but he puts it in a different style. ' I argue that the phantasmogenetic agency at work -whatever that may be-may be able to produce effects of light more easily than definite figures. . . . A similar argument will hold good in the case of the vague hallucinatory noises which frequently accompany definite veridical phantasms, and frequently also occur apart from any definite phantasm in houses reputed haunted.' ${ }^{1}$ Now where Mr. Myers says 'phantasmogenetic agency,' we say 'ghost'. J'appelle un chat, un chat, et Rollet un fripon. We urge that the ghost cannot, as it were, express himself as plainly as he would like to do, that he suffers from aphasia. Now he shows as a black dog, now as a green lady, now as an old man, and often he can only rap and knock, or display a light, or tugthe bed-clothes. Thus the Rev. F. G. Lee tells us that a ghost first sat on his breast invisibly, then glided about his room like a man in grey, and, finally, took to thumping on the walls, the bed and in the chimney. Dr. Lee kindly recited certain psalms, and was greeted with applause, ' a very tornado of knocks ... was the distinct and intelligible response'. ${ }^{2}$ Now, on our theory, the ghost, if he could, would have said, 'Thank you very much,' or the like, but 
he could not, so his sentiments translated themselves into thumps. On another occasion, he might have merely shown a light, or he might have sat on Dr. Lee's chest, 'pressed unduly on my chest,' says the learned divine,-or pulled his blankets off, as is not unusual. Such are the peculiarities of spectral aphasia, or rather asemia. The ghost can makc signs, but not the right signs.

Very fortunately for science, we have similar examples of imperfect expression in the living. Thus Dr. Gibotteau, formerly interne at a hospital in Paris, published, in Amnales des Scionces Psychiques (Oct. and Dec , I892), his experiments on a hospital nurse, and her experiments on him. She used to try to send him hallucinations. Once at 8 P.M. in summer as he stood on a balcony, he saw a curious reflet blanc, 'a shining shadow' like that in The Strange Story. It resembled the reflection of the sun from a window, "but there was neither sun, nor moon, nor lighted lamps'. This white shadow was the partial failure of Berthe, the nurse, "to show herself to me on the balcony'. In precisely the same way, lights in haunted houses are partial failures of ghosts to appear in form As for the knocks, Dr. Binns, in his Anatomy of Sleep, mentions a gentleman who could push a door at a distance,if he could push, he could knock. Perhaps a rather larger collection of such instances is desirable, still, these cases illustrate our theory. That theory certainly does drive the cold calm psychical researcher back upon the primitive explanation: 'A 
I6O COCK LANE AND COMMON-SENSE.

ghaist's a ghaist for a' that!' We must come to this, we must relapse into savage and superstitious psychology, if once we admit a 'phantasmogenetic agency'. But science is in quest of Truth, regardless of consequences. 


\section{COCK LANE AND COMMON-SENSE.}

Cock Lane Ghost discredited. Popular Theory of Imposture. Dr. Johnson. Story of the Ghost. The Deceased Wife's Sister. Beginning of the Phenomena. Deaith of Fanny. Recurrence of Phenomena. Scratchings. Parallel Cases. Ignorance and Malevolence of the Ghost. Possible Literary Sources. Investigation. Imitative Scratihings: a Failure. Trial of the Parsonses. Professor Barrett's Irish parallel. Cause undetected. The Theories of Common-sense. The St. Maur Affair. The Amiens Case. The Sportive Highland Fox. The Brightling Case.

IF one phantom is more discredited than another, it is the Cock Lane ghost.

The ghost has been a proverb for impudent trickery, and stern exposure, yet its history remains a puzzle, and is a good, if vulgar type, of all similar marvels. The very people who 'exposed' the ghost, were well aware that their explanation was worthless, and frankly admitted the fact. Yet they, no more than we, were prepared to believe that the phenomena were produced by the spiritual part of Miss Fanny L.-known after her decease, as 'Scratching Fanny'. We still wander in Cock Lane, with a sense of amused antiquarian curiosity, and the same feeling accompanies us in all our explorations of this branch of mythology. It may be easy for some people 
of common-sense to believe that all London was turned upside down, that Walpole, the Duke of York, Lady Mary Coke, and two other ladies were drawn to Cock Lane (five in a hackney coach), that Dr. Johnson gave up his leisure and incurred ridicule, merely because a naughty child was scratching on a little wooden board.

The matter cannot have been so simple as that, but from the true solution of the problem we are as remote as ever. We can, indeed, study even the Cock Lane Ghost in the light of the Comparative, or Anthropological Method. We can ascertain that the occurrences which puzzled London in I762, were puzzling heathen philosophers and Fathers of the Church 1400 years earlier. We can trace a chain of 'Scratching Fannies' through the ages, and among races in every grade of civilisation. And then the veil drops, or we run our heads against a blank wall in a dark alley. Chaldeans, Egyptians, Greeks, Eskimo, Red Men, Dyaks, Fellows of the Royal Society, Inquisitors, Saints, have perlustrated Cock Lane, and have come away nothing the wiser. Some, of course, have thought they had the secret, have recognised the work of God, 'dæmons,' 'spirits,' ' ghosts,' 'devils,' 'fairies' and of ordinary impostors : others have made a push at a theory of disengaged nervous force, or animal magnetism. We prefer to leave theory alone, not even accepting with enthusiasm, the hypothesis of Dr. Johnson. 'He expressed great indignation at the imposture of the Cock Lane ghost, and related, with much satisfaction, how he had assisted in detecting the cheat, and had published 
an account of it in the newspapers. Upon this subject I incautiously offended him, by pressing him with too many questions,' says Boswell,-questions which the good doctor was obviously unable to answer.

It is in January, I762, that the London newspapers begin to be full of a popular mystery, the Cock Lane ghost. Reports, articles, letters, appeared, and the ghost made what is now called a 'sensation'. Perhaps, the most clear, if the most prejudiced account, is that given in a pamphlet entitled The Mystery Revealed, published by Bristow, in St. Paul's Churchyard ( 1762 ). Comparing this treatise (which Goldsmith is said to have written for three guineas) with the newspapers, The Gentleman's Magazine and the Ammal Register, we get a more or less distinct view of the subject. But the various newspapers repeat each other's versions, with slight alterations; The Gentleman's Magazine, and Ammal Register, follow suit, the nariatives are 'synoptic,' while Goldsmith's tract, if it be Goldsmith's, is obviously written in defence of the unlucky Mr. K., falsely accused of murder by the ghost.

Mr. K.'s version is the version given by Goldsmith, and thus leads up to the 'phenomena' through a romance of middle-class life. In $I 756$, this Mr. K., a person of some means, married Miss E. L. of L. in Norfolk. In eleven months the young wife died, in childbed, and her sister, Miss Fanny, came to keep house for Mr. K. The usual passionate desire to marry his deceased wife's sister assailed Mr. K., and Fanny shared his 
flame. According to Goldsmith, the canon law would have permitted the nuptials, if the wife had not born a child which lived, though only for a few minutes. However this may be, Mr. K. lionourably fled from Fanny, who, unhappily, pursued him with letters, and followed him to town. Here they took lodgings together, but when Mr. K. left the rooms, being unable to recover some money which he had lent his landlord, the pair looked out for new apartments. These they found in Cock Lane, in the house of Mr. Parsons, clerk of St. Sepulchre's.

It chanced (here we turn to the Anmual Register for I762) that Mr. K. left Fanny alone in Cock Lane while he went to a wedding in the country. She asked little Elizabeth Parsons, her landlord's daughter, to share her bed, and both of them were disturbed by strange scratchings and rappings. These were attributed by Mrs. Parsons to the industry of a neighbouring cobbler, but when they occurred on a Sunday, this theory was abandoned. Poor Fanny, according to the newspapers, thought the noises were a warning of her own death. Others, after the event, imagined that they were caused by the jealous or admonishing spirit of her dead sister. Fanny and Mr. K. (having sued Mr. Parsons for money lent) left his rooms in dudgeon, and went to Bartlet Court, Clerkenwell. Here Fanny died on February 2, I 760 , of a disease which her physician and apothecary certified to be small-pox, and her coffin was laid in the vault of St. John's Church. Now the noises in Cock Lane had ceased for a year and a half after Fanny left the house, but they returned in force in $176 \mathrm{I}-62$. 
Mr. Parsons in vain took down the wainscotting, to see whether some mischievous neighbour produced the sounds. ${ }^{1} \quad$ The raps and scratches seemed to come on the bed of little Elizabeth Parsons, just as in the case of the Tedworth drummer, investigated by Glanvill, a hundred years earlier; and in the case at Orleans, 230 years earlier. The Orleans case is published, with full legal documents, from MS. 40, 7r70, 4, Bibliothèque du Roi, in Recueil de Dissertations Anciennes et Nouvelles sur les Apparitions, ii. 90 (à Avignon, I75I). 'Scratching' was usually the first manifestation in this affair, and the scratches were heard in the bedroom occupied by certain children. The Cock Lane child 'was always affected with tremblings and shiverings at the coming and going of the ghost'. It was stated that the child had seen a shrouded figure without hands; two other witnesses (one of them a publican) had seen a luminous apparition, with hands. This brilliant being lit up the figures on the dial of a clock. "The noises followed the child to other houses,' and multitudes of people, clergy, nobles, and princes, also followed the child. A certain $\mathrm{Mr}$. Brown was an early investigator, and published his report. Like Adrien de Montalembert, in I526, like the Franciscans about I530, he asked the ghost to reply, affirmatively or negatively, to questions, by one knock for 'yes,' two for ' no'. This method was suggested, it seems, by a certain Mary Frazer, in attendance on the child. Thus it was elicited that Fanny had been poisoned by Mr. K. with 'red arsenic,' in a draught of purl to which

${ }^{1}$ British Chronicle, January I8, 1762 . 
she was partial. She added that she wished to see Mr.

K. hanged.

She would answer other questions, now right, and now wrong. She called her father John, while his real name was Thomas. In fact she was what Porphyry, the Neoplatonist, would have called a 'deceitful demon'. Her chief effects were raps, scratchings, and a sound as of whirring wings, which filled the room. This phenomenon occurs in a 'haunted house' mentioned in the Fournal of the Psychical Society. It is infinitely more curious to recall, that, when Mr. Im Thurn, in British Guiana, submitted to the doctoring of a peayman (see p. 39), he heard a sound, 'at first low and indistinct, and then gathering in volume as if some big winged thing came from far toward the house, passed through the roof, and then settled heavily on the floor, and again, after an interval, as if the same winged thing rose and passed away as it had come'. Mr. Im Thurn thinks the impression was caused by the waving of boughs. These Cock Lane occurrences were attributed to ventriloquism, but, after a surgeon had held his hand on the child's stomach and chest while the noises were being produced, this probable explanation was abandoned. 'The girl was said to be constantly attended by the usual noises, though bound and muifled hand and foot, and that without any motion of her lips, and when she appeared to be asleep.' ${ }^{1}$ This binding is practised by Eskimo Angakut, or sorcerers, as of

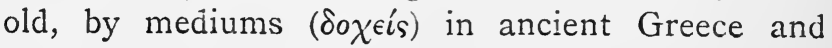


Egypt, so we gather from Iamblichus, and some lines quoted from Porphyry by Eusebius. ${ }^{1}$ A kind of 'cabinet,' as modern spiritualists call a curtain, seems to have been used. In fact the phenomena, luminous apparition, 'tumultuous sounds,' and all, were familiar to the ancients. Nobody seems to have noted this, but one unusually sensible correspondent of a newspaper quoted cases of knockings from Baxter's Certainty of the Worlds of Spirits, and thought that Baxter's popular book might have suggested the imposture. Though the educated classes had buried superstition, it lived, of course, among the people, who probably thumbed Baxter and Glanvill.

Thus things went on, crowds gathering to amuse themselves with the ghost. On February I, Mr. Aldrich, a clergyman of Clerkenwell, assembled in his house a number of gentlemen and ladies, having persuaded Parsons to let his child be carried thither and tested. Dr. Johnson was there, and Dr. Macaulay suggested the admission of a Mrs. Oakes. Dr. Johnson supplied the newspapers with an account of what happened. The child was put to bed by several ladies, about ten o'clock, and the company sat 'for rather more than an hour,' during which nothing occurred. The men then went down-stairs and talked to Parsons, when they were interrupted by some of the ladies, who said that scratching and knocking had set in. The company returned, and made the child hold her hands outside the bedclothes. No phenomena followed. Now the sprite had promised to rap on its own coffin in the vault of

${ }^{1}$ Praep. Evang., v. ix. 4 . 
St. John's, so thither they adjourned (without the medium), but there was never a scratch! 'It is therefore the opinion of the whole assembly, that the child has some art of making or counterfeiting particular noises, and that there is no agency of any higher cause.'

In precisely the same way the judges in the Franciscan case of 1533 , visited the bed of the child where the spirit had been used to scratch and rap, heard nothing, and decided that the affair was a hoax. The nature of the fraud was not discovered, but the Franciscans were severely punished. At Lyons, the bishop and some other clerics could get no response from the rapping spirit which was so familiar with the king's chaplain, Adrien de Montalembert (I526-7). Thus ' the ghost in some measure remains undetected,' says Goldsmith, and, indeed, Walpole visited Cock Lane, but could not get in, apparently after the detection. But, writing on February 2, he may speak of an earlier date.

Meanwhile matters were very uncomfortable for Mr. K. Accused by a ghost, he had no legal remedy. Goldsmith, like most writers, assumes that Parsons undertook the imposture, in revenge for having been sued for money lent by Mr. K. He adds that Mr. $K$. was engaged in a Chancery suit by his relations, and seems to suspect their agency. Meanwhile, Elizabeth was being 'tested' in various ways. Finally the unlucky child was swung up in a kind of hammock, 'her hands and feet extended wide,' and, for two nights, no noises were heard. Next day she was told that, if there were no noises, she and 
her father would be committed to Newgate. She accordingly concealed a little board, on which a kettle usually stood, a piece of wood six inches by four. She managed this with so little art that the maids saw her place the wood in her dress, and informed the investigators of the circumstances. Scratches were now produced, but the child herself said that they were not like the former sounds, and 'the concurrent opinion of the whole assembly was that the child had been frightened by threats into this attempt. . . The master of the house and his friend both declared that the noises the girl had made this morning had not the least likeness to the former noises.' In the same way the Wesleys at Epworth, in I7I6, found that they could not imitate the perplexing sounds produced in the parsonage. The end of the affair was that Parsons, Mary Frazer, a clergyman, a tradesman, and others were tried at the Guildhall and convicted of a conspiracy, on July Io, I762. Parsons was pilloried, and 'a handsome collection' was made for him by the spectators. His later fortunes, or misfortunes, and those of the miserable little Elizabeth, are unknown. One thing is certain, the noises did not begin in an attempt at imposture on Parsons's part; he was on good terms with his lodgers, when Fanny was first disturbed. Again, the child could not counterfeit the sounds successfully when she was driven by threats to make the effort. The séance $0_{1}$ rather more than an hour, in which Johnson took part, was certainly inadequate. The phenomena were such as had been familiar to law and divinity, 
at least since 856 , A.D. ${ }^{1}$ The agencies always made accusations, usually false. The knocling spirit at Kembden, near Bingen, in 856 charged a priest with a scandalous intrigue. The raps on the bed of the children examined by the Franciscans, about I530, assailed the reputation of a dead lady. When the Foxes, at Rochester, in I848-49, set up alphabetic communication with the knocks, they told a silly tale of a murder. The Cock Lane ghost lied in the same way. The Fox girls started modern spiritualism on its wild and mischievous career, as Elizabeth Parsons might have done, in a more favourable environment. There was never anything new in all these cases. The lowest savages have their séances, levitations, bindings of the medium, trance-speakers; Peruvians, Indians, have their objects moved without contact. Simon Magus, or St. Paul under that offensive pseudonym, was said to make the furniture move at will. ${ }^{2}$

There is a curious recent Cock Lane case in Ireland where 'the ghost' brought no accusations against anybody. The affair was investigated by Mr. Barrett, a Professor in the Royal College of Science, Dublin, who published the results in the Dublin University Magazine, for December, I877. The scene was a small lonely farm house at Derrygonnelly, near Enniskillen. The farmer's wife had died a few weeks before Easter, I877, leaving him

${ }^{1}$ Rudolfi Fuldensis, Annal., 858, in Pertz, i. 372. See Grimm's Teutonic Mythology, Engl. transl., p. 5 I4.

2 Pseudo-Clemens, Homil., ii. 32, 638. In Mr. Myers's Classical Essays, p. 66. 
with four girls, and one boy, of various ages, the eldest, Maggie, being twenty. The noises were chiefly heard in her neighbourhood. When the children had been put to bed, Maggie lay down, without undressing, in the bedroom off the kitchen. A sof $t$ pattering noise was soon heard, then raps, from all parts of the room, then scratchings, as in Cock Lane. When Mr. Barrett, his friend, and the farmer entered with a candle, the sounds ceased, but began again 'as if growing accustomed to the presence of the light'. The hands and feet of the young people were watched, but nothing was detected, while the raps were going on everywhere around, on the chairs, on the quilt, and on the big four-post wooden bedsteads where they were lying. Mr. Barrett now played Moro with the raps, that is, he extended so many fingers, keeping his hand in the pocket of a loose great-coat, and the sounds always responded the right number. Four trials were made. Then came a noise like the beating of a drum, 'with violent scratching and tearing sounds'.

The trouble began three weeks after the wife's death. Once a number of small stones were found on Maggie's bed. All the family suffered from sleeplessness, and their candles, even when concealed, were constantly stolen. 'It took a boot from a locked drawer,' and the boot was found in a great chest of feathers in a loft. A Bible was spirited about, and a Methodist teacher (the family were Methodists) made no impression on the agency. They tried to get some communication by an alphabet, but, said the farmer, 'it tells lies as often as truth, ana oftener, I think'. 
Mr. Barrett, and a friend, on two occasions, could detect no method of imposture, and, as the farmer did not believe that his children, sorely distressed by the loss of their mother, would play such tricks, at such a time, even if they could, the mystery remains unsolved. The family found that the less attention they paid to the disturbances, the less they were vexed. Mr. Barrett, examining some other cases, found that Dr. Carpenter's and other theories did not account for them. But it is certain that the children, as Methodists, had read Wesley's account of the spirit at Epworth, in I7I6. Mr. Barrett was aware of this circumstance, but was unable to discover how the thing was managed, on the hypothesis of fraudulent imitation. The Irish household seems to have reaped no profit by the affair, but rather trouble, annoyance, and the expense of hospitality to strange visitors.

The agency was mendacious, as usual, for Porphyry complains that the 'spirits' were always as deceitful as the Cock Lane ghost, feigning to be gods, heroes, or the souls of the dead. It is very interesting to note how, in Greece, as Christianity waxed, and paganism waned, such inquiring minds as that of Porphyry fell back on séances and spiritualism, or superstitions unmentioned by Homer, and almost unheard of in the later classical literature. Religion, which began in Shamanism, in the trances of Angakut and Birraark, returned to these again, and everywhere found marvel, mystery, imposture, conscious, or unconscious. The phenomena have never ceased, imposture has always been 
detected or asserted, but that hypothesis rarely covers the whole field, and so, if we walk in Cock Lane at all, we wander darkling, in good and bad company, among diviners, philosophers, saints, witches, charlatans, hypnotists. Many a heart has been broken, like that of Mr. Dale Owen, by the late discovery of life-long delusion, for we meet in

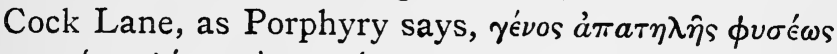

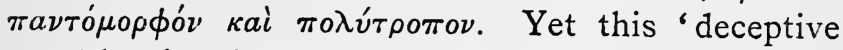
race' has had its stroke in the making of creeds, and has played its part in human history, while it contributes not a little to human amusement. Meanwhile, of all wanderers in Cock Lane, none is more beguiled than sturdy Common-sense, if an explanation is to be provided. When once we ask for more than ' all stuff and nonsense,' we speedily receive a very mixed theory in which rats, indigestion, dreams, and of late, hypnotism, are mingled much at random, for Common-sense shows more valour than discretion, when she pronounces on matters (or spirits) which she has never studied.

Beautiful instances of common-sense explanations, occur in two stories of the last century, the St. Maur affair (IFo6), and the haunted house of Amiens, (I746). The author of ' $\mathrm{Ce}$ qu'on doit penser de l'aventure arrivée a Saint Maur,' was M. Poupart, canon of St. Maur, near Paris. The good canon, of course, admits Biblical apparitions, which are miraculous, and admits hallucination caused by the state of the visual organs and by fever, while he believes in something like the Lucretian idea, that bodies, dead bodies, at least, shell off a kind of peel, 
which may, on occasion, be visible. Common ghosts he dismisses on grounds of common-sense ; if spirits in Purgatory could appear, they would appear more frequently, and would not draw the curtains of beds, drag at coverlets, turn tables upside down, and make terrible noises, all of which feats are traditional among ghosts.

M. Poupart then comes to the adventure at St. Maur. The percipient, M. de S., was a man of twenty-five: his mother seems to have been a visionary, and his constitution is described as 'melancholic'. He was living alone, however, and his mother has no part in the business. The trouble began with loud knocks at his door, and the servant, when she went to open it, found nobody there. The curtains of his bed were drawn, when he was alone in the room, and here, of course, we have only his evidence. One evening about eleven, he and his servants heard the papers on a table being turned over, and, though they suspected the cat, no cat could be found. When S. went to bed, the same noise persisted in his sitting-room, where the cat, no doubt, could easily conceal herself, for it is not easy to find a cat who has motives for not being found. S. again hunted for the animal, but only heard a great rap on the wall. No sooner had S. gone back to bed, than the bed gave a violent leap, and dashed itself against the wall: the jump covered four feet. He called his servants, who replaced the bed, but the curtains, in their sight, were drawn, and the bed made a wild rush at the fireplace. This happened again twice, though the servants held 
on gallantly to the bed. Monsieur S. had no sleep, his bed continued to bound and run, and he sent on the following day, for a friend. In that gentleman's presence the leaps made by the bed ended in its breaking its left foot, on which the visitor observed that he had seen quite enough. $\mathrm{He}$ is said, later, to have expressed sorrow that he spoke, but he may have had various motives for this repentance.

On the following night, S. slept well, and if his bed did rise and fall gently, the movement rather cradled him to repose. In the afternoon, the bolts of his parlour door closed of their own accord, and the door of a large armoire opened. A voice then bade S. do certain things, which he was to keep secret, go to a certain place, and find people who would give him further orders. S. then fainted, hurt himself, and with difficulty unbolted his door. A fortnight later, S., his mother, and a friend heard more rapping, and a heavy knock on the windows.

M. Poupart now gives the explanations of common-sense. The early noises might have had physical causes: master, servants, and neighbours all heard them, but that proves nothing. As to the papers, a wind, or a mouse may have interfered with them. The movements of the bed are more serious, as there are several witnesses. But 'suppose the bed was on castors'. The inquirer does not ask whether it really was on castors, or not, he supposes the case. Then suppose S., that melancholy man, wants a lark (a envie de se rejouir), he therefore tosses about in bed, and the bed rushes, consequently, round the room. This experiment may be attempted by any 
philosopher. Let him lie in a bed with castors, and try how far he can make it run, while he kicks about in it. This explanation, dear to common-sense, is based on a physical impossibility, as any one may ascertain for himself. Then the servants tried in vain to hold back the excited couch, well, these servants may have lied, and, at most, could not examine 'les ressorts secrets qui causaient ce mouvement'. Now, M. Poupart deserts the theory that we can make a bed run about, by lying kicking on it, and he falls back on hidden machinery. The independent witness is said to have said that he was sorry he spoke, but this evidence proves nothing. What happened in the room when the door was bolted, is not evidence, of course, and we may imagine that $\mathrm{S}$. himself made the noises on walls and windows, when his friend and mother were present. Thus M. S. was both melancholy, and anxious se donner un divertissement, by frightening his servants, to which end he supplied his bed with machinery that made it jump, and drew the curtains. What kind of secret springs would perform these feats, M. Poupart does not explain. It would have been wiser in him to say that he did not believe a word of it, than to give such silly reasons for a disbelief that made no exact inquiry into the circum. stances. The frivolities of the bed are reported in the case of Home and others, nor can we do much more than remark the conservatism of the phenomena ; the knocks, and the animated furniture. The Amiens case (I746) is reported and attested by Father Charles Louis Richard, Professor in 
Theology, a Dominican friar. The haunted house was in the Rue de l'Aventure, parish of St. Jacques. The tenant was a M. Leleu, aged thirty-six. The troubles had lasted for fourteen years, and there was evidence for their occurrence earlier, before Leleu occupied the house. The disturbances were of the usual kind, a sound of heavy planks being tossed about, as in the experience of Scott at Abbotsford, raps, the fastening of doors so that they could not be opened for long, and then suddenly gave way (this, also, is frequent in modern tales), a sound of sweeping the floor, as in the Epworth case, in the Wesleys' parsonage, heavy knocks and thumps, the dragging of heavy bodies, steps on the stairs, lights, the dancing of all the furniture in the room of Mlle. Marie de Lâtie, rattling of crockery, a noise of whirring in the air, a jingling as of coins (familiar at Epworth), and, briefly, all the usually reported tintamarre. Twenty persons, priests, women, girls, men of all sorts, attest those phenomena which are simply the ordinary occurrences still alleged to be prevalent.

The narrator believes in diabolical agency, but he gives the explanations of common-sense. I. M. Leleu is a visionary. But, as no one says that all the other witnesses are visionaries, this helps us little. 2. M. Leleu makes all the noise himself. That is, he chimbs to the roof with a heavy sack of grain on his shoulder, and lets it fall; he runs up and down the chimneys with his heavy sack on his shoulder, he frolics with weighty planks all over the house, thumps the walls, makes furniture dance, and 
how? What is his motive? His tenants leave him, he is called a fool, a devil, a possessed person : his business is threatened, they talk of putting him in jail, and that is all he has got by his partiality for making a racket. 3. The neighbours make the noises, and again the narrator asks 'how?' and 'why?' 4. Some priests slept in the house once and heard nothing. But nobody pretends that there is always something to hear. The Bishop of Amiens licenses the publication 'with the more confidence, as we have ourselves received the depositions of ten witnesses, a number more than sufficient to attest a fact which nobody has any interest in feigning'.

In a tale like this, which is only one out of a vast number, exactly analogous, Common-sense is ill-advised in simply alleging imposture, so long maintained, so motiveless, and, on the whole, so very difficult to execute. M. Leleu brought in the Church, with its exorcisms, but our Dominican authority does not say whether or not the noises ceased after the rites had been performed. Dufresnoy, in whose Dissertations ${ }^{1}$ these documents are republished, mentions that Bouchel, in his Bibliothéque du Droit François, d. v. 'Louage,' treats of the legal aspect of haunted houses. Thus the profession has not wholly disdained the inquiry.

Of all common sensible explanations, the most sporting and good-humoured is that given by the step-daughter of Alexander Dingwall, a tenant in Inverinsh, in $176 \mathrm{r}$. Poor Dingwall in his cornyard ${ }^{1}$ Avignon, $175 \mathrm{r}$. 
' heard very grievous lamentations, which continued, as he imagined, all the way to the seashore'. These he regarded as a warning of his end, but his stepdaughter sensibly suggested that, as the morning was cold, 'the voice must be that of a fox, to cause dogs run after him to give him heat'. Dingwall took to bed and died, but the suggestion that the fox not only likes being hunted, but provokes it as a form of healthy exercise, is invaluable. The tale is in Theophilus Insulanus, on the second sight.

There is no conclusion to be drawn from this mass of Cock Lane stories. Occasionally an impostor is caught, as at Brightling, in $16_{59}$. Mr. Joseph Bennet, a minister in that town, wrote an account of the affair, published in Increase Mather's Remarkable Providences. 'Several things were thrown by an invisible hand,' including crabs! 'Yet there was a seeming blur cast, though not on the whole, yet upon some part of it, for their servant girl was at last found throwing some things.' She averred that an old woman had bidden her do so, saying that 'her master and dame were bewitched, and that they should hear a great fluttering about their house for the space of two days'. This Cock Lane phenomenon, however, is not reported to have occurred. The most credulous will admit that the maid is enough to account for the Brightling manifestations; some of the others are more puzzling and remain in the region of the unexplained. 


\section{APPARITIONS, GHOSTS, AND HALLUCI- NATIONS.}

Apparitions appear. Apparitions are not necessarily Ghosts. Superstition, Common-sense, and Science. Hallucinations : their kinds, and causes. Aristotle. Mr. Gurney's definition. Various sources of Halluiination, external and internal. The Organ of Sense. The Sensory Centre. The Higher Tracts of the Brain. Nature of Evidence. Dr. Hibhert. Claz'erhouse. Lady Lee. Dr. Donne. Dr. Hibbert's complaint of want of evidence. His neglect of contemporary cases. Criticism of his tales. The question of coincidental Hallucinations. The Calculus of Probabilities: M. Richet, MM. Binet et Fíré; their Conciusions. A step beyond Hibbert. Examples of empty and unexciting Wraiths. Our ignorance of causes of Solitary Hallucinations. The theory of 'Telepathy'. Savage metaplyysics of $M$. d'Assier. Breakdown of theory of Teiepaihy, when hallucinatory figure causes changes in physical objects. Animals as Ghost-seers - difficult to explain this by Telepathy. Strange case of a cat. General propriety and lack of superstition in cats. The Beresford Ghost, zeil-meaning but probably mythical. Mrs. Henry Sidgwick: her sewcrity as regards conscientious Ghosts. Case of Mr. Harry. Case of Miss Morton. A difficult case. Examples in favour of old-fashioned theory of Ghosts. Contradictory cases. Perplexities of the anxious inquirer.

ONLY one thing is certain about apparitions, namely 
APPARITIONS, GHOSTS, AND HALLUCINATIONS. I8I

this, that they do appear. They really are perceived. Now, as popular language confuses apparitions with ghosts, this statement sounds like an expression of the belief that ghosts appear. It has, of course, no such meaning. When Le Loyer, in I $_{5}$ S6, boldly set out to found a 'science of spectres,' he carefully distinguished between his method, and the want of method observable in the telling of ghost stories. He began by drawing up long lists of apparitions which are not spectres, or ghosts, but the results of madness, malady, drink, fanaticism, illusions and so forth. It is true that Le Loyer, with all his deductions, left plenty of genuine spectres for the amusement of his readers. Like him we must be careful not to confound 'apparitions,' with ' ghosts '.

When a fist, applied to the eye, makes us 'see star's'; when a liver not in good working order makes us see musca volitantes, or 'spiders'; when alcohol produces 'the horrors,'-visions of threatening persons or animals, - when a lesion of the brain, or delirium, or a disease of the organs of sense causes visions, or when they occur to starved and enthusiastic ascetics, all these false perceptions are just as much 'apparitions,' as the view of a friend at a distance, beheld at the moment of his death, or as the unrecognised spectre seen in a haunted house.

In popular phrase, however, the two last kinds of apparitions are called ' ghosts,' or 'wraiths,' and the popular tendency is to think of these, and of these alone, when 'apparitions' are mentioned. On the other hand the tendency of common-sense is to rank the two last sorts of apparition, the wraith and ghost, 
with all the other kinds, which are undeniably caused by accident, by malady, mental or bodily, or by mere confusion and misapprehension, as when one, seeing a post in the moonlight, takes it for a ghost. Science, following a third path, would class all perceptions which 'have not the basis in fact that they seem to have' as 'hallucinations'. The stars seen after a blow on the eye are hallucinations,-there are no real stars in view,-and the friend, whose body seems to fill space before our sight, when his body is really on a death-bed far away;- and again, the appearance of the living friend whom we see in the drawing-room while he is really in the smokingroom or in Timbuctoo,--are hallucinations also. The common-sense of the matter is stated by Aristotle. The reason of the hallucinations is that appearances present themselves, not only when the object of sense is itself in motion, but also when the sense is stirred, as it would be by the presence of the object' ( $D e$ Insomn., ii. 46o, b, 23-26).

The ghost in a haunted house is taken for a figure, say, of a monk, or of a monthly nurse, or what not, but no monthly nurse or monk is in the establishment. The 'percept,' is a 'percept,' for those who perceive it; the apparition is an apparition, for them, but the perception is hallucinatory.

So far, everybody is agreed : the differences begin when we ask what causes hallucinations, and what difierent classes of hallucinations exist? Taking the second question first, we find hallucinations divided into those which the percipient (or percipients) believes, at the moment, and perhaps later, to be real; 
APPARITIONS, GHOSTS, AND HALLUCINATIONS. I $\delta_{3}$

and those which his judgment pronounces to be false. Famous cases of the latter class are the idola which beset Nicolai, who studied them, and wrote an account of them. After a period of trouble and trial, and neglect of blood-letting, Nicolai saw, first a dead man whom he had known, and, later, crowds of people, dead, living, known or unknown. The malady yielded to leeches. ${ }^{1}$ Examples of the first sort of apparitions taken by the judgment to be real, are common in madness, in the intemperate, and in ghost stories. The maniac believes in his visionary attendant or enemy, the drunkard in his rats and snakes, the ghost-seer often supposes that he has actually seen an acquaintance (where no mistaken identity is possible) and only learns later that the person,-_dead, or alive and well,-was at a distance. Thus the writer is acquainted with the story of a gentleman who, when at work in his study at a distance from England, saw a colleague in his profession enter the room. 'Just wait till I finish this business,' he said, but when he had hastily concluded his letter, or whatever he was engaged on, his friend had disappeared. That was the day of his friend's death, in England. Here then the hallucination was taken for a reality; indeed, there was nothing to suggest that it was anything else. Mr. Gurney has defined a hallucination as ' a percept which lacks, but which can only by distinct reflection be recognised as lacking, the objective basis which it suggests'-and by 'objective

${ }^{1}$ Compare the case of John Beaumont, F.R.S., in his Treatise of Spirits $(1705)$. 
basis,' he means 'the possibility of being shared by all persons with normal senses'. Nobody but the 'percipient' was present on the occasion just described, so we cannot say whether other people would have seen the visitor, or not. But reflection could not recognise the unreality of this 'percept,' till it was found that, in fact, the visitor had vanished, and had never been in the neighbourhood at all.

Here then, are two classes of hallucinations, those which reflection shows us to be false (as if a sane man were to have the hallucination of a crocodile, or of a dead friend, entering the room), and those which reflection does not, at the moment, show to be false, as if a friend were to enter, who could be proved to have been absent.

In either case, what causes the hallucination, or are there various possible sorts of causes? Now defects in the eye, or in the optic nerve, to speak roughly, may cause hallucinations from without. An injured external organ conveys a false and distorted message to the brain and to the intelligence. A nascent malady of the ear may produce buzzings, and these may develop into hallucinatory voices. Here be hallucinations from without. But when a patient begins with a hallucination of the intellect, as that inquisitors are plotting to catch him, or witches to enchant him, and when he later comes to see inquisitors and witches, where there are none, we have, apparently, a hallucination from within. Again, some persons, like Blake the painter, voluntarily start a hallucination. 'Draw me Edward I.,' a friend would say, Blake would, voluntarily, establish 
a hailucination of the monarch on a chair, in a good light, and sketch him, if nobody came between his eye and the royal sitter. Here, then, are examples of hallucinations begotten from within, either voluntarily, by a singular exercise of fancy, or involuntarily, as the suggestion of madness, of cerebral disease, or abnormal cerebral activity.

Again a certain amount of intensity of activity, at a 'sensory centre' in the brain, will start a 'percept'. Activity of the necessary force at the right place, may' be nomally caused by the organ of sense, say the eye, when fixed on a real object, say a candlestick. Or the necessary activity at the sensory centre may be produced, abnormally, by irritation of the eye, or along the line of nerve from the eye to the 'sensory centre'. (2) Or thirdly, there may be a morbid, but spontaneous activity in the sensory centre itself. In case one, we have a natural sensation converted into a perception of a real object. In case two, we have an abnormal origin of a perception of something unreal, a hallucination, begotten from without, that is by a vice in an external organ, the eye. In case three, we have the origin of an abnormal perception of something unreal, a hallucination, begotten by a vicious activity within, in the sensory centre. But, while all these three sets of stimuli set the machinery in motion, it is the 'highest parts of the brain' that, in response to the stimuli, create the full perception, real or hallucinatory.

But there remains a fourth way of setting the machinery in motion. The first way, in normal sensation and perception, was the natural action of 
the organ of sense, stimulated by a material object. The second way was by the stimulus of a vice in the organ of sense. The third way was a vicious activity in a sensory centre. All three stimuli reach the 'central terminus' of the brain, and are there created into perceptions, the first real and normal, the second a hallucination from an organ of sense, from without, the third a hallucination from a sensory centre, from within. The fourth way is illustrated when the machinery is set a-going from the 'central terminus' itself, 'from the higher parts of the brain, from the seats of ideation and memory'. Now, as long as these parts only produce and retain ideas or memories in the usual way, we think, or we remember, but we have no hallucination. But when the activity starting from the central terminus 'escapes downwards,' in sufficient force, it reaches the 'lower centre' and the organ of sense, and then the idea, or memory, stands visibly before us as a hallucination.

This, omitting many technical details, and much that is matter of more dispute than common, is a statement, rough, and as popular as possible, of the ideas expressed in Mr. Gurney's remarkable essay on hallucinations. ${ }^{1}$ Here, then, we have a rude working notion of various ways in which hallucinations may be produced. But there are many degrees in being hallucinated, or enphantosmé, as the old French has it. If we are interested in the most popular kind of hallucinations, ghosts and wraiths, we first discard like Le Loyer, the evidence of many kinds of witnesses, diversely but undeni-

${ }^{1}$ Proceedings S. P. R., viii. I5I-I8g. 
ably hallucinated. A man whose eyes are so vicious as habitually to give him false information is not accepted as a witness, nor a man whose brain is drugged with alcohol, nor a man whose 'central terminus' is abandoned to religious excitement, to remorse, to grief, to anxiety, to an apprehension of secret enemies, nor even to a habit of being hallucinated, though, like Nicolai, he knows that his visionary friends are unreal. Thus we would not listen credulously to a ghost story out of his own experience from a man whose eyes were untrustworthy, nor from a short-sighted man who had recognised a dead or dying friend on the street, nor from a drunkard. A tale of a vision of a religious character from Pascal, or from a Red Indian boy during his Medicine Fast, or even from a colonel of dragoons who fell at Prestonpans, might be interesting, but would not be evidence for our special purpose. The ghosts beheld by conscience-stricken murderers, by sorrowing widowers, by spiritualists in dark rooms, haunted by humbugs, or those seen by lunatics, or by children, or by timid people in lonely old houses, or by people who, though sane at the time, go mad twenty years later, or by sane people habitually visionary, these and many other ghosts, we must begin, like Le Loyer, by rejecting. These witnesses have too much cerebral activity at the wrong time and place. They start their hallucinations from the external terminus, the unhealthy organ of sense; from the morbid central terminus; or from some dilapidated cerebral station along the line. But, when we have, in a sane 
man's experience, say one hallucination whether that hallucination does, or does not coincide with a crisis in the life, or perhaps with the death of the person who seems to be seen, what are we to think? Or again, when several witnesses simultaneously have the same hallucination,- - not to be explained as a common misinterpretation of a real object,- - what are we to think?

This is the true question of ghosts and wraiths. That apparitions, so named by the world, do appear, is certain, just as it is certain that visionary rats appear to drunkards in delirium tremens. But, as we are only to take the evidence of sane and healthy witnesses, who were neither in anxiety, grief, or other excitement, when they perceived their one hallucination, there seems to be a difference between their hallucinations and those of alcoholism, fanaticism, sorrow, or anxiety. Now the common mistakes in dealing with this topic have been to make too much, or to make too little, of the coincidences between the halluciratory appearance of an absent person, and his death, or some other grave crisis affecting him. Too little is made of such coincidences by Dr. Hibbert, in his Philosophy of Apparitions (p. 23I). He 'attempts a physical explanation of many ghost stories which may be considered most authentic'. So he says, but he only touches on three, the apparition of Claverhouse, on the night of Killiecrankie, to Lord Balcarres, in an Edinburgh prison; the apparition of her dead mother to Miss Lee, in I662; and the apparition of his wife, who had born a dead child on that day in England, to Dr. Donne in Paris, early in the seventeenth century. 
Dr. Hibbert dedicated his book, in I825, to Sir Walter Scott, of Abbotsford, Bart., President of the Royal Society of Edinburgh Sir Walter, at heart as great a ghost-hunter as ever lived, was conceived to have a scientific interest in 'the mental principles to which certain popular illusions may be referred'. Thus Dr. Hibbert's business, if he would satisfy the President of the Royal Society of Edinburgh, was to 'provide a physical explanation of many ghost stories which may be considered most authentic'. In our prosaic age, he would have begun with those most recent, such as the tall man in brown, viewed by Sir Walter on the moor near Ashestiel, and other still remembered contemporary hallucinations. Far from that, Dr. Hibbert deliberately goes back two centuries for all the three stories which represent the 'many' of his promise. The Wynyard ghost was near him, Mrs. Ricketts's haunted house was near him, plenty of other cases were lying ready to his hand. ${ }^{1}$ But he went back two centuries, and then, - complained of lack of evidence about 'interesting particulars'! Dr. Hibbert represents the science and common-sense of seventy years ago, and his criticism probably represents the contemporary ideas about evidence.

${ }^{1}$ Mrs. Ricketts was a sister of Lord St. Vincent, who tried, ir. vain, to discover the cause of the disturbances. Scott says (Demonology and Witchcraft, p. 360): "Who has heard or seen an authentic account from Lord St. Vincent?' There is a full account in the Fournal of the S. P. R. It appeared much too late for Sir Walter. Scott also complains of lack of details for the Wynyard story. They are now accessible. People were, in his time, afiaid to make their experiences public. 
The Balcarres tale, as told by him, is that the Earl was 'in prison, in Edinburgh Castle, on the suspicion of Jacobitism'. 'Suspicion' is good; he was the King's agent for civil, as Dundee was for military affairs in Scotland. He and Dundee, and Ailesbury, stood by the King in London, to the last. Lord Balcarres himself, in his memoirs, tells James II. how he was confined, 'in close prison,' in Edinburgh, till the castle was surrendered to the Prince of Orange. In Dr. Hibbert's tale, the spectre of Dundee enters Balcarres's room at night, 'draws his curtain,' looks at him for some time, and walks out of the room, Lord Balcarres believing it to be Dundee himself.

Dr. Hibbert never even asks for the authority on which this legend reposes; certainly Balcarres does not tell the tale in his own report, or memoirs, for James II. (Bannatyne Club, I84I). The doctor then grumbles that he does not know 'a syllable of the state of Lord Balcarres's health at the time'. The friend of Bayle and of Marlborough, an honourable politician, a man at once loyal and plain-spoken in dealings with his master, Lord Balcarres's word would go for much, if he gave it. ${ }^{1}$ But Dr. Hibbert asks for no authority, cites none. He only argues that, 'agreeably to the well-known doctrine of chances,' Balcarres might as well have this hallucination at the time of Dundee's death as at any other (p. 232). Now, that is a question which

1 The story is told by Charles Kirkpatrick Sharpe, in his Introduction to Law's Memorialls, p. xci. Sharpe cites no source of the tradition. 
we cannot settle, without knowihg whether Lord Balcarres was subject to hallucinations. If he was, cadit qurestio, if he was noi, then the case is different. It is, manifestly, a problem in statistics, and only by statistics of wide scope, can it be solved. ${ }^{1}$ But Dr. Hibbert was content to produce his easy solution, without wor ing out the problem.

His second case is of 1662 and was taken down, he says, by the Bishop of Gibucester, from the lips of the father of Miss Lee. This young lady, in bed, saw a light, then a hallucination which called itself her mother. The figure prophessied the daughter's death at noon next day and at noon next day the daughter died. A physician, when she announced her vision, attended her, bled her, an 1 could find nothing wrong in her health. Dr. Hiblert conjectures that her medical attendant did not know his business. 'The coincidence was a fortunatif one,' that is all his criticism. Where there is no coi cidence, the stories, he says, are forgotten For thit very reason, he should have collected contemporiry stories, capable of being investigated, but that did not occur to $\mathrm{Dr}$. Hibbert. His last case is the apparition of Mrs. Donne, with a dead child, to Dri Donne, in Paris, as recorded by Walton. As Donne was a poet, very fond of his wife, and very anxious about her health, this case is not evidential, and miny be dismissed for 'a fortuitous coincidence' (p. 332).

Certainly Dr. Hibbert could come to no conclu-

${ }^{1}$ We are not discussing Dreams, which are many, but waking hallucinations, which are, relatively rare, and are remembered, unlike Dreams, whether they are coincidental or not. 
sion, save his ovin, on the evidence he adduces. But it was by his own fault that he chose only evidence very rerbote, incapable of being crossexamined, and scanty, while we know that plenty of contemporary eividence was within his reach. Possibly the possesiors of these experiences would not have put them $a_{i j}$ his disposal, but, if he could get no materials, he avas in no position to form a theory. All this wold have been recognised in any other matter, fiut in this obscure branch of psychology, beset, 2 it is, by superstition, science was content to be casual.

The error which lies at the opposite pole from Dr. Hibbert's mista:ke in not collecting instances, is the error of collecting only affirmative instances. We hear constantl'y about 'hallucinations of sight, sound, or touch, which suggest the presence of an absent person, and'which occur simultaneously with some exceptional crisis in that person's life, or, most frequently of all, with his death '. ${ }^{1}$ Now Mr. Gurney himself was muct, too fair a reasoner to avoid the collection of instintice contradictoria, examples in which the hallucination occurs, but does not coincide with any crisis watever in the life of the absent person who seems to be present. Of these cases, Dr. Hibbert could find only one on record, in the Mercure Gallant, January, I6go. The writer tells us how he dreamed thiat a dead relation of his came to his bedside, and announced that he must die that day. Unlike $\mathrm{N}$.iss Lee, he went on living. Yet the dream impressed him so much that he noted it down ${ }^{1}$ Gurney, op. cit., p. 187 . 
in writing as soon as he awoke. Dr. Johnson also mentions an instantia contradictoria. A friend of Boswell's, near Kilmarnock, heard his brother's voice call him by name: now his brother was dead, or dying, in America. Johnson capped this by his tale of having, when at Oxford, heard his name pronounced by his mother. She was then at Lichfield, but nothing ensued. In Dr. Hibbert's opinion, this proves that coincidences, when they do occur, are purely matters of chance. ${ }^{1}$ There are many hallucinations, a death may correspond with one of them, that case is noted, the others are forgotten. Yet the coincidences are so many, or so striking, that when a Maori woman has a hallucination representing her absent husband, she may marry without giving him recognised ground for resentment, if he happens to be alive. This curious fact proves that the coincidence between death and hallucinatory presence has been marked enough to suggest a belief which can modify savage jealousy. ${ }^{2}$

${ }^{1}$ The writer knows a case in which a gentleman, who had gone to bed about eleven P.M., in Scotland, was roused by hearing his own name lourly called. He searched his room in vain. His brother died suddenly, at the hour when he heard the voice, in Canada. But the difference of time proves that the voice was heard several hours $b$ ffore the death. Here, then, is a chance coincidence, which looked very like a case of Telepathy. Another will be found in Mr. Dale Owen's Debatable Land, p. 364. A gentleman died 'after breakfast' in Rhenish Prussia, and appeared, before noon, in New York. Thus he appeared hours before he died, but Mr. Dale Owen did not notice this fact.

${ }^{2}$ Since writing the passage on the Maori belief in death-wraiths the author has received several examples of the opinion as it exists among the Maoris, from Mr. Edward Tregear, F.G.S. 
By comparing coincidental with non-coincidental hallucinations known to him, Mr. Gurney is said to have decided that the chances against a death coinciding with a hallucination, were forty to one,-long odds. ${ }^{1}$ But it is clear that only a very large collection of facts would give us any materials for a decision. Suppose that some 20,000 people answer such questions as :-

I. Have you ever had any hallucination?

2. Was there any coincidence between the hallucination and facts at the time unknown to you?

The majority of sane people will be able to answer the first question in the negative.

Of those who answer both questions in the affirmative, several things are to be said. First, we must allow for jokes, then for illusions of memory. Corroborative contemporary evidence must be produced. Again, of the 20,000, many are likely to be selected instances. The inquirer is tempted to go to a person who, as he or she already knows, has a story to tell. Again, the inquirers are likely to be persons who take ar interest in the subject on the affirmative side, and their acquaintances may have been partly chosen because they were of the same intellectual complexion. ${ }^{2}$

All these drawbacks are acknowledged to exist, and are allowed for, and, as far as possible, provided against, by the very fair-minded people who have conducted this inquisition. Thus Mr. Henry Sidgwick, in I889, said, ' I do not think we can be

1 Proceedings S. P. R., xv. Io.

2 The writer has known a case in which a collector of these statistics disdained non-coincidental hallucinations as 'of no use' 
satisfied with less than 50,000 answers.. ${ }^{1}$ But these 50,000 answers have not been received. When we reflect that, to our knowledge, out of twent $t_{y}$-five questions asked among our acquaintances in one place, none would be answered in the affirmative: while, by selecting, we could get twenty-five affirmative replies, the delicacy and difficulty of the inquisition becomes painfully evident. Mr. Sidgwick, after making deductions on all sides of the most sportsmanlike character, still holds that the coincidences are more numerous by far than the Calculus of Probabilities admits. This is a question for the advanced mathematician. $M$. Richet once made some experiments which illustrate the problem. One man in a room thought of a series of names which, ex hypothesi, he kept to himself. Three persons sat at a table, which, as tables will do, 'tilted,' and each tilt rang an electric bell. Two other persons, concealed from the view of the table tilters, ran through an alphabet with a pencil, marking each letter at which the bell rang. These letters were compared with the names secretly thought of by the person at neither table.
He thought of
I. Jean Racine
2. Legros
3. Esther
4. Henrietta
5. Cheuvreux
6. Doremond
7. Chevalon
8. Allouand

The answers were

I. Igard

2. Neghn

3. Foqdem

4. Higiegmsd

5. Dievoreq

6. Epjerod

7. Cheval

8. Iko

${ }^{1}$ Proceedings S. P. R., xv. 7 . 
Here the non-mathematical reader will exclaim: 'Total failure, except in case 7 !' And, about that case, he will have his private doubts. But, arguing mathematically, M. Richet proves that the table was right, beyond the limits of mere chance, by fourteen to two. He concludes, on the whole of his experiments, that, probably, intellectual force in one brain may be echoed in another brain. But MM. Binet and Féré, who report this, decide that 'the calculation of chances is, for the most part, incapable of affording a peremptory proof; it produces uncertainty, disquietude, and doubt'. ' 'Yet something is gained by substituting doubt for systematic denial. Richet has obtained this important result, that henceforth the possibility of mental suggestion cannot be met with contemptuous rejection.'

Mental suggestion on this limited scale, is a phenomenon much less startling to belief than the reality, and causal nature, of coincidental hallucinations, of wraiths. But it is plain that, as far as general opinion goes, the doctrine of chances, applied to such statistics of hallucinations as have been collected, can at most, only 'produce uncertainty, disquietude, and doubt'. Yet if even these are produced, a step has been made beyond the blank negation of Hibbert.

The general reader, even if credulously inclined, is more staggered by a few examples of non-coincidental hallucinations, than confirmed by a pile of coincidental examples. Now it seems to be a defect in the method of the friends of wraiths, that they do 
not publish, with full and impressive details, as many examples of non-coincidental as of coincidental hallucinations. It is the story that takes the public : if we are to be fair we must give the non-coincidental story in all its features, as is done in the matter of wraiths with a kind of message or meaning.

Let us set a good example, by adducing wraiths which, in slang phrase, were 'sells'. Those which we have at first hand are marked '(A),' those at second hand '(B)'. But the world will accept the story of a ghost that failed on very poor evidence indeed.

I. (A) A young lady, in the dubious state between awake and asleep, unable, in fact, to feel certain whether she was awake or asleep, beheld her late grandmother. The old lady wept as she sat by the bedside.

'Why do you weep, grandmamma, are you not happy where you are ?' asked the girl.

'Yes, I am happy, but I am weeping for your mother.'

'Is she going to die?'

'No, but she is going to lose you.'

'Am I going to die, grandmamma?'

'Yes, my dear.'

'Soon?'

'Yes, my dear, very soon.'

The young lady, with great courage, concealed her dream from her mother, but confided it to a brother. She did her best to be good while she was on earth, where she is still, after an interval of many years.

Except for the conclusion, and the absence of a mystic bright light in the bedroom, this case exactly 
answers to that of Miss Lee, in 1662. Dr. Hibbert would have liked this example.

2. (B) A lady, staying with a friend, observed that one morning she was much depressed. The friend conficed to her that, in the past night, she had seen her brother, dripping wet. He told her that he had been drowned by the upsetting of a boat, which was attached by a rope to a ship. At this time, he was on his way home from Australia. The dream, or vision, was recorded in writing. When next the first lady met her friend, she was entertaining her brother at luncheon. He had never even been in a boat dragged behind a ship, and was perfectly safe.

3. (B) A lady, residing at a distance from Oxford wrote to tell her son, who was at Merton College, that he had just entered her room and vanished. Was he well? Yes, he was perfectly well, and bowling for the College Eleven.

4. (B) A lady in bed saw her absent husband. $\mathrm{He}$ announced his death by cholera, and gave her his blessing, she, of course, was very anxious and miserable, but the vision was a lying vision. The husband was perfectly well. In all these four cases, anxiety was caused by the vision, and in three at least, action was taken, the vision was recorded orally, or in writing. In the following set, the visions were waking hallucinations of sane persons never in any other instance hallucinated.

5. (A) A person of distinction, walking in a certain Cambridge quadrangle, met a very well-known clergyman. The former held out his hand, but 
APPARITIONS, GHOSTS, AND HALLUCINATIONS. I99

there was before him only open space. No feeling of excitement or anxiety followed.

6. (A) The writer, standing before dinner, at a table in a large and brilliantly lit hall, saw the door of the drawing-room open, and a little girl, related to himself, come out, and run across the hall into another room. He spoke to her, but she did not answer. He instantly entered the drawing-room, where the child was sitting in a white evening-dress. When she ran across the hall, the moment before, she was dressed in dark blue serge. No explanation of the puzzle could be discovered, but it is fair to add that no anxiety was excited.

7. (A) A young lady had a cold, and was wearing a brown shawl. After lunch she went to her room. A few minutes later, her sister came out, saw her in the hall, and went upstairs after her, telling her an anecdote. At the top of the stairs, the brown-shawled sister vanished. The elder sister was in her room, in a white shavl. She was visible, when absent on another occasion, to another spectator.

In two other cases (A) ladies, in their usual health, saw their husbands in their rooms, when, in fact, they were in the drawing-room or study. Here then are eight cases of non-coincidental hallucination, some of people awake, some of people probably on the verge of sleep, which are wholly without 'coincidence,' wholly unveridical. None of the 'percipients' was addicted to seeing 'visions about'.1

${ }^{1}$ The Psychical Society has published the writer's encounter with Professor Conington, at Oxford, in I869, when the professor was lying within one or two days of his death at Boston, a 
On the other side, though the writer knows several people who have 'seen ghosts' in haunted houses, and other odd phenomena, he knows nobody, at first hand, who has seen a 'veridical hallucination,' or rather, knows only one, a very young one indeed. Thus, between these personally collected statistics of spectral 'sells' on one part, and the world-wide diffusion of belief in 'coincidental ' hallucination on the other, the human mind is left in a balance which mathematics, and the Calculus of Probabilities (especially if one does not understand it) fail to affect.

Meanwhile, we still do not know what causes these solitary hallucinations of the sane. They can hardly come from diseased organs of sense, for these would not confine themselves to a single mistaken message of great vivacity. And why should either the 'sensory centre' or the 'central terminus' just once in a lifetime develop this uncanny activity, and represent to us a person to whom we may be wholly indifferent? The explanation is less difficult when the person represented is a husband or child, but even then, why does the activity occur once, and only once, and not in a moment of anxiety?

circumstance wholly unknown to the percipient. But no jury would accept this as anything but a case of mistaken identity, natural in a short-sighted man's vague experiences. Mr. Conington was not a man easily to be mistaken for another, nor were many men likely to be mistaken for Mr. Conington. Yet this is what must have occurred. There was no conceivable reason why the professor should 'telepathically' communicate with the percipient, who had never exchanged a word with him, except in an examination. 
The coincidental hallucinations are laid to the door of 'telepathy,' to 'a telepathic impact from the mind of an absent agent,' who is dying, or in some other state of rare or exciting experience, perhaps being married, as in Col. Meadows Taylor's case. This is a theory as old as Lavaterus, and was proclaimed by Mayo in the middle of the century; while, substituting 'angels' for human agents, Frazer of Tiree used it, in I700, to explain second sight. Nay, it is the Norse theory of a 'sending' by a sorcerer, as we read in the Icelandic sagas. But, admitting that telepathy may be a cause of hallucinations, we often find the effect where the cause is not alleged to exist. Nobody, perhaps, will explain our nine empty hallucinations by 'telepathy,' yet, from the supposed effects of telepathy they were indistinguishable. Are all such cases of casual hallucination in the sane to be explained by telepathy, by an impact of force from a distant brain on the central terminus of our own brains? At all events, a casual hallucination of the presence of an absent friend need obviously cause us very little anxiety. We need not adopt the hypothesis of the Maoris.

The telepathic theory has the advantage of cutting down the marvellous to the minimum. It also accounts for that old puzzle, the clothes worn by the ghosts. These are reproduced by the 'agent's' theory of himself, perhaps with some unconscious assistance from 'the percipient'. For lack of this light on the matter, M. d'Assier, a positivist, who believed in spectres, had to suggest that the ghosts 
wear the ghosts of garments! Thus positivism, in this disciple, returned to the artless metaphysics of savages. Telepathy saves the believer from such a humiliating relapse, and, perhaps, telepathy also may be made to explain 'collective' hallucinations, when several people see the same apparition. If a distant mind can thus demoralise the central terminus of one brain, it may do as much for two or more brains, or they may demoralise each other.

All this is very promising, but telepathy breaks down when the apparition causes some change in the relations of material objects. If there be a physical effect which endures after the phantasm has vanished, then there was an actual agent, a real being, a 'ghost' on the scene. For instance, the lady in Scott's ballad, 'The Eve of St. John,' might see and might hear the ghost of her lover by a telepathic hallucination of two senses. But if

The sable score, of fingers four,

Remained on the board impressed

by the spectre, then there was no telepathic hallucination, but an actual being of an awful kind was in Smailholm Tower. Again, the cases in which dogs and horses, as Paracelsus avers, display terror when men and women behold a phantasm, are not easily accounted for by telepathy, especially when the beast is alarmed before the man or woman suspects the presence of anything unusual. There is, of course, the notion that the horse shies, or the dog turns craven, in sympathy with its master's exhibition of fear. Owners of dogs and horses may counterfeit horror and see whether their favourites do sympathise. Cats don't. 
APPARITIONS, GHOSTS, AND HALLUCINATIONS. 203

In one of three cases known to us where a cat showed consciousness of a spectral presence, the apparition took the form of a cat. The evidence is only that of Richard Bovet, in his Pandemonium; or, the Devil's Cloyster (I684). In Mr. J. G. Wood's Man and Beast, a lady tells a story of being alone, in firelight, playing with a favourite cat, Lady Catherine. Suddenly puss bristled all over, her back rose in an arch, and the lady, looking up, saw a hideously malignant female watching her. Lady Catherine now rushed wildly round the room, leaped at the upper panels of the door, and seemed to have gone mad. This new terror recalled the lady to herself. She shrieked, and the phantasm vanished. She saw it on a later day. In a third case, a cat merely kept a watchful eye on the ghost, and adopted a dignified attitude of calm expectancy. If beasts can be telepathically affected, then beasts have more of a 'psychical' element in their composition than they usually receive credit for ; whereas if a ghost is actually in view, there is no reason why beasts should not see it.

The best and most valid proof that an abnormal being is actually present was that devised by the ghost of Sir Richard of Coldinghame in the ballad, and by the Beresford ghost, who threw a heavy curtain over the bed-pole. Unluckily, Sir Richard is a poetical figment, and the Beresford ghost is a myth, like William Tell: he may be traced back through various mediæval authorities almost to the date of the Norman Conquest. We have examined the story in a little book of folk-lore, Etudes Tra- 
ditionistes. Always there is a compact to appear, always the ghost burns or injures the hand or wrist of the spectator. A version occurs in William of Malmesbury.

What we need, to prove a ghost, and disprove an exclusively telepathic theory, is a ghost who is not only seen, heard, or even touched, but a ghost who produces some change in physical objects. Most provokingly, there are agencies at every successful séance, and in every affair of the Poltergeist, who do lift tables, chairs, beds, bookcases, candles, and so forth, while others play accordions. But then nobody or not everybody sees these agencies at work, while the spontaneous phantasms which are seen do not so much as lift a loo-table, generally speaking. In the spiritualistic cases, we have the effect, with no visible cause; in ghost stories, we have the visible presence, but he very seldom indeed causes any physical change in any object. No ghost who does not do this has any strict legal claim to be regarded as other than a telepathic hallucination at best, though, as we shall see, some presumptions exist in favour of some ghosts being real entities.

These rare facts have not escaped a ghost-hunter so intelligent as Mrs. Henry Sidgwick. This lady is almost too sportsmanlike, for a psychical researcher, in her habit of giving an apparition the benefit of every imaginable doubt which may absolve him from the charge of being a real genuine ghost. 'It is true,' she says, 'that ghosts are alleged sometimes to produce a physical effect on the external world;' but to admit this is 'to come into prima facie 
APPARITIONS, GHOSTS, AND HALLUCINATIONS. 205

collision with the physical sciences' (an awful risk to run), so Mrs. Sidgwick, in a rather cavalier manner leaves ghosts who produce physical effects to be dealt with among the phenomena alleged to occur at séances. Now this is hardly fair to the spontaneous apparition, who is doing his very best to demonstrate his existence in the only convincing way. The phenomena of séances are looked on with deserved distrust, and, generally, may be regarded as an outworn mode of swindling. Yet it is to this society that Mrs. Sidgwick relegates the most meritorious and conscientious class of apparitions.

Let us examine a few instances of the ghost who visibly moves material objects. We take one (already cited) from Mrs. Sidgwick's own article. ${ }^{1}$ In this case a gentleman named John D. Harry scolded his daughters for saying that they had seen a ghost, with which he himself was perfectly familiar. 'The figure,' a fair woman draped in white, 'on seven or eight occasions appeared in my bedroom, and twice in the library, and on one occasion it lifted up the mosquito-curtains, and looked closely into my face'. Now, could a hallucination lift a mosquito-curtain, or even produce the impression that it did so, while the curtain was really unmoved? Clearly a hallucination, however artful, and well got up, could do no such thing. Therefore a being - a ghost with very little maidenly reservehaunted the bedroom of Mr. Harry, if he tells a true tale. Again (p. II5), a lady (on whose veracity I am ready to pledge my all) had doors opened for her

${ }^{1}$ Proceedings of Society for Psychical Research, viii. III. 
frequently, 'as if a hand had turned the handle'. And once she not only saw the door open, but a grey woman came in. Another witness, years afterwards, beheld the same figure and the same performance. Once more, Miss A. M.'s mother followed a ghost, who opened a door and entered a room, where she could not be found when she was wanted (p. I2I). Again, ${ }^{1}$ a lady saw a ghost which, "with one hand, the left, drew back the curtain'. There are many other cases in which apparitions are seen in houses where mysterious thumps and raps occur, especially in General Campbell's experience (p. 483). If the apparition gave the thumps then he (or, in this instance, she) was material, and could produce effects on matter. Indeed, this ghost was seen to take up and lay down some books, and to tuck in the bed-clothes.

Hallucinations (which are all in one's eye or sensory centre, or cerebral central terminus), cannot draw curtains, or open doors, or pick up books, or tuck in bed-clothes, or cause thumps-not real thumps, hallucinatory thumps are different. Consequently, if the stories are true, some apparitions are ghosts, real objective entities, filling space. The senses of a hallucinated person may be deceived as to touch, and as to feeling the breath of a phantasm (a likely story), as well as in sight and hearing. But a visible ghost which produces changes in the visible world cannot be a hallucination. On the other hand Dr. Binns, in his Anatomy of Sleep tells us of 'a gentleman who, in a dream, pushed against a door in a distant house, so that those in the room were scarcely able

1 Proceedings of Socicty for Psychical Research, xiv. 442. 
to resist the pressure' ${ }^{1}$ Now if this rather staggering anecdote be true, the spirit of a living man, being abie to affect matter, is also, so to speak, material, and is an actual entity, an astral body. Moreover, Mrs. Frederica Hauffe, when in the magnetic sleep, 'could rap at a distance'.

These arguments, then, make in favour of the oldfashioned theory of ghosts and wraiths, as things objectively existing, which is very comforting to a conservative philosopher. Unluckily, just as many, or more, anecdotes look quite the other way. For instance, General Barter sees, hears, and recognises the dead Lieutenant B., wearing a beard which he had grown since the general saw him in life. He also sees the hill-pony ridden by $\mathrm{Mr}$. B., and killed by him - a steed with which, in its mortal days, the general had no acquaintance. This is all very well: a dead pony may have a ghost, like Miss A. B.'s dog which was heard by one Miss B., and seen by the other, some time after its decease. On mature reflection, as both ladies were well-known persons of letters, we suppress their names, which would carry the weight of excellent character and distinguished sense. But Lieutenant B. was also accompanied by two grooms. Now, it is too much to ask us to believe that he had killed two grooms, as he killed the pony. ${ }^{2}$ Consequently, they, at least, were hallucinations; so what was Lieutenant B. ? When Mr. $\mathrm{K}$., on board the Racoon, saw his dead father lying

${ }^{1}$ Modern Spirit Manifestations. By Adin Ballou. Liverpool, 1853 .

${ }^{2}$ Proceedings of Socicty for Psychical Research, xiv. 469 . 
in his coffin (p. 46I), there was no real coffin there, at all events; and hence, probably, no real dead father's ghost,-only a 'telepathic hallucination'. Miss Rose Morton could never touch the female ghost which she often chased about the house, nor did this ghost break or displace the threads stretched by Miss Morton across the stairs down which the apparition walked. Yet its footsteps did make a noise, and the family often heard the ghost walking downstairs, followed by Miss Morton. Thus this ghost was both material and immaterial, for surely, only matter can make a noise when in contact with matter. On the whole, if the evidence is worth anything, there are real objective ghosts, and there are also telepathic hallucinations: so that the scientific attitude is to believe in both, if in either. And this was the view of Petrus Thyræus, S.J., in his Loca Infesta (I598). The alternative is to believe in neither.

We have thus, according to the advice of Socrates, permitted the argument to lead us whither it would. And whither has it led us? The old, savage, natural theory of ghosts and wraiths is that they are spirits, yet not so immaterial but that they can fill space, be seen, heard, touched, and affect material objects. Mídiæval and other theologians preferred to regard them as angelic or diabolic manifestations, made out of compressed air, or by aid of bodies of the dead, or begotten by the action of angel or devil on the substance of the brain. Modern science looks on them as hallucinations, sometimes morbid, as in madness or delirium, or in a vicious condition of the organ of sense; sometimes abnormal, but not 
necessarily a proof of chronic disease of any description. The psychical theory then explains a sifted remnant of apparitions ; the coincidental, 'veridical' hallucinations of the sane, by telepathy. There is a wide chasm, however, to be bridged over between that hypothesis, and its general acceptance, either by science, or by reflective yet unscientific inquirers. The existence of thought-transference, especially among people wide awake, has to be demonstrated more unimpeachably, and then either the telepathic explanation must be shown to fit all the cases collected, or many interesting cases must be thrown overboard, or these must be referred to some other cause. That cause will be something very like the old-fashioned ghosts. Perhaps, the most remarkable collective hallucination in history is that vouched for by Patrick Walker, the Covenanter; in his Biographia Presbyteriana. ${ }^{1}$ In 1686 , says Walker, about two miles below Lanark, on the water of Clyde 'many people gathered together for several afternoons, where there were showers of bonnets, hats, guns, and swords, which covered the trees and ground, companies of men in arms marching in order, upon the waterside, companies meeting companies, ... and then all falling to the ground and disappearing, and other companies immediately appearing in the same way'. This occurred in June and July, in the afternoons. Now the Westland Whigs were then, as usual, in a very excitable frame of mind, and filled with fears, inspired both by events, and by the prophecies of Peden and other saints. Patrick Walker himself

${ }^{1}$ Edinburgh, 1827, vol. i. p. xxxii. 
was a high-flying Covenanter, he was present: 'I went there three afternoons together'-and he saw nothing unusual occur. About two-thirds of the crowd did see the phenomena he reckons, the others, like himself, saw nothing strange. 'There was a fright and trembling upon them that did see,' and, at least in one case, the hallucination was contagious. A gentleman standing next Walker exclaimed: 'A pack of damned witches and warlocks, that have the second sight, the deil ha't do I see'. 'And immediately there was a discernable change in his countenance, with as much fear and trembling as any woman I saw there, who cried out: " $O$ all ye that do not see, say nothing; for I perswade you it is matter of fact, and discernable to all that is not stone-blind".' Those who did see minutely described "what handles the swords had, whether small or three-barred, or Highland guards, and the closing knots of the bonnets, black or blue. . . . I have been at a loss ever since what to make of this last,' says Patrick Walker, and who is not at a loss? The contagion of the hallucination, so to speak, did not affect him, fanatic as he was, and did affect a cursing and swearing cavalier, whose prejudices, whose 'dominant idea,' were all on the other side. The Psychical Society has published an account of a similar collective hallucination of crowds of people, 'appearing and disappearing,' shared by two young ladies and their maid, on a walk home from church. But this occurred in a fog, and no one was present who was not hallucinated. Patrick Walker's account is triumphantly honest, and is, perhaps, as odd a piece of psychology 
as any on record, thanks to his escape from the prevalent illusion, which, no doubt, he would gladly have shared. Wodrow, it should be said, in his History of the Sufferings of the Kirk, mentions visions of bonnets, which, he thinks, indicated a future muster of militia! But he gives the date as $168_{4}$. 


\section{SCRYING OR CRYSTAL-GAZING.}

Revival of crystal-gazing. Antiquity of the practice. Its general harmlessness. Superstitious explanations. Crystal-gazing and 'illusions hypnagogiques'. Visualisers. Poetic vision. Ancient and savage practices analogous to crystal-gazing. New Zealand. North America. Egypt. Sir Walter's interest in the subject. Mr. Kinglake. Greek examples. Dr. Dee. Miss X. Another modern instance. Successes and failures. Revival of lost memories. Possible thought-transference. Inferences from antiquity and diffusion of practice. Based on actual experience. Anecdotes of Dr. Gregory. Children as visionaries. Not to be encouraged.

THE practice of 'scrying,' 'peeping,' or 'crystal-gazing,' has been revived in recent years, and is, perhaps, the only 'occult' diversion which may be free from psychological or physical risk, and which it is easy not to mix with superstition. The antiquity and world-wide diffusion of scrying, in one form or other, interests the student of human nature. Meanwhile the comparatively few persons who can see pictures in a clear depth, may be as innocently employed while so doing, as if they were watching the clouds, or the embers. 'May be,' one must say, for crystalseers are very apt to fall back on our old friend, the animistic hypothesis, and to explain what they see, or fancy they see, by the theory that 'spirits' are at the 
bottom of it all. In Mrs. de Morgan's work From Matter to Spirit, suggestions of this kind are not absent: 'As an explanation of crystal-seeing, a spiritual drawing was once made, representing a spirit directing on the crystal a stream of influence,' and so forth. Mrs. de Morgan herself seemed rather to hold that the act of staring at a crystal mesmerises the observer. The person who looks at it often becomes sleepy. 'Sometimes the eyes close, at other times tears flow.' People who become sleepy, or cry, or get hypnotised, will probably consult their own health and comfort by leaving crystal balls alone.

There are others, however, who are no more hypnotised by crystal-gazing than tea-drinking, or gardening, or reading a book, and who can still enjoy visions as beautiful as those of the opium eater, without any of the reaction. Their condition remains perfectly normal, that is, they are wide awake to all that is going on. In some way their fancy is enlivened, and they can behold, in the glass, just such vivid pictures as many persons habitually see between sleeping and waking, illusions hypnagogiques. These 'hypnagogic illusions' Pontus de Tyard described in a pretty sonnet, more than three hundred years ago. Maury, in his book on dreams has recorded, and analysed them. They represent faces, places, a page of print, a flame of fire, and so forth, and it is one of their peculiarities that the faces rapidly shift and alter, generally trom beautiful to ugly. A crystal-seer seems to be a person who can see, in a glass, while awake and 
with open eyes, visions akin to those which perhaps the majority of people see with shut eyes, between sleeping and waking: ${ }^{1}$ It seems probable that people who, when they think, see a mental picture of the subject of their thoughts, people who are good 'visualisers,' are likely to succeed best with the crystal, some of them can 'visualise' purposely, in the crystal, while others cannot. Many who are very bad 'visualisers,' like the writer, who think in words, not in pictures, see bright and distinct hypnagogic illusions, yet see nothing in the crystal, however long they stare at it. And there are crystalseers who are not subject to hypnagogic illusions. These facts, like the analogous facts of the visualisation of arithmetical figures, analysed by Mr. Galton, show interesting varieties in the conduct of mental operations. Thus we speak of 'vision' in a poet, or novelist, and it seems likely that men of genius 'see' their fictitious characters and landscapes, while people of critical temperament, if they attempt creative work, are conscious that they do not create, but construct. On the other hand many incompetent novelists are convinced that they have 'vision,' that they see and hear their characters, but they do not, as genius does, transfer the 'vision' to their readers.

This is a digression from the topic of hallucinations caused by gazing into a clear depth. Forms

${ }^{3}$ In the author's case the hypnagogic phantasms seem to be created out of the floating spots of light which remain when the eyes are shut. Some crystal-gazers find that similar points de repère in the glass, are the starting-points of pictures in the crystal. Others cannot trace any such connection. 
of crystal-gazing, it is well known, are found among savages. The New Zealanders, according to Taylor, gaze in a drop of blood, as the Egyptians do in a drop of ink. In North America, the Père le Jeune found that a kind of thought reading was practised thus: it was believed that a sick person had certain desires, if these could be gratified, he would recover. The sorcerers, therefore, gazed into water in a bowl expecting to see there visions of the desired objects. The Egyptian process with the boy and the ink, is too familiar to need description. In Scott's Fournal (ii. 4I9) we read of the excitement which the reports of Lord Prudhoe ${ }^{1}$ and Colonel Felix, caused among the curious. A boy, selected by these English gentlemen, saw and described Shakspeare, and Colonel Felix's brother, who had lost an arm. The ceremonies of fumigation, and the preliminary visions of flags, and a sultan, are not necessary in modern crystal-gazing. Scott made inquiries at Malta, and wished to visit Alexandria. $\mathrm{He}$ was attracted, doubtless, by the resemblance to Dr. Dee's tales of his magic ball, and to the legends of his own Aunt Margaret's Mirror. The Quarterly Review (No. II7, pp. I96-208) offers an explanation which explains nothing. The experiments of Mr. Lane were tolerably successful, those of Mr. Kinglake, in Eothen, were amusingly the reverse. Dr. Keate, the flogging headmaster of Eton, was described by the seer as a beautiful girl, with golden hair and blue eyes. The modern explanation of successes would

${ }^{1}$ Compare Blackzood, August, I831, in Noctes Ambrosiana. 
apparently be that the boy does, occasionally, see the reflection of his interrogator's thoughts.

In a paper in the Proceedings of the Society for Psychical Research (part xiv.), an anonymous writer gives the results of some historical investigation into the antiquities of crystal-gazing. The stories of cups, 'wherein my lord divines,' like Joseph, need not necessarily indicate gazing into the deeps of the cup. There were other modes of using cups and drops of wine, not connected with visions. At Patrae, in Greece, Pausanias describes the dropping of a mirror on to the surface of a well, the burning of incense, and the vision of the patient who consults the oracle in the deeps of the mirror. ${ }^{1}$ A Christian Father asserts that, in some cases, a basin with a glass bottom was used, through which the gazer saw persons concealed in a room below, and took them for real visions. ${ }^{2}$ In mirror-magic (catoptromancy), the child seer's eyes were bandaged, and he saw with the top of his head! The Specularii continued the tradition through the Middle Ages, and, in the sixteenth century Dr. Dee ruined himself by his infatuation for 'show-stones,' in which Kelly saw, or pretended to see, visions which Dr. Dee interpreted. Dee kept voluminous diaries of his experiments, part of which is published in a folio by Meric Casaubon. The work is flighty, indeed crazy; Dee thought that the hallucinations were spirits, and believed that his 'show-stones' were occasionally spirited away by the demons. Kelly pretended to hear noises in the stones, and to receive messages.

$$
1 \text { Paus., ii. 24, I. }
$$

2 Bouché Leclercq, i. 339. 
In our own time, while many can see pictures, few know what the pictures represent. Some explain them by interpreting the accompanying 'raps,' or by 'automatic writing'. The intelligence thus conveyed is then found to exist in county histories, newspapers, and elsewhere, a circumstance which lends itself to interpretation of more sorts than one. Without these very dubious modes of getting at the meaning of the crystal pictures, they remain, of course, mere picturesque hallucinations. The author of the paper referred to, is herself a crystal-seer, and (in Borderland No. 2) mentions one very interesting vision. She and a friend stared into one of Dr. Dee's 'showstones,' at the Stuart exhibition, and both beheld the same scene, not a scene they could have guessed at, which was going on at the seer's own house. As this writer, though versed in hallucinations, entirely rejects any 'spiritual' theory, and conceives that she is dealing with purely psychological curiosities, her evidence is the better worth notice, and may be compared with that of a crystal-seer for whose evidence the present writer can vouch, as far as one mortal may vouch for that of another.

Miss X., the writer in the Psychical Proceedings, has been able to see pictures in crystals and other polished surfaces, or, indeed, independently of these, since childhood. She thinks that the visions are:-

I. After-images, or recrudescent memories (often memories of things not consciously noted).

2. Objectivations of ideas or images, consciously or unconsciously present to the mind.

3. Visions, possibly telepathic or clairvoyant, 
implying acquirement of knowledge by supernormal means. The first class is much the most frequent in this lady's experience. She can occasionally refresh her memory by looking into the crystal.

The other seer, known to the writer, cannot do this, and her pictures, as far as she knows, are purely fanciful. Perhaps an 'automatic writer' might interpret them, in the rather dubious manner of that ar't. As far as the 'scryer' knows, however, her pictures of places and people are not revivals of memory. For example, she sees an ancient ship, with a bird's beak for prow, come into harbour, and behind it a man carrying a crown. This is a mere fancy picture. On one occasion she saw a man, like an Oriental priest, with a white caftan, contemplating the rise and fall of a fountain of fire: suddenly, at the summit of the fire, appeared a human hand, pointing downwards, to which the old priest looked up. This was in August, I893. Later in the month the author happened to take up, at Loch Sheil, Lady Burton's Life of Sir Richard Burton. On the back of the cover is a singular design in gold. A woman in widow's weeds is bowing beneath rays of light, over which appears a human hand, marked R. F. B. on the wrist. The author at once wrote asking his friend the crystal-gazer if she had seen this work of art, which might have unconsciously suggested the picture. The lady, however, was certain that she had not seen the Life of Sir Richard Burton, though her eye, of course, may have fallen on it in a bookseller's shop, while her mind did not consciously take it in. If this was a revival of a 
sub-conscious memory in the crystal, it was the only case of that process in her experience.

On the other hand Miss $X$. can trace many of her visions to memories, as Maury could in his illusions hypnagogiques. Thus, Miss X. saw in the crystal, the printed announcement of a friend's death. She had not consciously read the Times, but remembered that she had held it up before her face as a firescreen. This kind of revival, as she says, corresponds to the writing, with planchette, of scraps from the Chanson de Roland, by a person who had never conscionsly read a line of it, and who did not even know what stratum of Ofd French was represented by the fragments. Miss X. seems not to know either; for she calls it 'Provençal'. Similar instances of memory revived are not very uncommon in dreams. Miss X. can consciously put a group of fanciful characters into the crystal, while this is heyond the power of the seer known to the writer, wh $\mathrm{w}_{\mathrm{u}}$ has attempted to perceive what a friend is doing at a distance, but with no success. Thus she tried to discover what the writer might be about, and secured a view of two large sunny rooms, with a shadowy figure therein. Now it is very probable that the writer was in just such a room, at - Castle, but the seer saw, on the library table, a singular mirror, which did not exist there, and a model of a castle, also non-existent. The knowledge that the person sought for was staying at a 'castle,' may have unconsciously suggested this model in the picture.

A pretty case of revived memory is given by Miss X. She wanted the date of Ptolemy Phila- 
delphus. Later, in the crystal, she saw a conventional old Jew, writing in a book with massive clasps. Using a magnifying glass, she found that he was writing Greek, but the lines faded, and she only saw the Roman numerals LXX. These suggested the seventy Hebrews who wrote the Septuagint, with the date, 277 B.C., which served for Ptolemy Philadelphus. Miss X. later remembered a memoria technica which she had once learned, with the clue, 'Now Jewish elders indite a Greek copy'. It is obvious that these queer symbolical reawakenings of memory explain much of the (apparently) ' unknown' information given by 'ghosts,' and in dreams. A lady, who had long been in very bad health, was one evening seized by a violent recrudescence of memory, and for hours poured out the minutest details of the most trivial occurrences; the attack was followed by a cerebral malady from which she fortunately recovered. The same phenomenon of awakened memory has occasionally been reported by people who were with difficulty restored after being seven-eighths drowned.

The crystal ball, in the proper hands, merely illustrates the possibility of artificially reviving memory, while the fanciful visions, akin to illusions hypnagogiques, have, in all ages, been interpreted by superstition as revelations of the distant or the future. Of course, if there is such a thing as occasional transference of thought, so that the idea in the inquirer's mind is reflected in the crystalgazer's vision, the hypothesis of the superstitious will fix on this as a miracle, still more will that 
hypothesis be strengthened, if future or distant events, not consciously known, are beheld. Such things must occasionally occur, by chance, in the myriad confusions of dreams, and, to the same extent, in crystal visions. Miss X.'s three cases of possible telepathy in her own experience are trivial, and do not seem to rise beyond the possibility of fortuitous coincidence: and her possible clairvoyant visions she leaves to the judgment of the reader, "to interpret as clairvoyance, or coincidence, or prevision, or whatever else he will'. The crystal-gazer known to the author once managed to see the person (unknown to her) who was in the mind of the other party in the experiment. But she has made scarcely any experiments of this description.

The inferences to be drawn from crystal-gazing are not unimportant. First, we note that the practice is very ancient and widely diffused, among civilised and uncivilised people. In this diffusion it answers to the other practices, the magical rites of Australian blacks, Greeks, Eskimo; to the stories of 'death-bed wraiths,' of rappings, and so forth. Now this uniformity, as far as regards the latter phenomena, may be explained by transmission of ideas, or by the uniformity of human nature, while the phenomena themselves may be mere inventions like other myths. In the case of crystal-gazing, however, we can scarcely push scepticism so far as to deny that the facts exist, that hallucinations are actually provoked. The inference is that a presumption is raised in favour of the actuality of the other phenomena universally reported. They, too, may con- 
ceivably be hallucinatory; the rappings and 'haunting' noises may be auditory, as the crystal visions are ocular hallucinations. The sounds so widely attested may not cause vibrations in the air, just as the visions are not really in the crystal ball. As the unconscious self suggests the pictures in the ball, so it may suggest the unexplained noises. But while, as a rule, only one gazer sees the visions, the sounds (usually but not invariably) are heard by all present. On the whole, the one case wherein we find facts, if only facts of hallucination, at the bottom of the belief in a world-wide and world-old practice, rather tends in the direction of belief in the other facts, not less universally alleged. We know too much about mythology to agree with Dr. Johnson, in holding that 'a beliet, which prevails as far as human nature is diffused, could become universal only by its truth,' that 'those who never heard of one another would not have agreed in a tale which nothing but experience could make credible'. But, on the other hand, a belief is not necessarily untrue, because it is universally diffused.

In the second place, crystal-gazing shows how a substratum of fact may be so overlaid with mystic mummeries, incantations, fumigations, pentacles: and so overwhelmed in superstitious interpretations, introducing fairies and spirits, that the facts run the risk of being swept away in the litter and dust of nonsense. Science has hardly thought crystal-gazing worthy even of contempt, yet it appears to deserve the notice of psychologists To persons who can 'scry,' and who do not see hideous illusions, or 
become hypnotised, or superstitious, or incur headaches, scrying is a harmless gateway into Les Paradis Artificiels. "And the rest, they may live and learn.' 1

A very few experiments will show people whether they are scryers, or not. The phenomena, it seems, are usually preceded by a mistiness, or milkiness, of the glass: this clears off, and pictures appear. Even the best scryers often fail to see anything in the crystal which maintains its natural 'diaphaneity,' as Dr. Dee says. Thus the conditions under which the scryer can scry, are, as yet, unascertained.

The phenomena of scrying were not unknown to Dr. Gregory, Professor of Chemistry in the University of Edinburgh. Dr. Gregory believed in 'odylic fluid' on the evidence of Reichenbach's experiments, which nobody seems to have repeated successfully under strict tests. Clairvoyance also was part of Dr. Gregory's faith, and, to be fair, phenomena were exhibited at his house, in the presence of a learned and distinguished witness known to the writer, which could only be accounted for either by thought transference, or by an almost, or quite incredible combination of astuteness, and imposture on the side of Dr. Gregory himself. In presence of the clairvoyante the nobleman of whom we speak thought not of his own house, but of a room in the house of a friend. It possessed a very singular feature which it is

1 The accomplished scryer can see as well in a crystal ringstone, or in a glass of water, as in a big crystal ball. The latter may really be dangerous, if left on a cloth in the sun it may set the cloth on fire. 
needless to describe here, but which was entirely out of the experience of the clairvoyante. She described it, however, expressing astonishment at what she 'saw'. This, unless Dr. Gregory guessed what was likely to be thought of, and was guilty of collusion, can only be explained by thought transference. In other cases the doctor was convinced that he had evidence of actual clairvoyance, and it is difficult to estimate the amount of evidence which will clear such a belief of the charge of credulity. As to 'scrying' the doctor thought it could be done in 'mesmerised water,' water bewitched. There is no reason to imagine that 'mesmerised' is different from ordinary water. ${ }^{1} \mathrm{He}$ knew that folk-lore retained the belief in scrying in crystal balls, and added some superfluous magical incantations The doctor himself was lucky enough to buy an old magical crystal in which some boys, after long staring, saw persons unknown to themselves, but known to the professor, and also persons known to neither. A little girl, casually picking up a crystal ball, cried, 'There's a ship in it, with its cloth all in rags. Now it tumbles down, and a woman is working at it, and holds her head in her hand.' This is a very fair example of a crystal fancy picture. The child's mother, not having heard what the child said, saw the same vision (p. I65). But this is a story at third hand. The doctor has a number of cases, and held that crystal possesses an 'odylic' quality. But a ball of glass serves just as well as a ball of crystal, and is much less expensive.

${ }^{1}$ Animal Magnetism, second edition, p. 135. 
Children are naturally visionaries, and, as such, are good subjects for experiment But it may be a cruel, and is a most injudicious thing, to set children a-scrying. Superstition may be excited, or the halfconscious tendency to deceive may be put in motion.

Socrates and Joan of Arc were visionaries as children. Had Joan's ears been soundly boxed, as Robert de Baudricourt advised, France might now be an English province. But they were not boxed, happily for mankind. Certainly much that is curious may be learned by any one who, having the confidence of a child, will listen to his, or her, accounts of spontaneous visions. The writer, as a boy, knew a child who used to lie prone on the grass watching fairies at play in the miniature forest of blades and leaves This child had a favourite familiar whom he described freely, but as his rema:ks were received with good-humoured scepticism, no harm came to him $\mathrm{He}$ would have made a splendid scryer, still, ' I speak of him but brotherly,' his revelations would have been taken with the largest allowances If scrying, on examination, proves to be of real psychological interest, science will owe another debt to folk-lore, to the folk who kept alive a practice which common-sense would not deign even to examine. 


\section{THE SECOND SIGHT.}

The Gillie and the fire-raising. Survival of belief in second sight. Belief in ancient Greece and elsezrhere. Examples in Lapland. Early evidence as to Scotch second sight. Witches burned for this gift. Examples among the Covenanting Ministers. Early investigations by English authors: Pepys, Aubrey, Boyle, Dicky Steele, De Foe, Martin, Kirk, Frazer, Dr. Johnson. Theory of visions as caused by Fairies. Modern example of Miss $H$. Theory of Frazer of Tiree (1 700). 'Revived impressions of sense.' Examples. Agency of Angels. Martin. Modern cases. Bodily condition of the seer. Not epileptic. The second-sighted Minister. The visionary Beadle. Transference of vision by touch. Conchusion.

Some years ago, the author was fishing in a river of Inverness-shire. He drove to the stream, picked up an old gillie named Campbell, and then went on towards the spot where he meant to begin angling. A sheep that lay on the road jumped up suddenly, almost under the horse's feet, the horse shied, and knocked the dogcart against a wall. On the homeward way we observed a house burning, opposite the place where the horse shied, and found that a farmer had been evicted, and his cottage set on fire. This unhappy person, it seems, was in debt to all his tradesmen, not to his landlord only. The fire-raising, however, was an excessively barbaric method of 
getting him to leave the parish, and the view justified the indignation of the gillie. The old gillie, much excited, declared that the horse had foreseen this event in the morning, and had, consequently, shied. In a more sceptical spirit the author reminded Campbell of the sheep which started up. "That sheep was the devil,' Campbell explained, nor could this rational belief of his be shaken. The affair led to a conversation on the second sight, and Campbell said, ' he had it not,' ' but his sister (or sister-in-law) had it'.

Campbell was a very agreeable companion, interested in old events, and a sympathiser, as he said, in spite of his name, with the great Montrose. His remarks led the author to infer that, contrary to what some inquirers wrote in the last, and Graham Dalyell in the present century, the belief in the second sight is still quite common in the Highlands. As will be shown later, this inference was correct.

We must not, from this survival only, draw the conclusion that the Highlanders are more superstitious than many educated people south of the Highland line. Second sight is only a Scotch name which covers many cases called telepathy and clairvoyance by psychical students, and casual or morbid hallucinations by other people. In second sight the percipient beholds events occurring at a distance, sees people whom he never saw with the bodily eye, and who afterwards arrive in his neighbourhood; or foresees events approaching but still remote in time. The chief peculiarity of second sight is, that the visions often, though not always, 
are of a symbolical character. A shroud is observed around the living man who is doomed; boding animals, mostly black dogs, vex the seer; funerals are witnessed before they occur, and 'corpse-candles' (some sort of light) are watched flitting above the road whereby a burial procession is to take its way. ${ }^{1}$ 'Though we most frequently hear the term 'second sight' applied as a phrase of Scotch superstition, the belief in this kind of ominous illusion is obviously universal. Theoclymenus, in the Odyssey, a prophet by descent, and of the same clan as the soothsayer Melampus, beholds the bodies and faces of the doomed wooers, 'shrouded in night'. The Pythia at Delphi announced a similar symbolic vision of blood-dripping walls to the Athenians, during the Persian War. Again, symbolic visions, especially of blood-dripping walls, are so common in the Icelandic sagas that the reader need only be referred to the prodigies before the burning of $\mathrm{Njal}$, in the Saga of Burnt $\mathrm{Njal}$. Second sight was as popular a belief among the Vikings as among the Highlanders who retain a large share of their blood. It may be argued by students who believe in the borrowing rather than in the independent evolution of ideas, that the Gaelic second sight is a direct inheritance from the Northmen, who have left so many Scandinavian local names in the isles and along the coasts.

1 Thus an educated gentleman, a Highlander, tells the author that he once saw a light of this kind 'not a meteor,' passing in air along a road where a funeral went soon afterwards. His companions could see nothing, but one of them said: 'It will be a death-candle'. It seems to have been hallucinatory, otherwise ail would have shared the experience. 
However this may be, the Highland second sight is different, in many points, from the clairvoyance and magic of the Lapps, those famous sorcerers. On this matter the History of Lapland, by Scheffer, Professor of Law in Upsala, is generally cited (Oxford, I674). "When the devil takes a liking to any person in his infancy,' says Scheffer, 'he presently seizes on him by a disease, in which he haunts him with several apparitions.' This answers, in magical education, to Smalls, or Little Go.

Some Lapps advance to a kind of mystic Moderations, and the great sorcerers attain to Final Schools. and are Bachelors in Black Arts. "They become so knowing that, without the drum they can see things at the greatest distances; and are so possessed by the devil that they see things even against their will.' The 'drum' is a piece of hollow wood covered with a skin, on which rude pictures are drawn. An index is laid on the skin, the drum is tapped, and omens are taken from the picture on which the index happens to rest. But this practice has nothing to do with clairvoyance. In Scheffer's account of Lapp seers we recognise the usual hysterical or epileptic lads, who, in various societies become saints, mediums, warlocks, or conjurers. But Scheffer shows that the Lapp experts try, voluntarily, to see sights, whereas, except when wrapped in a bull's hide of old, or cowering in a boiler at the present day, the Highland seconrl-sighted man lets his visions come to him spontaneously and uninvoked. Scheffer wished to take a magical drum from a Lapp, who confessed with tears, that, drum or no drum, he would still see 
visions, as he proved by giving Scheffer a minute relation 'of whatever particulars had happened to me in my journey to Lapland. And he further complained, that he knew not how to make use of his eyes, since things altogether distant were presented to them.' When a wizard is consulted he dances round till he falls, lies on the ground as if dead, and, finally, rises and declares the result of his clairvoyance. His body is guarded by his friends, and no living thing is allowed to touch it. Tornaeus was told many details of his journey by a Lapp, ' which, although it was true, Tornaeus dissembled to him, lest he might glory too much in his devilish practices'. Olaus Magnus gives a similar account. The whole performance, except that the seer is not bound, resembles the Eskimo 'sleep of the shadow' more than ordinary Highland second sight. The soul of the seer is understood to be wandering away, released from his body.

The belief in clairroyance, in the power of seeing what is distant, and foreseeing what is in the future, obviously and undeniably occurs everywhere, in ancient Israel, as in Mexico bofore the Spanish Conquest, and among the Red Indian tribes as among the $Z$ ulus. It is more probable that similar hallucinatory experiences, morbid, or feigned, or natural, have produced the same beliefs everywhere, than that the beliefs were evolved only by 'Aryans,' -Greeks or Scandinavians-and by them diffused all over the world, to Zulus, Lapps, Indians of Guiana, Maoris.

One of the earliest references to Scotch second 
sight is quoted by Graham Dalyell from Higden's Polychronicon (i. lxiv.).' 'There oft by daye tyme, men of that islonde seen men that bey dede to fore honde, byheded' (like Argyll, in I66I), 'or hole, and what dethe they deyde. Alyens setten theyr feet upon feet of the men of that londe, for to see such syghtes as the men of that londe doon.' This method of communicating the hallucination by touch is described in the later books, such as Kirk's Secret Commoneealth (I6gI), and Mr. Napier, in his Folklore, mentions the practice as surviving in the present century. From some records of the Orknevs, Mr. Dalyell produces a trial for witchcraft on Oct. 2, $15 \mathrm{I} 6 .^{2}$ This case included second sight. The husband of Jonka Dyneis being in a fishing-boat at Walls, six miles from her residence at Aith, and in peril, she was 'fund and sein standing at hir awin hous wall, in ane trans, that same hour he was in danger; and being trappit, she could not give answer, bot stude as bereft of hir senssis : and quhen she was speirit at quhy she wes so movit, she answerit, "Gif our boit be not tynt, she is in great hazard,"-and wes tryit so to be'.

Elspeth Reoch, in I6I6, was tried as a witch for a simple piece of clairvoyance, or of charlatanism, as we may choose to believe. The offence is styled 'secund sicht' in the official report. Again, Issobell Sinclair, in I633, was accused, almost in modern spiritualistic phrase, of 'bein controlled with the phairie, and that be thame, shoe hath the second

${ }^{1}$ Darker Superstitions of Scotland, p. 48r, Edinburgh, I834.

${ }^{2}$ Op. cit., p. 473 . 
sight'. ${ }^{1}$ Here, then, we find it officially recorded that the second-sighted person is entranced, and more or less unconscious of the outer world, at the moment of the vision. Something like le petit mal, in epilepsy, seems to be intended, the patient 'stude as bereft of hir senssis'.2 Again, we have the official explanation of the second sight, and that is the spiritualistic explanation. The seer has a fairy 'control'. This mode of accounting for what 'gertle King Jamie' calls 'a sooth dreame, since they see it walking,' inspires the whole theory of Kirk (I6gI), but he sees no harm either in 'the phairie,' or in the persons whom the fairies control. In Kirk's own time we shall find another minister, Frazer of Tiree, explaining the visions as 'revived impressions of sense' (I705), and rejecting various superstitious hypotheses.

The detestable cruelty of the ministers who urged magistrates to burn second-sighted people, and the discomfort and horror of the hallucinations themselves, combined to make patients try to free themselves from the involuntary experience. As a correspondent of Aubrey's says, towards the end of the sixteenth century: 'It is a thing very troublesome to them that have it, and would gladly be rid of it . . . they are seen to sweat and tremble, and shreek at the apparition'. 'They are troubled for having it judging it a sin,' and they used to apply to the presbytery for public prayers and sermons. Others

1 Op. cit., p. 470 .

${ }^{2}$ It is, perhaps, needless to add that the unhappy patients were executed.

${ }^{3}$ Miscellanics, 1857, p. 184. 
protested that it was a harmless accident, tried to teach it, and endeavoured to communicate the visions by touch.

As usual among the Presbyterians a minister might have abnormal accomplishments, work miracles of healing, see and converse with the devil, shine in a refulgence of 'odic' light, or be second-sighted. But, if a layman encroached on these privileges, he was in danger of the tar-barrel, and was prosecuted. On the day of the battle of Bothwell Brig, Mr. Cameron, minister of Lochend, in remote Kintyre, had a clairvoyant view of the fight. 'I see them (the Whigs) flying as clearly as I see the wall,' and, as near as could be calculated, the Covenanters ran at that very moment. ${ }^{1}$ How Mr. Cameron came to be thought a saint, while Jonka Dyneis was burned as a sinner, for precisely similar experiences, is a question hard to answer. But Joan of Arc, the saviour of France, was blimed for hearing voices, while St. Joseph of Cupertino, in spite of his flights in the air, was canonised. Minister or medium, saint or sorcerer, it was all a question of the point of view. As to Cameron's and Jonka's visions of distant contemporary events, they correspond to what is told of Apollonius of Tyana, that, at Ephesus, he saw and applauded the murder of Domitian at Rome ; that one Cornelius, in Padua, saw Cesar triumph at Pharsalia; that a maniac in Gascony beheld Coligny murdered in Paris." In the whole belief

${ }^{1}$ Wodrow, i. 44.

${ }^{2}$ Aulus Gellius, xv. I8. Dio Cassius, lib. Ixvii. Crespet, De lu Hayne de Diable, cited by Dalyell. 
there is nothing peculiarly Scotch or Celtic, and Wodrow gives examples among the Dutch.

Second Sight, in the days of James VI. had been a burning matter. After the Restoration, a habit of jesting at everything of the kind came in, on one hand; on the other, a desire to investigate and probe the stories of Scotch clairvoyance. Many fellows of the Royal Society, and learned men, like Robert Boyle, Henry More, Glanvill, Pepys, Aubrey, and others, wrote eagerly to correspondents in the Highlands, while Sacheverell and Waldron discussed the topic as regarded the Isle of Man. Then came special writers on the theme, as Aubrey, Kirk, Frazer, Martin, De Foe (who compiled a catch-penny treatise on Duncan Campbell, a Highland fortune-teller in London), Theophilus Insulanus (who was urged to his task by Sir Richard Steele), Wodrow, a great ghost-hunter: and so we reach Dr. Johnson, who was 'willing to be convinced,' but was not under conviction. In answer to queries circulated for Aubrey, he learned that 'the godly' have not the faculty, but 'the virtuous' may have it. But Wodrow's saint who saw Bothwell Brig, and another very savoury Christian who saw Dundee slain at Killiecrankie, may surely be counted among 'the godly'. There was difference of opinion as to the hereditary character of the complaint. A correspondent of Aubrey's vouches for a second-sighted man who babbled too much 'about the phairie,' and "was suddenly removed to the farther end of the house, and was there almost strangled'. ${ }^{1}$ This implies that 
spirits or 'Phairies' lifted him, as they did to a seer spoken of by Kirk, and do to the tribal medicine-men of the Australians, and of course, to 'mediums'.

Contemporary with Aubrey was the Rev. Robert Kirk of Aberfoyle, a Celtic scholar who translated the Bible into Gaelic. In I69I he finished his Secret Commonrealth of Elves, Faunes and Fairies, whereof only a fragment has reached us. It has been maintained that the book was printed in I6gI, but no mortal eye has seen a copy. In I8I5 Sir Walter Scott printed a hundred copies from a manuscript in the Advocates' Library in Edinburgh. He did not put his name on the bcok, but Charles Kirkpatrick Sharpe, in a note on his own copy, affirms that Sir Walter was the editor. ${ }^{1}$ Another edition was edited, for Mr. Nutt, by the present writer, in I893. In the year following the completion of his book Mr. Kirk died, or, as local tradition avers, was carried avay to fairyland.

Mr. Kirk has none of the Presbyterian abhorrence of fairies and fauns, though, like the accusers of the Orkney witches, he believes that 'phairie control' inspires the second-sighted men, who see them eat at funerals. The seers were wont to observe doubles of living people, and these doubles are explained as 'co-walkers' from the fairy world. This 'co-ivalker' 'wes also often seen of old to enter a hous, by which the people knew that the person of that liknes wes to visite them within a few days'.

Now this belief is probabiy founded on actual

${ }^{1}$ A copy presented by Scott to Sir Alexander Boswell of Auchinleck is in the author's possession; it bears Scott's autograph. 
hallucinatory experience, of which we may give a modern example. In the early spring of I89o, a lady, known to the author, saw the 'copy, echo, or living picture,' of a stranger, who intended (unknown to her) to visit her house, but who did not carry out his intention. The author can vouch for her perfect integrity, and freedom both from superstition, and from illusions, except in this case. Miss $H$. lives in Edinburgh, and takes in young men as boarders. At the time of this event, she had four such inmates. Two, as she believed, were in their study on the second floor; two were in the drawing-room on the first floor, where she herself was sitting. The hour was seven o'clock in the evening, and the lamp on the stair was lit. Miss $H$. left the drawing-room, and went into a cupboard on the landing, immediately above the lamp. She saw a young gentleman, of fair complexion, in a suit of dark blue, coming down the staircase from the second floor. Supposing him to be a friend of her boarders whose study was on that floor, she came out of the cupboard, closed the door to let him pass, and made him a slight bow. She did not hear him go out, nor did the maid who was standing near the street door. She did not see her two friends of the upstairs study till nine o'clock: they had been at a lecture. - When they met, she said: 'Did you take your friend with you?'

'What friend?'

'The fair young man who left your rooms at seven.'

'We were out before seven, we don't know whom you mean.' 
The mystery of the young man, who could not have entered the house without ringing, was unsolved. Next day a lady living exactly opposite Miss H.'s house, asked that lady if she could give hospitality to a young man who was coming to Edinburgh from the country. Miss $H$. assented, and prepared a room, but the visitor, she was informed, went to stay with a relation of his own. Two days later Miss $\mathrm{H}$. was looking out of her dining-room window after luncheon.

'Why, there's my ghost!' she exclaimed, and her friends, running to the window, allowed that he answered to the description. The 'ghost' went into the house of Miss H.'s friend on the other side of the street, and Miss H., with natural curiosity, sallied out, and asked who he was. He was the young man for whom she had prepared a room. During his absence in the country, his 'co-walker' had visited the house at which he intended to stay!

Coincidences of this kind, then, gave rise to the belief in this branch of second sight.

Though fairies are the 'phantasmogenetic agencies' in second sight, a man may acquire the art by magic. A hair rope which has bound a corpse to a bier is wound about him, and then he looks backward 'through his legs' till he sees a funeral. The vision of a seer can be communicated to any one who puts his left foot under the wizard's right foot.

This is still practised in some parts of the Highlands, as we shall see, but, near Inverness, the custom only survives in the memory of some old people. ${ }^{1}$ Mr. Kirk's wizards defended the lawfulness

${ }^{1}$ Information from Mr. Mackay, Craigmonie. 
of their clairvoyance by the example of Elisha seeing Gehazi at a distance. ${ }^{1}$ The second sight was hereditary in some families: this is no longer thought to be the case. Kirk gives some examples of clairvoyance, and prescience: he then quotes and criticises Lord Tarbatt's letters to Robert Boyle. Second sight ' is a trouble to most of them, and they would be rid of it at any rate, if they could '. One of our own informants says that the modern seers are anxious when they feel the vision beginning: they do not, however, regard the power as unholy or disieputable. Another informant mentions a belief that children born between midnight and one o'clock will be second-sighted. People attempt to hasten or delay the birth, so as to avoid the witching hour; clearly then they regard the second sight as an unenviable accomplishment. 'It is certane' says Kirk, 'he sie more fatall and fearfull things, than he do gladsome.' For the physical condition of the seer, Kirk describes it as 'a rapture, transport, and sort of death'. Our contemporary informants deny that, in their experience, any kind of convulsion or fit accompanies the visions, as in Scott's account of Allan Macaulay, in the Legend of Montrose.

Strangely unlike Mr. Kirk, in style and mode of thought, is his contemporary, the Rev. Mr. Frazer of Tiree and Coll; Dean of the Isles. We cannot call a clergyman superstitious because, 200 years ago, he believed in good and bad angels. Save for this element in his creed, Mr. Frazer may be called 
strictly and unexpectedly scientific. $\mathrm{He}$ was born in Mull in I647, being the son of the Rev. Farquhard Frazer, a cadet of the house of Lovat. The father was one of the first Masters of Arts who ever held the living of Coll and Tiree: in his time only three landed gentlemen of the McLeans could read and write. The son, John, was educated at Glasgow University, and succeeded to his father's charge, converting the lairds and others 'to the true Protestant faith ' (I680). At the Revolution, or later, being an Episcopalian and Jacobite, he was deprived of his stipend, but was not superseded, and continued the exercise of his ministry till his death in I702. Being in Edinburgh in I700, he met Andrew Symson, a relation of his wife: they fell into discourse on the second sight, and he sent his little manuscript to Symson who published it in I707. There is an Edinburgh reprint, by Webster, in I820. The work is dedicated to Lord Cromartie, the Lord Tarbatt of Kirk's book, and the correspondent of Pepys. Symson adds a preface, apologising for Mr. Frazer's lack of books and learned society, and giving an example oi transference of second sight: the seer placed his foot on that of the person interested, who then saw a ship labouring in a storm. The tale was not at first hand.

Mr. Frazer, in his tractate, first deals with the question of fact, of the hallucinations called second sight: "That such representations are made to the eyes of men and women, is to me out of all doubt, and that affects follow answerable thereto, as little questionable'. But many doubt as to the question of 
fact, 'wherefore so little has been written about it'. Four or five instances, he thinks, will suffice. I. A servant of his left a barn where he slept, 'because nightly he had seen a dead corps in his winding sheet, straighted beside him'. In about half a year a young man died and was buried in the barn. 2. Mr. Frazer went to stay in Mull with Sir William Sacheverell, who wrote on second sight in the Isle of Man, and was then engaged in trying to recover treasures from the vessel of the Armada sunk in Tobermory Bay. The Duke of Argyll has a cannon taken from Francis I. at Pavia, which was raised from this vessel, and, lately, the fluke of a ship's anchor brought up a doubloon. But the treasure still lies in Tobermory Bay. Mr. Frazer's tale merely is that a woman told a sailor to bid him leave a certain boy behind. The sailor did not give the message, the boy died, and the woman said that she had seen the lad 'walking with me in his winding sheets, sewed up from top to toe,' that this portent never deceived her. 3. A funeral was seen by Duncan Campbell, in Kintyre, he soon found himself at the real funeral.

4. John Macdonald saw a sea-captain all wet, who was drowned, 'about a year thereafter'. The seer 'was none of the strictest life'. 5. A man in Eigg foretold an invasion and calamities. The vision was fulfilled by a landing of English forces in 1689 , when Mr. Frazer himself was a prisoner of Captain Pottinger's, in Eigg. He next mentions an old woman who, in a syncope or catalepsy, believed she had been in heaven. She had a charm of barbarous word's, 
whereby she could see the answers to questions 'in live images before her eyes, or upon the wall, but the images were not tractable (tangible), which she found by putting to her hand, but could find nothing'. In place of burning this poor crone, Mr. Frazer reasoned with her, 'taught her the danger and vanity of her practice,' and saw her die peacefully in extreme old age.

Seeking for an explanation Mr. Frazer gives a thoroughly modern doctrine of visual and auditory hallucinations, as revived impressions of sense. The impressions, 'laid up in the brain, will be reversed back to the retiform coat and crystalline humour,' hence ' a lively seeing, as if, de novo, the object had been placed before the eye'. He illustrates this by experiments in after-images. $\mathrm{He}$ will not deny, however, that angels, good or bad, may intentionally cause the revival of impressions, and so, for their own purposes, produce the hallucinations from within. The coincidence of the hallucination with future events may arise from the fore-knowledge of the said angels, who, if evil, are deceptive, like Ahab's false prophets. The angel then, who, through one channel or another, fore-knows, or anticipates an event, 'has no more to do than to reverse the species of these things from a man's brain to the organ of the eye'. Substitute telepathy, the effect produced by a distant mind, for angels, and we have here the very theory of some modern inquirers. Mr. Frazer thinks it unlikely that bad angels delude 'several men that I have known to be of considerable sense, and pious and good conversation'. He will not hear of angels 
making bodies of 'compressed air' (an old mystic idea), which they place before men's eyes. His own hypothesis is more economical of marvel. He has not observed second sight to be hereditary. If asked why it is confined to ignorant islanders, he denies the fact. It is as common elsewhere, but is concealed, for fear of ridicule and odium. He admits that credulity and ignorance give opportunities to evil spirits 'to juggle more frequently than otherwise they would have done'. So he 'humbly submits himself to the judgment of his betters'. Setting aside the hypothesis of angels, Mr. Frazer makes only one mistake, he does not give instantia contradictoria, where the hallucination existed without the fulfilment. He shows a good deal of reading, and a liking for Sir Thomas Browne. The difference between him and his contemporary, Mr. Kirk, is as great as that between Herodotus and Thucydides.

Contemporary with Frazer is Martin Martin, whose Description of the Western Isles (I703, second edition I7I6) was a favourite book of Dr. Johnson's, and the cause of his voyage to the Hebrides. Martin took his M.A. degree at Edinburgh University in I68I. He was a curious observer, political and social, and an antiquarian. He offers no theory of the second sight, and merely recounts the current beliefs in the islands. The habit is not, in his opinion, hereditary, nor does he think that the vision can be communicated by touch, except by one to another seer. Where several seers are present, all do not necessarily see the vision. 'At the sight of a vision, the eyelids of the person are erected, and 
the eyes continue staring until the object vanish,' as Martin knew by observing seers at the moment of the experience. Sometimes it was necessary to draw down the eyelids with the fingers. Sickness and swooning occasionally accompanied the hallucination. The visions were usually symbolical, shrouds, coffins, funerals. Visitors were seen before their arrival. 'I have been seen thus myself by seers of both sexes at some roo miles distance; some that saw me in this manner had never seen me personally, and it happened according to their visions, without any previous design of mine to go to those places, my coming there being purely accidental.' Children are subject to the vision, the horse of a seer, or the cow a second-sighted woman is milking, receives the infection, at the moment of a vision, sweats and trembles. Horses are very nervous animals, cows not so much so.

As to objections, the people are very temperate, and maciness is unknown, hence they are not usually visionary. That the learned 'are not able to oblige the world with a satisfying account of those visions,' is no argument against the fact of their occurrence. The seers are not malevolent impostors, and there are cases of second-sighted folk of birth and education, 'nor can a reasonable man believe that children, horses, and cows could be pre-engaged in a combination to persuade the world of the reality of the second sight'. The gift is not confined to the Western Islands, and Martin gives a Dutch example, with others from the Isle of Man. His instances are of the usual sort, the rulfilment was sometimes 
long deferred. He mentions a case, but not that given by Mr. Frazer, in the Isle of Eigg. Thise natives had been at Killiecrankie, and one of them murdered an English soldier in Skye, hence the English invasion of 1689 , in which a pretty girl (as had been prophesied by a seer) was brutally illtreated. The most interesting cases are those in which strangers are seen, and peculiarities in their dress observed before their arrival. In the Pirate Scott shows how Norna of the Fitful Head managed to utter such predictions by aid of early information; and so, as Cleveland said, 'prophesied on velvet'. There are a few cases of a brownie being seen, once by a second-sighted butler, who observed brownie directing a man's game at chess. Martin's book was certainly not calculated to convince Dr. Johnson; his personal evidence only proves that a kind of hallucinatory trance existed, or was feigned.

Later than Martin we have the long work of Theophilus Insulanus, which contains many ' cases,' of more or less interest or absurdity. But Theophilus is of no service to the framer of philosophical or physiological theories of the second sight. The Presbyterian clergy generally made war on the belief, but one of them, as Mrs. Grant reports in her Essays, ${ }^{1}$ had an experience of his own. This good old pastor's 'daidling bit,' or lounge, was his churchyard. In an October twilight, he saw two small lights rise from a spot unmarked by any stone or memorial. These 'corpse-candles' crossed the river, stopped at a hamlet, and returned, attended by a 1 i. 259. Longmans, London, I8Ir. 
larger light. All three sank into the earth on the spot whence the two lights had risen. The minister threw a few stones on the spot, and next day asked the sexton who lay there. The man remembered having buried there two children of a blacksmith who lived at the hamlet on the opposite side of the water. The blacksmith died next day! This did more for second sight, probably, than all the minister's sermons could do against the belier.

As we began by stating, it is a popular superstition among the learned that the belief in second sight has died out among the Highlanders. Fifty years ago, Dr. McCulloch, in his Description of the Western Islands, wrote thus: 'Second sight has undergone the fate of witchcraft ; ceasing to be believed, it has ceased to exist'.' Now, as to whether second sight exists or not, we may think as we please, but the belief in second sight is still vivacious in the Highlands, and has not altered in a single feature. A well-known Highland minister has been kind enough to answer a few questions on the belief as it is in his parish. $\mathrm{He}$ first met a second-sighted man in his own beadle, 'a most respectable person of entirely blameless life'. After citing a few examples of the beadle's successful hits, our informant says: 'He told me that he felt the thing coming on, and that it was always preceded by a sense of discomfort and anxiety. . . . There was no epilepsy, and no convulsion of any kind. He felt a sense of great relief when the vision had passed away, and he assured me repeatedly that the gift was an annoyance rather than a plcasure ${ }^{1}$ Tylor, Primitive Culture, i. 143 . 
to him,' as the Lapp also confessed to Scheffer. 'Others who had the same gift have told me the same thing.' Out of seven or eight people liable to this malady, or whatever we are to call it, only one, we learn, was other than robust, healthy, and steady. In two instances the seers were examined by a physician of experience, and got clean bills of mental and bodily health. An instance is mentioned in which the beadle, alone in a boat with a friend, on a salt-water loch, at night, saw a vision of a man drowning in a certain pool of a certain river. A shepherd's plaid lay on the bank. The beadle told his companion what he saw, and set his foot on his friend's, who then shared his experience. This proves the continuity of the belief that the hallucination can be communicated by contact. $^{1}$ As a matter of evidence, it would have been better if the beadle had not first told his friend what he saw. Both men told our informant next day, and the vision was fulfilled 'scarcely a week afterwards'. This vision, granting the honesty of the seers, was a case of 'clairvoyance,' but 'symbolical hallucinations' frequently occur. In our informant's experience the gift is not hereditary.

On the whole subject Dr. Stewart, of Nether Lochaber, wrote several articles in the Inverness Courier, during the autumn of 1893 . The Highland

1 This belief is not confined to the Highlands. Mr. Podmore quotes Ghost 636 in the Psychical Society's collections: 'The narrator's mother is said to have seen the figure of a man'. The father saw nothing till his wife laid her hand on his shoulder, when he exclaimed, 'I see him now' (S. P. R., Nov., I889, p. 247). 
clergy have, doubtless, some dificulty in dealing with the belief among their parishioners. But, as the possession of the accomplishment is no longer regarded as criminal, and as the old theories of diabolical possession, or fairy inspiration, are not entertained, at least by the educated, the seers are probably to be regarded as merely harmless visionaries. At most we may say, with the poet :-

Lo, the sublime telepathist is here.

The belief in witchcraft is also as lively in the Highlands, as in Devonshire, but, while the law takes no cognisance of it, no great harm is done. The witchcraft mainly relies on 'sympathetic magic,' on perforating a clay image of an enemy with needles and so forth. There is a very recent specimen in the Pitt Rivers collection, at the museum in Oxford. It was presented, in a scientific spirit, by the victim, who was 'not a penny the worse,' unlike Sir George Maxwell of Pollok, two centuries ago.

Though second sight is so firmly rooted in Celtic opinion, the tourist or angler who 'has no Gaelic' is not likely to hear much of it. But, when trout refuse to rise, and time hangs heavy in a boat on a loch, it is a good plan to tell the boatman some ghostly Sassenach tales. Then, perhaps, he will cap them from his own store, but point-blank questions from an inquiring southron are of very little use. Nobody likes to be cross-examined on such matters. Unluckily the evidence, for facts not for folk-lore, is worthless till it has stood the severest cross-examination. 


\section{GHOSTS BEFORE THE LAW.}

Sir Walter Scott on rarity of ghostly evidence. His famphlet for the Bannatyne Club. His other examples. Case of Mirabel. The spectre, the treasure, the deposit repudiated. Trials of Auguier and Mirabel. The case of Clenche's murder. The murder of Sergeant Davies. Acquittal of the prisoners. An example from Aubrey. The murder of Anne Walker. The case of Mr. Booty. An example from Maryland, the story of Briggs and Harris. The Valogne phantasm. Trials in the matter of haunted houses. Cases from Le Loyer. Modern instances of haunted houses before the law. Unsatisfactory results of legal investisations.

'What I do not know is not knowledge,' Sir Walter Scott might have said, with regard to bogles and bar-ghaists. His collection at Abbotsford of such works as the Ephesian converts burned, is extensive and peculiar, while his memory was rich in tradition and legend. But as his Major Bellenden sings,

Was never wight so starkly made,

But time and years will overthrow.

When Sir Walter in I83I, wrote a brief essay on ghosts before the law, his memory was no longer the extraordinary engine, wax to receive, and marble to retain, that it had been. It is an example of his dauntless energy that, even in I83I, he was not only toiling at novels, and histories, and reviews, to wipe 
out his debts, but that, as a pure labour of love, he edited, for the Bannatyne Club, 'The trial of Duncan Terig alias Clerk, and Alexander Bane Macdonald, for the murder of Arthur Davis, sergeant in General Guise's regiment of foot, June, I754'.

The trial, as Sir Walter says, in his dedication to the Bannatyne Club, 'involves a curious point of evidence,' a piece of 'spectral evidence' as Cotton Mather calls it. In another dedication (for there are two) Scott addresses Sir Samuel Shepherd, remarking that the tract deals with 'perhaps the only subject of legal inquiry which has escaped being investigated by his skill, and illustrated by his genius '. That point is the amount of credit due to the evidence of a ghost. In his preface Sir Walter cites the familiar objection of a learned judge that ' the ghost must be sworn in usual form, but in case he does not come forward, he cannot be heard, as now proposed, through the medium' (medium indeed!) ' of a third party'. It seems to be a rule of evidence that what a dead man said may be received, on the report of the person with whom he communicated. A ghost is a dead man, and yet he is deprived, according to the learned judge's ruling, of his privilege. Scott does not cite the similar legend in Hibernian Tales, the chap book quoted by Thackeray in his Irish Sketch-book. In that affair, when the judge asked the gloost to give his own evidence: 'Instantly there came a dreadful rumbling noise into the court- "Here am I that was murdered by the prisoner at the bar" '. The Hibernian Tales are of no legal authority, nor can we give chapter and 
verse for another well-known anecdote. A prisoner on a charge of murder was about to escape, when the court observed him looking suspiciously over his shoulder. 'Is there no one present,' the learned judge asked in general, 'who can give better testimony?' 'My lord,' exclaimed the prisoner, 'that wound he shows in his chest is twice as big as the one I gave him.' In this anecdote, however, the prisoner was clearly suffering from a hallucination, as the judge detected, and we do not propose to consider cases in which phantasms bred of remorse drove a guilty man to make confession.

To return to Scott; he remarks that believers in ghosts must be surprised 'to find how seldom in any country an allusion hath been made to such evidence in a court of justice'. Scott himself has only 'detected one or two cases of such apparition evidence,' which he gives. Now it is certain, as we shall see, that he must have been acquainted with several other examples, which did not recur to his memory: the memory of $\mathrm{r} 83 \mathrm{I}$ was no longer that of better years. Again, there were instances of which he had probably never possessed any knowledge, while others have occurred since his death. We shall first consider the cases of spectral evidence (evidence that is of a dead man's ghost, not of a mere wraith) recorded by Sir Walter, and deal later with those beyond his memory or knowledge. ${ }^{1}$ Sir Walter's first instance

1 Spectral evidence' was common in witch trials. Wierus (b. 1515) mentions a woman who confessed that she had been at a witch's covin, or 'sabbath,' when her body was in bed with her husband. If there was any confirmatory testimony, if any one chose 
is from Causes Célèbres, (vol. xii., La Haye, I749, Amsterdam, I775, p. 247). Unluckily the narrator, in this collection, is an esprit fort, and is assiduous in attempts to display his wit. We have not a plain unvarnished tale, but something more like a facetious leading article based on a trial.

Honoré Mirabel was a labouring lad, under age, near Marseilles. His story was that, in May (year not given), about eleven at night, he was lying under an almond tree, near the farm of a lady named Gay. In the moonlight he saw a man at an upper window of a building distant five or six paces, the house belonged to a Madame Placasse. Mirabel asked the person what he was doing there; got no answer, entered, and could see nobody. Rather alarmed he went to a well, drew some water, drank, and then heard a weak voice, bidding him dig there for treasure, and asking that masses might be said for the soul of the informant. A stone then fell on a certain spot; stone-throwing is a favourite exercise with ghosts everywhere.

With another labourer, one Bernard, Mirabel dug, found a packet of dirty linen, and, fearing that it might hold the infection of plague, dipped it in wine, for lack of vinegar. The parcel contained more than a thousand Portuguese gold coins. Bernard and his mistress were present at the opening of the parcel, but Mirabel managed to conceal from

to say that he saw her at the 'sabbath,' that was 'spectral evidence'. This kind of testimony made it vain for a witch to take Mr. Weller's advice, and plead 'a halibi,' but even Cotton Mather admits that 'spectral evidence' is inconclusive. 
them the place where he hid it, not a very likely story. He was grateful enough to pay for the desired masses, and he had himself bled four times to relieve his agitation. Mírabel now consulted a merchant in Marseilles, one Auguier, who advised him to keep his old coins a mystery, as to put them into circulation would lead to inquiry and inconvenience. $\mathrm{He}$ lent Mirabel some ready money, and, finally, induced Mirabel to entrust the Portuguese hoard to his care. The money was in two bags, one fastened with goldcoloured ribbon, the other with linen thread. Auguier gave a receipt, and now we get a date, Marseilles, September 27, I726. Later Auguier (it seems) tried to murder Mirabel, and refused to return the deposit. Mirabel went to law with him: Auguier admitted that Mirabel had spoken to him about having found a treasure which he would entrust to Auguier, but denied the rest. In his house was found a ribbon of a golden hue, such as Mirabel used to tie up his bag, and a little basket which has no obvious connection with the matter. The case was allowed to come on, there were sixteen witnesses. A woman named Caillot swore to Mirabel's having told her about the ghost: she saw the treasure excavated, saw the bags, and recognised the ribbon. A man had seen Mirabel on his way to give Auguier his bags, and, indeed, saw him do so, and receive a piece of paper. He also found, next day, a gold coin on the scene of the interview. A third witness, a woman, was shown the treasure by Mirabel.

The narrator here makes the important reflection that Providence could not allow a ghost to appear 
merely to enrich a foolish peasant. But, granting ghosts (as the narrator does), we can only say that, in ordinary life, Providence permits a number of undesirable events to occur. Why should the behaviour of ghosts be an exception?

Other witnesses swore to corroborating circumstances. Auguier denied everything, experts admitted that the receipt was like his writing, but declared it to be forged; the ribbon was explained as part of his little daughter's dress. The judge decided-no one will guess what-that Auguier should be put to the torture!

Auguier appealed: his advocate urged the absurdity of a ghost-story on a priori grounds : if there was no ghost, then there was no treasure: if there was a treasure, would not the other digger have secured his share? That digger, Bernard, was not called. Then Auguier pled an alibi, he was eight leagues away when he was said to have received the treasure. Why he did not urge this earlier does not appear.

I. Iirabel's advocate first defended from the Bible and the Fathers, the existence of ghosts. The Faculty of Theology, in Paris, had vouched for them only two years before this case, in I724. The Sorbonne had been as explicit, in I5I8. 'The Parliament of Paris often permitted the tenant of a haunted house to break his contract.' 1 Ghosts or no ghosts,

1 Papon. Arrets., xx. 5, 9. Charondas, Lib. viii. Resp. 77. Covarruvias, iv. 6. Mornac, s. v., Habitations, $27 \mathrm{ff}$., Locat. and Conduct. Other doctors do not deny hauntings, but allege that a brave man should disregard tlem, and that they do not fulfil he 
Mirabel's counsel said, there $x^{\prime} a$ a treasure. In his receipt Auguier, to deceive a simple peasant, partially disguised his hand. Auguier's alibi is worthless, he might easily have been at Marseilles and at Pertuis on the same day: the distance is eight leagues.

Bernard was now at last called in; he admitted that Mirabel told him of the ghost, that they dug, and found some linen, but that he never saw any gold. He had carried the money from Mirabel to pay for the masses due to the ghost. Mirabel had shown him a document, for which he said he had paid a crown, and Bernard (who probably could not read) believed it to be like Auguier's receipt. Bernard, of course, having been denied his share, was not a friendly witness. A legal document was put in, showing that Madame Placasse (on whose land the treasure lay) summoned Mirabel to refund it to her. The document was a summons to him. But this document was forged, and Mirabel, according to a barrister whom he had consulted about it, said it was handed to him by a man unknown. Why the barrister should have betrayed his client is not clear. Mirabel and Marguérite Caillot, his first witness, who had deposed to his telling her about the ghost, and to seeing the excavation of the packet, were now arrested, while Auguier remained in prison. Marguérite now denied her original deposition, she had

legal condition, Metus cadens in constantem virum. These doctors may never have seen a ghost, or may have been unusually courageous. They held that a man might get accustomed to the annoyances of bogles, s'apprivoiser avec cette frayeur, like the Procter family at Willington. 
only spoken to oblige Mirabel. One Étienne Barthélemy was next arrested : he admitted that he had 'financed' Mirabel during the trial, but denied that he had suborned any witnesses. Two experts differed, as usual, about Auguier's receipt; a third was called in, and then they unanimously decided that it was not in his hand. On February 18, I729, Auguier was acquitted, Mirabel was condemned to the torture, and to the galley, for life. Marguérite Caillot was fined ten francs. Under torture Mirabel accused Barthélemy of having made him bring his charge against Auguier, supplying him with the forged receipt and with the sham document, the summons to restore the gold to Madame Placasse. Oddly enough he still said that he had handed sacks of coin to Auguier, and that one of them was tied up with the gold-coloured ribbon. Two of his witnesses, under torture, stuck to their original statements. They were sentenced to be hung up by the armpits, and Barthélemy was condemned to the galleys for life.

It is a singular tale, and shows strange ideas of justice. Once condemned to the galleys, Mirabel might as well have made a clean breast of it; but this he did not do: he stuck to his bags and goldcoloured ribbon. Manifestly Mirabel would have had a better chance of being believed in court if he had dropped the ghost altogether. It is notable that Sir Walter probably gave his version of this affair from memory : he says that Mirabel 'was non-suited upon the ground that, if his own story was true, the treasure. by the ancient laws of France, belonged to the crown'.

Scott's next case is very uninteresting, at least as 
far as it is given in Howell's State Trials, vol. xii. (I692), p. 875 .

A gentleman named Harrison had been accused of beguiling a Dr. Clenche into a hackney coach, on pretence of taking him to see a patient. There were two men in the coach, besides the doctor. They sent the coachman on an errand, and when he came back he found the men fled and Clenche murdered. He had been strangled with a handkerchief. On evidence which was chiefly circumstantial, Harrison was found guilty, and died protesting his innocence. Later a Mrs. Milward declared that her husband, before his death, confessed to her that he and a man named Cole were the murderers of Dr. Clenche. The ghost of her husband persecuted her, she said, till Cole was arrested. Mr. Justice Dolber asked her in court for the story, but feared that the jury would laugh at her. She asserted the truth of her story, but, if she gave any details, they are not reported. Cole was acquitted, and the motives of Mrs. Milward remain obscure.

Coming to the tract which he reprints, Sir Walter says that his notice was first drawn to it, in $=792$, by Robert McIntosh, Esq., one of the counsel in the case, which was heard in Edinburgh, June Io, I754. Grant of Prestongrange, the Lord Advocate well known to readers of Mr. Stevenson's Catriona, prosecuted Duncan Terig or Clerk, and Alexander Bain Macdonald, for the murder of Sergeant Arthur Davies on September 28, I749. They shot him on Christie Hill, at the head of Glenconie. There his body remained concealed for some time, and was later found 
with a hat marked with his initials, A. R. D. They are also charged with taking his watch, two gold rings, and a purse of gold, whereby Clerk, previously penniless, was enabled to take and stock two farms.

Donald Farquharson, in Glendee, deposes that, in June, I750, Alexander Macpherson sent for him, and said that he was much troubled by the ghost of the serjeant, who insisted that he should bury his bones, and should consult Farquharson. Donald did not believe this quite, but trembled lest the ghost should vex him. He went with Macpherson, who showed the body in a peat-moss. The body was much decayed, the dress all in tatters. Donald asked Macpherson whether the apparition denounced the murderers: he replied that the ghost said it would have done so, had Macpherson not asked the question. They buried the body on the spot, Donald attested that he had seen the serjeant's rings on the hand of Clerk's wife. For three years the prisoners had been suspected by the country side.

Macpherson declared that he had seen an apparition of a man in blue, who said, 'I am Serjeant Davies,' that he at first took this man for a brother of Donald Farquharson's, that he followed the man, or phantasm, to the door, where the spectre repeated its assertions, and pointed out the spot where the bones lay. He found them, and then went, as already shown, to Donald Farquharson. Between the first vision and the burying, the ghost came to him naked, and this led him to inter the remains. On the second appearance, the ghost denounced the prisoners. Macpherson gave other evidence, not spectral, which im- 
plicated Clerk. But, when asked what language the ghost spoke in, he answered, 'as good Gaelic as he had ever heard in Lochaber'. 'Pretty well,' said his counsel, Scott's informant, McIntosh, 'for the ghost of an English serjeant.' 'This was probably conclusive with the jury, for they acquitted the prisoners, in the face of the other incriminating evidence. This was illogical. Modern students of ghosts, of course, would not have been staggered by the ghost's command of Gaelic: they would explain it as a convenient hallucinatory impression made by the ghost on the mind of the 'percipient'. The old theologians would have declared that a good spirit took Davies's form, and talked in the tongue best known to Macpherson. Scott's remark is, that McIntosh's was 'no sound jest, for there was nothing more ridiculous in a ghost speaking a language which he did not understand when in the body, than there was in his appearing at all'. But jurymen are not logicians. Macpherson added that he told his tale to none of the people with him in the sheiling, but that Isobel McHardie assured him she 'saw such a vision'. Isobel, in whose service Macpherson had been, deponed that, while she lay at one end of the sheiling and Macpherson at the other, 'she saw something naked come in at the door, which frighted her so much that she drew the clothes over her head'. Next day she asked Macpherson what it was, and he replied 'she might be easy, for that it would not trouble them any more'.

The rest of the evidence went very strongly against the accused, but the jury unanimously found them 'Not Guilty'. 
Scott conjectures that Macpherson knew of the murder (as indeed he had good reason, if his non-spectral evidence is true), but that he invented the ghost, whose commands must be obeyed, that he might escape the prejudice entertained by the Celtic race against citizens who do their duty. Davies, poor fellow, was a civil good-humoured man, and dealt leniently (as evidence showed) with Highlanders who wore the tartan. Their national costume was abolished, as we all know, by English law, after the plaid had liberally displayed itself, six miles south of Derby, in I745.

So far it is plain that 'what the ghost said is not evidence,' and may even ruin a very fair case, for there can be little doubt as to who killed Serjeant Davies. But examples which Scott forgot, for of course he knew them, prove that, in earlier times, a ghost's testimony was not contemned by English law. Cases are given, with extracts from documents, in a book so familiar to Sir Walter as Aubrey's Miscellanics. Aubrey (b. I626, d. I697) was a F.R.S., and, like several other contemporary Fellows of the Royal Society, was a keen ghost hunter. He published ${ }^{\prime}$ 'A full and true Relation of the Examination and Confession of William Barwick, and Edward Mangall, of two horrid murders'.

Barwick killed his wife, who was about to bear a child, near Cawood in Yorkshire, on April I4, I6go. Barwick had intrigued with his wife before marriage, and perhaps was 'passing weary of her love'. On April I4, Palm Monday, he went to his brother-inlaw, Thomas Lofthouse, near York, who had married

${ }^{1}$ Miscellanies, p. 94, London, 1857 . 
Mrs. Barwick's sister. He informed Lofthouse that he had taken Mrs. Barwick, for her confinement, to the house of his uncle, Harrison, in Selby. On September I7, at York assizes, Lofthouse swore that on Easter Tuesday (eight days after Palm Monday, namely April 22), he was watering a quickset hedge, at mid-day, when he saw 'the apparition in the shape of a woman walking before him'. She sat down opposite the pool whence he drew water, he passed her as he went, and, returning with his pail filled, saw her again. She was dandling on her lap some white object which he had not observed before. He emptied his pail, and, 'standing in his yard' looked for her again. She was no longer present. She wore a brown dress and a white hood, 'such as his wife's sister usually wore, and her face looked extream pale, her teeth in sight, no gums appearing, her visage being like his wife's sister'.

It certainly seems as if this resemblance was an after-thought of Lofthouse's, for he dismissed the matter from his mind till prayers, when it 'discomposed his devotions'. He then mentioned the affair to his wife, who inferred that her sister had met with foul play. On April 23, that is the day after the vision, he went to Selby, where Harrison denied all knowledge of Mrs. Barwick. On April 24, Lofthouse made a deposition to this effect before the mayor of York, but, in his published statement of that date, he only avers that 'hearing nothing of the said Barwick's wife, he imagined Barwick had done her some mischief'. There is not a word here of the phantasm sworn to by Lofthouse at the assizes on September I7. 
Nevertheless, on April 24, Barwick confessed to the mayor of York, that ' on Monday was seventh night' (there seems to be an error here) he 'found the conveniency of a pond' (as Aubrey puts it) 'adjoining to a quickwood hedge,' and there drowned the woman, and buried her hard by. At the assizes, Barwick withdrew his confession, and pleaded 'Not Guilty'. Lofthouse, his wife, and a third person swore, however, that the dead woman was found buried in her clothes by the pond side, and on the prisoner's confession being read, he was found guilty, and hanged in chains. Probably he was guilty, but Aubrey's dates are confused, and we are not even sure whether there were two ponds, and two quickset hedges, or only one of each. Lofthouse may have seen a stranger, dressed like his sister-in-law, this may have made him reflect on Barwick's tale about taking her to Selby; he visited that town, detected Barwick's falsehood, and the terror of that discovery made Barwick confess.

Surtees, in his History of Durham, published another tale, which Scott's memory did not retain. In 1630, a girl named Anne Walker was about to have a child by a kinsman, also a Walker, for whom she kept house. Walker took her to Dame Care, in Chester le Street, whence he and Mark Sharp removed her one evening late in November. Fourteen days afterwards, late at night, Graime, a fuller, who lived six miles from Walker's village, Lumley, saw a woman, dishevelled, blood-stained, and with five wounds in her head, standing in a room in his mill. She said she was Anne Walker, 
that Mark Sharp had slain her with a collier's pick, and thrown her body into a coal-pit, hiding the pick unjer the bank. After several visitations, Graime went with his legend to a magistrate, the body and pick-axe were discovered, IValker and Sharp were arrested, and tried at Durham, in August, I63I. Sharp's boots, all bloody, were found where the ghost said he had concealed them 'in a stream'; how they remained bloody, if in water, is hard to explain. Against Walker there was no direct evidence. The prisoners, the judge summing up against them, were found guilty and hanged, protesting their innocence.

It is suggested that Graime himself was the murderer, else, how did he know so much about it? But Walker and Sharp were seen last with the woman, and the respectable Walker was not without a motive, while, at this distance, we can conjecture no motive in the case of Graime. ${ }^{1}$ Cockburn's Voyage up the Mediterranean is the authority (ii. 35) for a very odd trial in the Court of King's Bench, London. The logs of three ships, under Captains Barnaby, Bristow and Brown, were put in to prove that, on Friday, I5th May, I687, these men, with many others, were shooting rabbits on Stromboli: that when beaters and all were collected, about a quarter to four, they all saw a man in grey, and a man in black run towards them, the one in grey

${ }^{1}$ Hibbert, Philosophy of Apparitions, second edition, p. 224. Hibbert finds Graime guilty, but only because he knew where the body lay. 
leading, that Barnaby exclaimed, "The foremost is old Booty, my next door neighbour,' that the figures vanished into the flames of the volcano. This occurrence, by Barnaby's desire, they noted in their journals. They were all making merry, on October 6, I687, at Gravesend, when Mrs. Barnaby remarked to her husband: 'My dear, old Booty is dead!' The captain replied: "We all saw him run into hell '. Mrs. Booty, hearing of this remark, sued Barnaby for libel, putting her damages at £Iooo. The case came on, the clothes of old Booty were shown in court: the date and hour of his death were stated, and corresponded, within two minutes, to the moment when the mariners beheld the apparition in Stromboli, 'so the widow lost her cause'. A mediæval legend has been revived in this example.

All these curious legal cases were, no doubt, familiar to Sir Walter Scott. He probably had no access to an American example which was reprinted four years after his death, by a member of the club which he founded, the Bannatyne Club, ${ }^{1}$ in 1836 .

The evidence of the ghost-seer was republished by Mrs. Crowe, in her Night Side of Nature. But Mrs. Crowe neither gives the facts of the trial correctly, nor indicates the sources of the narrative. The source was a periodical, The Opera Glass, February 3, I827, thirty years after the date of the trial. The document, however, had existed 'for many years,' in the possession of the anonymous contributor to The Opera Glass. He received it from

${ }^{i}$ Notices Relative to the Bannatyne Club, 1836, p. 191. Remarkable Trial in Maryland. 
one of the counsel in the case, Mr. Nicholson, afterwards a judge in Maryland, who compiled it from attested notes made by himself in court.

The suit was that of James, Fanny, Robert, and Thomas Harris, devisees of Thomas Harris, v. Mary Harris, relict and administratrix of James Harris, brother of Thomas, aforesaid (I798-99). Thomas Harris had four illegitimate children. He held, as he supposed, a piece of land in fee, but, in fact, he was only seized in tail. Thus he could not sell or devise it, and his brother James was heir in tail, the children being bastards. These legal facts were unknown both to James and Thomas. Thomas made a will, leaving James his executor, and directing that the land should be sold, and the money divided among his own children. James, when Thomas died, sold the land, and, in drawing the conveyance, it was discovered that he had no right to do so for Thomas, as it was held by Thomas in tail. James then conveyed his right to the purchaser, and kept the money as legal heir. Why James could sell, if Thomas could not, the present writer is unable to explain. In two years, James died intestate, and the children of Thomas brought a suit against James's widow. Before James's death, the ghost of Thomas had appeared frequently to one Briggs, an old soldier in the Colonial Revolt, bidding James 'return the proceeds of the sale to the orphans' court, and when James heard of this from Briggs he did go to the orphans' court, and returned himself to the estate of his brother, to the amount of the purchase money of the land'. 
Now, before the jury were sworn, the counsel, Wright and Nicholson for the plaintiffs, Scott and Earle for the defendant, privately agreed that the money could not be recovered, for excellent legal reasons. But they kept this to themselves, and let the suit go on, merely for the pleasure of hearing Briggs, ' a man of character, of firm, undaunted spirit,' swear to his ghost in a court of law. He had been intimate with Thomas Harris from boyhood. It may be said that he invented the ghost, in the interest of his friend's children. He certainly mentioned it, however, some time before he had any conversation with it.

Briggs's evidence may be condensed very much, as the learned Mrs. Crowe quotes it correctly in her Night Side of Nature. In March, I79I, about nine A.M., Briggs was riding a horse that had belonged to Harris. In a lane adjoining the field where Harris was buried, the horse shied, looked into the field where the tomb was, and 'neighed very loud'. Briggs now saw Harris coming through the field, in his usual dress, a blue coat. Harris vanished, and the horse went on. As Briggs was ploughing, in June, Harris walked by him for two hundred yards. A lad named Bailey, who came up, made no remark, nor did Harris tell him about the hallucination. In August, after dark, Harris came and laid his arms on Briggs's shoulder. Briggs had already spoken to James Harris, 'brither to the corp,' about these and other related phenomena, a groan, a smack on the nose from a viewless hand, and so forth. In October Briggs saw Harris, about twilight in the morning. 
Later, at eight o'clock in the morning, he was busy in the field with Bailey, aforesaid, when Harris passed and vanished: Bailey saw nothing. At halfpast nine, the spectre returned, and leaned on a railing: Briggs vainly tried to make Bailey see him. Briggs now crossed the fence, and walked some hundreds of yards with Harris, telling him that his will was disputed. Harris bade Briggs go to his aforesaid brother James, and remind him of a conversation they had held, 'on the east side of the wheat-stacks,' on the day when Harris's fatal illness began. James remembered the conversation, and saic he would fulfil his brother's desire which he actually did. There was a later interview between Briggs and Harris, the matter then discussed Briggs declined to impart to the court, and the court overruled the question. 'He had never related to any person the last conversation, and never would.'

Bailey was sworn, and deposed that Briggs had called his attention to Harris, whom he could not see, had climbed the fence, and walked for some distance, 'apparently in deep conversation with some person. Witness saw no one.'

It is plain that the ghost never really understood the legal question at issue. The dates are difficult to reconcile. Thomas Harris died in I790. His ghost appeared in I79I. Why was there no trial of the case till 'about I798 or I799'? Perhaps research in the Maryland records would elucidate these and other questions; we do but give the tale, with such authority as it possesses. Possibly it is an elaborate hoax, played off by Nicholson, the 
plaintiffs' counsel, on the correspondent of The Opera Glass, or by him on the editor of that periodical.

The hallucinations of Briggs, which were fortunate enough, it is said, to get into a court of justice, singularly resemble those of M. Bezuel, in July and August, 1697, though these were not matter of a sworn deposition. The evidence is in Histoire d'une Apparition Arrivée à Valogne. ${ }^{1}$ The narrator of I708, having heard much talk of the affair, was invited to meet Bezuel, a priest, at dinner, January 7, I7o8. He told his one story 'with much simplicity'.

In I695, when about fifteen, Bezuel was a friend of a younger boy, one of two brothers, Desfontaines. In I696, when Desfontaines minor was going to study at Caen, he worried Bezuel into signing, in his blood, a covenant that the first who died should appear to the survivor. The lads corresponded frequently, every six weeks. On July 3I, I697, at half-past two, Bezuel, who was hay-making, had a fainting fit. On August I, at the same hour, he felt faint on a road, and rested under a shady tree. On August 2, at half-past two, he fainted in a hay-loft, and vaguely remembered seeing a half-naked body. He came down the ladder, and seated himself on a block, in the Place des Capucins. Here he lost sight of his companions, but did see Desfontaines, who came up, took his left arm, and led him into an alley. The servant followed, and told Bezuel's tutor that he was talking to himself. The tutor went to him, and heard him asking and answering questions. Bezuel,

${ }^{1}$ Paris, 1708 . Reprinted by Lenglet Dufresnoy, in his Dissertations sur les Apparitions. Avignon, 175I, vol, iii. p. 38. 
for three-quarters of an hour, conversed, as he believed, with Desfontaines, who said that he had been drowned, while bathing, at Caen, about halfpast two on July 3I. The appearance was naked to the waist, his head bare, showing his beautiful yellow locks. He asked Bezuel to learn a school task that had been set him as a penalty, the seven penitential psalms: he described a tree at Caen, where he had cut some words; two years later Bezuel visited it and them; he gave other pieces of information, which were verified, but not a word would he say of heaven, hell, or purgatory; 'he seemed not to hear my questions'. There were two or three later interviews, till Bezuel carried out the wishes of the phantasm.

When the spectral Desfontaines went away, on the first occasion, Bezuel told another boy that Desfontaines was drowned. The lad ran to the parents of Desfontaines, who had just received a letter to that effect. By some error, the boy thought that the clder Desfontaines had perished, and said so to Bezuel, who denied it, and, on a second inquiry, Bezuel was found to be right.

The explanation that Bezuel was ill (as he certainly was), that he had heard of the death of his friend just before his hallucination, and had forgotten an impressive piece of news, which, however, caused the apparition, is given by the narrator of 1708 . The kind of illusion in which a man is seen and heard to converse with empty air, is common to the cases of Bezuel and of Briggs, and the writer is acquainted, at first hand, with a modern example. 
Mrs. Crowe cites, on the authority of the late Mir. Maurice Lothian, solicitor for the plaintiff, a suit which arose out of 'hauntings,' and was heard in the sheriff's court, at Edinburgh, in I835-37. But we are unable to discover the official records, or extracts of evidence from them. This is to be regretted, but, by way of consolation, we have the pleadings on both sides in an ancient French case of a haunted house. These are preserved in his Discours des Spectres, a closely printed quarto of nearly Iooo pages, by Pierre le Loyer, Conseiller du Roy au Siège Présidial d'Angers. ${ }^{1}$ Le Loyer says, 'De gayétè de coeur semble m'estre voulu engager au combat contre ceux qui impugnent les spectres!' As Le Loyer observes, ghosts seldom come into court in civil cases, except when indicted as nuisances, namely, when they make a hired house uninhabitable by their frolics. Then the tenant often wants to quit the house, and to have his contract annulled. The landlord resists, an action is brought, and is generally settled in accordance with the suggestion of Alphenus, in his Digests, book ii. Alphenus says, in brief, that the fear must be a genuine fear, and that reason for no ordinary dread must be proved. Hence Arnault Ferton, in his Customal of Burgundy, advises that 'legitimate dread of phantasms which trouble men's rest and make night hideous' is reason good for leaving a house, and declining to pay rent after the day of departure. Covarruvias, a Spanish legist, already quoted, agrees with Arnault Ferton. The Parliament of Grenada, in one or two cases, decided in

${ }^{1}$ Second edition, Buon, Paris, 1605. First edition, Angers, ${ }_{5} 86$. 
favour of the tenant, and against the landlord of houses where spectres racketed. Le Loyer now reports the pleadings in a famous case, of which he does not give the date. Incidentally, however, we learn that it can hardly have been earlier than I55O. The cause was heard, on appeal, before the Parlement de Paris.

Pierre Piquet, guardian of Nicolas Macquereau (a minor), let to Giles Bolacre a house in the suburbs of Tours. Poor Bolacre was promptly disturbed by a noise and routing of invisible spirits, which suffered neither himself nor his family to sleep o' nights. He then cited Piquet, also Daniel Macquereau, who was concerned in the letting of the house, before the local seat of Themis. The case was heard, and the judge at Tours broke the lease, the hauntings being insupportable nuisances. But this he did without letters royal. The lessors then appealed, and the case came before the Cour de Parlement in Paris. Maitre Chopin was for the lessors, Nau appeared for the tenant. Chopin first took the formal point, the Tours judge was formally wrong in breaking a covenant without letters royal, a thing particularly bad in the case of a minor, Nicolas Macquereau.

So much for the point of form ; as to the matter, Maître Chopin laughed at the bare idea of noisy spirits. This is notable because, in an age when witches were burned frequently, the idea of a haunted house could be treated by the learned counsel as a mere waggery. Yet the belief in haunted houses has survived the legal prosecution of witches. 'The judge in Tours has merely and mischievously 
encouraged superstition.' All ghosts, brownies, lutins, are mere bugbears of children; here Maître Chopin quotes Plato, and Philo Judæus in the original, also Empedocles, Marcus Aurelius, Tertullian, Quintilian, Dioscorides. Perhaps Bolacre and his family suffer from nightmare. If so, a physician, not a solicitor, is their man. Or again, granting that their house is haunted, they should appeal to the clergy, not to the law.

Manifestly this is a point to be argued. Do the expenses of exorcism fall on landlord or tenant? This, we think, can hardly be decided by a quotation from Epictetus. Alexis Comnenus bids us seek a bishop in the case of psychical phenomena ( $\tau \dot{a} \psi \mathbf{\psi} v \iota \kappa a ̀$

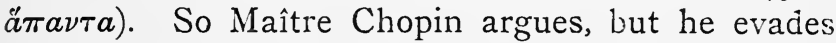
the point. Is it not the business of the owner of the house to 'whustle on his ain parten,' to have his own bogie exorcised? Of course Piquet and Macquereau may argue that the bogie is Bolacre's bogie, that it flitted to the house with Bolacre ; but that is a question of fact and evidence.

Chopin concludes that a lease is only voidable in case of material defect, or nuisance, as of pestilential air, not in a case which, after all, is a mere vice d'esprit. Here Maître Chopin sits down, with a wink at the court, and Nau pleads for the tenant. First, why abuse the judge at Tours? The lessors argued the case before him, and cannot blame him for credulity. The Romans, far from rejecting such ideas (as Chopin had maintained), used a ritual service for ejecting spooks, so Ovid testifies. Greek and Roman hauntings are cited from Pliny, Plutarch, Suetonius; in the 
last case (ghost of Caligula), the house had to be destroyed, like the house at Wolflee where the ghost, resenting Presbyterian exorcism, killed the Rev. Mr. Thomson of Southdean, father of the author of The Castle of Indolence. 'As to Plato, cited by my learned brother, Plato believed in hauntings, as we read in the Phaedo,' Nau has him here. In brief, 'the defendants have let a house as habitable, well knowing the same to be infested by spirits'. The Fathers are then cited as witnesses for ghosts. The learned counsel's argument about a vice d'esprit is a pitiable pun.

The decision of the court, unluckily, is not preserved by Le Loyer. The counsel for Bolacre told Le Loyer that the case was adjourned on the formal point, but, that, having obtained letters royal for his client, he succeeded in getting the remainder of the lease declared void. Comparing, however, Bouchel, s. v. Louage, in his Bibliothèque du droit François, one finds that the higher court reversed the decision of the judge at Tours. In the Edinburgh case, I835, the tenant, Captain Molesworth, did not try to have his lease quashed, but he did tear up floors, pull down wainscots, and bore a hole into the next house, that of his landlord, Mr. Webster, in search of the cause of the noises. Mr. Webster, therefore, brought an action to restrain him from these experiments.

Le Loyer gives two cases of ghosts appearing to denounce murderers in criminal cases. He possessed the speech of the President Brisson (at that time an advocate), in which he cited the testimony of the spectre of Madame de Colommiers, mysteriously 
murdered in full day, with her children and their nurse. Her ghost appeared to her husband, when wide awake, and denounced her own cousins. As there was no other evidence, beyond the existence of motive, the accused were discharged. In another well-known case, before the Parlement de Bretagne, the ghost of a man who had mysteriously vanished, guided his brother to the spot where his wife and her paramour had buried him, after murdering him. Le Loyer does not give the date of this trial. The wife was strangled, and her body was burned.

Modern times have known dream-evidence in cases of murder, as in the Assynt murder, and the famous Red Barns affair. But Thomas Harris's is probably the last ghost cited in a court of law. On the whole, the ghosts have gained little by these legally attested appearances, but the trials do throw a curious light on the juridical procedure of our ancestors. The famous action against the ghosts in the Eyrbyggja Saga was not before a Christian court, and is too well known for quotation. ${ }^{1}$

${ }^{1}$ Dr. Lee, in Sights and Sounds (p. 43), quotes an Irish law. suit in 1890 . The tenants were anxious not to pay rent, but were non-suited. No reference to authorities is given. There was also a case at Dublin in r885. Waldron's house was disturbed, 'stones were thrown at the windows and doors,' and Waldron accused his neighbour, Kiernan, of these assaults. He lost his case (Evening Standard, February $23,188_{5}$, is cited). 


\section{A MODERN TRIAL FOR WITCHCRAFT.}

Thorel v. Tinel. Action for libel in 1851. Mr. Dale Owen's incomplete version of this affair. The suit really a trial for witchcraft. Spectral obsession. Movements of objects. Rappings. Incidental folk-lore. Old $G$. Thorel and the curé. The wizard's revenge. The haunted parlour boarder. Examples of magical tripping up, and provoked hallucinations. Case of Dr. Gibotteau and Berthe the hospital nurse. Similar case in the Salem affair, 1602. Evidence of witnesses to abnormal phenomena. Mr. Robert de Saint Victor. M. de Mirville. Thorel nonsuited. Other modern French examples of witchcraft.

PERHAPS the last trial for witchcraft was the case of Thorel v. Tinel, heard before the juge de paix of Yerville, on January 28, and February 3 and 4, I85I. The trial was, in form, the converse of those with which old jurisprudence was familiar. Tinel, the Curé of Cideville, did not accuse the shepherd Thorel of sorcery, but Thorel accused Tinel of defaming his character by the charge of being a warlock. Just as when a man prosecutes another for saying that he cheated at cards, or when a woman prosecutes another for saying that the plaintiff stole diamonds, it is really the guilt or innocence of the plaintiff that is in question, so the issue before the court at Yerville was: 'Is Thorel a warlock or not?' The court decided that he himself had been the chief 
agent in spreading the slander against himself, he was non-suited, and had to pay costs, but as to the real cause of the events which were attributed to the magic of Thorel, the court was unable to pronounce an opinion.

This curious case has often been cited, as by Mr. Robert Dale Owen, in his Footfalls on the Boundary of Another World, ${ }^{1}$ but Mr. Owen, by accident or design, omitted almost all the essential particulars, everything which connects the affair with such transactions as the witch epidemic at Salen, and the trials for sorcery before and during the Restoration. Yet, in the events at Cideville, and the depositions of witnesses, we have all the characteristics of witchcraft. First we have men by habit and repute sorcerers. Then we have cause of offence given to these. Then we have their threats, malum minatum, then we have evil following the threats, dammm sccutum. Just as of old, that dammum, that damage, declares itself in the 'possession' of young pecple, who become, more or less, subject to trances and convulsions. One of them is haunted, as in the old witchcraft cases, by the phantasm of the sorcerer. The phantasm (as in Cotton Mather's examples) is wouncied, a parallel wound is found on the suspected warlock. Finally, the house where the obsessed victims live is disturbed by knocks, raps, flight of objects, and inexplicable movements of heavy furniture. Thus all the notes of a bad affair of witchcraft are attested in a modern trial, under the third Empire. Finally, some curious folk-lore is laid bare, light is 
cast on rural life and superstition, and a singular corroboration of a singular statement, much more recent than the occurrences at Cideville, is obtained. A more astonishing example of survival cannot be imagined, of survival, or of disconnected and spontaneous revival and recrudescence. ${ }^{1}$

There was at Auzebosc, near famous Yvetot, an old shepherd named G- : he was the recognised 'wise man,' or white witch of the district, and some less noted rural adepts gave themselves out as his pupils. In March, I849, M. Tinel, Curé of Cideville, visited a sick peasant, and advised him to discard old G., the shepherd magical, and send for a physician. G. was present, though concealed, heard the curés criticisms, and said: "Why does he meddle in my business, I shall meddle in his; he has pupils in his house, we'll see how long he keeps them.' In a few days, G. was arrested, as practising medicine unauthorised, was imprisoned for some months, and fancied that the curé had a share in this persecution. All this, of course, we must take as 'the clash of the country side,' intent, as there was certainly dammum secutum, on establishing malum minatum.

On a farm near the curé's house in Cideville was another shepherd, named Thorel, a man of forty, described as dull, illiterate, and given to boasting about his powers as a disciple of the venerable $G$. Popular opinion decided that G. employed Thorel to procure his vengeance; it was necessary that a

${ }^{1}$ The account followed here is that of the narrator in La Table Parlante, p. 130, who differs in some points from the Marquis de Mirville in his Fragment d'un Ouvrage Inédit, Paris, 1852. 
sorcerer should touch his intendeả victim, and $\mathrm{G}$. had not the same conveniency for doing so as Thorel. In old witch trials we sometimes find the witch kissing her destined prey. ${ }^{1}$ Thorel, so it was said, succeeded in touching, on Nov. 25, I850, M. Tinel's two pupils, in a crowd at a sale of wood. The lads, of fifteen and twelve, were named Lemonier and Bunel. For what had gone before, we have, so tar, only public chatter, for what followed we have the sworn evidence in court of the curés pupils, in January and February, I85I. According to Lemonier, on Nov. 26, while studying, he heard light blows of a hammer, these recurred daily, about 5. P.M. When M. Tinel, his tutor, said plus fort, the noises were louder. To condense evidence which becomes tedious by its eternal uniformity, popular airs were beaten on demand; the noise grew unbearable, tables moved untouched, a breviary, a knife, a spit, a shoe flew wildly about. Lemonier was buffeted by a black hand, attached to nobody. 'A kind of human phantasm, clad in a blouse, haunted me for fifteen days wherever I went; none but myself could see it.' He was dragged by the leg by a mysterious force. On a certain day, when Thorel found a pretext for visiting the house, M. Tinel made him beg Lemonier's pardon, clearly on the ground that the swain had bewitched the boy. 'As soon as I saw him I recognised the phantasm which had haunted me for a fortnight, and I said to M. Tinel: "There is the man who follows me", Thorel knelt

${ }^{1}$ For bewitching by touch see Cotton Mather's Wonders of the Invisible World, p. I50. 'Library of Old Authors,' London, 1862. 
to the boy, asked his pardon, and pulled violently at his clothes. As defendant, perhaps, the curé could not be asked to corroborate these statements. The evidence of the other boy, Bunel, was that, on Nov. 26, he heard first a rush of wind, then tappings on the wall. He corroborated Lemonier's testimony to the musical airs knocked out, the volatile furniture, and the recognition in Thorel of the phantom. 'In the evening,' said Bunel, 'Lemonier en eut une crise de nerfs dans laquelle il avait perdu connaissance.'

Leaving the boys' sworn evidence, and returning to the narrative with its gossip, we learn that Thorel boasted of his success, and said that, if he could but touch one of the lads again, the furniture would dance, and the windows would be broken. Meanwhile, we are told, nails were driven into points in the floor where Lemonier saw the spectral figure standing. One nail became red hot, and the wood round it smoked: Lemonier said that this nail had hit 'the man in the blouse' on the cheek. Now, when Thorel was made to ask the boy's pardon, and was recognised by him as the phantom, after the experiment with the nail, Thorel bore on his cheek the mark of the wound!

This is in accordance with good precedents in witchcraft. A witch-hare is wounded, the witch, in her natural form, has the same wound. At the trial of Bridget Bishop, in the court of Oyer and Terminer, held at Salem, June 2, 1692, there was testimony brought in that a man striking once at the place where a bewitched person said the shape of Mrs, 
Bishop stood, the bewitched cried out, that he had tore her coat, in the place then particularly specified, and Bishop's coat was found to be torn in that very place. ${ }^{1}$ Next day, after Thorel touched the boy, the windows broke, as he had prophesied. Then followed a curious scene in which Thorel tried, in presence of the maive, to touch the curé, who retreated to the end of the room, and struck the shepherd with his cane. Thereupon Thorel brought his action for libel and assault against the curé. Forty-two witnesses were heard, it was proved that Thorel had, in tact, frequently accused himself, and he was non-suited: his counsel spoke of appealing, but, unluckily, the case was not carried to a higher court. In a few weeks the boys were sent to their homes, when (according to the narrative) there were disturbances at the home of the younger lad. Thus the curé lost his pupils.

A curious piece of traditional folk-lore came out, but only as hearsay, in court. M. Cheval, Maire of Cideville, deposed that a M. Savoye told him that Thorel had once been shepherd to a M. Tricot. At that time Thorel said to one of two persons in his company: 'Every time I strike my cabin (a shelter on wheels used by shepherds) you will fall,' and, at each stroke, the victim felt something seize his throat, and fell! ${ }^{2}$ This anecdote is curious, because in the Proceedings of the Society for Psychical Research is a long paper by Dr. Gibotteau, on his experiments with

1 Cotton Mather, op. cit., p. I3I.

${ }^{2}$ Table Parlante, p. I5I. A somewhat different version is given p. I45. The narrator seems to say that Cheval himseif deposed to having witnessed this experiment. 
a hospital nurse called Berthe. This woman, according to the doctor, had the power of making him see hallucinations, of a nature more or less horrible, from a distance. . She had been taught some traditional feats of rural sorcery, among others that of making a man stumble, or fall, as he walked. The doctor does not make any allusion to the Cideville affair, and it seems probable that this trick is part of the peasant's magical repertoire, or, rather, that the peasant warlocks boast of being able to perform the trick. But, if we can accept the physician's evidence, as 'true for him,' at least, then a person like Berthe really might affect, from a distance, a boy like Lemonier with a haunting hallucination. To do this is witchcraft, and for crimes of this kind, or on false charges of this kind, poor Mrs. Bishop was burned at Salem in I6g2.

At the lowest, we have all the notes of sorcery as our rude ancestors knew it, in this modern affair. Two hundred years earlier, Thorel would have been burned, and G., too, probably, for the Maire of Cideville swore that before the disturbances, and three weeks after G. was let out of prison, Thorel had warned him of the trouble which G. would bring on the curé. Meanwhile the evidence shows no conscious malignity on the part of the two boys. They at first took very little notice of the raps, attributing the noises to mice. Not till the sounds increased, and showed intelligence, as by drumming tunes, did the lads concern themselves much about the matter. At no time (it seems) did they ask to be sent home, and, of course, to be relieved from 
their lessons and sent home would be their motive, if they practised a fraud. We may admit that, from rural tradition, the boys might have learned what the customary phenomena are, knocks, raps, moving tables, heavy objects sailing tranquilly about a room. It would be less easy for them to produce these phenomena, nor did the people of all classes. who flocked to Cideville detect any imposture.

A land surveyor swore that the raps went on when he had placed the boy in an attitude which made fraud (in his opinion) impossible. A gentleman M. de B. 'took all possible precautions' but, nevertheless, was entertained by 'a noise which performed the tunes demanded'. He could discover no cause of the noise. M. Huet, touching a table with his finger, received responsive raps, which answered questions, 'at the very place where I struck, and beneath my finger. I cannot explain the fact, which, I am convinced, was not caused by the child, nor by any one in the house.' M. Cheval saw things fly about, he slept in the boy's room, and his pillow flew from under his head. He lay down between the children, holding their hands, and placing his feet on theirs, when the coverlet of the bed arose, and floated away. The Marquis de Mirville had a number of answers by raps, which staggered him very much, but the force was quite feeble when he asked for portions of Italian music. Madame de St. Victor felt herself pushed, and her clothes pulled in the curés house, when no one was near her. She also saw furniture behave in a fantastic manner, and M. Raoul Robert de St. Victor had many such experiences. M. Paul de St. 
Victor was not present. A desk sailed along: paused in air, and fell: ' I had never seen a movement of this kind, and I admit that I was alarmed'. Le Seigneur, a farmer, saw 'a variety of objects arise and sail about': he was certain that the boys did not throw them, and when in their company, in the open air, between Cideville and Anzooville, 'I saw stones come to us, without striking us, hurled by some invisible force'. There was other confirmatory evidence, from men of physic, and of the law.

The juge de paix, as we have seen, pronounced that the clearest point in the case was 'the absence of known cause for the effects,' and he non-suited Thorel, the plaintiff.

The cause of the phenomena is, of course, as obscure for us as for the worthy magistrate. We can only say that, when precisely similar evidence was brought before judges and juries in England and New England, at a period when medicine, law, and religion all recognised the existence of witchcraft, magic, and diabolical possession, they had scarcely any choice but to condemn the accused. Causa patet, they said: "The devil is at the bottom of it all, and the witch is his minister'.

The affair of Cideville by no means stands alone in modern France. In 1853 , two doctors and other witnesses signed a deposition as to precisely similar phenomena attending Adelaide Françoise Millet, a girl of twelve, at Songhien, in Champagne. The trouble, as at Cock Lane, began by a sound of scratching on the wood of her bed. The clerk of the jug de la paix, the master of the Douane, two 
doctors, and others visited her, and tied her hands and feet. The noise continued. Mysterious missiles pursued a girl in Martinique, in I854. The house, which was stormed by showers of stone, in Paris (I8 46 ), entirely baffled the police. ${ }^{1}$ There is a more singular parallel to the Cideville affair, the account was printed from the letter of a correspondent in the Abeille of Chartres, March II, I849. ${ }^{2}$ At Gaubert, near Guillonville, a man was imprisoned for thefts of hay, the property of a M. Dolléans. Two days after his arrest, namely, on December $3 \mathrm{I}$, I848, the servant of M. Dolleans had things of all sorts thrown at her from all directions. She fell ill, and went into hospital for five days, where she was untroubled. On her return, in the middle of a conversation, ribbons and bits of string would fly at her, and twist themselves round her neck, as in the case of Francis Fey, of Spraiton, given by Aubrey and Bovet. Mademoiselle Dolléans carefully watched the girl for a fortnight, and never let her out of her sight, but could not discover any fraud. After about a month the maid was sent home, where she was not molested. Naturally we see in her the half-insane cunning of hysteria, but that explanation does not apply to little Master Dolléans, a baby of three months old. The curse fell on him: however closely his parents watched him, pots and pans showered into his cradle, the narrator himself saw a miscellaneous collection of household furniture mysteriously amassed there.

1 Gazette des Tribunaux, February 2, 1846, quoted in Tablc Parlante, p. 306.

${ }^{2}$ Table Parlante, p. 174 . 
The Abeille of Chartres held this letter over, till two of its reporters had visited the scene of action, and interviewed doctors, priests, and farmers, who all attested the facts. Happily, in this case, an exorcism by a priest proved efficacious. At Cideville, holy water and consecrated medals were laughed at by the sprite, who, by the way, answered to the name of Robert. 


\section{PRESBYTERIAN GHOST HUNTERS.}

Religious excitement and hallucination. St. Anthony. Zulu catechumens. Haunted Covenanters. Strange case of Thomas Smeaton. Law's 'Memorialls'. A deceitful spirit. Examples of insane and morbidly sensitive ghosts. 'Le revenant qui s'accuse s'excuse.' Raising the devil in Iraine. Mode of evocation. Wodrou. His account of Margaret Lang, and Miss Shaw of Barsarran. The unlucky Shawes. Lord Torphichen's son. Cases from Wodrou'. Lord Middleton's story. Haunted house. Wraiths. Lord Orrery's ghost no metaphysician. The Bride of Lammermoor. Visions of the saints. Their cautiousness. Ghost appearing to a Jacobite. Ghost of a country tradesman. Case of telepathy known to Wodrow. Avenging spectres. Lack of evidence. Tale of Cotton liather.

IN spite of a very general opinion to the opposite effect, it is not really easy to determine in what kind of age, and in what conditions of thought and civilisation, ghosts will most frequently appear, and ghostly phenomena will chiefly abound. We are all ready to aver that 'ghaists and eldritch fantasies' will be most common 'in the dark ages,' in periods of ignorance or superstition. But research in mediæval chronicles, and in lives of the saints makes it apparent that, while marvels on a large and imposing scale were frequent, simple ordinary apparitions 
and haunted houses occur comparatively seldom. Perhaps they were too common to be thought worth noticing, yet they are noticed occasionally, and, even in these periods of superstition, were apparently regarded as not quite everyday phenomena.

One thing in this matter is tolerably certain, namely, that intense religious excitement produces a tendency to believe in marvels of all sorts, and also begets a capacity for being hallucinated, for beholding spectres, strange lights, dubious miracles. Thus every one has heard of the temptation of St. Anthony, and of other early Christian Fathers. They were wont to be surrounded by threatening aspects of wild beasts, which had no real existence. In the same way the early $Z$ ulu converts of Bishop Callaway, when they retired to lonely places to pray, were haunted by visionary lions, and phantasms of enemies with assegais. They, probably, had never heard of St. Anthony's similar experiences, nor, again, of the diabolical attacks on the converts of Catholic missionaries in Cochin China, and in Peru.

Probably the most recent period of general religious excitement in our country was that of the Covenant in Scotland. Not a mere scattered congregation or two, as in the rise of Irvingism, but a vast proportion of a whole people lived lives of prolonged ecstatic prayer, and often neglected food for days. Consequently devout Covenanters, retired in lonely places to pray, were apt to be infested by spectral animals, black dogs as a rule, and they doubted not at all that the black dog was the Accuser of the Brethren. We have Catholic evidence, in Father Piatti's Life 
of Father Elphinstone, S.F., to black dogs haunting Thomas Smeaton, the friend of Andrew Melville (I58). But Father Piatti thinks that the dogs were avenging devils, Smeaton being an apostate (MS. Life of Elphinstone). Again Covenanters would see mysterious floods of light, as the heathen also used, but, like the heathen, they were not certain as to whether the light was produced by good or bad spirits. Like poor bewildered Porphyry, many centuries earlier, they found the spirits 'very deceitful'. You never can depend on them. This is well illustrated by the Rev. Mr. Robert Law, a Covenanting minister, but not a friend of fanaticism and sedition.

In his Memorialls, a work not published till long after his death, he gives this instance of the deceitfulness of sprites. The Rev. Mr. John Shaw, in Ireland, was much troubled by witches, and by 'cats coming into his chamber and bed'. He died, so did his wife, 'and, as was supposed, witched'. Before Mr. Shaw's death his groom, in the stable, saw 'a great heap of hay rolling toward him, and then appeared '(the hay not the groom) 'in the shape and lykness of a bair. He charges it to appear in human shape, which it did.' The appearance made a tryst to meet the groom, but Mr. Shaw forbade this tampering with evil in the lykness of a bair. However a stone was thrown at the groom, which he took for a fresh invitation from the bair, so he went to the place appointed. 'The divill appears in human shape, with his heid running down with blood,' and explains that he is 'the spirit of a murdered man who lay under his bed, and buried in the ground, 
and who was murdered by such a man, naming him by name'. The groom, very naturally, dug in the spot pointed out by this versatile phantom, 'but finds nothing of bones or anything lyke a grave, and shortly after this man dyes,' having failed to discover that the person accused of murder had ever existed at all.

Many ghosts have a perfect craze for announcing that bodies or treasures, are buried where there is nothing of the sort. Glanvill has a tale of a ghost who accused himself of a murder, and led a man to a place in a wood where the corpse of the slain was to be found. There was no corpse, the ghost was mad. The Psychical Society have published the narratives of a housemaid and a butler who saw a lady ghost. She, later, communicated through a table her intention to appear at eleven P.M. The butler and two ladies saw her, the gentlemen present did not. The ghost insisted that jewels were buried in the cellar; the butler dug, but found none. The writer is acquainted with another ghost, not published, who labours under morbid delusions. For reasons wholly untounded on fact she gave a great deal of trouble to a positive stranger. Now there was literally no sense in these proceedings. Such is ghostly evidence, ever deceitful!

'It's not good,' says Mr. Law, 'to come in communing terms with Satan, there is a snare in the end of it; 'yet people have actually been hanged, in England, on the evidence of a ghost! On the evidence of the devil, some other persons were accused of theft, in I682. This is a remarkable instance; we often hear 
of raising the ghostly foe, but we are seldom told how it can be done. This is how it was done in February, I682, at the house of the Hon. Robert Montgomery, in Irvine. Some objects of silver plate were stolen, a maid was suspected, she said 'she would raise the devil, but she would know who the thief was'. Taking, therefore, a Bible, she went into a cellar, where she drew a circle round her, and turned a sieve on end twice, from right to left. In her hand she held nine feathers from the tail of a black cock. She next read Psalm li. forwards, and then backwards Revelations ix. I9. ' $\mathrm{He}$ ' then appeared, dressed as a sailor with a blue cap. At each question she threw three feathers at him: finally he showed as a black man with a long tail. Meanwhile all the dogs in Irvine were barking, as in Greece when Hecate stood by the cross-ways. The maid now came and told Mrs. Montgomery (on information received) that the stolen plate was in the box of a certain servant, where, of course, she had probably placed it herself. However the raiser of the devil was imprisoned for the spiritual offence. She had learned the rite 'at Dr. Colvin's house in Ireland, who used to practise this'.

The experiment may easily be repeated by the scientific.

Though Mr. Law is strong in witches and magic, he has very few ghost stories; indeed, according to his philosophy, even a common wraith of a living person is really the devil in that disguise. The learned Mr. Wodrow, too, for all his extreme pains, cannot be called a very successful amateur of spectres. A mighty ghost hunter was the Rev. Robert Wod- 
row of Eastwood, in Renfrewshire, the learned historian of the sufferings of the Kirk of Scotland (I679-I734). Mr. Wodrow was an industrious antiquarian, a student of geology, as it was then beginning to exist, a correspondent for twenty years of Cotton Mather, and a good-hearted kind man, that would hurt nobody but a witch or a Papist. He had no opportunity to injure members of either class, but it is plain, from his four large quarto volumes, called Analecta, that he did not lack the will. In his Analecta Mr. Wodrow noted down all the news that reached him, scandals about 'The Pretender,' Court Gossip, Heresies of Ministers, Remarkable Providences, Woful Apparitions, and 'Strange Steps of Providence'. Ghosts, second sight, dreams, omens, premonitions, visions, did greatly delight him, but it is fair to note that he does not vouch for all his marvels, but merely jots them down, as matters of hearsay. Thus his pages are valuable to the student of superstition, because they contain 'the clash of the country' for about forty years, and illustrate the rural or ecclesiastical aberglaube of our ancestors, at the moment when witchcraft was ceasing to be a recognised criminal offence.

A diary of Wodrow's exists, dating from April 3, 1697, when he was but nineteen years of age. On June Io, I697, he announces the execution of some witches at Paisley: seven were burned, among them one, Margaret Lang, who accused herself of horrible crimes. The victim of the witches burned in 1697 was a child of eleven, daughter of John Shaw of Bargarran. This family was unlucky in its spiritual accidents. 
The previous laird, as we learn from the contemporary Law, in his Memorialls, rode his horse into a river at night, and did not arrive at the opposite bank. Every effort was made to find his body in the stream, which was searched as far as the sea. The corpse was at last discovered in a ditch, two miles away, shamefully mutilated. The money of the laird, and other objects of value, were still in his pockets. This was regarded as the work of fiends, but there is a more plausible explanation. Nobody but his groom saw the laird ride into the river; the chances are that he was murdered in revenge,-certain circumstances point to this,-and that the servant was obliged to keep the secret, and invent the story about riding the ford.

The daughter of Bargarran's successor and heir was probably a hysterical child, who was led, by the prevailing superstition, to believe that witches caused her malady. How keen the apprehensions were among children, we learn from a document preserved by Wodrow. An eminent Christian of his acquaintance thought in boyhood that an old woman looked crossly at him, and he went in dread of being bewitched for a whole summer. The mere terror might have caused fits, he would then have denounced the old woman, and she would probably have been burned. Charles Kirkpatrick Sharpe, in his preface to Law's Memorialls (p. xcii.), says that Miss Shaw was 'antient in wickedness,' and thus accounts for her 'pretending to be bewitched,' by way of revenging herself on ore of the maid-servants. Twenty people were finally implicated, several were executed, and one 
killed himself. The child, probably hysterical, and certainly subject to convulsions, was really less to blame than 'the absurd credulity of various otherwise worthy ministers, and some topping professors in and about Glasgow, as Sharpe quotes the MS. 'Treatise on witchcraft' of the Rev. Mr. Bell. Strangely enough the great thread manufactories of Renfrewshire owed their origin to this Miss Shaw, aided by a friend who had acquired some technical secrets in Holland. She married a minister in I7I 8 , and probably her share in an abominable crime lay light on her conscience. Her fellow-sufferer from witchcraft, a young Sandilands, son of Lord Torphichen (I720), became a naval officer of distinguished gallantry.

Wodrow does not appear to have witnessed the execution at Paisley, one of the last in Scotland, but he had no doubt that witches should be put to death. In I720, when the son of Lord Torphichen exhibited some curious phenomena, exaggerated by report into clairvoyance and flying in the air, nobody was punished. In spite of his superstition in regard to witches, Wodrow (September 20, I697) sensibly explains a death-wraith by the anxiety of the lady who beheld it. He also, still in the diary, records a case of second sight, but that occurred in Argyleshire. It will be found, in fact, that all the secondsighted people except some ministers during the sufferings (and they reckoned as prophets) were Highlanders. Considering his avidity for ghoststories, it is remarkable that he scarcely ever receives them at even second hand, and that most 
of them are remote in point of time. On the other side, he secures a few religious visions, as of shining lights comforting devout ladies, from the person concerned. His narratives fall into regular categories, Haunted Houses, Ghosts, Wraiths, Second Sight, Consolatory Divine Visions. Thus Mr. Stewart's uncle, Harry, ' ane eminent Christian, and very joviall,' at a drinking party saw himself in bed, and his coffin at his bed-foot. This may be explained as a case of 'the horrors,' a malady incident to the jovial. He died in a week, In vino veritas.

Lord Middleton's ghost-story Wodrow got from the son of a man who, as Lauderdale's chaplain, heard Middleton tell it at dinner. He had made a covenant with the Laird of Babigni that the first who died should appear to the survivor. Babigni was slain in battle, Middleton was put in the Tower, where Babigni appeared to him, sat with him for an hour by the clock, and predicted the Restoration. ' His hand was hote and soft,' but Middleton, brave in the field, was much alarmed. He had probably drunk a good deal in the Tower. This anecdote was very widely rumoured. Aubrey publishes a version of it in his Misccllanies, and Law gives another in his Memorialls (p. I62). He calls 'Babigni - 'Barbigno,' and 'Balbegno'. According to Law, it was not the laird's ghost that appeared, but 'the devil in his lykness'. Law and Aubrey make the spirit depart after uttering a couplet, which they quote variously.

For a haunted house, Wodrow provides us with that of Johnstone of Mellantae, in Annandale (I707). The authority is Mr. Cowan, who had it from Mr. 
Murray, minister of St. Mungo's, who got it from Mellantae himself, the worthy gentleman weeping as he described his misfortunes. His daughter, Miss Johnstone, was milking a cow in the byre, by daylight, when she saw a tall man, almost naked, probably a tramp, who frightened her into a swoon. The house was then 'troubled and disturbed' by flights of stones, and disappearance of objects. Young Dornock, after a visit to Mellantae, came back with a story that loud knockings were heard on the beds, and sounds of pewter vessels being thrown about, though, in the morning, all were found in their places. The ghost used also to pull the medium, Miss Johnstone, by the foot, and toss her bed-clothes about.

Next, at first hand from Mr. Short, we have a death-wraith beheld by him of his friend Mr. Scrim. geour. The hour was five A.M. on a summer morning, and Mr. Scrimgeour expired at that time in Edinburgh. Again, we have the affair of Mr. Blair, of St. Andrews, the probationer, and the devil, who, in return for a written compact, presented the probationer with an excellent sermon. On the petition of Mr. Blair, the compact fell from the roof of the church. The tale is told by Increase Mather about a French Protestant minister, and, as Increase wrote twenty years before Wodrow, we may regard Wodrow's anecdote as a myth; for the incident is of an unusual character, and not likely to repeat itself. We may also set aside, though vouched for by Lord Tullibardine's butler, 'ane litle old man with a fearful ougly face,' who appeared to the Rev. Mr. Lesly. Being asked whence he came, he said, 
'From hell,' and, being further interrogated as to why he came, he observed: "To warn the nation to repent'. This struck Mr. Lesly as improbable on the face of it ; however, he was a good deal alarmed.

Lord Orrery is well known in ghostly circles, as the evidence for a gentleman's butler being levitated, and floating about a room in his house. It may be less familiar that his lordship's own ghost appeared to his sister. She consulted Robert Boyle, F.R.S., who advised her, it Orrery appeared again, to ask him some metaphysical questions. She did so, and 'I know these questions come from my brother,' said the appearance. ' $\mathrm{He}$ is too curious.' $\mathrm{He}$ admitted, however, that his body was 'an aerial body,' but declined to be explicit on other matters. This anecdote was told by Mr. Smith, who had it from Mr. Wallace, who had it from 'an English gentleman'. Mr. Menzies, minister of Erskine, once beheld the wraith of a friend smoking a pipe, but the owner of the wraith did not die, or do anything remarkable. To see a friendly wraith smoking a pipe, even if he take the liberty of doing so in one's bedroom, is not very ill-boding. To be sure Mr. Menzies' own father died not long after, but the attempt to connect the wraith of a third person with that event is somewhat desperate.

Wodrow has a tame commonplace account of the Bride of Lammermoor's affair. On the other hand, he tells us concerning a daughter of Lord Stair, the Countess of Dumfries, that she 'was under a very odd kind of distemper, and did frequently fly from one end of the room to the other, and from the 
one side of the garden to the other. ... The matter of fact is certain.' At a garden party this accomplishment would have been invaluable.

We now, for a change, have a religious marvel. Mrs. Zuil, 'a very judiciouse Christian,' had a friend of devout character. This lady, being in bed, and in 'a ravishing frame,' 'observed a pleasant light, and one of the pleasantest forms, like a young child, standing on her shoulder'. Not being certain that she was not delirious, she bade her nurse draw her curtains, and bring her some posset. Thrice the nurse came in with posset, and thrice drew back in dread. The appearance then vanished, and for the fourth time the nurse drew the curtains, but, on this occasion, she presented the invalid with the posset. Being asked why she had always withdrawn before, she said she had seen 'like a boyn (halo?) above her mistress's head,' and added, 'it was her wraith, and a signe she would dye'. 'From this the lady was convinced that she was in no reverie.' A similar halo shone round pious $\mathrm{Mr}$. Welsh, when in meditation, and also (according to Patrick Walker) round two of the Sweet Singers, followers of Meikle John Gibb, before they burned a Bible! Gibb, a raving fanatic, went to America, where he was greatly admired by the Red Indians, 'because of his much converse with the devil'. The pious of Wodrow's date distrusted these luminous appearances, as they might be angelical, but might also be diabolical temptations to spiritual pride. Thus the blasphemous followers of $\mathrm{Gibb}$ were surrounded by a bright light, no less than pious $\mathrm{Mr}$. Welsh, a very distinguished 
Presbyterian minister. Indeed, this was taken advantage of by Mr. Welsh's enemies, who, says his biographer Kirkton, 'were so bold as to call him no less than a wizard'. When Mr. Shields and Mr. John Dickson were imprisoned on the Bass Rock, and Mr. Shields was singing psalms in his cell, Mr. Dickson peeping in, saw ' a figure all in white,' of whose presence Mr. Shields was unconscious $\mathrm{He}$ had only felt ' in a heavenly and elevated frame'.

A clairvoyant dream is recorded on the authority of 'Dr. Clerk at London, who writes on the Trinity, and may be depended on in such accounts'. The doctor's father was Mayor of Norwich, 'or some other town,' and a lady came to him, bidding him arrest a tailor for murdering his wife. The mayor was not unnaturally annoyed by this appeal, but the lady persisted. She had dreamed twice: first she saw the beginning of the murder, then the end of it. As she was talking to the mayor, the tailor came in, demanding a warrant to arrest his wife's murderers! He was promptly arrested, tried, and acquitted, but later confessed, and 'he was execut for the fact'. This is a highly improbable story, and is capped by another from Wodrow's mother-in-law. A man was poisoned: later his nephew slept in his room, and heard a voice cry, 'Avenge the blood of your uncle'. This happened twice, and led to an inquiry, and the detection of the guilty. The nephew who received the warning was Sir John Clerk of Penicuik, ancestor of Sir Walter Scott's friend.

We next have a Mahatma-like tale about Cotton 
Mather, from Mr. Stirling, who had it from a person who had it from the doctor's own mouth. Briefly, Cotton lost his sermon as he was riding to a place where he had to preach. He prayed for better luck, and 'no sooner was his prayer over, but his papers wer conveyed to him, flying in the air upon him when riding, which was very surprizing'. It was, indeed! Wodrow adds: 'Mind to write to the doctor about this'. This letter, if he ever wrote it, is not in the three portly volumes of his correspondence.

The occurrence is more remarkable than the mysterious dispensation which enabled another minister to compose a sermon in his sleep. Mr. James Guthrie, at Stirling, 'had his house haunted by the devil, which was a great exercise to worthy Mr. Guthrie,' and, indeed, would have been a great exercise to almost any gentleman. Details are wanting, and as Mr. Guthrie had now been hanged for sixty years (I723), the facts are 'remote'. Mr. Guthrie, it seems, was unpopular at Stirling, and was once mobbed there. The devil may have been his political opponent in disguise. Mr. John Anderson is responsible for the story of a great light seen, and a melodious sound heard over the house of ' $a$ most singular Christian of the old sort,' at the moment of her death. Her name, unluckily, is uncertain.

A case of 'telepathy' we have, at first hand, from Mrs. Luke. When in bed 'a horror of darknes' came upon her about her daughter Martha, who was in Edinburgh. 'Sometimes she began to think that 
her daughter was dead, or had run away with some person.' She remained in this anxiety till six in the morning, when the cloud lifted. It turned out that Martha had been in some peril at sea, but got safe into Leith Roads at six in the morning. A clairvoyant diream was also vouchsafed to Dr. Pitcairn, though 'a Jacobite, and a person of considerable sense,' as Wodrow quaintly remarks about another individual.

The doctor was at Paris when a friend of his, 'David' (surname unknown), died in Edinburgh. The doctor dreamed for several nights running that David came to him, and that they tried to enter several taverns, which were shut. David then went away in a ship. As the doctor was in the habit of frequenting taverns with David, the dreams do not appear to deserve our serious consideration. To be sure David 'said he was dead'. 'Strange vouchsafments of Providence to a person of the doctor's temper and sense,' moralises Wodrow.

Curiously enough, a different version of Dr. Pitcairn's dream is in existence. Several anecdotes about the doctor are prefixed, in manuscript, to a volume of his Latin poems, which was shown to Dr. Hibbert by Mr. David Laing, the well-knorvn historian and antiquarian. Dr. Hibbert says: 'The anecdotes are from some one obviously on terms of intimacy with Pitcairn'. According to this note Robert Lindsay, a descendant of Sir David Lindsay of the Mount, was at college with the doctor. They made the covenant that 'whoever dyed first should give account of his condition if possible'. 'This was 
in $167 \mathrm{I}$, in 1675 Lindsay died, while Pitcairn was in Paris. On the night of Lindsay's death, Pitcairn dreamed that he was in Edinburgh, where Lindsay met him and said, 'Archie, perhaps ye heard I'm dead?' 'No, Roben.' The vision said he was to be buried in the Grey Friars, and offered to carry Pitcairn to a happy spiritual country, 'in a ivell sailing small ship,' like Odysseus. Pitcairn said he must first see his parents. Lindsay promised to call again. 'Since which time A. P. never slept a night without dreaming that Lindsay told him he was alive. And, having a dangerous sickness, anno I694, he was told by Roben that he was delayed for a time, and that it was properly his task to carry him off, but was discharged to tell when.' 1 Dr. Hibbert thinks that Pitcairn himself dictated this account, much more marvellous than the form in which Wodrow received the story.

Leaving a solitary Jacobite vision, for a true blue Presbyterian 'experience,' we learn that Wodrow's own wedded wife had a pious vision, 'a glorious, inexpressible brightness'. The thought which came presently was, "This perhaps may be Satan, transforming himself into an angel of light'. 'It mout or it moutn't.' In I729, Wodrow heard of the ghost of the Laird of Coul, which used to ride one of his late tenants, transformed into a spectral horse. A chap-book containing Coul's discourse with Mr. Ogilby, a minister, was very popular in the last century. Mr. Ooilby left an account in manuscript, on which the chap-book was said to be based.

${ }^{1}$ Hibbert, Apparitions, p. $2 \mathrm{rr}$. 
Another ghost of a very moral turn appeared, and gave ministers information about a case of lawless love. This is said to be recorded in the registers of the Presbytery of Fordoun, but Wodrow is vague about the whole affair.

We next come to a very good ghost of the old and now rather unfashionable sort. The authority is Mr. William Brown, who had it from the Rev. Mr. Mercer of Aberdalgie, 'as what was generally belived as to Dr. Rule, Principal at Edinburgh'. Such is Wodrow's way, his ideas of evidence are quite rudimentary. Give him a ghost, and he does not care for 'contemporary record,' or ' corroborative testimony'. To come to the story. Dr. Rule, finding no room at an inn near Carnie Mount, had a fire lit in a chamber of a large deserted house hard by. He went to bed, leaving a bright fire burning, when 'the room dore is opened, and an apparition, in shape of a country tradsman, came in, and opened the courtains without speaking a word'. The doctor determined not to begin a conversation, so the apparition lighted the candles, brought them to the bedside, and backed to the door. Dr. Rule, like old Brer Rabbit, 'kept on a-saying nothing'. 'Then the apparition took an effectuall way to raise the doctor. He caryed back the candles to the table, and, with the tongs, took doun the kindled coals, and laid them on the deal chamber floor.' Dr. Rule now ' thought it was time to rise,' and followed the appearance, who carried the candles downstairs, set them on the lowest step, and vanished. Dr. Rule then lifted the candles, and went back to bed. Next morn- 
ing he went to the sheriff, and told him there 'was murder in it'. The sheriff said, 'it might be so,' but, even if so, the crime was not recent, as the house for thirty years had stood empty. The step was taken up, and a dead body was found, ' and bones, to the conviction of all'. The doctor then preached on these unusual events, and an old man of eighty fell a-weeping, confessing that, as a mason lad, he had killed a companion, and buried him in that spot, while the house was being built. Consequently the house, though a new one, was haunted from the first, and was soon deserted. The narrator, Mr. Mercer, had himself seen two ghosts of murdered boys frequently in Dundee. He did not speak, nor did they, and as the rooms were comfortable he did not leave them. To have talked about the incident would only have been injurious to his landlady. "The longer I live, the more unexpected things I meet with, and even among my own relations,' says Mr. Wodrow with much simplicity. But he never met with a ghost, nor even with any one who had met with a ghost, except $\mathrm{Mr}$. Mercer.

In the same age, or earlier, Increase Mather represents apparitions as uncommonly scarce in New England, though diabolical possession and witchcraft were as familiar as influenza. It has been shown that, in nearly forty years of earnest collecting, $\mathrm{Mr}$. Wodrow did not find a single supernatural occurrence which was worth investigating by the curious. Every tale was old, or some simple natural cause was at the bottom of the mystery, or the narrative rested on vague gossip, or was a myth. To-day, at any dinner 
party, you may hear of bogles and wraiths at first or at second hand, in an abundance which would have rejoiced Wodrow. Charles Kirkpatrick Sharpe vainly brags, in Law's Memorialls, that 'good sense and widely diffused information have driven our ghosts to a few remote castles in the North of Scotland' (I8I9). But, however we are to explain it, the ghosts have come forth again, and, like golf, have crossed the Tweed. Now this is a queer result of science, common-sense, cheap newspapers, popular education, and progress in general. We may all confess to a belief in ghosts, because we call them 'phantasmogenetic agencies,' and in as much of witchcraft as we style 'hypnotic suggestion'. So great, it seems, is the force of language ! ${ }^{1}$

${ }^{1}$ Mather's own account of the lost sermon (p. 29S) is in his Life, by Mr. Barrett Wendell, p. II8. It is by no means so romantic as Wodrow's version. 


\section{THE LOGIC OF TABLE-TURNING.}

Bias in belief. Diffculty of examining problems in which unknoze'n personal conditions are dominant. Comte Agénor de Gasparin on table-turning. The rise of modern table-turning. Rapping. French examples. A lady' bitten by a spirit. Flying objects. The 'via media' of $M$. de Gasparin. Tables are turned by recondite physical causes: not by muscular or spiritual actions. The author's own experiments. Motion without contact. Dr. Carpenter's views. Incredulity of M. de Gasparin as to phenomena beyond his own experience. Ancient Greek phenomena. M. de Gasparin rejects 'spirits'. Dr. Carpenter neglects $M$. de Gasparin's evidence. Survival and revival. Delacourt's case. Home's case. Simon Magus. Early scientific training. Its results. Conclusion.

While reason is fondly supposed to govern our conduct, and direct our conclusions, there is no doubt that our opinions are really regulated by custom, temperament, hope, and fear. We believe or disbelieve because other people do so, because our character is attracted to, or repelled by the unusual, the mysterious; because, from one motive or another, we wish things to be thus, or fear that they may be thus, or hope that they may be so, and cannot but dread that they are otherwise. Again, the laws of Nature which have been ascertained are enough for the conduct of life, and science constantly, and with excellent reason, resists to the last gasp every attempt to recognise the existence of a new law, 
which, after all, can apparently do little for the benefit of mankind, and may conceivably do something by no means beneficial. Again, science is accustomed to deal with constant phenomena, which, given the conditions, will always result. The phenomena of the marvellous are not constant, or, rather, the conditions cannot be definitely ascertained. When Mr. Crookes made certain experiments on Home's power of causing a balance to move without contact he succeeded; in the presence of some Russian savants a similar experiment failed. Granting that $\mathrm{Mr}$. Crookes's tests were accurate (and the lay mind, at least, can see no flaw in them), we must suppose that the personal conditions, in the Russian case, were not the same.

Now an electric current will inevitably do its work, if known and ascertained conditions are present; a personal current, so to speak, depends on personal conditions which are unascertainable. It is inevitable that science, accustomed to the invariable, should turn away from phenomena which, if they do occur, seem, so far, to have a will of their own. That they have a will of their own is precisely their attraction for another class of minds, which recognises in them the action of unknown intelligences. There are also people who so dislike our detention in the prison house of old unvarying laws, that their bias is in favour of anything which may tend to prove that science, in her contemporary mood, is not infallible. As the Frenchman did not care what sort of scheme he invested money in, "provided that it annoys the English,' so many persons do not care what they 
invest belief in, provided that it irritates men of science. Just as rationally, some men of science denounce all investigation of the abnormal phenomena of which history and rumour are so full, because the research may bring back distasteful beliefs, and revive the 'ancestral tendency' to superstition. Yet the question is not whether the results of research may be dangerous, but whether the phenomena occur. The speculations of Copernicus, of Galileo, of the geologists, of Mr. Darwin, were 'dangerous,' and it does not appear that they have added to the sum of human delight. But men of science are still happiest when denouncing the 'obscurantism' of those who opposed Copernicus, Mr. Darwin, and the rest, in dread of the moral results. We owe the strugforlifeur of M. Daudet to Mr. Darwin and Mr. Alfred Wallace, and the strugforlifeur is as dangerous and disagreeable as the half-crazy. spiritualist. Science is only concerned with truth, not with the mischievous inferences which people may draw from truth. And yet certain friends of science, quite naturally and normally, fall back on the attitude of the opponents of Copernicus: 'These things,' they say, 'should not even be examined'.

Such are the hostile and distracting influences, the contending currents, in the midst of which Reason has to operate as well as she can. Meanwhile every one of us probably supposes himself to be a model of pure reason, and if people would only listen to him, the measure of the universe. This happy and universal frame of mind is agreeably illustrated in a work by the late Comte Agénor de Gasparin, Les 
Tables Tournantes (Deuxième edition: Levy, Paris, I888). The first edition is of I854, and was published at a time of general excitement about 'table-turning' and 'spirit-rapping,' an excitement which only old people remember, and which it is amazing to read about.

Modern spirit-rapping, of which table-turning is a branch, began, as we know, in $18_{47-4} 8$. A family of Methodists named Fox, entered, in 1847 , on the tenancy of a house in Hydesville, in the State of New York. The previous occupants had been disturbed by 'knocking,' this continued in the Fox régime, one of the little girls found that the raps would answer (a discovery often made before) a system of alphabetic communication was opened, and spiritualism was launched. ${ }^{1}$ In March, I853, a packet of American newspapers reached Bremen, and, as Dr. Andrée wrote to the Gazette d'Augsbourg (March 30, I $8_{53}$ ), all Bremen took to experiments in turning tables. The practice spread like a new disease, even men of science and academicians were puzzled, it is a fact that, at a breakfast party in Macaulay's rooms in the Albany, a long and heavy table became vivacious, to Macaulay's disgust, when the usual experiment was tried. Men of science were, in some cases, puzzled, in others believed that a new force must be recognised, in others talked of unconscious pushing or of imposture. M. Babinet, a member of the Institute, writing in the Revue des Deux Mondes (May, I854), explained the 'raps' or percussive noises,

${ }^{1}$ An account of the method by which the Miss Foxes rapped is given, by a cousin of theirs, in Dr. Carpenter's Mesmerism (F. I5O) 
as the result of ventriloquism! A similar explanation was urged, and withdrawn, in the case of the Cock Lane ghost, and it does not appear that M. Babinet produced a ventriloquist who could do the trick. Raps may be counterfeited in many ways, but hardly by ventriloquism. The raps were, in Europe, a later phenomenon than the table-turning, and aroused far more interest. The higher clergy investigated the matter, and the Bishop of Mans in a charge, set down the phenomena to the agency of some kind of spirits, with whom Christian men should have no commerce. Granting the facts, the bishop was undeniably right.

- There was published at that time a journal called La Table Parlante, which contained recitals of phenomena, correspondence, and so forth. Among the narratives, that of a M. Benezet was typical, and is curious. In recent years, about I872-So, the Rev. Mr. Stainton Moses, a clergyman and scholar of the best moral reputation, believed himself to be the centre of extraorclinary, and practically incredible, occurrences, a belief shared by observers among his friends. M. Benezet's narrative is full of precisely parallel details. M. Benezet lived at Toulouse, in 1853; and his experiences had for their scene his own house, and that of his relations, M. and Mme. L. The affair began in table-turning and table-tilting; the tilts indicated the presence of 'spirits,' which answered questions, right or wrong: under the hands of the L.'s the table became vivacious, and chased a butterfly. Then the spirit said it could appear as an old lady, who was viewed 
by one of the children. The L.'s being alarmed, gave up making experiments, but one day, at dinner, thumps were struck on the table. M. Benezet was called in, and heard the noises with awe. He went away, but the knocks sounded under the chair of Mime. L., she threw some holy water under the chair, when her thumb was bitten, and marks of teeth were left on it. Presently her shoulder was bitten, whether on a place which she could reach with her teeth or not, we are not informed. Raps went on, the L.'s fled to M. Benezet's house, which was instantly disturbed in the same fashion. Objects were spirited away, and reappeared as oddly as they had vanished. Packets of bonbons turned up unbelnown, sailed about the room, and suddenly fell on the table at dinner. The L.'s went back to their own house, where their hats and boots contracted a habit of floating dreamily about in the air. Things were hurled at them, practical jokes were played, and in September these monstrous annoyances gradually ceased. The most obvious explanation is that Mme. L. demoralised by turning tables, took. consciously or unconsciously, to imitating the tricks of which history and legend are full. Her modus operandi, in some phenomena, is difficult to conjecture.

While opinion was agitated by these violent events, and contending hypotheses, while La Table Parlante took a Catholic view, and Science a negative view, M. Agénor de Gasparin, a Protestant, chose a via media.

M. de Gasparin, the husband of the well-known 
author of The Near and the Heavenly Horizons, was a table-turner, without being a spiritualist. His experiments were made in Switzerland, in I853; he published a book on them, as we said; M. Figuier attacked it in Les My'steres de la Science, after M. de Gasparin's death, and the widow of the author replied by republishing part of the original work. M. de Gasparin, in the early Empire, was a Liberal, an anti-Radical, an opponent of negro slavery, a Christian, an energetic honest man, absolu et ardent, as he confesses.

His purpose was to demonstrate that tables turn, that the phenomenon is purely physical, that it cannot be explained by the mechanical action of the muscles, nor by that of 'spirits'. His allies were his personal friends, and it is pretty clear that two ladies were the chief 'agents'. The process was conducted thus: a 'chain' of eight or ten people surrounded a table, lightly resting their fingers, all in contact, on its surface. It revolved, and, by request, would raise one of its legs, and tap the floor. All this, of course, can be explained either by cheating, or by the unconscious pushes administered. If any one will place his hands on a light table, he will find that the mere come and go of pulse and breath have a tendency to agitate the object. It moves a little, accompanying it you unconsciously move it more. The experiment is curious because, on some days, the table will not bucige, on others it instantly sets up a peculiar gliding movement, in which it almost seems to escape from the superimposed hands, while the most wakeful attention cannot detect any conscious action of the 
muscles. If you try the opposite experiment, namely conscious pushing of the most gradual kind, you find that the exertion is very distinctly sensible. The author has made the following simple experiment.

Two persons for whom the table would not move laid their hands on it firmly and flatly. Two others (for whom it danced) just touched the hands of the former pair. Any pressure or push from the upper hands would be felt, of course, by the under hands. No such pressure was felt, yet the table began to rotate. In another experiment with another subject, the pressure was felt (indeed the owner of the upper hands was conscious of pressing), yet the table did not move. These experiments are, physiologically, curious, but, of course, they demonstrate nothing. Muscles can move the table, muscles can apparently act without the consciousness of their owner, therefore the movement is caused, or may be irrefutably said to be caused, by unconscious muscular action.

M. de Gasparin, of course, was aware of all this; he therefore aimed at producing movement without contact. In his early experiments the table was first set agoing by contact; all hands were then lifted at a signal, to half an inch above the table, and still the table revolved. Of course it will not do this, if it is set agoing by conscious muscular action, as any one may prove by trying. As it was possible that some one might still be touching the table, and escaping in the crowd the notice of the observers outside the circle, two ladies tried alone. The observer, Mr. 'Thury, saw the daylight between their hands and the 
table, which revolved four or five times. To make assurance doubly sure, a thin coating of flour was scattered over the whole table, and still it moved, while the four was unmarked. M. de Gasparin was therefore convinced that the phenomena of movement without mechanical agency were real. His experiments got rid of Mr. Faraday's theory of unconscious pressure and pushing, because you cannot push with your muscles what you do not touch with any portion of your body, and De Gasparin had assured himself that there was no physical contact between his friends and this table.

M. de Gasparin now turned upon Dr. Carpenter, to whom an article in the Quarterly Review, dealing with the whole topic of abnormal occurrences, was attributed. Dr. Carpenter, at this time, had admitted the existence of the hypnotic state, and the amenability of the hypnotised person to the wildest suggestions. He had also begun to develop his doctrine of 'unconscious cerebration,' that is, the existence of mental processes beneath, or apart from our consciousness. ${ }^{1}$ An 'ideational change' may take place in the cerebrum. The sensorium is ' unreceptive,' so the idea does not reach consciousness. Sometimes, however, the idea oozes out from the fingers, through muscular action, also unconscious. This moves the table to the appropriate tilts. These two ideas are capable, if we admit them, of explaining many singular psychological facts, but they certainly do

${ }^{1}$ See Dr. Carpenter's brief and lucid statement about 'Latent Thought' and 'Unconscious Cerebration,' in the Quarterly Review, vol. cxxxi. pp. 316-3 I9. 
not explain the morements of tables which nobody is touching. In face of M. de Gasparin's evidence, which probably was not before him, Dr. Carpenter could only have denied the facts, or alleged that the witnesses, including observers outside the chaine, or circle, were all self-hypnotised, all uncier the influence of self-suggestion, and all honestly asserting the occurrence of events which did not occur. His essay touched but lightly on this particular marvel. He remarked that 'the turning of tables, and the supposed communications of spirits through their agency' are due 'to the mental state of the performers themselves'. Now M. de Gasparin, in his via media, repudiated 'spirits' energetically. Dr. Carpenter then explained witchcraft, and the vagaries of 'campmeetings' by the 'dominant idea'. But M. de Gasparin could reply that persons whose 'dominant idea' was incredulity attested many singular occurrences. At the end of his article, Dr. Carpenter decides that table-turners push unconsciously, as they assuredly do, but they cannot push when not in contact with the object. The doctor did not allege that tableturners are 'biologised' as he calls it, and under a glamour. But M. de Gasparin averred that no single example of trance, rigidity, loss of ordinary consciousness, or other morbid symptoms, had ever occurred in his experiments. There is thus, as it were, no common ground on which he and Dr. Carpenter can meet and fight. He dissected the doctor's rather inconsequent argument with a good deal of acuteness and wit.

M. de Gasparin then exhibited some of the 
besetting sins of all who indulge in argument. He accepted all his own private phenomena, but none of those, such as 'raps ' and so forth, for which other people were vouching. Things must occur as he had seen them, and not otherwise. What he had seen was a chaine of people surrounding a table, all in contact with the table, and with each other. The table had moved, and had answered questions by knocking the floor with its foot. It had also moved, when the hands were held close to it, but not in contact with it. Nothing beyond that was orthodor, as nothing beyond hypnotism and unconscious cerebration was orthodox with Dr. Carpenter. Moreover M. de Gasparin had his own physical explanation of the phenomena. There is, in man's constitution, a 'fluid' which can be concentrated by his will, and which then, given a table and a chainc, will produce M. de Gasparin's phenomena: but no more. He knows that 'fluids' are going out of fashion in science, and he is ready to call the 'fluid' the 'force' or 'agency,' or ' condition of matter' or what you please. 'Substances, forces, vibrations, let it be what you choose, as long as it is something.' The objection that the phenomena are 'of no use' was made, and is still very common, but, of course, is in no case scientifically valid. Electricity was 'of no use' once, and the most useless phenomenon is none the less worthy of examination.

M. de Gasparin now examines another class of objections. First, the phenomena were denied; next, they were said to be as old as history, and familiar to the Greeks. We elsewhere show that this is quite true, 
that the movement of objects without contact was as familiar to the Greeks as to the Peruvians, the Thibetans, the Eskimo, and in modern stories of haunted houses. But, as will presently appear, these ivilder facts would by no means coalesce with the hypothesis of M. de Gasparin. To his mind, tables turn, but they turn by virtue of the will of a 'circle,' consciously exerted, through the means of some physical force, fluid, or what not, produced by the imposition of hands. Now these processes do not characterise the phenomena among Greeks, Thibetans, Eskimo, Peruvians, in haunted houses, or in presence of Home and Eusapia Paladino,--granting the facts as alleged. In these instances, nobody is ' circling' round a chair, a bed, or what not, yet the chair or bed moves, as in the story of Monsieur S. at St. Maur (I706), and in countless other examples. All this would not, as we shall see, be convenient for the theory of M. de Gasparin.

His line of argument is that the Greek and Latin texts are misunderstood, but that, if the Greeks did turn tables, that is no proof that tables do not turn, but rather the reverse. A favourite text is taken from Ammianus Marcellinus, lib. xxix. ch. i. M. de Gasparin does not appear to have read the passage carefully. About 37I A.D. one Hilarius was tortured on a charge of magical operations against the Emperor Valens. He confessed. A little table, made of Delphic laurel, was produced in court. 'We made it,' he said, ' that confounded little table, under strange rites and imprecations, and we set it in movement, thus: it was placed in a room charged 
with perfumes, above a round plate fashioned of various metals. The edge of the plate was marked with the letters of the alphabet separated by certain spaces. A priest, linen clad, bowed himself over the table, balancing a ring tied to a thin thread. The ring, bounding from letter to letter, picks out letters forming hexameters, like those of Delphi.' This is confusing. Probably the movements of the table, communicated to the thread, caused the bounds of the ring, otherwise there was no use in the table moving. At all events the ring touched THEo (which is not a word that could begin a hexameter) when they asked who was to succeed Valens. Some one called out 'Theodore' and they pursued the experiment no farther. A number of Theodores and Theophiles were put to death, but when Theodosius was joined with Gratian in the Empire, the believers held that the table had been well inspired. Here there was no chaine, or circle, the table is not said to lever le pied legèrement, as the song advises, therefore M. de Gasparin rules the case out of court. The object, however, really was analogous to planchette, Ouija, and other modern modes of automatic divination. The experiment of Hilarius with the 'confounded little table' led to a massacre of Neoplatonists, martyrs of Psychical Research! In Hilarius's confession we omit a set of ritual invocations; as unessential as the mystic rites used by savages in making curari.

The spiritus percutiens, or 'rapping spirit'(?)conjured away by old Catholic formulæ at the benediction of churches, was brought forward by some of M. de 
Gasparin's critics. As his tables did not rap, he had nothing to do with the spiritus percutiens, who proves, however, that the Church was acquainted with raps, and explained them by the spiritualistic hypothesis. ${ }^{1}$

A text in Tertullian's Apologetic was also cited. Here tabula and capree, 'tables and she-goats,' are said to divine. What have she-goats to do in the matter? De Morgan wished to read tabulce et crepa, which he construes 'tables and raps,' but he only finds crepa in Festus, who says, that goats are called crepa, quod cruribus crepent, 'because they rattle with their legs'. De Morgan's guess is ingenious, but lacks confirmation. We are not, so far, aware of communication with spirits by raps before 856 A.D.

Finally, M. de Gasparin denies that his researches are 'superstitious'. Will can move my limbs, if it also moves my table, what is there superstitious in that? It is a new fact, that is all. 'Tout est si matériel, si physique dans les experiences des tables.' It was not so at Toulouse !

Meanwhile M. de Gasparin, firm in his 'Trewth,' -the need of a chaine of persons, the physical origin of the phenomena, the entire absence of spirits, was so unlucky, when he dealt with 'spirits,' as to drop into the very line of argument which he had been denouncing. 'Spirits' are 'superstitious,'well, his adversaries had found superstition in his own experiments and beliefs. To believe that spirits

1 A learned priest has kindly looked for the alleged spiritus percutiens in dedicatory and other ecclesiastical formulæ. He only finds it in benedictions of bridal chambers, and thinks it refers to the slaying spirit in the Book of Tobit. 
are engaged, is 'to reduce our relations with the invisible world to the grossest definition'. But why not, as we know nothing about our relations with the invisible world? The theology of the spirits is 'contrary to Scripture'; very well, your tales of tables moved without contact are contrary to science. 'No spiritualistic story has ever been told which is not to be classed among the phenomena of animal magnetism....' This, of course, is a mere example of a statement made without examination, a sin alleged by $M$. de Gasparin against his opponents. Vast numbers of such stories, not explicable by the now rejected theory of 'animal magnetism,' have certainly been told.

In another volume $M$. de Gasparin demolished the tales, but he was only at the beginning of his subject. The historical and anthropological evidence for the movement of objects without contact, not under his conditions, is very vast in bulk. The modern experiments are sometimes more scientific than his own, and the evidence for the most startling events of all kinds is quite as good as that on which he relies for his prodigies, themselves sufficiently startling. His hypothesis, at all events, of will directing a force or fluid, by no means explains phenomena quite as well provided with evidence as his own. So M. de Gasparin disposes of the rival miracles as the result of chance, imposture, or hallucination, the very weapons of his scientific adversaries. His own prodigies he has seen, and is satisfied. His opponents say: 'You cannot register your force sur l'inclinaison d'une aignille'. He 
could not, but Home could do so to the satisfaction of a scientific expert, and probably M. de Gasparin would have believed it, if he had seen it. M. de Gasparin is horrified at the idea of 'trespassing on the territory of acts beyond our power'. But, if it were possible to do the miracles of Home, it would be possible because it is not beyond our power. 'The spiritualistic opinion is opposed to the doctrine of the resurrection: it merely announces the immortality of the soul.' But that has nothing to do with the matter in hand.

The theology of spirits, of course, is neither here nor there. A 'spirit' will say anything or everything. But Mr. C. C. Massey when he saw a chair move at a word (and even without one), in the presence of such a double-dyed impostor as Slade, had as much right to believe his own eyes as M. de Gasparin, and what he saw does not square with M. de Gasparin's private 'Trewth'. The chair in Mr. Massey's experience, was 'unattached' to a piece of string; it fell, and, at request, jumped up again, and approached Mr. Massey, "just as if some one had picked it up in order to take a seat beside me'. ${ }^{1}$

Such were the idola specus, the private personal prepossessions of $\mathrm{M}$ de Gasparin, undeniably an honourable man. Now, in I877, his old adversary, Dr. Carpenter, C.B., M.D., LL.D., F.R.S., F.G.S., V.P.L.S., corresponding member of the Institute of France, tout ce qu'il $y$ a de plus officiel, de plus décoré, returned to the charge. He published a work on Mesmerism, Spiritualism, etc. ${ }^{2}$ Perhaps the unscientific reader supposes 
that Dr. Carpenter replied to the arguments of M. de Gasparin? This would have been sportsmanlike, but no, Dr. Carpenter firmly ignored them! He devoted three pages to table-turning (pp. 96, 97, 98). He exhibited Mr. Faraday's little machine for detecting muscular pressure, a machine which would also detect pressure which is not muscular. He explained answers given by tilts, answers not consciously known to the operators, as the results of unconscious cerebration. People may thus get answers which they do expect, or answers which they do not expect, as may happen. But not one word did Dr. Carpenter say to a popular audience at the London Institution about $\mathrm{M}$. de Gasparin's assertion, and the assertion of M. de Gasparin's witnesses, that motion had been observed without any contact at all. He might, if he pleased, have alleged that M. de Gasparin and the others fabled; or that they were self-hypnotised, or were cheated, but he absolutely ignored the evidence altogether. Now this behaviour, if scientific, was hardly quite sportsmanlike, to use a simple British phrase which does credit to our language and national character. Mr. Alfred Wallace stated a similar conclusion as to Dr. Carpenter's method of argument, in language of some strength. 'Dr. Carpenter,' he said, ' habitually gives only one side of the question, and completely ignores all facts which tell against his theory.' 1 Without going so far as Mr. Wallace, and alleging that what Dr. Carpenter dicl in the case of M. de Gasparin, he did 'habitually,' we may

Quoted by Dr. Carpenter, op. cit., p. vii. 
briefly examine some portions of his book which; perhaps, leave something to be desired. It is written with much acuteness, with considerable fairness, and is certainly calculated to convince any reader who has not been perplexed by circumstances on which Dr. Carpenter throws little light.

Our own chief perplexity is the continuity and uniformity of the historical and anthropological evidence for certain marvels. We have already shown the difficulty of attributing this harmony of evidence, first to savage modes of thought, and then to their survival and revival. The evidence, in full civilisation, ancient and modern, of educated and even sceptical witnesses to phenomena, which are usually grotesque, but are always the same everywhere, in every age and land, and the constant attend. ance of these phenomena on persons of a peculiar temperament, are our stumbling-blocks on the path to absolute negation. Epilepsy, convulsions, hysterical diseases are startling affairs, we admit. It was natural that savages and the ignorant should attribute them to diabolical possession, and then look out for, and invent, manifestations of the diabolical energy outside the body of the patient, say in movements of objects, knucks, and so forth. As in these maladies the patient may be subject to hallucinations, it was natural that savages or ignorant men, or polytheists, or ardent Catholics, or excitable Covenanters, should regard these hallucinations as 'lucid' or 'clairvoyant'. A tew lucky coincidences would establish this opinion among such observers as we have indicated, while failures of lucidity would not 
be counted. The professional epileptic medicineman, moreover, would strengthen his case by 'prophesying on velvet,' like Norna of the Fitful Head, on private and early information. Imposture would imitate the 'spiritual' feats of 'raps,' 'physical movements of objects,' and 'luminous forms'. All this would continue after savagery, after paganism, after 'Popery' among the peasants who were for so long, and in superstition are even now, a conservative class.

All that 'expectancy,' hysterics, 'the dominant idea' and rude hypnotism, 'the sleep of the shadow,' could do, would be done, as witch trials show. All these elements in folk-lore, magic and belief would endure, in the peasant class, under the veneer of civilisation. Now and again these elements of superstition would break through the veneer, would come to the surface among the educated classes, and would 'carry silly women captive,' and silly men. They, too, though born in the educated class, would attest impossible occurrences.

In all this, we might only see survival, wonderfully vivacious, and revival astonishingly close to the ancient savage lines.

We are unable to state the case for survival and revival more strenuously, and the hypothesis is most attractive. This hypothesis appears to be Dr. Carpenter's, though he does not, in the limits of popular lectures, unfold it at any length. After stating ( $p$. I) that a continuous belief in 'occult agencies' has existed, he adds:-

'While this very continuity is maintained by 
some to be an evidence of the real existence of such [occult] agencies, it will be my purpose to show you that it proves nothing more than the wide-spread diffusion, alike amongst minds of the highest and lowest culture, of certain tendencies to thought, which have either created ideal marvels possessing no foundation whatever in fact, or have, by exaggeration and distortion, invested with a preternatural character occurrences which are perfectly capable of a natural explanation'.

Here Dr. Carpenter does not attempt to show cause why the 'manifestations' are always the same, for example, why spirits rap in the Australian Bush, among blacks not infiuenced by modern spiritualism : why tables moved, untouched, in Thibet and India, long before 'table-turning' was heard of in modern Europe. We have filled up the lacuna in the doctor's argument, by suggesting that the phenomena (which are not such as a civilised taste would desire) were invented by savages, and handed on in an unbroken catena, a chain of tradition.

But, in following Dr. Carpenter, we are brought up short at one of our old obstacles, we trip on one of our old stumbling-blocks. Granting that an epileptic patient made strange bounds and springs, we can conceive savages going farther in fancy, and averring that he flew, or was levitated, or miraculously transported through space. Let this become matter of traditional belief, as a thing possible in epilepsy, i.e., in 'diabolical,' or 'angelical possession'. Add the honest but hallucinatory persuasion of the patient that he was so levitated, and let him be a 
person of honour and of sanctity, say St. Theresa, St. Francis, or St. Joseph of Cupertino. Granting the survival of a savage exaggeration, granting the hallucinated saint, we may, perhaps, explain the innumerable anecdotes about miraculous levitation of which a few are repeated in our paper on 'Comparative Psychical Research.' The witnesses in witch trials, and in ecclesiastical inquiries, and Lord Orrery, and Mr. Greatrakes, and the Cromwellian soldiery in Scotland, the Spanish in Peru, Cotton Mather in New England, saw what they expected to see, what tradition taught them to look for, in the case of a convulsionary, or a saint, or a catechumen. The consensus in illusion was wonderful, but let us grant, for the sake of argument, that it was possible. Let us add another example, from Cochin China.

The witness and narrator is Delacourt, a French missionary. The source is a letter of his of November 25, I738, to Winslow the anatomist, Membie de l'Academie des Sciences à Paris. It is printed in the Institutiones Theologica of Collet, who attests the probity of the missionary. ${ }^{1}$

In May or June, I733, Delacourt was asked to view a young native Christian, said by his friends to be 'possessed'.

'Rather increảulous,' as he says, Delacourt went to the lad, who had communicated, as he believed, unworthily, and was therefore a prey to religious excitement, which, as Bishop Callaway fourd among

1 Tom. ii. pp. 312, 435, edition of 1768 . 
his Zulu converts, and as Wodrow attests among 'savoury Christians,' begets precisely such hallucinations as annoyed the early hermits like St. Anthony. Delacourt addressed the youth in Latin: he replied, Ego nescio loqui Latine, a tag which he might easily have picked up, let us say. Delacourt led him into church, where the patient was violently convulsed. Delacourt then (remembering the example set by the Bishop of Tilopolis) ordered the demon in Latin, to carry the boy to the ceiling. 'His body became stiff, he was dragged from the middle of the church to a pillar, and there, his feet joined, his back fixed (collé) against the pillar, he was transported in the twinkling of an eye to the ceiling, like a weight rapidly drawn up, without any apparent action on his part. I kept him in the air for half an hour, and then bade him drop without hurting himself,' when he fell 'like a packet of dirty linen'. While he was up aloft, Delacourt preached at him in Latin, and he became, 'perhaps the best Christian in Cochin China'.

Dr. Carpenter's explanation must either be that Delacourt lied; or that a tradition, surviving from savagery, and enforced by the example of the Bishop of Tilopolis, made a missionary, un peu incrédule, as he says, believe that he saw, and watched for half an hour, a phenomenon which he never saw at all. But then Dr. Carpenter also dismisses, with none but the general theory already quoted, the experience of 'a nobleman of high scientific attainments,' who 'seriously assures us' that he saw Home 'sail in the air, by moonlight, out of one window and in at 
another, at the height of seventy feet from the ground '. ${ }^{1}$

Here is the stumbling-block. A nobleman of high scientific attainment, in company with another nobleman, and a captain in the army, all vouched for this performance of Home. Now could the savage tradition, which attributes flight to convulsive and entranced persons, exercise such an influence on these three educated modern witnesses; could an old piece of folk-lore, in company with 'expectancy,' so wildly delude them? Can 'high scientific attainments' leave their possessor with such humble powers of observation? But, to be sure, Dr. Carpenter does not tell his readers that there were three witnesses. Dr. Carpenter says that, if we believe Lord Crawford (and his friends), we can 'have no reason for refusing credit to the historical evidence of the demoniacal elevation of Simon Magus '. Let us point out that we have no contemporary evidence at all about Simon's feat, while for Home's, we have the evidence of three living and honourable men, whom Dr. Carpenter might have cross-examined. The doings of Home and of Simon were parallel, but nothing can be more different than the nature of the evidence for what they are said to

${ }^{1}$ In the Quarterly Review, vol. cxxxi. pp. 336-337, Dr. Carpenter criticises an account given by Lord Crawford of this performance. He asks for the evidence of the other witnesses. This was supplied. He detects a colloquial slovenliness in a phrase. This was cleared up. He complains that the light was moonlight. 'The moon was shining full into the room.' Surely the light was good enough to see whether a man did or did not go out of an open window. Had he been a burglar, the light would have been reckoned adequate. 
have done. This, perhaps, might have been patent to a man like Dr. Carpenter of 'early scientific training'. But he illustrated his own doctrine of 'the dominant idea'; he did not see that he was guilty of a fallacy, because his 'idea' dominated him. Stumbling into as deep a gulf, Dr. Carpenter put Lord Crawford's evidence (he omitted that of his friends) on a level with, or below, the depositions of witnesses as to 'the aerial transport of witches to attend their demoniacal festivities'. But who ever swore that he saw witches so transported? The evidence was not to witnessed facts, but only to a current belief, backed by confessions under torture. No testimony could be less on a par with that of a living ' nobleman of high scientific attainments,' to his own experience.

In three pages Dr. Carpenter has shown that ' early scientific training' in physiology and pathology, does not necessarily enable its possessor to state a case fully. Nor does it prompt him to discriminate between rumours coming, a hundred and fifty years after the date of the alleged occurrences, from a remote, credulous, and unscientific age : and the statements of witnesses all living, all honourable, and, in one case, of 'high scientific attainments'. 1

It is this solemn belief in his own infallibility as a judge of evidence combined with his almost incredible ignorance of what evidence is, that makes Dr. Carpenter such an amusing controversialist.

If any piece of fact is to be proved, it is plain that

${ }^{1}$ Lord Crawford's evidence is in the Report of the Dialectical Society, p. $21_{4}$. 
the concurrent testimony of three living and honourable men is worth more than a bit of gossip, which, after filtering through a century or two, is reported by an early Christian Father. In matters wholly marvellous, like Home's flight in the air, the evidence of three living and honourable men need not, of course, convince us of the fact. But this evidence is in itself a fact to be considered- "Why do these gentlemen tell this tale?' we ask; but Dr. Carpenter puts the testimony on the level of patristic tattle many centuries old, written down, on no authority, long after the event. Yet the worthy doctor calmly talks about 'want of scientific culture preventing people from appreciating the force of scien. tific reasoning,' and that after giving such examples of 'scientific reasoning' as we have examined. ${ }^{1}$ It is in this way that Science makes herself disliked. By aid of ordinary intelligence, and of an ordinary classical education, every on $\epsilon$ (however uncultivated in 'science') can satisfy $h$ nself that Dr. Carpenter argued at random. Yet $v$ ? do not assert that "early scientific training' prevents reople from understanding the nature of evidence. Dr. Carpenter had the training, but he was impetuous, and under a dominant idea, so he blundered along.

Dr. Carpenter frequently invokes for the explanation of marvels, a cause which is vera causa, expectancy. :The expectation of a certain result is often enough to produce it' (p. I2). 'This he proves by cases of hypnotised patients who did, or suffered, what they

${ }^{1}$ Quarterly Revicw, vol. cxxxi. p. 303. 
expected to be ordered to suffer or do, though no such order was really given to them. Again (p. 40) he urges that imaginative people, who sit for a couple of hours, 'especially if in the dark,' believing or hoping to see a human body, or a table, rise in the air, probably 'pass into a state which is neither sleeping nor waking, but between the two, in which they see, hear, or feel by touch, anything they have been led to expect will present itself'.

This is, indeed, highly probable. But we must suppose that all present fall into this ambiguous state, described of old by Porphyry. One waking spectator who sees nothing would make the statements of the others even more worthless than usual. And it is certain that it is not even pretended that all, always, see the same phenomena.

'One saw an arm, and one a hand, and one the waving of a gown,' in that séance at Branxholme, where only IVilliam of Deloraine beheld all,

And knew, but how it mattered not,

It was the wizard, Michael Scott. ${ }^{1}$

Granting the ambiguous state, granting darkness, and expectancy, anything may seem to happen. But Dr. Carpenter wholly omits such cases as that of Mr. Hamilton Aïdé, and of M. Alphonse Karr. Both were absolutely sceptical. Both disliked Home very much, and thought him an underbred Yankee

${ }^{1}$ Observe the caution of the Mosstrooper, even in that agitating moment! How good it is, and how wonderfully Sir Walter forecasts a séance. 
quack and charlatan. Both were in the 'expectancy' of seeing no marvels, were under 'the dominant idea' that nothing unusual would occur. Both, in a brilliantly lighted room of a villa near Nice, saw a chair make a rush from the wall into the middle of the room, and saw a very large and heavy table, untouched, rise majestically in the air. M. Karr at once got under the table, and hunted, vainly, for mechanical appliances. Then he and Mr. Aïdé went home, disconcerted, and in very bad humour. How do 'expectancy' and the 'dominant idea' explain this experience, which Mr. Aïé has published in the Nineteenth Century? The expectancy and dominant ideas of these gentlemen should have made them see the table and chair sit tight, while believers observed them in active motion. Again, how could Mr. Crookes's lack of ' a special training in the bodily and mental constitution, abnormal as well as normal,' of 'mediums,' affect his power of observing whether a plank of wood did, or did not, move to a certain extent untouched, or slightly touched, and whether the difference of position was, or was not, registered mechanically? (p. 70). It was a pure matter of skilled and trained observation in mechanics. Dr. Huggins was also present at this experiment in a mode of motion. Him Dr. Carpenter gracefully discredited as an 'amateur,' without 'a broad basis of general scientific culture'. He had devoted himself 'to a branch of research which tasks the keenest powers of observation'. Now it was precisely powers of observation that were required. 'There are moral sources of error,' of which a mere observer like Dr. 
Huggins would be unaware. And 'one of the most potent of these is a proclivity to believe in the reality of spiritual communications,' particularly dangerous in a case where 'spiritual communications,' were not in question! The question was, did an indicator move, or not, under a certain amount of pressure? Indiscreetly enough, to be sure, the pressure was attributed to 'psychic force,' and perhaps that was what Dr. Carpenter had in his mind, when he warned Dr. Huggins against 'the proclivity to believe in the reality of spiritual communications'.

About a wilderness of other phenomena, attested by scores of sane people, from Lord Crawford to Mr. S. C. Hall, Dr. Carpenter 'left himself no time to speak' (p. I05). This was convenient, but the lack of time prevented Dr. Carpenter from removing our stumbling-block, the one obstacle which keeps us from adopting, with no shadow of doubt, the theory that explains all the marvels by the survival and revival of savage delusions. Dr. Carpenter's hypothesis of expectancy, of a dominant idea, acting on believers, in an ambiguous state, and in the dark, can do much, but it cannot account for the experience of wide-awake sceptics, under the opposite dominant idea, in a brilliant light.

Dr. Carpenter exposed and exploded a quantity of mesmeric spiritualistic myths narrated by Dr. Gregory, by Miss Martineau, and by less respectable if equally gullible authorities. But, speaking merely as perplexed and unconvinced students oí argument and evidence, we cannot say that he removed the difficulties which have been illustrated and described. 
'Table-turning, after what is called a 'boom' in I853-60, is now an abandoned amusement. It is deserted, like croquet, and it is even less to be regretted. But its existence enabled disputants to illustrate the ordinary processes of reasoning; each making assertions up to the limit of his personal experience; each attacking, as 'superstitious,' all who had seen, or fancied they had seen, more than himself, and each tighting gallantly for his own explanatory hypothesis, which never did explain any phenomena beyond those attested by his own senses. The others were declared not to exist, or to be the result of imposture and mal-observation,-and perhaps they were.

The truly diverting thing is that Home did not believe in the other 'mediums,' nor in anything in the way of a marvel (such as matter passing through matter) which he had not seen with his own eyes. Whether Home's incredulity should be reckoned as a proof of his belief in his own powers, might be argued either way. 


\section{THE GHOST THEORY OF THE ORIGIN OF RELIGION.}

Evolutionary Theory of the Origin of Religion. Facts misunderstood suggest ghosts, which develop into gods. This process lies hehind history and experience. Difficulties of the Theory. The Theory of Lucretius. Objections. Mr. Tylor's Theory. The question of abnormal facts not discussed by Mr. 7ylor. Possibility that such 'psychical' facts are real, and are elements in development of savage religion. The evidence for psychical phenomena compared with that which, in other matters, satisfies anthropologists. Examples. Conclusion.

Among the many hypotheses as to the origin of religion, that which we may call the evolutionary, or anthropological, is most congenial to modern habits of thought. The old belief in a sudden, miraculous revelation is commonly rejected, though, in one sense, religion was none the less ' revealed,' even if man was obliged to work his way to the conception of deity by degrees. To attain that conception was the necessary result of man's refiection on the sum of his relations to the universe. The attainment, however, of the monotheistic idea is not now generally regarded as immediate and instinctive. A slow advance, a prolonged evolution was required, whether we accept Mr. Max Muller's theory of 'the sense of the Infinite,' or 
whether we prefer the anthropological hypothesis. The latter scheme, with various modifications, is the scheme of Epicurus, Lucretius, Hume, Mr. Tylor, and Mr. Herbert Spencer. Man half consciously transferred his implicit sense that he was a living and rational being to nature in general, and recognised that earth, sky, wind, clouds, trees, the lower animals, and so on, were persons like himself, persons perhaps more powerful and awful than himself. This transference of personality can scarcely be called the result of a conscious process of reasoning. Man might recognise personality everywhere, without much more thought or argument than a kitten exerts when it takes a cork or a ball for a living playmate. But consciousness must have reached a more explicit stage, when man began to ask himself what a person is, what life is, and when he arrived at the conclusion that life is a spirit. To advance from that conclusion; to explain all life as the manifestation of indwelling spirits; then to withdraw the conception of life and personality from inanimate things, to select from among spirits One more powerful than the rest, to recognise that One as disembodied, as superior, then as supreme, then as unique, and so to attain the monotheistic conception, has been, according to the evolutionary hypothesis, the tendency of human thought.

Unluckily we cannot study the process in its course of action. Perhaps there is no savage race so lowly endowed, that it does not possess, in addition to a world of 'spirits,' something that answers to the conception of God. Whether that is so, or not, is a question of evidence. We have often been told that 
this or the other people 'has no religious ideas at all'. But later we hear that they do possess a belief in spirits, and very often better information proves that, in one stage or other of advance or degradation, the theistic conception of a Maker and Judge of the world is also present. Meanwhile even civilised and monotheistic peoples also admit the existence of a world of spirits of the dead, of 'demons' (as in Platonism), of saints (as in Catholicism), of devils, of angels, or of subordinate deities. Thus the elements of religion are universally distributed in all degrees of culture, though one element is more conspicuous in one place or mood, another more conspicuous in another. In one mood the savage, or the civilised man, may be called monotheistic, in another mood atheistic, in a third, practically polytheistic. Only a few men anywhere, and they only when consciously engaged in speculation, assume a really definite and exclusive mental attitude on the subject. The orthodox monotheistic Mussulman has his afreets, and djinns; the Jew, or the Christian, has his angels, the Catholic has his saints; the Platonist has his demons; Superstition has its ghosts. The question is whether all these spiritual beings are only ghosts raised to higher powers: or (in the case of deity), to the highest conceivable power, while, even when this last process has been accomplished, we ask whether other ghosts, on lower grades, continue to be recognised. Meanwhile the whole anthropological hypothesis, whether valid or invalid, lies behind history, behind the experience of even the most backward races at present extant. If it be urged, as by Hume, 
that the conception of a supreme deity is only a reflection of kingship in human society, we must observe that some monarchical races, like the Aztecs, seem to have possessed no recognised monarchical Zeus; while something very like the monotheistic conception is found among races so remote from the monarchical state of society as to have no obvious distinctions of rank, like the Australian blacks. Moreover the evidence, on such difficult points, is obscure, and fluctuating, and capable of various interpretation. Even among the most backward peoples, the traceable shadow of a munotheistic idea often seems to bear marks of degradation and disuse, rather than of nascent development. There is a God, but $\mathrm{He}$ is neglected, and tribal spirits receive prayer and sacrifice. Just as in art there is a point where we find it difficult to decide whether an object is decadent, or archaic, so it is in the study of religious conceptions.

These are a few among the inevitable difficulties and obscurities which haunt the anthropological or evolutionary theory of the origin of religion. Other difficulties meet us at the very beginning. The theory regards gods as merely ghosts or spirits, raised to a higher, or to the highest power. Mankind, according to the system, was inevitably led, by the action of reason upon apparent facts, to endow all things, from humanity itself to earth, sky, rain, sea, fire, with conscious personality, life, spirit; and these attributes were as gradually withdrawn again, under stress of better knowledge, till only man was left with a soul, and only the universe was left with a 
God. The last scientific step, then, it may be inferred, is to deprive the universe of a God, and mankind of souls.

This step may be naturally taken by those who conceive that the whole process of ghost and godmaking is based on a mere set of natural and inevitable fallacies, and who decline to recognise that these progressive fallacies (if fallacies they are) may be steps on a divinely appointed road towards truth; that $\mathrm{He}$ led us by a way that we knew not, and a path we did not understand. Yet, of course, it is plain that a conclusion may be correct, although it was reached by erroneous processes. All scientific verities have been attained in this manner, by a gradual modification and improvement of inadequate working hypotheses, by the slow substitution of correctness for error. Thus monotheism and the doctrine of the soul may be in no worse case than the Copernican theory, or the theory of the circulation of the blood, or the Darwinian theory; itself the successor of innumerable savage guesses, conjectures of Empedocles, ideas of Cuvier, of the elder Darwin, of Lamarck, and of Chambers.

At present, of course, the theistic hypothesis, and the hypothesis of a soul, do not admit of scientific verification. The difficulty is to demonstrate that 'mind' may exist, and work, apart from 'matter'. But it may conceivably become verifiable that the relations of 'mind' and 'matter' are, at all events, less obviously and immediately interdependent, that will and judgment are less closely and exclusively attached to physical organisms 
than modern science has believed. Now, according to the anthropological theory of the origin of religion, it was precisely from the opposite of the scientific belief,-it was from the belief that consciousness and will may be exerted apart from, at a distance from, the physical organism,- - that the savage fallacies began, which ended, ex hypothesi, in monotheism, and in the doctrine of the soul. The savage, it is said, started from normal facts, which he misinterpreted. But suppose he started, not from normal facts alone, but also from abnormal facts,--from facts which science does not yet recognise at all,-then it is possible that the conclusions of the savage, though far too sweeping, and in parts undeniably erroneous, are yet, to a certain extent, not mistaken. He may have had 'a sane spot in his mind,' and a sane impulse may have led him into the right direction. Man may have faculties which savages recognise, and which physical science does not recognise. Man may be surrounded by agencies which savages exaggerate, and which science disregarảs altogether, and these faculties and agencies may point to an element of truth which is often cast aside as a survival of superstition, as the 'after-image' of an illusion.

The lowest known stage, and, according to the evolutionary hypothesis, the earliest stage in religion, is the belief in the ghosts of the dead, and in no other spiritual entities. Whether this belief anywhere exists alone, and untempered by higher creeds, is another question. These ghosts are fed, propitiated, receive worship, and, to put it briefly, the fittest ghosts survive, and become gods. Meanwhile the 
conception of ghosts of the dead is more or less consciously extended, so that spirits who never were incarnate as men become credible beings. They may inform inanimate objects, trees, rivers, fire, clouds, earth, sky, the great natural departments, and thence polytheism results. There are political processes, the consolidation of a state, for example, which help to blend these gods of various different origins into a divine consistory. One of these gods, it may be of sky, or air: becomes king, and reflection may gradually come to recognise him not only as supreme, but as, theoretically, unique, and thus Zeus, from a very limited monarchy, may rise to solitary all-fatherhood. Yet Zeus may, originally, have been only the ghost of a dead medicine-man who was called 'Sky,' or he may have been the departmental spirit who presided over the sky, or he may have been sky conceived of as a personality, or these different elements may have been mingled in $Z$ eus. But the whole conception of spirit, in any case, was derived, it is argued, from the conception of ghosts, and that conception may be traced to erroneous savage interpretations of natural and normal facts.

If all this be valid, the idea of God is derived from a savage fallacy, though, of course, it does not follow that an idea is erroneous, because it was attained by mistaken processes and from false premises. That, however, is the inference which many minds are inclined to draw from the evolutionary hypothesis. But if the facts on which the savage reasoned are, some of them, rare, abnormal, and not scientifically accepted; if, in short, they are facts demonstrative 
of unrecognised human faculties, if these faculties raise a presumption that will, mind, and organism are less closely interdependent than science supposes, then the savage reasoning may contain an important element of rejected truth. It may even seem, at least, conceivable that certain factors in the conception of 'spirit' were not necessarily evolved as the anthropological hypothesis conceives them to have been.

Science had scarcely begun her secular conflict with religion, when she discovered that the battle must be fought on haunted ground, on the field of the ghosts of the dead. 'There are no gods, or only dei otiosi, careless, indolent deities. There is nothing conscious that survives death, no soul that can exist apart from the fleshly body.' Such were the doctrines of Epicurus and Lucretius, but to these human nature opposed 'facts'; we see, people said, men long dead in our dreams, or even when awake: the Homeric Achilles, beholding Patroclus in a dream, instantly infers that there verily is a shadow, an eidolon, a shadowy consciousness, shadowy presence, which outlasts the death of the body. To this Epicurus and Lucretius reply, that the belief is caused by fallacious inferences from facts, these facts, appearances beheld in sleep or vision, these spectral faces of the long dead, are caused by 'films peeled off from the surface of objects, which fly to and fro through the air, and do likewise frighten our minds when they present themselves to us awake as well as in sleep, what time we behold strange shapes, and "idols" of the lightbereaved,' Lucretius expressly advances this doctrine 
GHOST THEORY OF THE ORIGIN OF RELIGION. 34I

of 'films' (an application of the Democritean theory of perception), 'that we may not believe that souls break loose from Acheron, or that shades fly about among the living, or that any part of us is left behind after death '. ${ }^{1}$ Believers in ghosts must have replied that they do not see, in sleep or awake, 'films' representing a mouldering corpse, as they ought to do on the Lucretian hypothesis, but the image, or idolon of a living face. Plutarch says that if philosophers may laugh, these long enduring 'films,' from a body perhaps many ages deep in dust, are laughable.' However Lucretius is so wedded to his 'films' that he explains a purely fanciful being, like a centaur, by a fortuitous combination of the film of a man with the film of a horse. A 'ghost' then, is, to the mind of Lucretius, merely a casual persistent film of a dead man, composed of atoms very light which can fly at inconceivable speed, and are not arrested by material obstacles. By parity of reasoning no doubt, if Pythagoras is seen at the same moment in Thurii and Metapontum, only a film of him is beheld at one of these two places. The Democritean theory of ordinary perception thus becomes the Lucretian theory of dreams and ghosts. Not that Lucretius denies the existence of a rational soul, in living men, ${ }^{3}$ a portion of it may even leave the body during sleep, and only a spark may be left in the embers of the physical organism. If even that spark

${ }^{1}$ Lucretius, iv. 26-75, Munro's translation.

${ }^{2}$ Def. Orac., I9. $\quad 3$ Ibid., iv. 193. 
withdraws, death follows, and the soul, no longer warmly housed in the body, ceases to exist. For the 'film' (ghost) is not the soul, and the soul is not the film, whereas savage philosophy identifies the soul with the ghost. Even Lucretius retains the savage conception of the soul as a thing of rarer matter, a thing partly separable from the body, but that thing is resolved for ever into its elements on the death of the body. His imaginary 'film,' on the other hand, may apparently endure for ages.

The Lucretian theory had, for Lucretius, the advantages of being physical, and of dealing a blow at the hated doctrine of a future life. For the public it had the disadvantages of being incapable of proof, of not explaining the facts, as conceived to exist, and of being highly ridiculous, as Plutarch observed. Much later philosophers explained all apparitions as impressions of sense, recorded on the brain, and so actively revived that they seemed to have an objective existence. One or two stock cases (Nicolai's, and Mrs. A.'s), in which people in a morbid condition, saw hallucinations which they knew to be hallucinations, did, and do, a great deal of duty. Mr. Sully has them, as Hibbert and Brewster have them, engaged as protagonists. Collective hallucinations, and the hallucinations of the sane which coincide with the death, or other crisis in the experience of the person who seemed to be seen, were set down to imagination, ' expectant attention,' imposture, mistaken identity, and so forth.

Without dwelling on the causes, physical or psychological, which have been said by Frazer of 
GHOST THEORY OF THE ORIGIN OF RELIGION. 343

Tiree (I707), Ferrier, Hibbert, Scott, and others, to account for the hallucinations of the sane, for 'ghosts,' Mr. Tylor has ably erected his theory of animism, or the belief in spirits. Thinking savages, he says, 'were deeply impressed by two groups of biological phenomena,' by the facts of living, dying, sleep, trance, waking and disease. They asked: "What is the difference between a living body and a dead one?' They wanted to know the causes of sleep, trance and death. They were also concerned to explain the appearances of dead or absent human beings in dreams and waking visions. Now it was plain that 'life' could go away, as it does in death, or seems to do in dreamless sleep. Again, a phantasm of a living man can go away and appear to waking or sleeping people at a distance. The conclusion was reached by savages that the phantasm which thus appears is identical with the life which 'goes away' in sleep or trance. Sometimes it returns, when the man wakes, or escapes from his trance. Sometimes it stays away, he dies, his body corrupts, but the phantasm endures, and is occasionally seen in sleeping or waking vision. The general result of savage thought is that man's life must be conceived as a personal and rational entity, called his 'soul,' while it remains in his body, his 'wraith,' when it is beheld at a distance during his life, his 'ghost,' when it is observed after his death. Many circumstances confirmed or illustrated this savage hypothesis. Breath remains with the body during life, deserts it at death. Hence the words spiritus, 'spirit,' $\pi \nu \epsilon \hat{v} \mu a$, anima, and, when the separable nature of the shadow 
is noticed, hence come 'shade,' 'umbra,' $\sigma \kappa \iota$, with analogues in many languages. 'The hypothesis was also strengthened, by the great difficulty which savages feel in discriminating between what occurs in dreams, and what occurs to men awake. Many civilised persons feel the same difficulty with regard to hallucinations beheld by them when in bed, asleep or awake they know not, on the dim border of existence. Reflection on all these experiences ended in the belief in spirits, in souls of the living, in wraiths of the living, in ghosts of the dead, and, finally, in God.

This theory is most cogently presented by $\mathrm{Mr}$. Tylor, and is confirmed by examples chosen from his wide range of reading. But, among these normal and natural facts, as of sleep, dream, breath, life, dying, Mr. Tylor includes (not as facts, but as examples of applied animistic theory) cases of 'clairvoyance,' apparitions of the dying seen by the living at a distance, second sight, ghostly disturbances of knocking and rapping, movements of objects, and so forth. It is not a question for Mr. Tylor whether clairvoyance ever occurs: whether 'death-bed wraiths' have been seen to an extent not explicable by the laws of chance, whether disturbances and movements of objects not to be accounted for by human agency are matters of universal and often well-attested report. Into the question of fact, Mr. Tylor explicitly declines to enter; these things only concern him because they have been commonly explained by the 'animistic hypothesis,' that is, by the fancied action of spirits. The animistic hypothesis, 
again, is the result, naturally fallacious, of savage man's reasonings on life, death, sleep, dreams, trance, breath, shadow and the other kindred biological phenomena. Thus clairvoyance (on the animistic hypothesis) is the flight of the conscious 'spirit' of a living man across space or time; the 'deathbed wraith' is the visible apparition of the newlyemancipated 'spirit,' and 'spirits' cause the unexplained disturbances and movements of objects. In fact it is certain that the animistic hypothesis (though a mere fallacy) does colligate a great number of facts very neatly, and has persisted from times of low savagery to the present age of reason. So here is a case of the savage origin and persistent 'survival' of a hypothesis,- - the most potent hypothesis in the history of humanity.

From Mr. Tylor's point of view, his concern with the subject ceases here, it is not his business to ascertain whether the abnormal facts are facts or fancies. Yet, to other students, this question is very important. First, if clairvoyance, wraiths, and the other alleged phenomena, really do occur, or have occurred, then savage man had much better grounds for the animistic hypothesis than if no such phenomena ever existed. For instance, if a medicine-man not only went into trances, but brought back from these expeditions knowledge otherwise inaccessible, then there were better grounds for believing in a consciousness exerted apart from the body than if there were no evidence but that of non-veridical dreams. If merely the dream-coincidences which the laws of chance permit were observed, the belief 
in the soul's dream-flight would win less favourable and general acceptance than it would if clairvoyance, 'the sleep of the shadow,' were a real if rare experience. The very name given by the Eskimos to the hypnotic state, 'the sleep of the shadow,' proves that savages do make distinctions between normal and abnormal conditions of slumber.

In the same way a few genuine wraiths, or ghosts, or 'veridical hallucinations,' would be enough to start the animistic hypothesis, or to confirm it notably, if it was already started. As to disturbances and movements of objects unexplained, these, in his own experience, suggested, even to De Morgan, the hypothesis of a conscious, active, and purposeful will, not that of any human being present. Now such a will is hardly to be defined otherwise than as 'spiritual'. This order of phenomena, like those of clairvoyance and wraiths, might either give rise to the savage animistic hypothesis, or, at least, might confirm it greatly. In fact, if the sets of abnormal phenomena existed, or were held to exist, savage man scarcely needed the normal phenomena for the basis of his spiritual belief. The normal phenomena lent him such terms as 'spirit,' 'shadow,' Dut much of his theory might have been built on the foundation of the abnormal phenomena alone. A "veridical hallucination' of the dying would give him a 'wraith'; a recognised hallucination of the dead would give him a ghost: the often reported and unexplained movements and disturbances would give him a vui, 'house spirit,' 'brownie,' 'domovoy,' follet, lar, or lutin. Or these occurrences might suggest to the 
thinking savage that some discontented influence survived from the recently dead.

Four thousand years have passed since houses were haunted in Egypt, and have left some sane, educated, and methodical men to meet the same annoyances as the ancient Egyptians did, by the same measures. We do not pretend to discover, without examination, the causes of the sounds and sights which baffle trained and not superstitious investigators. But we do say that similar occurrences, in a kraal or an Eskimo hut, in a wigwam, in a cave, or under a gunyeh, would greatly confirm the animistic hypothesis of savages. The theory of imposture (in some cases) does undeniably break down, for the people who hold it cannot even suggest a modus operandi within the reach of the human beings concerned, as in the case of the Wesleys. The theory of contagious hallucination of all the senses is the property of Coleridge alone. The hypothesis of a nervous force which sets up centres of conscious action is confined to Hartmann, and to certain Highland philosophers, cavalierly dismissed by the Rev. Robert Kirk as 'men illiterate'. Instead of making these guesses, the savage thinkers merely applied the animistic hypothesis, which they had found to work very well already, and, as De Morgan says, to colligate the phenomena. better than any other theory. We cannot easily conceive men who know neither sleep nor dreams, but if the normal phenomena of sleep and dreams had not existed, the abnormal phenomena already described, if they occurred, as they are universally 
said to do, could have given rise, when speculated upon, to the belief in spirits.

But, it may reasonably be urged, 'the natural familiar facts of life, death, sleep, waking, dreams, breath, and shadows, are all verse causa, do undeniably exist, and, without the aid of any of your abnormal facts, afford basis enough for the animistic hypothesis. Moreover, after countless thousands of years, during which superstition has muttered about your abnormal facts, official science still declines to hear a word on the topic of clairvoyance or telepathy. You don't find the Royal Society investigating second sight, or attending to legends about tables which rebel against the law of gravitation.'

These are cogent remarks. Normal facts, perhaps, may have suggested the belief in spirits, the animistic hypothesis. But we do not find the hypothesis (among the backward races) where abnormal facts are not alleged to be matters of comparatively frequent experience. Consequently we do not know that the normal facts, alone, suggested the existence of spirits to early thinkers, we can only make the statement on a priori grounds. Like George Eliot's rural sage we 'think it sounds a deal likelier'. But that, after all, though a taking, is not a powerful and conclusive syllogism.

Again, we certainly do not expect to see the Royal Society inquiring into second sight, or clairvoyance, or thought transference. When the Royal Society was first founded several of its members, Pepys, F.R.S.; Mr. Robert Boyle, F.R.S.; the Rev. Joseph Glanvill, F.R.S., went into these things a 
good deal. But, in spite of their title, they were only amateurs. They had no professional dignity to keep up. They were well aware that they, unlike the late Mr. Faraday, did not know, by inspiration or by common-sense, the limits of the possible. They tried all things, it was such a superstitious age. Now men of science, or the majority of them, for there are some exceptions, know what is, and what is not possible. They know that germs of life may possibly come down on meteorites from somewhere else, and they produced an argument for the existence of a bathybius. But they also know that a man is not a bird to be in two places at once, like Pythagoras, and that nobody can see through a stone wall. These, and similar allegations, they reckon impossible, and, if the facts happen, so much the worse for the facts. They can only be due to imposture or mal-observation, and there is an end of the matter. This is the view of official science. Unluckily, not many years ago, official science was equally certain that the ordinary phenomena of hypnotism were based on imposture and on malobservation. These phenomena, too, were tabooed. But so many people could testify to them, and they could be so easily explained by the suggestive force of suggestion, that they were reluctantly admitted within the sacred citadel. Many people, sane, not superstitious, healthy, and even renowned as scientific specialists, attest the existence of the still rarer phenomena which are said, in certain cases, to accompany the now more familiar incidents of hypnotism. But these phenomena have never yet been 
explained by any theory which science recognises, as she does recognise that suggestion is suggestive. Therefore these rarer phenomena manifestly do not exist, and cannot be the subject of legitimate inquiry.

These are unanswerable observations, and it is only the antiquarian who can venture, in his humble way, to reply to them. His answer has a certain force ad hominem, that is, as addressed to anthropologists. They, too, have but recently been admitted within the scientific fold; time was when their facts were regarded as mere travellers' tales. Mr. Max Müller is now, perhaps, almost alone in his very low estimate of anthropological evidence, and, possibly, even that sturdy champion is beginning to yield ground. Defending the validity of the testimony on which anthropologists reason about the evolution of religion, custom, manners, mythology, law, Mr. Tylor writes:-

'It is a matter worthy of consideration that the accounts of similar phenomena of culture, recurring in different parts of the world, actually supply incidental proof of their own authenticity. . . . The test of recurrence comes in. . . . The possibility of intentional or unintentional mystification is often barred by such a state of things as that a similar statement is made in two remote lands by two witnesses, of whom A lived a century before $B$, and $B$ appears never to have heard of A.'

If for 'similar phenomena of culture' here, we substitute 'similar abnormal phenomena' (such as clairvoyance, wraiths, unexplained disturbances), Mr. Tylor's argument in favour of his evidence for institutions applies equally well to our evidence for 
mysterious 'facts'. 'How distant are the countries,' he goes on, 'how wide apart are the dates, how different the creeds and characters in the catalogue of the facts of civilisation, needs no further showing' - to the student of Mr. Tylor's erudite footnotes. In place of 'facts of civilisation' read 'psychical phenomena,' and Mr. Tylor's argument applies to the evidence for these rejected and scouted beliefs.

The countries from which ' ghosts' and 'wraiths' and 'clairvoyance' are reported are 'distant'; the dates are 'wide apart'; the 'creeds and characters of the observers' are 'different'; yet the evidence is as uniform, and as recurrent, as it is in the case of institutions, manners, customs. Indeed the evidence for the rejected and abnormal phenomena is even more 'recurrent' than the evidence for customs and institutions. Polyandry, totemism, human sacrifice, the taboo, are only reported as existing in remote and semi-civilised countries. Clairvoyance, wraiths, ghosts, mysterious disturbances and movements of objects are reported as existing, not only in distant ages, but to-day; not only among savages or barbarians, but in London, Paris, Milan. No ages can be more wide apart, few countries much more distant, than ancient Egypt and modern England : no characters look more different than that of an old scribe under Pharaoh, and that of a distinguished soldier under Queen Victoria. Yet the scribe of Khemi and General Campbell suffer from the same inexplicable annoyance, attribute it to the same very abnormal agency, and attempt (not unsuccessfully) to communicate with that agency, in precisely the same way. 
This, though a striking, is an isolated and per. haps a casual example of recurrence and uniformity in evidence. Mr. Tylor's Primitive Culture is itself a store-house of other examples, to which more may easily be added. For example, there is the old and savage belief in a 'sending'. The medicine-man, or medium, or witch, can despatch a conscious, visible, and intelligent agent, non-normal, to do his bidding at a distance. This belief is often illustrated in the Scandinavian sagas. Rink testifies to it among the Eskimo, Grinnell among the Pawnees: Porphyry alleges that by some such 'telepathic impact' Plotinus, from a distance, made a hostile magician named Alexander 'double up like an empty bag,' and saw and reported this agreeable circumstance. ${ }^{1}$ Hardly any abnormal phenomenon or faculty sounds less plausible, and the 'spectral evidence' for the presence of a witch's 'sending,' when the poor woman could establish an alibi for her visible self, appeared dubious even to Cotton Mather. But, in their Phantasms of the Living, Messrs. Gurney and Myers give cases in which a visible 'sending' was intentionally emitted by Baron Schrenck Notzing, by a stock-broker, by a young student of engineering, and by a French hospital nurse, to take no other instances. The person visited frequently by the 'sendings' in the last cases was a French physician engaged in the hospital, who reports and attests the facts. All the cases are given at first hand on the testimony of the senders and of the recipients of the sendings. Bulwer Lytton was familiar with the 
belief, and uses the 'shining shadow' in $A$ Strange Story. Now here is uniform recurrent evidence from widely severed ages, from distant countries, from the Polar North, the American prairie, Neoplatonic Egypt and Greece, England and New England of the seventeenth century, and England and Germany of to-day. The 'creeds and characters of the observers' are as 'different' as Neoplatonism, Shamanism, Christianity of divers sects, and probably Agnosticism or indifference. All these conditions of unvarying testimony constitute good evidence for institutions and customs; anthropologists, who eagerly accept such testimony in their own studies, may decide as to whether they deserve total neglect when adduced in another field of anthropology.

Turning from 'sendings,' or 'telepathy' voluntarily brought to bear on one living person by another, we might examine 'death-bed wraiths,' or the telepathic impact-' if that hypothesis of theirs be sound '-produced by a dying on a living human being. A savage example, in which a Fuegian native on board an English ship saw his father, who was expiring in Tierra del Fuego, has the respectable authority of $\mathrm{Mr}$. Darwin's Cruise of the Beagle. Instances, on the other hand, in which Australian blacks, or Fijians, see the phantasms of dead kinsmen warning them of their decease (which follows punctually) may be found in Messrs. Fison and Howitt's Kamilaroi and Kumai.

From New Zealand Mr. Tylor cites, with his authorities, the following example ${ }^{1}$ 'A party of Maoris (one of whom told the story) were seated

${ }^{1}$ Primitive Culture, i. 404 . 
round a fire in the open air, when there appeared, seen only by two of them, the figure of a relative left ill at home. They exclaimed, the figure vanished, and, on the return of the party, it appeared that the sick man had died about the time of the vision.' A traveller in New Zealand illustrates the native belief in the death-wraith by an amusing anecdote. A Rangatira, or native gentleman, had gone on the war-path. One day he walked into his wife's house, but after a few moments could not be found. The military expedition did not return, so the lady, taking it for granted that her husband, the owner of the wraith, was dead, married an admirer. The hallucination, however, was not 'veridical'; the warrior came home, but he admitted that he had no remedy and no feud against his successor. The owner of a wraith which has been seen may be assumed to be dead. Such is Maori belief. The modern civilised examples of death-wraiths, attested and recorded in Phantasms of the Living, are numerous; but statistics prove that a lady who marries again on the strength of a wraith may commit an error of judgment, and become liable to the penalty of bigamy. The Maoris, no statisticians, take a more liberal and tolerant view. These are comparatively scanty examples from savage life, but then they are corroborated by the wealth of recurrent and coincident evidence from civilised races, ancient and modern.

On the point of clairvoyance, it is unnecessary to dwell. The second-sighted man, the seer of events remote in space or not yet accomplished in time, is familiar everywhere, from the Hebrides to the 
GHOST THEORY OF THE ORIGIN OF RELIGION. 355

Coppermine River, from the Samoyed and Eskimo to the Zulu, from the Euphrates to the Hague. The noises heard in ' haunted houses,' the knocking, routing, dragging of heavy bodies, is recorded, Mr. Tylor says, by Dayaks, Singhalese, Siamese, and Esths; Dennys, in his Folk-lore of China, notes the occurrences in the Celestial Empire; Grimm, in his German Mythology, gives examples, starting from the communicative knocks of a spirit near Bingen, in the chronicle of Rudolf (856), and Suetonius tells a similar tale from imperial Rome. The physician of Catherine de Médicis, Ambroise Paré, describes every one of the noises heard by the Wesleys, long after his day, as familiar, and as caused by devils. Recurrence and conformity of evidence cannot be found in greater force.

The anthropological test of evidence for faith in the rejected phenomena is thus amply satisfied. Unless we say that these phenomena are 'impossible,' whereas totemism, the couvade, cannibalism, are possible, the testimony to belief in clairvoyance, and the other peculiar occurrences, is as good in its way as the evidence for the practice of wild customs and institutions. There remains a last and notable circumstance. All the abnormal phenomena, in the modern and mediæval tales, occur most frequently in the presence of convulsionaries, like the so-called victims of witches, like the Hon. Master Sandilands, Lord Torphichen's son (I720), like the grandson of William Morse in New England (I680), and like Bovet's case of the demon of Spraiton. ${ }^{1}$

${ }^{1}$ In the Pandemonium, or Devil's Cloyster, of Richard Bovet, Gent. (I684). 
The 'mediums' of modern spiritualism, like Francis Fey, are, or pretend to be, subject to fits, anæsthesia, jerks, convulsive movements, and trance. As Mr. Tylor says about his savage jossakeeds, powwows, Birraarks, peaimen, everywhere 'these people suffer from hysterical, convulsive, and epileptic affections'. Thus the physical condition, all the world over, of persons who exhibit most freely the accepted phenomena, is identical. All the world over, too, the same persons are credited with the rejected phenomena, clairvoyance, 'discerning of spirits,' powers of voluntary 'telepathic' and 'telekinetic' impact. Thus we find that uniform and recurrent evidence vouches for a mass of phenomena which science scouts. Science has now accepted a portion of the mass, but still rejects the stranger occurrences. Our argument is that their invariably alleged presence, in attendance on the minor occurrences, is, at least, a point worthy of examination. The undesigned coincidences of testimony represent a great deal of smoke, and proverbial wisdom suggests a presumption in favour of a few sparks of fire. Now, if there are such sparks, the animistic hypothesis may not, of course, be valid,_-'spirits' may not exist,-but the universal belief in their existence may have had its origin, not in nornial facts only, but in abnormal facts. And these facts, at the lowest estimate, must suggest that man may have faculties, and be surrounded by agencies, which physical science does not take into account in its theory of the universe and of human nature.

We have already argued that the doctrines of 
theism and of the soul need not to be false, even if they were arrived at slowly, after a succession of grosser opinions. But if the doctrines were reached by a process which started from real facts of human nature, observed by savages, but not yet recognised by physical science, then there may have been grains of truth even in the cruder and earlier ideas, and these grains of gold may have been disengaged, and fashioned, not without Divine aid, into the sacred things of spiritual religion.

The stories which we have been considering are often trivial, sometimes comic; but they are universally diffused, and as well established as universally coincident testimony can establish anything. Now, if there be but one spark of real fire to all this smoke, then the purely materialistic theories of life and of the world must be reconsidered. They seem very well established, but so have many other theories seemed, that are long gone the way of all things human. The authority for the Maori belief (p. 354) is Polack's New Zealand, vol. i. p. 269.

THE END. 




\section{MESSRS. LONGMANS, GREEN, \& CO.'S}

\section{CLASSIFIED CATALOGUE}

$\mathrm{OF}$

\section{WORKS IN GENERAL LITERATURE.}

\section{History, Politics, Polity, Political Memoirs, \&c.}

Abbott.-A History of Greece. By Evelyn ABBotT, M.A., LL.D.

Part I.-From the Earliest Times to the Ionian Revolt. Crown 8vo., Ios. $6 d$.

Part II.-500-445 B.C. Cr. 8vo., Ios. $6 d$.

Acland and Ransome.-A HANDBOOK IN OUTLINE OF THE POLITICAL History OF ENGLAND TO I8go. Chronologically Arranged. By the Right Hon. A. H. DYKe ACLAND, M.P., and CYRIL Ransome, M.A. Crown 8vo., $6 s$.

ANNUAL REGISTER (THE). A Review of Public Events at Home and Abroad, for the year 1893. 8vo., I8s.

Volumes of the ANNUAL REgISTER for the years $1863-1892$ can still be had. I8s, each.

Armstrong.-ElizaBeth Farnese ; The Termagant of Spain. By EDwARD Akmstrong, M.A., Fellow of Queen's College, Oxford. 8vo., $16 s$.

Arnold.-Works by T. ARNold, D.D., formerly Head Master of Rugby School. INTRODUCTORY LEC'TURES ON MODERN HISTORY. 8vo., 7s. $6 d$.

Miscellaneous Works. 8vo., 7s. 6 d.

Bagwell.-IRELAND UNDER THE TUDORS. By RICHARD BAGWELL, LL.D. 3 vols. Vols. I. and II. From the first Invasion of the Northmen to the year 1578. 8vo., 32s. Vol. III. I578I603. 8vo., I $8 s$.

Ball.-Historical Review OF THE LEgislative Systems OPERATIVE IN IRELAND, from the Invasion of Henry the Second to the Union (II72-1800). By the Rt. Hon. J. T. BALl. 8vo, $6 s$.

Besant.-THE History of London. By Walter Besant. With 74 Illustrations. Crown 8vo., is. $9 d$. Or bound as a School Prize Book, 2s. $6 d$.

Brassey.-PAPERS AND AdDREsSES. By LORD BRASSEY. Naval and Maritime. 2 vols. Crown 8 vo., ros.
Bright.-A History of England. By the Rev. J. Frank BRIGHT, D.D.,

Period I. MEdieval MONARCHY : The Departure of the Romans to Richard III. A.D. 449 to 1485 . Crown 8vo., 4s. 6d.

Period II. Personal Monarchy : Henry VII. to James II. I485 to 1688. Crown 8vo., 5 s.

Period III. Constitutional MonARCHY : William and Mary, to William IV. 1689 to 1837 . Crown 8vo., 7s. $6 d$. Period IV. THE GROWTH OF DemoCRACY : Victoria. 1837 to $1880 . \mathrm{Cr}$. 8 vo., $6 s$.

Buckle.-History of Civilisation in ENGLAND AND France, SPAIN AND SCOTLAND. By HeNRY ThOMAS BUCKLE. 3 vols. Crown 8vo., 24 s.

Creighton.-History OF THE PAPACY DURING THE REFORMATION. By Mandell Creighton, D.D., LL.D., Bishop of Peterborough. Vols. I. and II., I 378-1464, 32s. Vols. III. and IV., 1464-I518., 24s. Vol. V., I 517-1 527, 8 vo., 15 s.

Curzon.-Works by the HoN. Gkorge N. Curzon, M.P.

Problems of the Far EAst : JAPAN, Corea, China. With 2 Maps and 5o Illustrations. 8vo., 2 Is.

Persia And The Persian Question. With 9 Maps, 96 Illustrations, Appendices, and an Index. 2 vols. 8 vo., $42 s$.

De Tocqueville.-Democracy is AMERICA. By Alexis DE TOCQUEVILLE. 2 vols. Crown 8 vo., I6s.

Ewald.-Works by HEINRICH EwaLD, Professor in the University of Göttengen.

The Antiquities of IsRael. 8vo., 12s. $6 d$.

THE History OF ISR AEL. 8 vols. $8 \mathrm{vo}$. Vols. I. and II., 24s. Vols. III. and IV., 2Is. Vol. V., i8s. Vol. VI., I6s. Vol. VII., 21s. Vol. VIII., I8s. 
History, Politics, Polity, Political Memoirs, \&c.-continued. Fitzpatrick.-SECRET SERvice
UNDFR PITT. By W. J. FITZPATRICK, F.S.A., Author of 'Correspondence of Daniel O'Connell'. 8vo., 7s. $6 d$.

Freeman.-The Historical GeoGRAPHY OF EUROPE. By EdWARD A. Freeman, D.C.L., LL.D. With 65 Maps. 2 vols. 8vo., 3Is. $6 d$.

Froude.-Works by J AMEs A. Froude, Regius Professor of Modern History in the University of Oxford.

The History of ENGLAND, from the Fall of Wolsey to the Defeat of the Spanish Armada.

Popular Edition. I2 vols. Crown 8vo., 3s. 6d. each.

Silver Library Edition. 12 vols. Crown 8vo., 3s. 6d. each

The Divorce of CATHERINe of ARAGON : the Story as told by the Imperial Ambassadors resident at the Court of Henry VIII. In usum Laicorum. Crown 8vo., 6 s.

The Spanish Story of the ARmada, and other Essays, Historical and Descriptive. Crown 8vo., 6s.

The ENglish IN IRELAND IN THE Eighteenth Century. 3 vols. $\mathrm{Cr}$. 8 vo., I 8 s.

Short Studies on Great Subjects. 4 vols. Cr. 8vo., 3s. $6 d$. each.

CAESAR: a Sketch. Cr. 8vo, , 3s. 6d.

Gardiner.-Works by SAMUEL RAwSON Gardiner, M.A., Hon. LL.D., Edinburgh.

History of ENGLAND, from the Accession of James I. to the Outbreak of the Civil War, I603-1642. Io vols. Crown 8vo., $6 s$. each.

History of the Great Civil War, I642-1549. 4 vols. Cr. 8vo., 6s. each.

History OF THE COMMONWEALTH AND The Protectorate, I649-I660. Vol. I., I649-I65I. 8vo., 2 Is.

The Student's History of England, With 378 Illustrations. Cr. 8vo., I2s. Also in Three Volumes.

Vol. I. B.C. 55-A.D. I509. With 173 Illustratic ns. Crown 8vo. $4 s$.

Vol. II. I509-1689. With 96 Illustrations. Crown 8 vo. $4 s$.

Vol. III. I689-1885. With rog Illusrations. Grown 8 vo. 4 s.
Greville.-A Journal of The Reigns of King GeORge IV., King William IV., AND QUEEN VICTORIA. BY Charles C. F. GReville, formerly Clerk of the Council. 8 vols. Crown 8 vo., 6 s. each.

Hart.--PRACTICAL ESSAYS IN AMERICAN Government. By Albert Bushnel. HART, Ph.D., \&c. Editor of 'Epochs of American History,' \&c., \&c. Crown 8 vo., $6 s$.

Hearn.-The Government of ENGLAND: its Structure and its Development By W. EDWARD HEARn. 8vo, i $6 s$.

Historic Towns.-Edited by E. A. FREEMAN, D.C.L., and Rev. William Hunt, M.A. With Maps and Plans. Crown 8vo., 3s. 6d. each.

Bristol. By the Rev. W. Hunt.

CARlisle. By MANDEll CREightoN, D.D., Bishop of Peterborough.

Cinque Ports. By Montagu BurRows.

Colchester. By Rev. E. L. Cutrs.

Exeter. By E. A. Freeman.

London. By Rev. W. J. Loftie.

OXFord. By Rev. C. W. BOASE.

Winchester. By Rev. G. W. Kit. CHIN, D.D.

YORK. By Rev. JAMES RAINE.

NEW YORK. By ThEODORE ROOSEVELT.

BOSTON (U.S.) By HENRY CABOT LODGE.

Joyce.-A Short HISTORY OF IRELAND, from the Earliest Times to I608. By P. W. Joyce, LL.D. Crown 8vo., Ios. $6 d$.

Lang.-ST. ANDREws. By ANDREw LANG. With 3 Plates and 24 Illustrations in the Text, by T. HodGe. 8vo., I5s. net.

Lecky.-Works by WILLIAM EDWARD HARTPOLE LECKY.

History of ENGLANd in the EighTEENTH CENTURY.

Library Edition. 8 vols. 8vo., $£ 74$ s. Cabinet Edition. ENGland. 7 vols. Cr. 8vo., 6s. each. IRELAND. 5 vols. Crown 8 vo., 6 s, each.

History of European MORALS FRON AUgustus TO CHARLEMAGNe. 2 vols. Crown 8 vo., I6s.

HISTORY OF THE RISE AND INFLUENCE OF THE SPIRIT OF RATIONALISM IN EUROPE. 2 vols. Crown 8vo., I6s. 


\section{History, Politics, Polity, Political Memoirs, \&c.-continued.}

Lecky.-Works by Wilitam EDWARD HARTPOLE LECKY - continued.

TIE EMPIRE: its Value and its Growth. An Inaugural Address delivered at the Imperial Institute, November 20, 1893 , under the Presidency of H.R.H. the Prince of Wales. Crown 8vo. Is. $6 d$.

Macaulay.-Works by LORD MACAULAY.

COMPLETE WORKS.

Cabinet Ed. I6 vols. Pt. 8vo., \&4 I6s. Library Edition. 8 vols. 8 vo., $\notin 55 s$.

HISTORY OF ENGLAND FROM THE ACCession of: JAMES the SECOND.

Popular Edition. 2 vols. Cr. 8vo., 5 s. Student's Edition. 2 vols. Cr. 8vo., I2s. People's Edition. 4 vols. Cr. 8vo., r6s. Cabinet Edition. 8 vols. Pt. 8vo., 48 s. Library Edition. 5 vols. 8vo., \&4.

Critical and Historical Essays, WITH LAYS OF ANCIENT ROME, in I volume.

Popular Edition. Crown 8vo., 2s. 6d. Authorised Edition. Crown 8vo., $2 s .6 d$., or $3 s .6 d$., gilt edges.

Silver Library Edition. Crown 8vo., 3s. $6 d$.

Critical and Historical Essays.

Student's Edition. I vol. Cr. 8vo., $6 s$. People's Edition. 2 vols. Cr. 8vo., $8 s$. Trevelyan Edition. 2 vols. Cr. 8vo., $9 s$. Cabinet Edition. 4 vols. Post 8vo., 24s. Library Edition. 3 vols. 8 vo., $36 s$.

EsSAYs which may be had separately, price $6 d$. each sewed, Is. each cloth.

Addison and Wal- Lord Clive. pole.

Frederick the Great.

I ord Bacon.

Croker's Boswell's Johnson.

Hallam's Constitutional History.

Warren Hastings (3d. swd., 6d. cl.).

\section{Miscellaneous}

SPEECHES.

Popular Edition.

The Earl of Chatham(Two Essays).

Ranke and Gladstone.

Milton and Machiavelli.

Lord Byron, and The Comic Dramatists of the Restoration.

\section{WRITINGS}

AND

Cabinet Edition.

Cr. 8vo., 2s. 6d.

Including Indian Penal Code, Lays of Ancient Rome, and Miscellaneous Poems. 4 vols. Post 8vo., 2.s.
Macaulay.-Works by LORD MACAULAY.-continued.

Miscellaneous Writings.

People's Ed. I vol. Cr. 8ro., $4 s .6 d$. Library Edition. 2 vols. 8vo., 2Is.

Selections from the Writings of LoRd Macaulay. Edited, with Occasional Notes, by the Right Hon. Sir G. O. Trevelyan, Bart. Crown 8 vo., $6 s$.

May.-The Constitutional History OF ENGLAND since the Accession of George III. 1760-1870. By Sir ThOMAS ERSKINE MAY, K.C.B. (Lord Farnborough). 3 vols. Crown 8vo., $18 s$.

Merivale.-Works by the Very Rev. Charles Merivale, late Dean of Ely.

History of the Romans UNder the EIIPIRE.

Cabinet Edition. 8 vols. Cr. 8 vo., $48 s$. Silver Library Edition. 8 vols. Cr. $8 \mathrm{vc}, 3$, 6 d. each.

The Fall of the Roman Republic: a Short History of the Last Century of the Commonwealth. 12mo., $7 s .6 d$.

Montague.-The Elements of EnGLish Constitutional History, from the Earliest Time to the Present Day. By F. C. Montague, M.A. Crown 8vo., 3s. $6 d$.

O'Brien.-IRISH IDEAS. REPRINTED AdDResses. By William O'Brien, M.P. Cr. 8 vo. $2 s .6 d$.

Prendergast.-Ireland fROM THE RESTORATION TO THE REVOLUTION, I660-169o. By JoHN P. PRENDERGAST, Author of 'The Cromwellian Settlement in Ireland'. 8vo., 5 s.

Seebohm. - The English Village CoMmunity Examined in its Relations to the Manorial and 'Tribal Systems, \&-c. By Frederic SEebohm. With I 3 Maps and Plates. 8vo., $16 s$.

Sharpe.-London And THF Kingdom: a History derived mainly from the Archives at Guildhall in the custody of the Corporation of the City of London. By Reginald R. Sharpe, D.C.L., Records Clerk in the Office of the Town Clerk of the City of London. 3 vols. 8 vo. Vols. I. and II., Ios. $6 d$, each. 


\section{History, Politics, Polity, Political Memoirs, \&c.-continued.}

Sheppard.-MEMORIALS OF ST. JAMES'S PALACE. By the Rev. EDGAR Sheppard, M.A., Sub-Dean of the Chapels Royal. With 4I Plates and 32 Illustrations in the Text. 2 Vols. 8 vo, 365 . net.

Smith.-CARTHAGE AND THE CARTHAGINIANS. By R. BOSwORTH SMITH, M.A., Assistant Master in Harrow School. With Maps, Plans, \&c. Cr. 8vo., $3^{s .} 6 a^{\prime}$.

Stephens.--A History OF THE FrENCH Revolution. By H. MorseStephens, Balliol College, Oxford. 3 vols. 8vo. Vols. I. and II. I8s, each.

Stubbs.-History of THE UNIVERSITY OF DUBLIN, from its Foundation to the End of the Eighteenth Century. By J. W. Stubbs. 8vo., r $2 s .6 d$.

Sutherland.-The History of AUSTRALIA AND NEW ZEALAND, from I6́6 to I8go. By Alexander SuTHERLAND, M.A., and GeORge SUTHERLAND, M.A. Crown 8vo., 2s. $6 d$.
Todd.-PARLiamentary Government IN THE BRItish Colonies. By Alpheus TODD, LL.D. 8 vo., 3os, net.

Wakeman and Hassall.-EssAYs INTRODUCTORY TO THE STUDY OF English Constitutional History. Edited by HENRY OFFLEY WAKEMAN, M.A., and ARThur HASSALI, M.A. Crown 8vo., $6 s$.

Walpole.-Works by SPENCER WALPOLE.

History OF ENGLAND FROM THE CONCLUSION OF THE GREAT WAR IN r 8 I $_{5}$ TO I 858 . 6 vols. Cr. 8 vo., $6 s$, each.

The LAND OF HoMe Rule: being an Account of the History and Institutions of the Isle of Man. Cr. 8vo., $6 s$.

Wylie.-History OF ENGLAND UNDER HENRY IV. By JAMES HAMILTON WYLIE, M.A., one of H. M. Inspectors of Schools. 3 vols. Crown 8 vo. Vol. I., I399-I404, Ios. 6d. Vol. II. I5s. Vol. III.
In preparation.

\section{Biography, Personal Memoirs, \&c.}

Armstrong.-The Life AND LetTERS OF EDMUND J. ARMSTRONG. Edited by G. F. Armstrong. Fep. 8vo., 7s. 6d.

Bacon.- LetTers AND Life OF FRANCIS BACON, INCLUDING ALL HIS OCCASIONAL WORKS. Edited by J. SPEDDING. 7 vols. 8vo., $£ 44$ s.

Bagehot.-BIOGRAPHICAL STUdies. By WaLter Bagefiot. 8vo., i2s.

Boyd.-Twenty-Five Years of St. ANDREWS, I865-189o. By A. K. H. BOyD. D.D., LL.D., Author of 'Recreations of a Country Parson,' \&c. 2 vols. 8vo. Vol. I., I2s. Vol. II., I5s.

Carlyle.-Thomas Carlyle: a History of his Life. By. J. A. Froude. I795-1835. 2 vols. Crown 8vo., $7 s$. I834-I88I. 2 vols. Crown 8vo., $7 s$.

Erasmu s.-LIFE AND LetTers of ERASMUS: a Series of Lectures delivered at Oxford. By I AMES ANTHONy FrounE. Crown 8vo., Gs.

Fabert.-ABRAham FABERT : Governor of Sedan and Marshal of France. His Lifeand Times, I 599-I662. By GEORGE HoOper. With a Portrait. 8vo., IOS. $6 d$.
Fox.-The Early History of Charles JAMES FoX. By the Right Hon. Sir G. O. Trevelyan, Bart.

Library Edition. 8vo., r8s.

Cabinet Edition. Crown 8vo., $6 s$.

Granville.--The LetTers of HARRIET CoUnTESS GRANVILlE, I8IO-I845. Edited by her Son, the Hon. F. LEvESON GOWER. 2 vols. 8vo., $32 s$.

Hamilton.-Life of Sir WilliaM Hamilton. By R. P. Graves. 3 vols. I5s. each. ADDENDUM. 8vo., 6d. sewed.

Havelock.-Memoirs of Sir Henry Havelock, K.C.B. By JOHN ClaRK marshman. Crown 8vo., $3^{s .} 6 d$.

Macaulay.-The Life AND LetTers OF LORD MACaulay. By the Right Hon. Sir G. O. Trevelyan, Bart.

Popular Edition. I vol. Cr. 8vo.,2s. 6d. Student's Edition. I vol. Cr. 8 vo., $6 \mathrm{~s}$. Cabinet Edition. 2 vols. Post 8vo., r2s. Library Edition. 2 vols. 8 vo., $3^{6 s}$. 


\section{Biography, Personal IVemoirs, \&c.-continued.}

Marbot.-The Memoirs of the Baron DE MARBOT. Translated from the French by ARTHUR JOHN BUTLER, M.A. Crown 8vo., 7s. $6 d$.

Montrose.-DeEds of Montrose: The Memoirs of James, MARQuis of MON'rkose, 1639-1650. By the Rev. GEORGE WisharT, D.D. (Bishop of Edinburgh, 1662-r671). Translated by the Rev. Alexander MURdoch, F.S.A. and H. F. MORELAND Simpson, 4to., 36s. net.

Seebohm.-The Oxford Reformers -JOHN COLET, ERASMUS AND THOMAS MORE : a History of their Fellow-Work. By FREDERIC SEebohu. 8vo., r4s.

Shakespeare.-OUTLINES OF THE Life of Shakespeare. By J. O. HaLliwell-PhillipPS. With numerous Illustrations and Fac-similes. 2 vols. Royal 8vo., fir Is.

Shakespeare's True Life. By JAs. WALTER. With 500 Illustrations by Gerald E. Moira. Imp. 8vo., 2is.
Sherbrooke.-LifE AND LetTERS OF THE Right HON. ROBERT LOWE, VISCount SHerbrooke, G.C.B., By A. Patchett Martin. With 5 Portraits. 2 vols. 8 vo., 36 s.

Stephen.-Essays in Ecclesiastical Biography. By Sir JaMes STEPHEN. Crown 8vo., $7 s .6 d$.

Verney.-MeMoirs of the Verney FAMILY DURING THE CIVIL WAR. Compiled from the Letters and Illustrated by the Portraits at Claydon House, Bucks. By Frances PARTHENOPE VERney. With a Preface by S. R. GARDINER, M.A., LL. D. With 38 Portraits, Woodcuts and Fac-simile. Vols. I. and II. Royal 8vo., $42 s$.

[Vol. III. In the Press.

Walford.-Twer.ve ENGLISH AUTHORESSES. By L. B. Walford. Crowin 8 vo., 4 s. 6 d.

Wellington.-LIFE OF THE DUKE OF WELlington. By the Rev. G. R. Gleig, M.A. Crown 8vo., 3s. $6 d$.

\section{Travel and Adventure, the Colonies, \&c.}

Arnold. - Works by Sir EDWIN ARNOLD, K.C.I.E.

SEAS AND LANDS. With 7I Illustrations. Cr. 8vo., 7s, 6il. Cheap Edition. Cr. 8vo., 3s. 6d.

WANDERING WORDS: Reprinted from Papers published in The Daily Telegraph and Foreign Journals and Magazines. With 45 Illustrations. 8vo., I8s.

AUSTRALIA AS IT IS, or Facts and Features, Sketches and Incidents of Australia and Australian Life, with Notices of New Zealand. By A ClergyMAN, thirteen years resident in the interior of New South Wales. Crown 8vo., 5 s.

Baker.-Works by Sir Samuel White BAKER.

Eight Years in Ceylon. With 6 Illustrations. Crown 8vo., 3s. $6 d$.

The Rifle and the Hound in CeyLON. 6 Illustrations. Cr. 8vo., 3s. $6 \%$.

Bent.-Works by J. THEOdore BENT, F.S.A., F.R.G.S.

The Ruined Cities of MashonaLAND: being a Record of Excavation and Exploration in $189 \mathrm{r}$. With Map, 13 Plates, and 104 Illustrations in the Text. Cr. 8vo., $7 s .6 d$.

Bent.-Works by J. THEODORE BENT, F.S.A., F.R.G.S.-continued.

THE SACRED CiTY OF THE E'THIOPIANS: being a Record of Travel and Research in Abyssinia in 1893. With 8 Plates and 65 Illustrations in the Text. 8vo., I8s.

Boothby.-ON THE Wallaby; or, Through the East and Across Australia. By Guy Boothby. 8vo., I8s.

Brassey.-Works by the late LADY BRASSEY.

THE LAST Voyage to INDIA AND Australia in the 'SUnbeam'. With Charts and Miaps, and 4o Illustrations in Monotone, and nearly 200 Illustrations in the Text. 8vo., 2Is.

A Voyage IN THE 'SUNBeAM'; OUR HOME on the OCEAN fOR EleveN Months.

Library Edition. With 8 Maps and Charts, and Ir8 Illustrations. 8vo.. 2 rs.

Cabinet Edition. With Map and 66 Illustrations. Crown 8vo., 7s. 6it.

Silver Library Edition. "With 65 Illustrations. Crown 8vo., 3s. $6 d$.

Popular Edition. With 6o Illustrations. 4to., $6 d$. sewed, Is. cloth.

School Edition. With 37 Illustrations. Fcp., 2s. cloth, or $3^{s}$. white parchmient. 


\section{Travel and Adyenture, the Colonies, \&c.-continued.}

Brassey.-Works by the late LADY BRASSEY-continued.

SUNSHINE AND STORM IN THE EAST.

Library Edition. With 2 Maps and I4I Illustrations. 8vo., 2 Is.

Cabinet Edition. With 2 Maps and I I4 Illustrations. Crown 8vo..7.7.6d.

Popular Edition. With 103 Illustrations. 4to., $6 d$. sewed, is. cloth.

IN THE TRADES, THE TROPICS, AND THE ' ROARING ForTiES'.

Cabinet Edition. With Map and 220 Illustrations. Crown 8vo., 7s. $6 d$.

Popular Edition. With 183 lllustrations. 4to., $6 d$. sewed, r.s. cloth.

'Three Vorages in The 'Sunbeam'. Popular Edition. 346 Illustrations. 4 to., 2s. 6d.

Bryden.-Kloof and Karoo: Sport, Legend, and Natural History in Cape Colony. By H. A. Bryden. I7 Illustrations. 8vo., $5^{s}$.

Froude.--Works by JAmes A. Froude. OCEANA : or England and her Colonies. With 9 Illustrations. Crown 8vo., 2s. boards, 2s. $6 d$. cloth.

The ENGLish in THE West INDIEs: or the Bow of Ulysses. With 9 Illustrations. Cr. 8vo., 2s. bds., 2s. $6 d$. cl.

Howard.--LiFe with Trans-Siberian Savages. By B. Douglas Howard, M.A. Crown 8vo., 6s.

Howitt.-Visits to Remarkable PLACES, Old Halls, Battle-Fields, Scenes illustrative of Striking Passages in English History and Poetry. By William HowitT. With 80 Illustrations. Crown 8vo., 3s. $6 d$.

Knight.-Works by E. F. KNIGHT.

The CRUise OF THE 'Alerte': the Narrative of a Search for 'Treasure on the Desert Island of Trinidad. 2 Maps and 23 Illustrations. Cr. 8vo., 3.s. $6 d$.

Where Three Empires Meet: a Narrative of Recent Travel in Kashmir, Western Tibet, Baltistan, Ladak, Gilgit, and the adjoining Countries. With a Map and 54 Illustrations. Cr. 8vo., 7s. 6d.

Lees and Clutterbuck.-B. C. 1887:

A RAMBle in BRITISH Columbia. By J. A. Lees and W. J. Clutterbuck, Authors of 'Three in Norway'. With Map and 75 Illustrations. Cr. 8vo., 3s. $6 d$.
Montague.-TALEs of A NOMAD ; or, Sport and Strife. By ChARLES MoNTAGUE. Crown 8 vo., $6 s$.

Murdoch.-From Edinburgh to the ANTARCTIC: An Artist's Notes and Sketches during the Dundee Antarctic Expedition of $1892-93$. By W. G. BuRN MURDCCH. With a Chapter by W. S. BRUCE, Naturalist of the Barque, "Balæna". With 2 Maps. 8vo., 18s.

Nansen.-Works by Dr. FridTJoF NANSEN.

The First Crossing of Greenland. With numerous Illustrations and a Map. Crown 8vo., 7s, 6d.

Eskimo LifE. Translated by William ARCHER. With 3 I Illustrations. 8vo., r6s.

Peary.-My Arctic Journal: a Year among Ice-Fields and Eskimos. By Josephine DiEbITSCH-PEARY. With I9 Plates, 3 Sketch Maps, and 44 Illustrations in the Text. 8vo., I2s.

Rockhill.-The Land of The LAmas : Notes of a Journey through China. Mongolia, and Tibet. By WILliAM WooDVILIE RockHill. With 2 Maps and 6I Illustrations. 8vo., i5s.

Smith.-Clinibing IN THE British Isles. By W. P. HasketT Smith. With Illustrations by ELLIS CARR.

Part I. ENGland. Fcp. 8vo., 3s. 6d. Part II. WALES. [In preparation. Part III. SCOTLAND. [In preparation.

Stephen. - The Playground oF EUROPE. By LESLIE S'TEPHEN, formerly President of the Alpine Club. New Edition, with Additions and 4 Illustrations, Crown 8vo., 6s. net.

THREE IN NORWAY. By Two of Them. With a Map and 59 Illustrations. Cr. 8vo., 2s. boards, 2s. $6 \mathrm{~d}$. cloth.

Von Hohnel.-Discovery of LAKes RUDOLF AND STEFANIE: A Narrative of Count SAMUEL TELEKI'S Exploring and Hunting Expedition in Eastern Equatorial Africa in 1887 and 1883 . By Ijeutenant LUDWIG vON HOHNEL. With 179 Illustrations and 5 Maps. 2 vols. 8vo., $42 s$.

Whishaw.-OUT OF Doors IN TSARLAND; a Record of the Seeings and Doings of a Wanderer in Russia. By FRED. J. WhISHAw. Cr. 8vo., 7s. 6d. 


\section{Sport and Pastime. \\ THE BADMINTON LIBRARY.}

Edited by the Duke of BeAufort, K.G., assisted by Alfred E. T. WAtson.

ARCHERY. By C. J. LONGMAN and Col. H. WALrond. With Contributions by Miss LEGH and Viscount Dillon. With r95 Illustrations. Crown 8vo., ros. $6 d$.

ATHLETICS AND FOOTBALL. By Muntague Shearman. With $5 \mathrm{I}$ Illustrations. Crown 8vo., ros. $6 d$.

BIG GAME SHOOTING. By C. PHILlipps-Wolley, F. C. Selous, St. George LitTledale, \&c. With ${ }^{\circ}$ Illustrations. 2 vols., Ios. $6 d$. each.

BOATING. By W. B. Woodgate. With an Introduction by the Rev. EDMOND WARRE, D.D., and a Chapter on 'Rowing at Eton,' by R. HARVEY MASON. With 49 Illustrations. Cr. 8vo., Ios. $6 d$.

COURSING AND FALCONRY.

HARDING COX and the Hon. GeraLD LASCELlES. With 76 Illustrations. Crown 8vo., ros. $6 d$.

CRICKET. By A. G. SteEL and the Hon. R. H. LytTelton. With Contributions by ANDREW LANG, R. A. H. MitCHEll, W. G. Grace, and F. Gale. With 64 Illustrations. Cr. 8vo., ros. $6 d$.

CYCLING. By Viscount Bury (Earl of Albemarle), K.C.M.G., and G. LACY Hillier. With 89 Illustrations. Crown 8vo., Ios. 6d.

DRIVING. By the DUkE OF BEAUFORT. With 65 Illustrations. Cr. 8vo., Ios. $6 d$.

FENCING, BOXING. AND WRESTLING. By WALTER H. POLlOCK, F. C.Grove.C.Prevost, E. B. Mitchell, and WAlter ARMSTRONG. With 42 Illustrations. Crown 8vo., ros. $6 d$.

FISHING. By H. ChOlMONDELEy-PENNELL. With Contributions by the MARquis of Exeter, Henry R. Francis, Major John P. TRAhERNe, G. Christopher Davies, R. B. MarSTON, \&c.

Vol. I. Salmon, Trout, and Grayling. With 158 Illustrations. Crown 8vo., Ios. $6 d$.

Vol. II. Pike and other Coarse Fish. With 133 Illustrations. Crown 8vo., Ios. $6 d$.

GOLF. By Horace G. Hutchinson, the Rt. Hon. A. J. Balfour, M.P., Sir W. G. Simpson, Bart., LORD WEl.LWOOD, H. S. C. EveraRd, ANDREW LANG, and other Writers. With 89 Illustrations. Crown 8vo., Ios. $6 d$.
K.G., and MOwBray MORRIS. WVitl, Contributions by the EARL OF SUFFOLK AND BERKSHIRE, Rev. E. W. L. Davies, Digry Collins, and Alfred E. T. WATson. With 53 Illustrations. Crown 8vo., ros. $6 d$.

MOUNTAINEERING. By C. T. DENT, Sir F. POllock, Bart., WV. M. CONWAY, Douglas Freshfield, C. E. MATHEWs, \&c. With ro8 Illustrations. Crown 8vo., ros. $6 d$.

RACING AND STEEPLE-CHASING. By the EARL OF SUFFolK AND BERKSHIRE, W. G. CRAVEN, ARTHuR Coventry, \&c. With 58 Illustrations. Crown 8vo., ios. $6 d$.

RIDING AND POLO. By Captain Robert Weir, J. MORAY Brown, the DukE OF BEAUFORT, K.G., the EARL of SUFFOLK AND BERKSHIRE, \&c. With 59 Illustrations. Cr. 8vo., IOs. $6 d$.

SHOOTING. By Lord WALSINGHAM and Sir Ralph PAYNe-Gallwwey, Bart. With Contributions by LORD LOVAT, LORD C. L. KERR, the Hon. G. LASCelles, and A. J. STuART-Wortley.

Vol. I. Field and Covert. With $\mathrm{IO}_{5}$ Illustrations. Crown 8vo., Ios. $6 d$. Vol. II. Moor and Marsh. With 65 Illustrations. Cr. 8vo., ros. $6 d$.

SKATING, CURLING, TOBOGANING, AND OTHER ICE SPORTS. By J. M. Heathcote, C. G. Tebiutt, T. MAXWell WithaM, the Rev. JoHn KERR, ORMOND HAKE, and Colonel BuCK With 284 Illustrations. Crown 8 vo., ros. $6 d$.

SWIMIMING. By ARCHIBALD SinclaIR and William HenRy. With ig Illustrations. Cr. 8vo., ros. $6 d$.

TENNIS, LAWN TENNIS, RACQUETS, AND FIVES. By J. M. and C. G. Heathcote, E. O. PleydellBouverie and A. C. AINGer. With Contributions by the Hon. A. LytTelton, W. C. Marshall, Miss L. Dod, \&c. With 79 Illustrations. C.8vo., ros. $6 d$. YACHTING.

Vol. I. Cruising, Construction, Racing, Rules, Fitting-Out, \&c. BySir EDWA RD Sullivan, Bart., LORD liRASSEY, K.C.B., C. E. Seth-SMith, C.B., \&c. With II4 Illust. Cr. 8vo., ros. $6 d$.

Vol. II. Yacht Clubs. Yachting in America and the Colonies, Yacht Racing, \&c. By R. T. PritchetT, the EARL OF ONSLOW, G.C.M.G., \&c With r95 lllus. Crown 8vo., Ios. $6 d$. 


\section{Sport and Pastime-continued. \\ Fur and FEATHER SERIES.}

Edited by A. E. T. WATSON.

THE PARTRIDGE. Natural History, THE GROUSE. Natural History by the by the Rev. H. A. MACPHERSON; Shooting, by A. J. STUART-WORTILY; Cookery, by George SAINTSBURY. With II full-page Illustrations and Vignette by A. THORBURN, A. J. STUART-WORTLEY, and C. WHYMPER, and $I_{5}$ Diagrams in the Text by A. J. STUART-WORTLEy. Crown 8vo., 5 s.

WILDFOWL. By the Hon. John SCOTTMontagu, M.P., \&c. Illustrated by A. J. Stuart Wortley, A. Thorburn, and others.

[In preparation.

Rev. H. A. MACPHERSON; Shooting, by A. J. StuART-Wortley ; Cookery, by GeORge SAINTSBURY. With I3 Illustrations by J. STUART-WORTLEY and A. THORBURN, and various Diagrams in the Text. Crown 8vo., 5 s.

THE HARE AND THE RABBIT. By the Hon. Gerald LAscelles, \&c.

[In preparation.

THE PHEASANT. By A. I. STUARTWORTLEY, the Rev.H.A.MACPHERSON, and A. J. INNES SHAND.

[In preparation.

Campbell-Walker.-The CORRECT CARD: or, How to Play at Whist; a Whist Catechism. By Major A. CAMPBELL-WALKER, F.R.G.S. Fcp. 8vo., 2s. $6 d$.

DEAD SHOT (THE) : or, Sportsman's Complete Guide. Being a Treatise on the Use of the Gun, with Rudimentary and Finishing Lessons on the Art of Shooting Game of all kinds, also Game Driving, Wild-Fowl and Pigeon Shooting, Dog Breaking, etc. MARKSMAN. Crown 8vo., Ios. $6 d$.

Falkene1.-GAMES, ANCIENT AND ORIental, and How to Play Them. By EdWARD FALKEnER. With numerous Photographs, Diagrams, \&c. 8vo., 2Is.

Ford.-The Theory AND PRACTICE OF ARChery. By HorACE FORD. New Edition, thoroughly Revised and Rewritten by W. BuTT, M.A. With a Preface by C. I. Longman, M.A. 8vo., I 4 s.

Fow le r.-Recollections of Old Country Life, Social, Political, Sporting, and Agricultural. By J. K. FowLER ("Rusticus"), formerly of Aylesbury. With Portrait and ro Illustrations. 8vo., Ics. $6 d$.

Francis.-A Book on ANGLng: or, Treatise on the Art of Fishing in every Branch; including full Illustrated I,ist of Salmon Flies. By Francis Francis. IVith Portrait and Coloured Plates. Cr. 8 vo., 15 s.

Hawker.-The Diary of Colonel PETER HAWKER, author of "Instructions to Young Sportsmen ". With an Introduction by Sir RALPH PAYNEGALLWEY, Bart. 2 vols. 8vo., $32 s$.

Longman.-Chess Openings. By FRED. W. LONGMAN. Fcp. 8vo., 2s. $6 d$. Maskelyne.-SharpS AND Flats: a Complete Revelation of the Secrets of Cheating at Games of Chance and Skill. By John Nevil Maskelyne, of the Egyptian Hall. With 62 Illustrations. Crown 8vo., $6 s$.

Payne-Gallwey.-Works by Sir RalPh Payne-Gallivey, Bart.

LETTERS TO YOUNG SHOOTERS (First Series). On the Choice and Use of a Gun. With 4I Illustrations. Cr. 8vo., 7s. $6 d$.

LetTersto Young Shooters. (Second Series). On the Production, Preservation, and Killing of Game. With Directions in Shooting Wood-Pigeons and Breaking-in Retrievers. With a Portrait of the Author, and IO3 Illustrations. Crown 8vo., I2s. $6 d$.

Pole.-The Theory of the Modern Scientific Game of Whist. By W. Pole, F.R.S. Fcp. 8vo., 2s. 6d.

Proctor.-Works by R. A. Proctor. How to Play WhIST: WITH THE LAWS AND ETIQUE'TTE OF Whist. Crown 8vo., 3 s. 6d.

Home Whist : an Easy Guide to Correct Play. I6mo., Is.

Ronalds.-THE FLY-FisheR's ENTOMOLOGY. By ALFRED RonAlds. With coloured Representations of the Natural and Artificial Insect. With 20 Coloured Plates. 8vo., I4s.

Wilcocks. THE SEA Fisherman : Comprising the Chief Methods of Hook and Line Fishing in the British and other Seas, and Remarks on Nets, Boats, and Boating. By J. C. Wilcocks. Illustrated. Crown 3vo., $6 s$. 


\section{Veterinary Medicine, \&c.}

Steel.-Works by John Henky StekL,

A TREatise on the Diseases of the Dog. 88 Illustrations. 8vo., Ios. $6 d$.

A Treatise on the Disliases of THE OX. With rig Illustrations. 8 vo., I5s.

A Treatise on the Diseases of the SHeEP. With roo Illustrations. 8vo., I2s.

OUTLINES OF EQUiNe ANATOMY: a Manual for the use of Veterinary Students in the Dissecting Room. Crown 8vo, 7 s. $6 d$.
Fitzwygram.--Horses AND STABLES. By Major-General Sir F. FitzWYGRAM, Bart. With 56 pages of Illustrations. 8 vo., 2s. $6 d$. net.

"Stonehenge."--The Dog in Health AND DiseASE. By "STONF.hENGE". With 84 Illustrations 8vo., 7s. 6d.

Youatt.-Works by IVILLIAM YouATT. THE Horse. With numerous Illustrations. 8vo., $7 s .6 d$.

The Dog. With numerous Illustra. tions. 8vo., $6 s$.

\section{Mental, Moral, and Political Philosophy.}

LOGIC, RHETORIC, PSYCHOLOGY, ETC.

Abbott.-The Elements of Logic. By T. K. Аввотт, B.D. 12mo., $3^{s}$.

Aristotle.--Works by.

ThE Politics: G. Bekker's Greek Text of Bocks I., III., IV. (VII.), with an English Translation by IV. E. BOLLAND, M.A. ; and short Introductory Essays by A. LANG, M.A. Crown 8vo., 7s. 6\%.

The POlitics: Introductory Essays. By ANDREW LANG (from Bolland and Lang's 'Politics'). Cr. 8vo., 2s. 6d.

The ETHics: Greek Text, Illustrated with Essay and Notes. By Sir ALExANDER GRANT, Bart. 2 vols. 8vo., $32 s$.

THE Nicomachean EThics: Newly Translated into English. By ROBERT Williams. Crown 8vo., 7s. $6 d$.

AN INTRODUCTION TO ARISTOTLE'S ETHICS. Books I.-IV. (Book X. c. vi.-ix. in an Appendix.) With a continuous Analysis and Notes. By the Rev. E. MOORE, D.D. Cr. 8vo., Ios.6d.

Bacon.-Works by Francis BACON.

Complete W'orks. Edited by R. L. Ellis, J. SPEdDiNG, and D. D. Heath. 7 vols. 8vo., f3 13.s. $6 a$.

LETTERS AND LIFE, including all his occasional Works. Edited by J AMES SPEDDING. 7 vols. 8 \%o., f4 4 s.

THE Essays: with Annotations. By Richard Whately, D.D. 8vo. IOs. $6 a$.

The Essays. With Introduction, Notes, and Index. By E. A. AвBOTT. D.D. 2 vols. Fcp. 8 vo., $6 s$. The Text and Index only, without Introduction and Notes, in One Volume. Fcp. 8vo., 2s. $6 . \mathrm{t}$.
Bain.-Works by Alexander BAIN, LL.D.

Mental Scienc:. Crown 8vo., 6s. 6d. Moral Science. Crown 8vo., $4 s .6 d$.

The two works as above can be had in one volume, price Ios. $6 d$.

SENSES AND THE INTELLECT. 8vo., I 5 s. EMOTIONS AND THE WILL. 8vo., I5s. Logic, Deductive AND Inductive. Part I., 4s. Part II., 6s. 6d.

Practical Essays. Crown 8vo., $3^{s}$.

Bray.-Works by Charles Bray.

The Philosophy of Necessity: or Law in Mind as in Matter. Cr. 8vo., 5 s.

The Education of the Feelings: a Moral System for Schools. Crown 8vo., 2s. $6 d$.

Bray.-Elements of Morality, in Easy Lessons for Home and School Teaching. By Mrs. CHARLES BRAY. Cr. 8vo., is. 6d.

Crozier.-Civilisation AND PROGress. By John Beattie Crozier, M.D. With New Preface, more fully explaining the nature of the New Organon used in the solution of its problems. 8vo., I4s.

Davidson.-The LogIC OF DEFINITION, Explained and Applied. By William L. Davidson, M.A. Crown 8 vo., $6 s$.

Green.-The Works of Thomas Hill Green. Edited by R. L. Nettleship. Vols. I. and II. Philosophical IVorks. 8 vo., I5s. each.

Vol. III. Miscellanies. With Index to the three Volumes, and Memcir. 8ro., ats. 


\section{Mental, Moral and Political Philosophy-continued.}

Hearn.-The ARyan Household: its Structure and its Development. An Introduction to Comparative Jurisprudence. By W. EDWARD HEARN. 8 vo., I6s.

\section{Hodgson.-Works by Shadworth H.} HODGSON.

Time And Space: a Metaphysical Essay. 8vo., I6s.

The THEORY OF PRACTICE : an Ethical Inquiry. 2 vols. 8vo., 24 s.

The Philosophy of Reflection. 2 vols. 8vo., $2 \mathrm{I} s$.

Hume.-The Philosophical Works OF DAvid Hume. Edited by T. $\mathrm{H}$. GrEeN and T. H. Grose. 4 vols. 8vo., 56s. Or separately, Essays. 2 vols. 28s. Treatise of Human Nature. 2 vols. $28 s$.

Johnstone.-A SHORT INTRODUCTION TO THE STUdy OF Logic. By LAURENCE JOHNSTONE. With Questions. Cr. 8vo., 2s. $6 d$.

Jones.-AN Introduction to GFNeRAL Logic. By E. E. CONSTANCE Jones. Cr. 8vo., 4s. $6 d$.

Justinian.-The Institutes of JusTINIAN: Latin Text, chiefly that of Huschke, with English Introduction, Translation, Notes, and Summary. By Thomas C. SANDARS, M.A. 8vo. I8s.

Kant.-Works by IMMANUEl Kant.

CRitique of PRACTICAL REASON, AND OTHER WORKS ON THE THEORY OF EтHics. Translated by'T. K. Aввотт, B.D. With Memoir. 8vo., I2s. $6 d$.

INTRODUCTION TO LOGIC, AND HIS Essay on the Mistaken SubTilty OF THE FOUR Figures. Translated by $T$. K. ABBoTT, and with Notes by S. T. COlERIDGE. 8vo, $6 s$.

Killick.-HANDBOOK TO MILL's SYSTEM OF Logic. By Rev. A. H. KILLICK, M.A. Crown 8vo., 3s. $6 d$.

Ladd.-Works by George Turnbull LADD.

Elements of Physiological PsyCHOLOGY. 8vo., $2 \mathrm{Is}$.

Outlines of Physiological PsyCHOLOGY. A Text-Book of Mc:-ial Science for Academies and Colleges. 8 vo., I2s.
Ladd.-Works by G. T. LADD.-cont. Psychology, Descriptive and ExPLANATORY : a Treatise of the Phenomena, Laws, and Development of Human Mental I.ife. 8vo., 21 s.

Lewes.-The History of Philosophy, from Thales to Comte. By GEORGE HENRY LEWES. 2 vols. 8vo., 32 s.

Max Müller.-Works by F. MAx MöLLER.

The Science of Thought. 8vo., 2 is. Three Introductory Lectures ON THE SCIENCE OF Thought. 8vo., 2s. $6 d$.

Mill.-Analysis of the Phenomena OF THE Human Mind. By James Mill. 2 vols. 8vo., 28 s.

Mill.-Works by John StuART Mill.

A System of Logic. Cr. 8vo., 3s. 6d. ON Liberty. Cr. 8vo., is. $4 d$.

On Representative GovernMent. Crown 8vo., $2 s$.

UTILITARIANISM. 8vo., $5^{s}$.

EXAMINATION OF SIR IVILLIAM HAMILton's Philosophy. 8vo., i6s.

NAtURE, THE UTILITy OF RELIGION, And Theism. Three Essays. 8vo., $5^{5}$.

Monck.-Introduction to Logic. By W. H. S. Monck. Crown 8vo., $5^{s}$.

Sidgwick.-Distinction: and the Criticism of Belief. By ALFRED SIDGWICK. Crown 8vo., $6 s$.

Stock.-Deductive Logic. By S'T. GeORge Stock. Fcp. 8vo., 3s. $6 d$.

Sully.-Works by James Sully.

The Human Mind: a Text-book of Psychology. 2 vols. 8vo., 21 s.

Outlines of Psychology. 8vo., 9s.

THE TEACHER'S HANDBOOK OF PSYCHOLOGY. Crown 8vo., $5^{5}$.

Swinburne.-Picture Logic: an Attempt to Popularise the Science of Reascning. By Alfreded James SwinBURNE, M.A. With 23 Woodcuts. Post 8vo., $5^{s}$. 


\section{Mental, Moral and Political Philosophy-continued.}

Thomson.-Outlines of THE NeCESSARY LAwS OF ThOUght: a Treatise on Pure and Applied Logic. By WILLIAM THOMSON, D.D., formerly Lord Archbishop of York. Post 8vo., 6s.

Webb.-THE VEIL OF IsIS: a Series of Essays on Idealism. By T. E. WebB. 8vo., ros. $6 d$.

Whately.-Works by R. WhATELY, D.D.

BACON's EssAYs. With Annotation. By R. Whately. 8vo., Ios. $6 d$.

Elements of Logic. Cr. 8vo., 4 s. $6 d$. Elements of Rhetoric. Cr. 8vo., $4 s, 6 d$.

Lessons on ReAsoning. Fcp. 8vo., Is. $6 d$.
Zeller.-Works by Dr. EdwaRD ZELLER, Professor in the University of Berlin.

The Stoics, Epicureans, AND SCePTICS. Translated by the Rev. O. J. REICHEL, M.A. Crown 8vo., I5s.

OUTLINES OF THE History OF GREEK Philosophy. Translated by SARAH F. Alleyne and Evelyn AbBott. Crown 8vo., Ios. $6 d$.

Plato AND THE Older ACAdemy. Translated by SARAH F. ALLEYNE and Alfred Goodwin, B.A. Crown 8vo., I8s.

SOCR ATES AND THE SOCRATIC SCHOOLS. Translated by the Rev. O. J. REICHEL, M.A. Crown 8vo., Ios. 6.

\section{MANUALS OF CATHOLIC PHILOSOPHY. (Stonyhurst Series.)}

A Manual of Political Economy. Moral Philosophy (Ethics and NatuBy C. S. Devas, M.A. Cr. 8vo., 6s. $6 d$.

First Principles of KNowledge. By JOHN RiCKABY, S. J. Crown 8vo., 5 s.

General Metaphysics. By John RickABY, S.J. Crown 8vo., $5^{s}$.

LOGIC. By RICHARD F. CLARKE, S.J. Crown 8vo., $5^{s}$. RAL LAW). By JOSEPH RICKABY, S.J. Crown 8vo., 5 s.

Natural Theology. By Bernard Boedder, S.J. Crown 8vo., 6s. $6 d$.

Psychology. By Michael Maher, S.J. Crown 8ro., 6s. 6d.

\section{History and Science of Language, \&c.}

Davidson.-Leading and Important ENGLISH WORDS: Explained and Exemplified. By William L. DavidSON, M.A. Fcp. 8vo., 3s. 6d.

Farrar.-Language and Languages. By F. W. FARraR, D.D., F.R.S., Cr. 8vo., 6s.

Graham.-English Synonyms, Classified and Explained: with Practical Exercises. By G. F. Grahan. Fcp. 8 vo., $6 s$.

Max Müller.-Works by F. MAx MÜLLER.

The Science of LANguage, Founded on Lectures delivered at the Roval Institution in $186 \mathrm{I}$ and 1863.2 vols. Crown 8vo., $21 s$.

BIOGRAPHIES OF WORDS, AND THE HOME OF THE ARYAS. Crown 8vo., 7s. $6 d$.
Max Muiller.-Works by F. Max MULLER-continued.

Three Lectures on the Science of Language, aNd its Place in General Education, delivered at Oxford, 1889. Crown 8vo., 3 s.

Roget.-Thesaurus of English Words ANd Phrases. Classified and Arranged so as to Facilitate the Expression of Ideas and assist in Literary Composition. By Peter Mark Roget, M.D., F.R.S. Recomposed throughout. enlarged and improved, partly from the Author's Notes, and with a full Index, by the Author's Son, JOHN LEWIS RCGET. Crown 8vo., Ios. $6 d$.

Whately.-English Syronyms. By E. JaNe Whately. Fcp. 8ro., 3 s. 


\section{Political Economy and Economics.}

Ashley.-English Economic History AND THEORY. By W. J. ASHLEY, M.A. Crown 8vo., Part I., 5s. Part II., ros. $6 d$.

Bagehot.-Economic Studies. By Walter Bagehot. 8vo., ros. $6 d$.

Barnett.-PRACTICABLE Socialism : Essays on Social Reform. By the Rev. S. A. and Mrs. BarnetT. Cr. 8vo., $6 s$. Brassey.-PAPERS AND ADDRESSES ON WORK AND WAGES. By Lord BRAsSEY. Edited by J. POTTER, and with Introduction by GEORGE HOWELL, M.P. Crown 8vo., 5 s.

Devas.-A Manual of Political Economy. By C. S. Devas, M.A. Crown 8vo., 6s. 6d. (Manuals of Catholic Philosophy.)

Dowell.-A History of Taxation AND TAXES in ENGland, from the Earliest Times to the Year 1885. By STEPHEN Dowel. (+ vols. 8vo.) Vols. I. and II. The History of Taxation, 2Is. Vols. III. and IV. The History of Taxes, 2 Is.

Jordan.-The Standard of Value. By William Leighton JoRdan. 8vo., $6 s$.

Leslie.-Essays in Political Economy. By T. E. Cliffe Leslie. 8vo., ros. 6 d.

Macleod.-Works by Henry Dunning MACLEOD, M.A.

BiMETALISM. 8vo., 5 s. net.

The Elements of Banking. Crown 8 vo., 3s. 6d.

The Theory and Practice of BankING. Vol. I. 8vo., I2s. Vol. II. I4s.

THE THEORY OF CREDit. 8vo. Vol. I. ros. net. Vol. II., Part I., 4 s. $6 d$. Vol. II. Part II., 1os. $6 d$.
Mill.-Political Economy. By John STUART MILL.

Popular Edition. Crown 8vo., 3s. 6.t. Library Edition. 2 vols. 8vo, 30s.

Shirres.-An ANALYSIS of THE IDEAS of EcoNonics. By L. P. SHIRREs, B.A., sometime Finance Under-Secretary of the Government of Bengal. Crown 8 vo., 6s.

Symes.-Political Economy : a Short Text-book of Political Econony. With Problems for Solution, and Hints for Supplementary Reading. By Prof. J. E. Symes, M.A., of University College, Nottingham. Crown 8vo., 2s. 6d.

Toynbee.-Lectures oN THE INDUSTRIAL REVOLUTION OF THF I8th Century in ENgland. By ARNold TOYNBEE. With a Memoir of the Author by B. JowetT. 8vo., ros. $6 d$.

W e b b.-The History of TRAde UNIONISM. By SIDNEY and BEATRJCE WEBB. With MIap and full Bibliography of the Subject. 8 vo., 18 s.

Wilson.-Works by A. I. WILson. Chiefiy reprinted from The Investors' Revieio.

Phactical, Hints to Small INvestors. Crown $8 *^{\circ}$, , is.

Plain Advice about Life Insurance. Crown 8vo., is.

\section{Exolution, Anthropology, \&c.}

Clodd.-Works by EDWARD CLODD.

THE STORY OF CREATION : a Plain Account of Evolution. With 77 Illustrations. Crown 8vo., 3s. 6d.

A Primer of Evolution: being a Popular Abridged Edition of "The Story of Creation'. With Illust. Fcp. 8vo., is. 6d. [In the Press.

Huth.-THE MARRIAGE OF NEAR Kin. considered with Respect to the Law of Nations, the Result of Experience, and the Teachings of Biology. By ALFRED HENRY HUTH. Royal 8vo., 7s. $6 d$.

Lang.-CUSTOM AND MYTH: Studies of Early Usage and Belief. By ANDREw LANG, M.A. With I5 Illustrations. Crown 8vo., 3s. $6 d$.
Lubbock.-THE Origin OF CivilisaTION and the Primitive Condition of Man. By Sir J. Lubвоск, Bart., M.P. With 5 Plates and 20 Illustrations in the Text. 8vo. 18 s.

Romanes.-Works by GEORGE JOHN ROMANES, M.A., LL.D., F.R.S.

DARWIN, AND AFTER DARWIN : an Exposition of the Darwinian Theory, and a Discussion on Post-Darwinian Questions. Part I. The Darwinian Theory. With Portrait of Darwin and 125 Illustrations. Crown 8vo., IOs. $6 d$.

an Examination of Weismannism. Crown 8vo., 6s. 


\section{Classical Literature and Translations, \&c.}

Abbott.-HellenicA. A Collection of Essays on Greek Poetry, Philosophy, History, and Religion. Edited by EVElyN Aввотt, M.A., LL.D. 8vo., $16 s$.

Aschylus.-Eumenides of ÆschyLUS. With Metrical English Translation. By J. F. Davies. 8vo., $7 s$.

Aristophanes.-The ACHarnians of AristophaNes, translated into English Verse. By R. Y. Tyrrell. Crown 8 vo., Is.

Becker.-Works by Professor BECKer.

Gallus : or, Roman Scenes in the Time of Augustus. Illustrated. Post 8vo., 7s. $6 d$.

CHARICLES : or, Illustrations of the Private Life of the Ancient Greeks. Illustrated. Post 8vo., 7s. 6d.

Cicero.-Cicero's CoRrespondence. By R. Y. TYrRell. Vols. I., II., III. 8vo., each i2s. Vol. IV., I5s.

Farnell.-Greek LyriC POETRY : a Complete. Collection of the Surviving Passages from the Greek Song-Writing. Arranged with Prefatory Articles, Introductory Matter and Commentary. By GeORge S. FARNELL, M.A. With 5 Plates. 8vo., I6s.

Harrison.-MYTHS OF THE ODYSSEY in ART AND Literature. By Jane E. HARRISON. Illustrated with Outline Drawings. 8\%o., I8s.

Lang.-HOMER AND THE EPIC. By ANDREw LaNG. Crown 8vo., gs. net.

Mackail.-SEleCt EPIGRAMS FROM THE Greek ANThology. By J. IV. MackaIL, Fellow of Balliol College, Oxford. Edited with a Revised Text, Introduction, 'Translation, and Notes. 8 vo., I6s.
Plato.-Parnenides of Plato, Text, with Introduction, Analysis, \&c. By $1 \%$ MAGUIRE. 8vo., $7 s .6 d$.

Rich.-A Dictionaky of Roman aNy GREek ANTIQuities. By A. Rich, B.A. With 2000 Woodcuts. Crown 8vo., 7s. $6 d$.

Sophocles.-Translated into English Verse. By ROBERT WHITELAW, M.A., Assistant Master in Rugby School : late Fellow of Trinity College, Cambridge. Crown 8 vo., $8 s, 6 d$.

Theocritus.-THE IDylls of TheOCRI'TUS. Translated into English Verse. By James HeNry Hallard, M.A. Oxon. Fcp. 4to., 6s. 6d.

Tyrrell.-Translations into Greek AND Latin Verse. Edited by R. Y. TYRRELL. 8 vo., 6 s.

Virgil.-The ÆNeID of VirgiL. Translated into English Verse by Jонx CoxINGTON. Crown 8vo., $6 s$.

The Poems of Virgil. Translated into English Prose by JoHN ConingTON. Crown 8vo., $6 s$.

THE ÆNEID OF VIRGIL, freely translated into English Blank Verse. By W. J. ThORNHILL. Crown 8vo., 7s. 6d.

THE ÆNeID OF VIRGIL. Books I. to VI. Translated into English Verse by JaMes RhoAdes. Crown 8vo., 5 s.

Wilkins.-THE Growth OF THE HoMERIC POEMS. By G. WilkiNs. 8vo. 6 s.

\section{Poetry and the Drama.}

\section{Allingham.-Works by William ALLINGHAM.}

Irish Songs and Poems. With Frontispiece of the Waterfall of Asaroe. Fcp. 8vo., 6 s.

Laurence Bloomfifld. With Portrait of the Author. Fcp. 8vo., 3s. 6d.

Flower Pieces; Day and Night Songs; Ballads. With 2 Designs by D. G. RossetTi. Fcp. 8vo., 6s.; large paper edition, I2s.
Life AND Phantasy: with Frontispiece by Sir J. E. Millais, Bart., and Design by ArThur Hughes. Fcp. 8vo., 6s. ; large paper edition, I2s.

Thought AND Word, AND AShby MANOR: a Play. With Portrait of the Author (1865), and four Theatrical Scenes drawn by Mr. Allingham. Fcp. 8vo., 6s.; large paper edition, r2s.

BLACKBERRIES. Imperial r6mo., $6 s$.

Sets of the above 6 vols. may be had in uniform half-parchment binding, price 3 os. 


\section{Poetry and the Drama-continued.}

Armstrong.-Works by G. F. SAvaGe- Goethe.

\section{ARMSTRONG.}

POEMS: Lyrical and Dramatic. Fcp. 8vo., 6s.

KING SAUL. (The Tragedy of Israel, Part I.) Fcp. 8vo. 5s.

KING DAvid. (The Tragedy of Israel, Part II.) Fcp. 8vo., 6s,

KING Solomon. (The Tragedy of Israel, Part III.) Fcp. 8vo., 6s.

UGONE: a Tragedy. Fcp. 8vo., 6s.

A Garland From GreEce: Poems. Fcp. 8vo., 7s. $6 d$.

StORIES OF Wicklow: Poems. Fcp. 8 vo., $7 s .6 d$.

Mephistopheles in BROAdCloth : a Satire. Fcp. 8vo., 4 s.

ONe IN the INfinite: a Poem. Cr. 8 vo., 7 s. $6 \%$.

Armstrong:- - The Poetical Works of EDMUND J. ARMistrong. Fcp. 8vo., $5^{s}$.

Arnold.--Works by Sir EDWIN ARNOLD, K.C.I.E., Author of 'The Light of Asia,' \&c.

THE Light OF THE WORLD: or, the Great Consummation. A Poem. Crown 8vo., 7 s. 6d. net.

Presentation Edition. With 14 Illustrations by W. HolmaN HUNT. 4to., 20s. net.

POTIPHAR'S WIFE, and other Poems. Crown 8vo., 5 s. net.

ADZuMA: or, the Japanese Wife. A Play. Crown 8vo., 6s. $6 d$. net.

Bell.-Chamber Comedies: a Collection of Plays and Monologues for the Drawing Room. By Mrs. HugH Bell. Crown 8vo., 6́s.

Björnsen.-Works by BJÖRNSTJERNE BJÖRNSEN.

PASTOR SANG : a Play. Translated by William Wilsox. Cr. 8vo., 5 s.

A Gauntlet: a Drama. Translated into English by OSMAN EDWARDS. With Portrait of the Author. Crown 8 vo., 5 s.

Cochrane.-'The Kestrel's Nest, and other Verses. By Alfred Cor.HRANE. Fcp. 8vo., 3s. $6 d$.

Dante.-LA Commedia di DANTE. A New Text, carefully revised with the aid of the most recent Editions and Collations. Small 8vo., $6 \mathrm{~s}$.
FAUsT, Part I., the German Text, with Introduction and Notes. By ALBERT M. Selss, Ph.D., M.A. Cr. 8vo., 5 s.

FAust. Translated, with Notes. By T. Е. Webi. 8vo., 12s. $6 d$.

Ingelow.-Works by JEAN INGELOW.

POETICAL Works. 2 vols. Fcp. 8vo., I2s.

Lyrical and Other Poems. Selected from the Writings of JEAN INGELOW. Fcp. 8vo., 2s. 6d.; cloth plain, $3^{s}$. cloth gilt.

Kendall.-Songs FROM DREAMLAND. By MaY KeNDAll. Fcp. 8vo., 5s. net.

Lang.-Works by ANDREw LANG.

BAN AND ARrière BAN. A Rally of Fugitive Rhymes. Fcp. 8vo., 5 s. net.

Grass OF Parnassus. Fcp. 8vo., 2s. $6 d$. net.

BALlads of Books. Edited by ANDREW LANG. Fcp. 8vo., 6s.

The Blue Poetry Book. Edited by ANDREW LANG. With 12 Plates and 88 Illustrations in the Text by H. J. FORD and LANCELOT SPEED. Crown 8 vo., $6 s$.

Special Edition, printed on Indian paper. With Notes, but without Illustrations. Crown 8vo., 7s. $6 d$.

Lecky.-Poems. By W. E. H. Lecky. Fcp. 8vo., $5^{s}$.

Leyton.-Works by FrANK LEYTON.

The SHadows of THE LAKE, and other Poems. Crown 8vo., 7s. $6 d$. Cheap Edition. Crown 8vo., 3s. $6 d$.

Skeletox Leaves: Poems. Crown 8 vo., $6 s$.

Lytton.-Works by THE EARL OH LyTtON (OWEN MEREdiTH).

MARAH. Fcp. 8vo., 6s. 6d.

KING POPPY: a Fantasia. With I Plate and Design on Title-Page by Sir ED. Burne-Jones, A. R.A. Crown 8 vo., IOS. $6 d$.

The Wanderer. Cr. 8vo., ios. $6 \mathrm{~d}$.

LuCile. Crown 8vo., Ios. $6 d$.

Selected Poems. Cr. 8 vo., ros. $6 d$. 


\section{Poetry and the Drama-continued.}

Macaulay.-LAys of ANcient Rome, \&c. By Lord MACALLAY.

Illustrated by G. Scharf. Fcp. 4to., IOS. $6 d$.

I8mo., 2s. 6d., gilt top.

Bijou Edition.

Popular Edition.

Fcp. fto., 6d. sewed, Is. cloth.

I!lustrated by J. R. Weguelix. Crown 8 ro., 3s. 6d.

Ánnotated Edition. Fcp. 8ro., Is. sewed, is. $6 d$. cloth.

Nesbit.-Lays AND Legexds. By E. Nesbit (Mrs. Hubert Bland). First

Series. Crown 8vo., 3s. 6d. Second

Series, with Portrait. Crown 8vo., $5 s$.

Piatt.-Works by SARAH PiatT.

POEMS. With portrait of the Author. 2 vols. Crown 8 ro., Ios.

AN Exchanted Castle, and other Poevs : Pictures, Portraits and People in Ireland. Crown 8vo., 3s. $6 d$.
Piatt.-Works by Johx JAMes PiAtT. IDYLS AND LYRICS OF THF. OHIO VAlley. Crown 8vo., 5 s.

Little New Morld IDYls. Cr. 8ro., $5 s$.

Rhoades.-TERESA AND OTHER POEMS. By JAMES RHOADEs. Crown 8vo., 3 s. $6 \dot{d}$.

Riley.-Works by JAMes WhitcomB RILEY.

Old FAshioned Roses: Poems. I $2 \mathrm{mo}$., $5^{s}$.

Poems Here at Home. Fcap. 8ro., $6 s$. net.

Roberts. - SoNgs of THE COMMON DAY, AND AVE: an Ode for the Shelley Centenary By CHARles G. D. ROBERTS. Crown 8ro., 3s. $6 d$.

Shakespeare.-BOwdLE's FAMILY SHAKESPEARE. With 36 Toodcuts. I vol. 8vo., Ifs. Or in 6 vols. Fcp. 8vo., $21 s$.

The Shakespeare Birthday Book. By Mary F. Dixbar. 32mo., is. 6d. Drawing-Room Edition, with Photographs. Fcp. 8ro., Ios. 6d.

Sturgis.-A Воок оF Sorg. By Juliax STURGIS. I6mo., 5 s.

\section{Works of Fiction, Humour, \&c.}

Anstey.-Works by F. AxsteY, Author of 'Vice Versâ'.

THE BLACK PoOdLE, and other Stories. Crown 8vo., 2s. boards, 2s. 6 d. cloth.

VOCES POPLLI. Reprinted from 'Punch'. First Series. With 20 Illustrations by J. BERNARD PARTRIDGE. Cr. 8vo., 3s. $6 d$.

The Trayelling Companions. Reprinted from 'Punch'. With 25 Iliustrations by J. BERNARD PARTRIDGE. Post 4to., 5 s.

THE MAN FROM BLANKLEY'S : a Story in Scenes, and other Sketches. With 24 Illustrations by J. BERNARD PARTRIDGE. Fcp. 4 to., 6 s.

Astor.-A Journey INOTHe; Morlds. a Romance of the Future. By JоHs JACOB AstoR. With ro Illustrations. Cr. 8vo., $6 s$.
Baker.-BY THE MESTERN SEA. By JAMES BAKER, Author of 'John Westacott'. Crown 8ro., 3s. 6.l.

Beaconsfield.-Works by the Earl of BEACONSFIELD.

Novels Axd Tales. Cheap Edition. Complete in I r vols. Cr. 8vo., is. 6.t. each.

Vivian Grey. $\quad$ Henrietta Temple.

TheYoungDuke, \&c. Venetia. Tancred. Alroy, Ixion, \&c. Coningsby. Sybil. Contarini Fleming. Lothair. Endymion. \&c.

Novels axd Tales. The Hughenden Edition. With 2 Portraits and II Vignettes. I I vols. Cr. 8vo., 42 .

Clegg.-DArid's Loom: a Story of Rochdale life in the early years of the Nineteenth Century. By JoHx TR.AFFORD CI.EGG. Cruwn sio. $6 s$. 


\section{Yorks of Fiction, Humour, \&c.-continued.}

Deland.-Works by MARGARET DE- Haggard.-Works by H. Rider HAGLAND, Author of 'John Ward'.

The Story of A Child. Cr. 8vo., 5 s.

Mr. Tommy Dove, and other Stories. Crown 8vo., $6 s$.

Philip AND His Wife. Cr. 8vo, $6 s$.

Dougal1.-Works by L. Dougall.

Beggars All. Crown 8vo., 3 s. $6 d$.

What Necessity Knows. Crown 8 vo., $6 s$.

Doyle.-Works by A. Conan Doyle.

MICAH CLARKE : a Tale of Monmouth's Rebellion. With Frontispiece and Vignette. Cr. 8vo., 3s. 6d.

The Captain of the Polestar, and other Tales. Cr. 8vo., 3s. $6 d$.

The Refugees: a Tale of Two Continents. Cr. 8vo., 6 s.

Farrar.-DARKNESS AND DAWN: or, Scenes in the Days of Nero. An Historic Tale. By Archdeacon FARRAR. Cr. 8vo., 7s. $6 d$.

Forster.-MAJOR Joshua. By Francis Forster. Crown 8vo., $6 s$.

Froude.-The Two Chiefs of DuNBOY: an Irish Romance of the Last Century. By J. A. Froune. Cr. 8vo., 3s. $6 d$.

Gilkes. - The Thing That Hath BEEN: or, a Young Man's Mistake. By A. H. Gilkes, M.A., Master of Dulwich College, Author of 'Boys and Masters'. Crown 8vo., $6 s$.

Haggard.-Works by H. RIDER HAGGARD.

SHE. With 32 Illustrations. Crown 8vo., 3 s. $6 d$.

Allan Quatermain. With 3 I Illustrations. Crown 8ro., $3^{s}$. $6 d$.

MAIWA'S REvENGE; or, The War of the Little Hand. Cr. 8vo., Is. boards, Is. $6 d$. cloth.

Colonel. Quaritch, V.C. Cr. 8vo., 3. $6 d$.

Cleopatra. With 29 Illustrations Crown 8vo., 3 s. $6 d$.

Beatrice. Cr. 8vo., 3 s. $6 d$.

GARD-continued.

ERIC Brighteyes. With 5I Illustrations. Cr. 8vo., 3s. 6d.

NADA THE LILy. With 23 Illustrations. Cr. 8vo., $6 s$.

Montezuma's Daughrer. With 24 Illustrations. Crown 8vo., $6 s$.

Allan's WrFe. With 34 Illustrations. Crown 8vo., $3^{s}$. $6 d$.

The Witch's Head. With r6 Illustrations. Crown 8vo., 3 s. $6 d$.

Mr. MeEson's WiLl. With I6 Illustrations. Crown 8vo., $3 s .6 d$.

DAws. With r6 Illustrations. Crown 8vo., $3^{s .6} 6$.

The People of the Mist. With 16 Illustrations. Cr. 8vo., 6 s.

Haggard and Lang.-THE WorLD's DESIRE. By H. RIDER HAGGARD and ANDREW LANG. With 27 Illustrations by M. GREIfFEnhagen. Cr. 8vo., $3 s .6 d$.

Harte.-IN THE CARQUiNEZ WOODS, and other Stories. By BRET HARTE. Cr. 8vo., 3s. 6d.

Hornung.--The UNEIDden Guest. By E. W. Hornung. Crown 8vo, $6 s$.

Lyall.-Works by EDNa LyaLL, Author of 'Donovan,' \&c.

The Autobiography of a Slander. Fcp. 8vo., Is. sewed.

Presentation Edition. With 20 Illustrations by LANCELOT SPEED. Cr. 8 vo., 2s. 6d. net.

Doreen: The Story of a Singer. Cr. 8 vo., $6 s$.

Melville.-Works by G. J. Whyte MELVILle.

The Gladiators.

The Interpreter.

Good for Nothing.

Holmby House. Kate Coventry. Digby Grand.

The Queen's Maries. General Bounce. Cr. 8vo., Is. 6d. each.

Oliphant.-Works by Mrs. Oliphant. MADAM. Cr. 8vo., is. $6 d$.

In Trust. Cr. 8vo., Is. $6 d$.

Parr.-CAN THIS BE Love? By Mrs. PARR, Author of 'Dorothy Fox'. Cr. 8vo., $6 s$. 


\section{Works of Fiction, Humour, \&c.-continused.}

Payn.-Works by JAMES PAYN.

THE LUCK OF THE DARRELls. Cr. 8 vo., Is. $6 d$.

Thicker than Water. Cr. 8vo., Is. $6 d$.

Phillipps-Wolley.-SNAP: a Legend of the Lone Mlountain. By C. PHILLIPPS-WOLLEY. With 13 Illustrations by H. G. Willink. Cr. 8vo., $3 s .6 d$.

Sewell.--Works by Elizabeth M. SEWELL.

A Glimpse of the World. Amy Herbert.

Laneton Parsonage.

Margaret Percival.

Katharine Ashton.

The Earl's Daughter.

Cleve Hall.

Gertrude.

Home Life.

After Life.

The Experience of Life. Ursula. I vors.

Cr. 8vo., Is. $6 d$. each cloth plain. $2 s .6 d$. each cloth extra, gilt edges.

Stevenson.-Works by ROBERT Louis Stevenson.

STRANGE CASE OF DR. JekYll and MR. HYDE. Fcp. 8ro., Is. sewed. Is. 6d. cloth.

The Dynamiter. Fcp. 8vo., is. sewed, Is. 6 d. cloth.

Stevenson and Osbourne.--THE

WRONG Box. By RoBERT LOUIS STEVENSON and Lloyd Osbourne. Cr. 8 vo., 3 s. $6 d$.

Suttner.-LAY Down Your ARMS Die Waffen Nieder: The Autobiography of Martha Tilling. By BERTHA VON SUTTNER. Translated by T. Holmes. Cr. 8vo., is. $6 d$.

Trollope.-Works by Anthony TroLLOPE.

The Warden. Cr. 8vo., is. $6 d$.

BARCHESTER TOWERs. Cr. 8vo., is. $6 d$.
TRUE, A, RELATION OF THE Travels and PHRILOUS AdVENTURES OF MATHEW DUDGEON, Gentleman: Wherein is truly set down the Manner of his Taking, the Long Time of his Slavery in Algiers, and Nleans of his Delivery. Written by Himself, and now for the first time printed Cr. 8vo., 5 s. Walford.-Works by L. B. WALFORD. Mr. Smith : a Part of his Life. Crown 8 vo., $2 s .6 d$.

The Baby's Grandmother. Crown 8vo., 2s. 6d

Cousins. Crown 8 vo. 2s. $5 d$.

Troublesone Daughters. 8 vo., 2s. $6 \%$.

Pauline. Crown 8vo. 2s. $6 d$.

Dick Netherby. Crown 8vo., 2s. $6 d$.

The History of a Week. Crown 8vo. 2s. $6 d$.

A Stiff-ni:Cked Generation. Crown 8 vo. $2 s .6 \%$.

NAN, and other Stories. Cr. 8vo., 2s. $6 d$.

The Miscinef of MoNica. Crown 8 vo., $25.6 d$.

The One Good Guest. Cr. 8vo. 2s. $6 d$.

'Ploughed,' and other Stories. Crown 8 vo., 6 s.

The Matchmaker. 3 Vols. Cr. 8vo. West.-Works by B. B. WVEST.

Half-Hours with the MillionAIRES : Showing how much harder it is to spend a million than to make it. Cr. 8vo., 6s.

SiR SiMON VANDERPETTER, AND MINDING HIS ANCESTORS. Two Rcformations. Crown 8 vo., $5 s$.

Weyman.-Works by S. J. WeYMan.

ThE House of THE TVOLf. Cr. 8vo., 3s. $6 d$.

A Gentleman of France. Cr. 8vo., $6 s$.

\section{Popular Science (Natural History, \&c.).}

Butler.-Our Housenold Insects. Hartwig.-Works by Dr. George An Account of the Insect-Pests found in Dwelling-Houses. By EDward A. Butler, B.A., B.Sc. (Lond.). With II3 Illustrations. Crown 8vo., 6 s.

Furneaux.-Works by W. Furneaux.

THE OUTDOOR WORLD; or, The Young Collector's Handbook. With 18 Plates, I6 of which are coloured, and 549 Illustrations in the Text. Crown 8vo., 7s. $6 d$.

BUtTERflies AND Moths (British). With 12 coloured Plates and 24I Illustrations in the Text. Crown 8vo., Ios. $6 d$. net.

HARTWIG.

The SEA ANd its Living Wonders. With 12 Plates and 303 Woodcuts. 8 vo., 7 s. net.

The Tropical World. With 8 Plates and 172 Woodcuts. 8vo., $7 s$. net.

The Polar World. With 3 N.Taps, 8 Plates and 85 Woodcuts. 8vo., $7 s$. net.

The Subterranean World. With 3 Maps and 80 Woodcuts. 8vo., 75 . net.

The Aerial World. With Map, 8 Plates and 60 Woodcuts. 8vo., $7 s$. nst. 


\section{Popular Science (Natural History, \&c.).}

Hartwig.-Works by Dr. George HARTWIG-continued.

Heroes OF THE POLAR World. I9 Illustrations. Crown 8vo., $2 s$.

WONDERS OF THE TROPICAL Forests. 40 Illustrations. Crown 8vo., 2 .

WORKERS UNDER THE GROUND. 29 Illustrations. Crown 8vo., 2s.

Marvels Over our Heads. 29 Illustrations. Crown 8vo., 25.

Sea Monsters and Sea Birds. 75 Illustrations. Crown 8vo., 2s. $6 d$.

Denizens OF THE DeEP. II 7 Illustrations. Crown 8vo., 2s. $6 d$.

VOlCANOES AND EARTHQUAKES. 30 Illustrations. Crown 8vo., 2s. $6 d$.

Wild Animals of the Tropics. 66 Illustrations. Crown 8vo., $3 s .6 d$.

Helmholtz.-POPUIAAR LECTURES ON SCIENTIFIC SubJects. By HermanN voN HELMHOITZ. With 68 Woodcuts. 2 vols. Crown 8 vo., $3^{s}$. $6 d$. each.

\section{Proctor.-Works by RICHARD PROCTOR.}

Light SCIENCE FOR Leisure Hours. Familiar Essays on Scientific Subjects. 3 vols. Crown 8vo., 5 s. each.

Chance AND LUCK: a Discussion of the Laws of Luck, Coincidence, Wagers, Lotteries and the Fallacies of Gambling, \&c. Cr. 8vo., $2 s$. boards, 2s. $6 d$. cloth.

Rough Ways made Smooth. Familiar Essays on Scientific Subjects. Silver Library Edition. Crown 8vo., 3s. $6 d$.

Pleasant Ways in Science. Cr. 8vo., 5s. Silver Library Edition. Crown 8vo., 3s. 6d.

The Great Pyramid, Observatory, TOMB AND TEMPLE. With Illustrations. Crown 8vo., $5^{s}$.

Nature Studies. By R. A. Proctor, Grant Allen, A. Wilson, T. Foster and E. Clodd. Crown 8 vo., 5s. Silver Library Edition. Crown 8vo., 3s. $6 d$.

Leisure ReAdings. By R. A. ProcTOR, E. ClODD, A. WILSON, T. Foster, and A. C. Ranyard. Cr. 8 vo., 5 s.
Stanley.-A Familiar History of Birds. By E. Stanley, D.D., formerly Bishop of Norwich. With Illustrations. Cr. 8 vo., 3 s. $6 d$.

Wood.-Works by the Rev. J. G. WooD.

Homes without Hands: a Description of the Habitation of Animals, classed according to the Principle of Construction. With r 40 Illustrations. 8vo., 7s. net.

INSECTS AT HOME : a Popular Account of British Insects, their Structure, Habits and Transformations. With 700 Illustrations. 8vo., 7s. net.

INSECTS ABROAD : a Popular Account of Foreign Insects, their Structure, Habits and Transformations. With 600 Illustrations. 8vo., 7 s. net.

Bible Animals: a Description of every Living Creature mentioned in the Scriptures. With II2 Illustrations. 8vo., $7 s$. net.

Petland Revisited. With 33 Illustrations. Cr. 8vo., 3s. $6 d$.

OUT OF DooRs; a Selection of Original Articles on Practical Natural History. With I I Illustrations. Cr. 8vo., $3^{s}$. $6 d$.

Strange Dwellings: a Description of the Habitations of Animals, abridged from 'Homes without Hands'. With 6o Illustrations. $\mathrm{Cr}$. 8vo., 3s. $6 d$.

Bird Life of the Bible. 32 Illustrations. Cr. 8vo., 3s. $6 d$.

Wonderful Nests. 30 Illustrations. Cr. 8vo., 3s. 6d.

HoMES UNDER THE GRoUnd. 28 Illustrations. Cr. 8vo., 3 s. $6 d$.

Wild ANimals of the Bible. 29 Illustrations. Cr. 8vo., 3s. 6d.

Domestic Animals of the Bible. 23 Illustrations. Cr. 8vo., $3^{\text {s. } 6 d \text {. }}$

The Branch Builders. 28 Illustrations. Cr. 8vo., 2s. $6 d$.

Social Habitations and Parasitic Nests. 18 Illustrations. $\mathrm{Cr}$. 8vo., $2 s$. 


\section{Works of Reference.}

Maunder's (Samuel) Treasuries.

BIOGRAPHICAL. TREASURY. With Supplement brought down to I88, By Rev. JAMES WOoD. Fcp. 8vo., $6 s$.

TREASURY OF NATURAL History : or, Popular Dictionary of Zoology. With 900 Woodcuts. Fcp. 8vo., 6 s.

Treasury of Geography, Physical, Historical, Descriptive, and Political. With 7 Maps and 16 Plates. Fcp. 8 vo., $6 s$.

The Treasury of Bible KnowLEDGE. By the Rev. J. AYre, M.A. With 5 Maps, I5 Plates, and 300 Woodcuts. Fcp. 8vo., $6 s$.

HISTORICAL TREASURY: Outlines of Universal History, Separate Histories of all Nations. Fcp. 8vo., $6 s$.

TREASURY OF KNOWLEDGE AND LIBRARY OF REFERENCE. COMprising an English Dictionary and Grammar, Universal Gazeteer, Classical Dictionary, Chronology, Law Dictionary, \&c. Fcp. 8vo., 6s.
Maunder's (Samuel) Treasuries -continued.

SCIENTIFIC AND Literary TREasUry. Fcp. 8vo., 6s.

The Treasury of Botany. Edited by J. LindLEY, F.R.S., and T. Moore, F.L.S. With 274 Woodcuts and 20 Steel Plates. 2 vols. Fcp. 8vo., I2s.

Roget.--Thesaurus OF ENGLISHWORDS AND PHrases. Classified and Arranged so as to Facilitate the Expression of Ideas and assist in Literary Composition. By PETER MARK ROGET, M.D., F.R.S. Recomposed throughout, enlarged and improved, partly from the Author's Notes, and with a full Index, by the Author's Son, JoHN LEwis Roget. Crown 8vo., Ios. $6 d$.

Willich.-POPULAR TABLES for giving information for ascertaining the value of Lifehold, Leasehold, and Church Property, the Public Funds, \&c. By Charles M. Willich. Edited by $\mathrm{H}$. BENCE Jones. Crown 8vo., Ios. $6 d$.

\section{Children's Books.}

Crake.-Works by Rev. A. D. CRAKE. EDwy THE FAIR; or, the First Chronicle of Escendune. Crown 8vo., 2s. $6 d$.

AlfGAR The DANE: or, the Second Chronicle of Escendune. Cr. 8vo., zs. 6d.

The Rival Heirs: being the Third and Last Chronicle of Æscendune. Cr. 8vo., 2s. $6 d$.

The House of Walderne. A Tale of the Cloister and the Forest in the Days of the Barons' Wars. Crown 8vo., 2s. $6 d$.

Brian Fitz-Count. A Story of Wallingford Castle and Dorchester Abbey. Cr. 8vo., 2s. $6 d$.

Ingelow.-Very Young, AND QUITE ANOTHER STORY. Two Stories. By JEAN INGElow. Crown 8vo., 2s. $6 d$.

Lang.-Works edited by ANDREW LANG.

The Blue Fairy Book. With ${ }^{3} 8$ Illustrations by $H$. J. FORD and G. P. JАСОмB Hood. Crown 8vo., $6 s$.
Lang.-Works edited by ANDREW LANG - continued.

THE RED FAIRY BOoK. With 100 Illustrations by $\mathrm{H}, \mathrm{J}$. FORD and LANCElot SPEED. Cr. 8vo., $6 s$.

The GrefN FAIRY Book. With IoI Illustrations by $\mathrm{H}$. J. FORD and L. BOGLE. Crown 8vo., $6 s$.

The Yellow Fairy Book. With ro4 Illustrations by H. J. FORD. Crown 8 vo., 6s.

The Blue Portry Book. With roo Illustrations by $\mathrm{H}$. J. FORD and Lancelot Speed. Crown 8vo., $6 s$.

The Blue Poetry Book. School Edition, without Illustrations. Fcp. 8vo., 2s. 6d.

The True Story Book. With 66 Illustrations by H. J. FORD, LUCIEN Davis, C. H. M. KeRr, LANCELOT SPEED, and LOCKHART BOGL.F. Crown 8vo., $6 s$. 


\section{Children's Books-continued.}

Meade.-Works by L. T. MEADE.

DADDY's BOY. Illustrated. Crown 8vo., 3s. 6d.

DEB AND THE DUChess. Illustrated. Crown 8vo., $3^{\text {s. }} 6 \mathrm{~d}$.

Stevenson.-A CHILD's GARDEN OF VERSES. By RoBert LOUis STEVENSON.

Small fcp. 8vo., 5 s.
Molesworth.-Works by Mrs. MOLESWORTH.

SILverTHORNS. Illustrated. Cr. 8vo., $5^{5}$. The Palace a the Garden. Illustrated. Crown 8vo., 5 s.

Neighbours. Illus. Crown 8 vo., $2 s .6 d$.

\section{Longmans' Series of Books for Girls.}

Crown 8vo., price 2s. 6d. each

. TEleler (The) Du Lys: or an Art Student in the Reign of Terror.

By the same Author.

MADEMOISELle MORI: a Tale of Modern Rome.

That ChILd. Illustrated by GoRdoN BROIYNE.

UNder a Cloud.

The FiddLer of LUgAU. With Illustrations by W. RALSTON.

A Ciilld of the Revolution. With Illustrations by C. J. STANilAND.

Hestek's VentURE.

IN THE Olden Time: a Tale of the Peasant War in Germany.

THE Younger Sister.
Atherstone Priory. By L. N. Comyn.

The Third Miss St. Quentin. By Mrs. MOLESWORTH.

The Story of A SPRING MORNING, \&c. By Mrs. MOLEsworth. Illustrated.

Neighbours. By Mrs. Molesworth. Illustrated.

Very Young; and QUITE ANother StORY. Two Stories. By JEAN INGELOW.

Keith Deramore. By the Author of 'Miss Molly'.

Sidney. By Margaret Deland.

LAST WORDS TO GIRLS ON LIFE AT SCHOOL AND AFTER SCHOOL. By Mrs. W. GREY.

\section{The Silyer Library.}

Crown 8vo. 3s. 6d. EACH VOlume.

Arnold's (Sir Edwin) Seas and Lands. With 7 I Illustrations. 3s. $6 d$.

Baker's (Sir S. W.) Eight Years in Ceylon. With 6 Illustrations. $3^{s .6 d}$.

Baker's (Sir S. W.) Rifle and Hound in Ceylon. With 6 Illustrations. $3 s .6 d$.

Baring-Gould's (Rey. S.) Curious Myths of the Middle Ages. 3s. $6 d$.

Baring-Gould's (Rey. S.) Origin and Development of Religious Belief. 2 vols. 3 s. $6 d$. each.

Brassey's (Lady) $A$ Yoyage in the 'Sunbeam'. With 66 Illustrations. $3^{5.6 d}$.

Clodd's (E.) Story of Creation : a Plain Account of Evolution. With 77 Illustrations. 3s. 6 d.

Conybeare (Rey. W. J.) and Howson's (Very Rex. J. S.) Life and Epistles of St. Paul. 46 Illustrations. $3 s .6 d$.

Dougall's (L.) Beggars All; a Novel. 3s. $6 d$.
Doyle's (A. Conan) Micah Clarke : a Tale of Monmouth's Rebellion. 3s. $6 d$.

Doyle's (A. Conan) The Captain of the Polestar, and other Tales. $3 s$. $6 d$.

Froude's (J. A.) Short Studies on Great Subjects. 4 vols. $3 s .6 d$. each.

Froude's (J. A.) Cæsar : a Sketch. 3s. 6 d.

Froude's (J. A.) Thomas Carlyle: a History of his Life. I795-1835. 2 vols. $7 s$. I834-I88r. 2 vols. 75 .

Froude's (J. A.) The Two Chiefs of Dunboy: an Irish Romance of the Last Century. 3s. $6 d$.

Froude's (J. A.) The History of England, from the Fall of Wolsey to the Defeat of the Spanish Armada. 12 vols. 3s. 6 d. each.

Gleig's (Rey. G. R.) Life of the Duke of Wellington. With Portrait. 3s. $6 d$. 


\section{The Gilver Library-continued.}

Haggard's (H. R.) She: A History of Adventure. 32 Illustrations. $35.6 d$.

Haggard's (H. R.) Ellan Quatermain. With 20 lllustrations. $3 s .6 d$.

Haggard's (H. R.) Colonel Quaritch, V.C. : a Tale of Country Life. $3^{s}$. $6 d$.

Haggard's (H. R.) Cleopatra. With 29 Full-page Illustrations. $\quad 3 s$. $6 d$.

Haǵgard's (H. R.) Eric Brighteyes. With 5 I Illustrations. $3 s$. $6 d$.

Haggard's (H. R.) Eeatrice. 3 s. $6 d$.

Kaggard's (H. R.) Allan's Wife. With 34 Illustrations. 3 . $6 d$.

Hagigard's (H. R.) The Witch's Head. With Illustrations. 3s. $6 d$.

Hagigard's (H. R.) Ihr. Heeson's Will. With Illustrations. $35.6 d$.

Hagfǵard's (H. R.) Dawn. With I6 Illustrations. $3 s .6 d$.

Haggard's (H. R.) and Lang's (A.) The World's Desire. With 27 Illustrations. 3s. $6 d$.

Harte's (Bret) In the Carquinez Woods, and other stories. $3 s .6 \mathrm{~d}$.

Helmholtz's (Hermann yon) Popular Lectures on Scientific Subjects. With 68 Woodcuts. 2 vols. $3 s .6 d$. each.

Howitt's (W.) Visits to Remarkable Places. 80 Illustrations. 3s. $6 d$.

Jefferies' (R.) The Story of My Heart: My Autobiography. With Portrait. $3 s .6 d$.

Jefferies'(R.) Field and Hedgerow. Last Essays of. With Portrait. 3s. $6 d$.

Jefferies' (R.) Red Deer. With I7 Illustrations by J. CHARLTON and $\mathrm{H}$. TuNALY. $3 s, 6 d$.

Jefieries' (R.) Wood Magic: a Fable. With Frontispiece and Vignette by $\mathrm{E}$. V. B. $3 s .6 d$.

Jefferies' (R.) The Toilers of the Field. With Portrait from the Bust in Salisbury Cathedral. 3s. $6 d$.

Knight's (E. F.) The Cruise of the 'Alerte': the Narrative of a Search for Treasure on the Desert Island of Trinidad. With 2 Maps and 23 Illustrations. $3 s$. $6 d$.

Lang's (A.) Custom and Myth: Studies of Early Usage and Belief. $3 s .6 d$.

Lees (J. A.) and Clutterbuck's (W. J.) B.C. 1887, A Ramble in British Coiumbia. With Maps and 75 Illustrations. $3^{s} .6 d$.
Macaulay's (Lord) Essays and Lays of Ancient Rome. With Portrait and Illuitrations. $3 s$. $6 d$.

Macleod (H. D.) The Elements of Banking. $35.6 d$.

Marshman's (J. C.) Memoirs of Sir Henry Hayelock. $3^{s}$. $6 d$.

Max Nïller's (F.) India, what can it teach us? $35.6 d$.

Max Müller's (F.) Introduction to the Science of Religion. 3 s. 6:\%.

Merivale's (Dean) History of the Romans under the Empire. 8 vols. $35.6 a$. ea.

Mill's (J. S.) Political Economy. 3 s. $6 d$. IIill's (J. S.) System of Logic. $3^{s .6}$.

Milner's (Geo.) Country Pleasures. 3 s. $6 d$.

Phillipps-Yolley's (C.) Snap: a Legend of the Lone Mountain. With $\mathrm{r}_{3}$ Illustrations. $3 s .6 d$.

Proctor's (R. A.) The Orbs Around Us. Essays on the Moon and Planets, Metors and Comets, the Sun and Coloured Pairs of Suns. $35.6 d$.

Proctor's (R. A.) The Expanse of Heaven. Essays on the Wonders of the Firnament. $35.6 d$.

Proctor's (R. A.) Other Worlds than Durs. $3 s .6 d$.

Proctor's (R. A.) Rough Ways made Smooth. 3s. 6 d.

Proctor's (R. A.) Pleasant Ways in Science. $3 s .6 d$.

Proctor's (R. A.) Myths and Maryels of Astronomy. $3 s .6 d$.

Proçtor's (R. A.) Nature Studies. $3 s .6 d$.

Rossetti's (Maria F.) A Shadow of Dante : being an Essay towards studying Himself, his World and his Pilgrimage. With Frontispiece by DANTE GABRIEL Rossetti. $3 s .6 d$.

Smith's (R. Bosworth) Carthage and the Carthaginians. $3 s .6 d$.

Stanley's (Bishop) Familiar History of Birds. I6o Illustrations. 3s. $6 d$.

Stevenson (Robert Louis) and Osbourne's (Lloyd) The Wrong Box. $3^{s .6}$.

Weyman's (Stanley J.) The House of the Wolf: a Romance. $3 s$. $6 d$.

Wood's (Rey. J. G.) Petiand Reyisited. With 33 Illustrations. 3 s. $6 d$.

Wood's (Rey. J. G.) Strange Dwellings. With 60 Illustrations. 3 s. $6 d$.

Wocd's (Rev. J. G.) Out of Doors. II Illustrations. 3 s. $6 d$. 


\section{Cookery, Domestic Management, \&c.}

Acton.-Modern Cookery. By Eliza ACtON. With 150 Woodcuts. Fcp. 8vo., 4 s. $6 d$.

Bull.-Works by Thomas Bull, M.D.

Hints to Mothers on the ManageMENT OF THEIR HEALTH DURING THE Period of Pregnancy. Fcp. 8vo., Is. $6 d$.

The Maternal Management of CHILDREN IN HEaITH AND Disease. Fcp. 8vo., Is. $6 d$.

De Salis.-Works by Mrs. De SAlis.

Cakes and Confections à La Mode. Fcp. 8vo., is. 6d.

Dogs: a Manual for Amateurs. Fcp. 8 vo.,

Dressed Game and Poultry A la MODE. Fcp. 8vo., is. 6d.

Dressed Vegetables À la Mode. Fcp. 8vo., is. 6d.

DRINks A la Mode. Fep. 8vo., is. 6d. Entrées À la Mode. Fcp. 8vo., is. $6 d$. Fioral Decorations. Suggestions and Descriptions. Fcp. 8vo., Is. 6d.

National Viands. Fcp. 8vo.

[In the Press.

New-LAid EgGs: Hints for Amateur Poultry Rearers. Fcp. 8vo., is. $6 d$.

Oysters a la Mode. Fcp. 8vo., is. $6 d$.
De Salis.-Works by Mrs. DE SALIScontinued.

PUdDINGS AND PASTRY À LA MODE. Fcp. 8vo., Is. 6d.

Savourif.s ì la Mode. Fcp. 8vo. Is. $6 d$.

SOUPS AND DRESSED Fish À LA MODE. Fcp. 8vo., Is. 6d.

SweEts ANd Supper Dishes à LA MODE. Fcp. 8vo., Is. 6d.

TEMPTING Dishes FOR SMALL INCOMEs. Fcp. 8vo., is. 6d.

WRINKLES AND NOTIONS FOR EVERI HOUSEHOLD. Cr. 8vo., Is. $6 d$.

Lear.-MAigre CoOkery. By H. L. SidNEy LEAR. I6mo., $2 s$.

Poole.-CoOkery for the Diabetic. By W. H. and Mrs. Poole. With Preface by Dr. PAVY. Fcp. 8vo., 2s. 6d. Walker.-A HANDBOOK FOR MOTHERS: being Simple Hints to Women on the Management of their Health during Pregnancy and Confinement, together with Plain Directions as to the Care of Infants. By JANE H. WALKER, L.R.C.P. and L.M., L.R.C.S. and M.D. (Brux.). Cr. 8vo., 2s, 6d.

West.-The Mother's Manual of Children's Diseases. By Charlees West, M.D. Fcp. 8vo., 2s. 6d.

\section{Miscellaneous and Critical Works.}

Allingham.--Varieties in Prose. Boyd ('A. K. H. B.').-Works by By William Allingham. 3 vols. Cr. 8 vo, I8s. (Vols. I and 2, Rambles, by Patricius Walker. Vol. 3, Irish Sketches, etc.)

Armstrong.--Essays and Sketches. By EDMund J. ARMSTRong. Fcp. 8 vo., 5 s.

Bagehot.-Literary Studies. By WALTER BAGEHOT. 2 vols. 8vo., $28 \mathrm{~s}$. Baring-Gould.-Curious Myths of THE MIDDLE AgES. By Rev. S. BARING-Gould. Crown 8vo., 3s. $6 d$.

Battye.-Pictures in Prose of NATURE, Wild SPORT, AND HuMble Life. By AubYN Trevor Battye, B.A. Crown 8vo., $6 s$.

Baynes.--Shakespeare Studies, AND OTHER Essays. By the late Thomas SPENCER BAYNES, LL.B., LL.D. With a biographical Preface by Prof. LEWIS CAMPBEll. Crown 8vo., 7s. $6 d$.

A. K. H. BOYD, D.D. LL. D.

And see MISCELLANEOUS THEOLOGICAL WORKS, p. 24.

AUTUMN Holidays OF a COUNTRY PARSON. Crown 8vo., $3 s .6 d$.

Commonplace Philosopher. Crown 8vo., 3s. $6 d$.

Critical Essays of a COUNTRY PARSON. Crown 8vo., 3 s. 6d.

EAST COAST DAYS AND MEMORIES. Crown 8vo., 3s. $6 d$.

LANDSCAPES, ChuRChes AND MORALiTiEs. Crown 8vo., 3s. 6 d.

LeISURE HOURS IN TOWN. Crown 8 vo., 3s. $6 d$.

Lessons of Middle Age. Cr.8vo., 3 s. 6 .

OUR LitTle Life. Two Series. Cr. 8 vo., $3 s .6 d$. each.

OUR Homely COMEdy: ANDTRAGEDY. Crown 8vo., 3s. 6 d.

RECREATIONS OF A COUNTRY PARSON. Three Series. Cr. 8vo., 3s. 6d. wach. Also First Series. Popular Ed. 8vo., 6d. 


\section{Miscellaneous and Critical Works-continued.}

Butler.-Works by SAMUel ButLer.

EREWHON. Cr. 8vo., 5 s.

The FAIR HAVEN. A Work in Defence of the Miraculous Element in our Lord's Ministry. Cr. 8vo., 7s. 6d.

LIFE AND HABIT. An Essay after a Completer View of Evolution. Cr. 8vo., 7s. $6 d$

Evolution, Old and New. Cr. 8vo., Ios. $6 d$.

ALPS AND SANCTUARIES OF PIEDMONT AND CANTON Ticino. Illustrated. Pott 4to., Ios.6d.

LUCK, OR CUNNING, AS THE MAIN MEANS OF ORGANIC MODIFICATION? Cr. 8vo., 7s. 6d.

Ex Voto. An Account of the Sacro Monte or New Jerusalem at VaralloSesia. Crown 8vo., Ios. $6 d$.

Francis.-Junius Revealed By his surviving Grandson, H. R. FRANCIS, M.A., late Fellow of St. John's College, Cambridge. 8vo., $6 s$.

Hodgson. - OUTCAST Essays AND Verse Translations. By H. ShadWORTh Hodgson. Crown 8vo., 8s. 6d. Hullah.-Works by J. HullaH, LL.D. CoURSE OF LECTURES ON THE HISTORY OF MODERN MUSIC. 8vo., 8 s. $6 \mathrm{~d}$.

COURSE OF LECTURES ON THE TRANSITION PERIOD OF MUSICAL History. 8vo., Ios. $6 d$.

Jefferies.-Works by R. JEFFERIES.

FIELD AND HEDGEROW: last Essays. With Portrait. Crown 8vo., 3s. 6d.

The Story OF MY HEART: With Portrait and New Pretace by C. J.

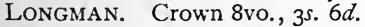

RED DEER. With 17 Illustrations. Cr. 8vo., 3 s. $6 d$.

THE TOILERS OF THE FIELD. Portrait. Crown 8vo., 3s. $6 d$.

WoOd MAgIC. With Frontispiece and Vignette by E. V. B. Cr. 8vo., 3s. $6 d$.

Johnson.-The PATENTEE's MANuAL:

a Treatise on the Law and Practice of Letters Patent. By J. \& J. H. JонNSON, Patent Agents, \&c. 8vo., IOs. $6 d$.

Iang.-Works by ANDREW LANG.

LETTERS TO DEAD AUTHORS. Fcp. 8 vo., 2s. $6 d$. net.

LETTEks ON Literature. Fcp. 8vo., 2s. $6 d$. net.

BoOKS AND BOOKMEN. With I9 Illustrations. Fcp. 8vo., 2s. 6d. net. Old Friends. Fcp. 8vo., 2s. 6d. net. Cock Lane and Common Sense. Fcp. 8vo., 6s. 6d. net.
Leonard.-The CAMEL : Its Uses and Management. By Major ARTHUR GLYN LEONARD. Royal 8vo., 2Is. net.

Macfarren.-LECTURESON HARMONy. By Sir Geo. A. MACFARREN. 8vo., I2s. Max Muller-Works by F. MAX MÜlLER. INDIA: WHAT CAN IT TEACH Us? Cr. 8vo., $3^{j}$. $6 d$.

Chips FROM a German Worksilop. New Edition in 4 Vols. Vol. I., Recent Essays and Addresses. Crown 8vo., 6s. 6d. net. (Ready).

In Preparation-Vol. II., Biographical Essays; Vol. III., Essays on Language and Literature; Vol. IV., Essays on the Sciences of Language, of Thought, and of Mythology.

Mendelssohn.-THE LetTers of Felix Mendelssohn. Translated by Lady WALLACE. 2 vols. Cr. 8vo., IOS. Milner.-Works by GEORGE MiLnER.

Country Pleasures: the Chronicle of a Year chiefly in a Garden. Cr. 8\%o., $3^{\text {s. } 6 d \text {. }}$

Studies OF NATURE ON THE CoAst OF ARRAN. With Illustrations by W. Noel Johnson. I6mo. ,6s. $6 d$. net. Perring.-HARd KNots iN SHakesPEARE. By Sir Philip PERRING, Bart. 8vo. $7 s, 6 d$.

Proctor.-Works by R. A. Proctor.

STRENGTH AND HAPPINESS. With 9 Illustrations. Crown 8vo., 5 s.

STRENGTH: How to get Strong and keep Strong, with Chapters on Rowing and Swimming, Fat, Age, and the Waist. With 9 Illus. Cr. 8vo, $2 s$.

Richardson.-NATIONAL HEALTH. A Review of the Works of Sir Edwin Chadwick, K.C.B. By Sir B. W. Richardson, M.D. Cr. 8vo., 4s. 6 $d$.

Rossetti.-A SHAdow OF DANTE : being an Essay towards studying Himself, his World, and his Pilgrimage. By Maria Francesca Rossetti. Cr. 8vo., 3s. $6 d$.

Southey.-Correspondence With Caroline Bowles. By R. Southey. Edited by E. DowDEN. 8vo., I4s.

Wallaschek.-PRIMITIVE Music : an Inquiry into the Origin and Development of Music, Songs, Instruments, Dances, and Pantomimes of Savage. Races. By RICHARD WALLASCHEK. With Musical Examples. 8vo., r2s. 6d. West.-Wills, AND How Not To MaKe THem. With a Selection of Leading Cases. By B. B. West. Fcp. 8vo., 2s. $6 d$. 


\section{Miscellaneous Theological Works.}

** For Church of England and Roman Catholic Works see MessRs. Longmans \& Co.'s Special Catalogues.

Boyd.-Works by A. K. H. BoyD, D.D., Macdonald.-Works by George MAC-

First Minister of St. Andrews, author of

'Recreations of a Country Parson,' \&c.

Council And COMFort FROM A City

Fulpit. Crown 8vo., 3.s. $6 d$.

SUNDAY AFTF.RNOONS IN THE PARISH CHURCH OF A SCOTTISH UNIVERSITY City. Crown 8vo., 3s. $6 d$.

Changed Aspects OF UNChanged TRUTHS. Crown 8vo., 3s. 6d.

Graver Thoughts of a Country PARSON. Three Series. Crown 8vo., 3s. $6 d$. each.

Present Day Thoughts. Crown 8vo., 35. $6 d$.

Seaside Musings. Cr. 8vo., 3 s. $6 d$.

-To MeET THE DAY' through the Christian Year; being a Text of Scripture, with an Original Meditation and a Short Selection in Verse for Every Day. Crown 8vo., 4s. 6d.

De La Saussaye.-A Manual of the Science of Religion. By Prof. Chantepie de la Saussaye. Translated by Mrs. COLYER FERGUSSON (nee Max Muller). Crown 8vo.. r2s. $6 d$.

Kalisch.-Works by M. M. KALISCH,

Bible Studies. Part I. The Prophecies of Balaam. 8vo., Ios. 6d. Part II. The Book of Jonah. 8vo., Ios. $6 d$.

CommentaRY ON THE OLD TESTAMENT: with a new Translation. Vol. I. Genesis. 8vo., r8s. Or adapted for the General Reader. I2s. Vol. II. Exodus. I5s. Or adapted for the General Reader. I2s. Vol. III. Leviticus, Part I. I5s. Or adapted for the General Reader. 8s. Vol. IV. Leviticus, Part II. I5s. Or adapted for the General Reader. 8s.

Martineau.-Works by JAMES MAR TINEAU, D.D., LL. D.

Hours of Thought ON SACRED Things. Two Volumes of Sermons. Crown 8vo., 7s. 6d.

ENDEAVOURS AFTER THE CHRISTIAN LifE. Discourses. Cr. 8vo., 7s. 6d.

The Seat of Authority in Religion. 8 vo., I4s.

EsSAys, Reviews, AND ADDREsSEs. 4

Vols. Crown 8vo., 7s. 6d. each.

I. Personal; Political.

II. Ecclesiastical ; Historical.

III. 'Theological; Philosophical.

IV. Academical; Religious

Home Prayers, with Two Services for

Public Worship. Crown 8vo. 3s. $6 d$. 50,000-II/94.

\section{DONALD, LL.D.}

Unspoken Sermons. Three Series. Crown 8vo., 3s. 6d. each.

The Miracles of OUR Lord. Crown 8 vo., $3 s .6 d$.

A BOok OF STRIfe, IN THE FORM OF The Diary of an Old Soul: Poems I8mo., $6 s$.

Max Müller.-Works by F. Max MÜLLER.

Hibbert Lectures oN the ORIGiN AND GROWTH OF RELigion, as illus. trated by the Religions of India. Crown 8vo., 7s. 6d.

INTRODUCtion TO THE SCIENCE OF RELigion : Four Lectures delivered at the Royal Institution. Cr. 8vo.,3s. 6d.

Natural REligion. The Gifford Lectures, delivered before the University of Glasgow in 1888. Cr. 8vo., IOs. $6 d$.

Physical Religion. The Gifford Lectures, delivered before the University of Glasgow in $\mathbf{1 8 9 0 .}$ Cr. 8vo., ros. $6 d$.

Anthropological Religion. The Gifford Lectures, delivered before the University of Glasgow in r89r. Cr. 8vo., ros. $6 d$.

THEOSOPHy OR PSYchological ReLIGION. The Gifford Lectures, delivered before theUniversity of Glasgow in 1892 . Cr. 8vo., Ios. $6 d$.

Three Lectures on the Vedanta Philosophy, delivered at the Royal Institution in March, 1894. 8vo., 5 s.

Scholler.-A Chapter OF CHurci History From SOUTH GERMANY: being Passages from the Life of Johann Evangelist Georg Lutz, formerly Parish Priest and Dean in Oberroth, Bavaria. By L. W. Scholler. Translated from the German by W. WALlis. Crown 8vo., 35. $6 d$.

SUPERNATURAL RELIGION : an Inquiry in to the Reality of Divine Revela. tion. 3 vols. 8 vo., 36 s.

REPLY (A)TO DR. LightFooT's EsSAYS. By the Author of 'Supernatural Religion'. 8vo., $6 s$.

THE Gospel ACCORdiNG TO ST: PETER: a Study. By the Author of 'Supernatural Religion'. 8vo., $6 s$. 
FOLJSORE

The book noEs nOT

chicititis 
